THIAGO DE OLIVEIRA NUNAN LEITE

\title{
MODELAGEM E SIMULAÇÃO DO CIRCUITO DE MOAGEM DA MINERAÇÃO SERRA GRANDE
}

\author{
São Paulo
}


THIAGO DE OLIVEIRA NUNAN LEITE

\title{
MODELAGEM E SIMULAÇÃO DO CIRCUITO DE MOAGEM DA MINERAÇÃO SERRA GRANDE
}

\author{
Dissertação apresentada à Escola \\ Politécnica da Universidade de São \\ Paulo para obtenção do título de Mestre \\ em Engenharia Mineral
}

\section{São Paulo}


THIAGO DE OLIVEIRA NUNAN LEITE

\title{
MODELAGEM E SIMULAÇÃO DO CIRCUITO DE MOAGEM DA MINERAÇÃO SERRA GRANDE
}

\author{
Dissertação apresentada à Escola \\ Politécnica da Universidade de São \\ Paulo para obtenção do título de Mestre \\ em Engenharia Mineral
}

Área de Concentração:

Engenharia Mineral

Orientador: Prof. Dr. Homero Delboni Junior

São Paulo 


\section{Catalogação-na-publicação}

Leite, Thiago de Oliveira Nunan

Modelagem e simulação do circuito de moagem da Mineração Serra Grande / T. O. N. Leite -- São Paulo, 2016.

$195 \mathrm{p}$.

Dissertação (Mestrado) - Escola Politécnica da Universidade de São Paulo. Departamento de Engenharia de Minas e Petróleo.

1.Cominuição 2.Simulação (Modelagem Matemática) I.Universidade de São Paulo. Escola Politécnica. Departamento de Engenharia de Minas e Petróleo II.t. 


\section{DEDICATÓRIA}

Dedico este trabalho à Thatá, minha esposa, e lhe agradeço por estar ao meu

lado em diversos momentos e diferentes lugares, embarcando junto nos sonhos e mostrando as oportunidades para eu ser melhor. 


\section{AGRADECIMENTOS}

À AngloGold Ashanti, por oferecer todo suporte necessário para que eu pudesse desenvolver e concluir este trabalho.

À minha mãe, por ter me mostrado a importância de ter conhecimento. Ela me incentivou, ensinou-me a andar e tem paciência e esperança ao me ver caminhando.

Aos meus irmãos Felipe e André, nossa fraternidade me mostra que pessoas unidas podem mudar seus destinos, realizar suas vontades e se desenvolver. Triangulação de fogos cruzados, essa é a chave.

Ao Eng. José Augusto Dumont e Dra. Flavia Mendes, pelo incentivo e recomendações.

Aos amigos Edson Gonçalves, Guilherme Peixoto, Herbert Guido, Isabella Viana, pelo auxílio no fornecimento das informações de MSG e pela convivência em Crixás.

Ao meu orientador, Prof. Dr. Homero Delboni Jr, por ter me indicado os melhores materiais e ferramentas para a construção deste conhecimento.

Aos Profs. Drs. Ana Carolina Chieregati, Mauricio Bergerman e Eduardo Sansone, pelos ensinamentos e auxílio na minha formação.

Aos amigos da UPS - Josiane, Wellington, Jatobá, Victor e Renato -, por tornarem boas minhas estadias em São Paulo e, claro, pelas informações extremamente relevantes para a elaboração do trabalho.

Ao Rosendo e Rogério, pela grande ajuda na realização dos ensaios.

Aos meus amigos. 


\section{RESUMO}

Durante o período de operação de um empreendimento mineiro, oportunidades de aumento de capacidade produtiva podem gerar ganhos significativos para uma empresa. Para os casos em que se viabiliza maior capacidade de produção da mina deve-se avaliar a capacidade de processamento da usina de beneficiamento, que assim inclui melhorias de desempenho ou expansão mediante adição de equipamentos. Este trabalho contempla a descrição das etapas de amostragem, caracterização do minério, a modelagem do circuito existente e a simulação para aumento da capacidade do circuito de moagem da usina da Mineração Serra Grande da AngloGold Ashanti, situada no município de Crixás no interior de Goiás. Os cenários simulados foram (1) adição de um terceiro moinho de bolas em série aos moinhos existentes, (2) adição de um terceiro moinho de bolas em paralelo ao circuito existente, (3) adição de um moinho vertical para processamento do produto dos dois moinhos de bolas existentes e (4) adição de uma prensa de rolos após o circuito de britagem. O propósito das quatro simulações foi avaliar a viabilidade técnica dos circuitos selecionados mediante modelagem matemática e simulação de processos, assim como dimensionar os novos equipamentos para tal fim.

Palavras-chave: Modelagem, moagem, moinho de bolas, moinho vertical, prensa de rolos, simulações. 


\begin{abstract}
During operation of the mining cycle, increases the throughput would generate significant capital savings for a company. For cases that enables higher mine production capacity, it must be evaluated plant capacity and also performance improvements or expansion by adding new equipment. This study includes the description of the sampling methodology, the minerals analysis, modeling of the existing circuit and simulation for a possible expansion, specifically for the grinding circuit at Mineração Serra Grande plant of AngloGold Ashanti group, located in Crixás, Goiás. the studied scenarios were: (1) adding a third ball mill in series with existing two ball mills, (2) adding a third ball mill in parallel with existing mills, (3) adding a vertical mill in series with existing mills and (4) adding high pressure grinding rolls to existing mills. The four simulations intend assess the technical feasibility of the circuits selected by mathematical modeling and simulation of processes and design new equipment for this purpose.
\end{abstract}

Keywords: Modeling, grinding, ball milling, vertical milling, simulations 


\section{LISTA DE ILUSTRAÇÕES}

Figura 1 - Preços históricos do ouro negociado na London Bullion Market Association (LBMA)

Figura 2 - Representação dos erros componentes ao Overall Estimation Error (OEE) - em português: Erro Global de Estimativa .26

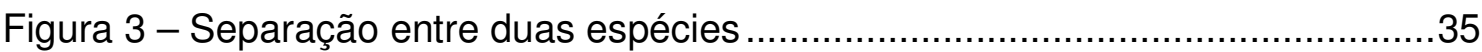

Figura 4 - Representação de moinho de bolas......................................................44

Figura 5 - Referência dos pontos onde são medidas as dimensões do diâmetro (D)

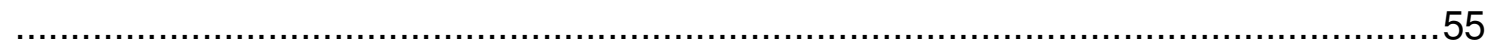

Figura 6 - Principais componentes e fluxos do ciclone ........................................56

Figura 7 - Curva de partição típica para ciclone ……..........................................57

Figura 8 - Faixa de operação de ciclones Cavex..................................................64

Figura 9 - Representação de uma seção de um HPGR, incluindo o sistema hidráulico

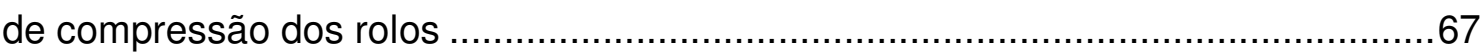

Figura 10 - Estrutura esquemática do modelo de HPGR .....................................68

Figura 11 - Sugestão de distância entre rolos para diferentes diâmetros e diferentes minérios .73

Figura 12 - Sugestão para velocidade tangencial máxima do rolo para diferentes diâmetros .75

Figura 13 - Granulometria do produto do moinho de Barras, moinho e bolas e HPGR .77

Figura 14 - Possibilidade de circuitos para uso de prensa de rolos. 81

Figura 15 - Fotografia da evidência de geração de microfraturas: (a) britagem convencional;

Figura 16 - Comparação de cinética de lixiviação de cobre entre britagem convencional

Figura 17 - Exemplo de moinhos verticais com cargas agitadas por impelidores: ...86 Figura 18 - Curvas de Distribuição granulométrica do Moinho de bolas de Bond ....89 
Figura 19 - Referências geométricas de moinhos verticais da série VTM da Metso 90 Figura 20 - Picnômetros utilizados no laboratório de processo da Mineração Serra Grande 92

Figura 21 - (a) Série de peneiras em peneirador vibratório; (b) peneiramento manual 95

Figura 22 - Representação gráfica do moinho de bolas utilizado para ensaio Wi de Bond .97

Figura 23 - Ilustração simplificada do Drop Weight Tester ou Célula de Impacto ..102 Figura 24 - Representação da fragmentação em decorrência da energia específica aplicada...... 104

Figura 25 - Unidade hidráulica e câmera de compressão utilizada em CLP 106

Figura 26 - Resultado de testes de CLP deslocamento do êmbolo versus força aplicada 107

Figura 27 - Localização da Mineração Serra Grande no estado de Goiás 109

Figura 28 - Histórico da produção da usina e dos teores de alimentação 110

Figura 29 - Fluxograma de Processo da Mineração Serra Grande 112

Figura 30 - Fluxograma do circuito de uma linha individual de moagem da MSG..115

Figura 31 - Percentual de consumo energético das principais áreas da MSN .......116

Figura 32 - Principais minérios e rochas encaixantes presentes nas minas da MSG

Figura 33 - Fotografias dos amostradores da alimentação nova dos Moinhos MO-01 e MO-02 122

Figura 34 - OptDensity- Medidor automático das densidades de alimentação ......124

Figura 35 - Amostradores utilizados para fazer amostragem no circuito da MSG..125

Figura 36 - Fotografias da realização do ensaio de Wi 128

Figura 37 - Fotografias obtidas durante a realização do ensaio DWT 130

Figura 38 - Fotografias obtidas durante o ensaio de CLP 132

Figura 39 - Corpos moedores de 12,7 mm e moinho 8" x 10" 133 
Figura 40 - Curvas granulométricas dos produtos das moagens 134

Figura 41 - Curva de moagem correlacionando o P80 com o tempo de moagem ...135

Figura 42 - Gráfico da granulometria dos fluxos amostrados para a linha de moagem 01

Figura 43 - Gráfico da granulometria dos fluxos amostrados para a linha de moagem 02

Figura 44 - Curva tn versus $t_{10}$ para o minério de MSG

Figura 45 - Curvas granulométricas dos produtos dos ensaios de jarro. 143

Figura 46 - Gráfico da energia específica consumida em cada ensaio de jarro versus o $\mathrm{P}_{80}$ do produto 144

Figura 47 - Comparação das granulometrias entre os dados experimentais 145

Figura 48 - Comparação das granulometrias entre os dados experimentais .........146

Figura 49 - Dados do balanço de massa versus dados experimentais 147

Figura 50 - Circuito original e otimizado por simulação no software JKSimMet .....152

Figura 51 - Faixa granulométrica de atuação de equipamentos utilizados para moagem

Figura 52 - Proposta de circuito para a simulação considerando moinho de bolas 157 Figura 53 - Fluxograma do circuito simulado para cenário 1. Moinho de bolas em série 161

Figura 54 - Circuito selecionado para simulação de uma terceira linha de moagem na usina da MSG. 162

Figura 55 - Curvas granulométricas dos produtos das moagens 01,02 e terceiro moinho em paralelo. 163

Figura 56 - Fluxograma do circuito simulado para o cenário 2. Terceiro moinho de bolas em paralelo 165

Figura 57 - Circuito para simulação considerando um moinho vertical em série....166 
Figura 58 - Gráfico da energia específica consumida versus $\mathrm{P}_{80}$ para ensaios de jarro, com regressão linear para estimativa de energia consumida para produto requerido de $109 \mu \mathrm{m}$. 168

Figura 59 - Curvas granulométricas para geração de material para ensaio de jarro 169

Figura 60 - Proposta de circuito para cenário 4. Prensa de Rolos 170

Figura 61 - Curvas granulométricas da simulação para o circuito de prensa de rolos 173

Figura 62 - Fluxograma do circuito simulado para cenário 4. Prensa de Rolos......174

Figura 63 - Fotografias equipamentos da planta de MSG …..............................183

Figura 64 - Fotografias equipamentos da planta de MSG ...................................184

Figura 65 - Alimentação nova do Moinho 01 durante amostragem .........................185

Figura 66 - Densidade na caixa de descarga do Moinho 01 durante amostragem.185 Figura 67 - Vazão de água na caixa de descarga do Moinho 01 durante amostragem 186

Figura 68 - Densidade de alimentação dos ciclones do Moinho 01 durante amostragem 186

Figura 69 - Densidade do overflow dos ciclones do Moinho 01 durante amostragem 187

Figura 70 - Pressão nos ciclones do Moinho 01 durante amostragem 187

Figura 71 - Potência do motor do Moinho 01 durante amostragem 188

Figura 72 - Alimentação nova do Moinho 02 durante amostragem 188

Figura 73 - Densidade da caixa de descarga do Moinho 02 durante amostragem.189 Figura 74 - Vazão de água na caixa de descarga do Moinho 02 durante amostragem 189

Figura 75 - Densidade de alimentação dos ciclones do Moinho 02 durante amostragem 190 
Figura 76 - Densidade do overflow dos ciclones do Moinho 02 durante amostragem 190

Figura 77 - Pressão dos ciclones do Moinho 02 durante amostragem ...................191

Figura 78 - Potência do motor do Moinho 02 durante amostragem.........................191

Figura 79 - Ensaios de CLP para fragmentos entre 4,75 e 6,35 mm....................193

Figura 80 - Ensaios de CLP para fragmentos entre 6,35 e 9,5 mm......................194

Figura 81 - Ensaios de CLP para fragmentos entre 9,5 e 12,7 mm......................195 


\section{LISTA DE TABELAS}

Tabela 1 - Ordenadas da distribuição normal ......................................................31

Tabela 2 - Fator de ineficiência para circuitos abertos ...........................................52

Tabela 3 - Fatores de eficiência do diâmetro do moinho ............................................53

Tabela 4 - Informações técnicas de parâmetros de moinhos de bolas.......................55

Tabela 5 - Dimensões ciclones comerciais fabricados pela Weir ............................65

Tabela 6 - Fatores que influenciam a capacidade das prensas de rolos ...................76

Tabela 7 - Parâmetros para seleção de Prensa de Rolos industriais ........................80

Tabela 8 - Comparação dos parâmetros entre moinho de bolas de Bond e moinho vertical de carga agitada por impelidor para moagem grosseira em laboratório para

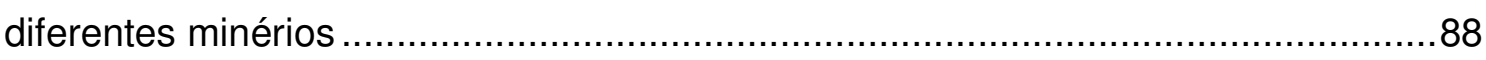

Tabela 9 - Informações técnicas de parâmetros de moinhos verticais da série VTM da

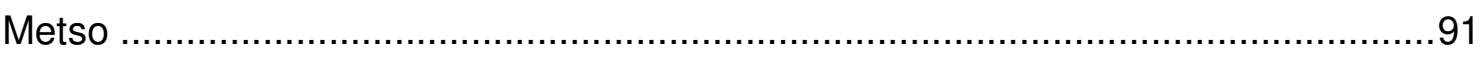

Tabela 10 - Especificação da carga moedora do ensaio Wi de Bond .......................97

Tabela 11 - Modelo de tabela para acompanhamento dos ciclos do teste de

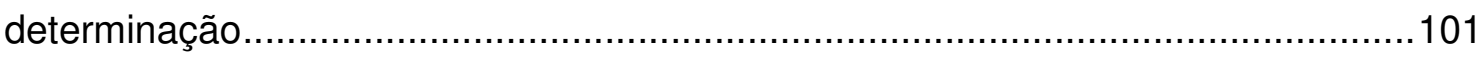

Tabela 12 - Consumo de energia das principais áreas da MSG ..........................116

Tabela 13 - Resultados da concentração dos elementos químicos em cada uma das amostras.

Tabela 14 - Variações das características físicas dos minérios das diferentes minas da MSG 120

Tabela15 - Local onde foram coletadas as amostras e tipo de procedimento ........121

Tabela 16 - Parâmetros monitorados e gravados durante amostragem dos dois moinhos

Tabela 17 - Tamanho de partículas e energias estipuladas para os lotes de amostra 
Tabela 19 - Dados dimensionais dos ciclones. 136

Tabela 20 - Percentual retido passante para os fluxos amostrados na linha de moagem do Moinho 01 138

Tabela 21 - Percentual retido passante para os fluxos amostrados na linha de moagem do Moinho 02 139

Tabela 22 - Valores medidos e calculados durante o teste de Wi 139

Tabela 23 - Parâmetros obtidos para o cálculo de Wi 140

Tabela 24 - Distribuição granulométrica da alimentação e do produto do ensaio ..140

Tabela 25 - Matriz quebra para ensaio de DWT. 141

Tabela 26 - Valores estimados de A, b e IQ para ensaio de DWT 142

Tabela 27 - Parâmetros A, b e IQ para os três ensaios de CLP 142

Tabela 28 - Matriz quebra para os três ensaios de CLP 142

Tabela 29 - Parâmetros para cálculo de energia específica para o ensaio de jarro 144

Tabela 30 - Valores calibrados para definição das curvas de $\ln \left(r / d^{*}\right)$ 147

Tabela 31 - Valores das constantes do modelo de Nageswararao calibrado 148

Tabela 32 - Parâmetros para o dimensionamento do consumo Global de energia da moagem para o cenário 2,0 mtpa.

Tabela 33 - Fatores de correção de Rowland para o dimensionamento da energia global do circuito 155

Tabela 34 - Resultados do dimensionamento do consumo de energia para moagem de 2,0 mtpa 156

Tabela 35 - Valores utilizados como referência de $\ln \left(r / d^{*}\right)$ para o moinho em série 159

Tabela 36 - Valores utilizados como referência para as constantes do modelo de Nageswararao 159

Tabela 37 - Dimensões e parâmetros para operação dos ciclones para cenário de moinho em paralelo 
Tabela 38 - Dimensões e parâmetros para operação do moinho de bolas para cenário

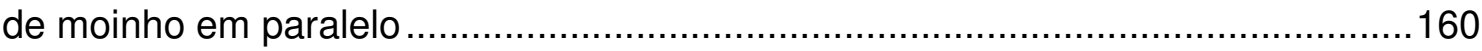

Tabela 39 - Dimensões e parâmetros para operação dos ciclones para cenário de

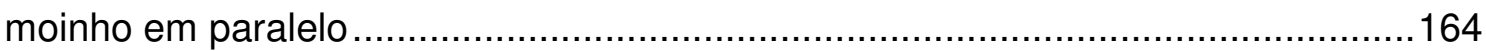

Tabela 40 - Dimensões e parâmetros para operação do moinho de bolas para cenário

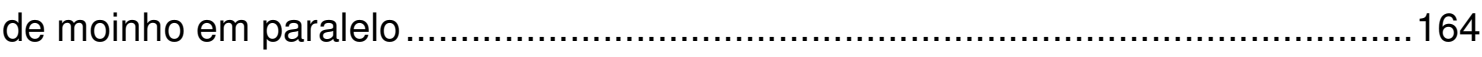

Tabela 41 - Características do moinho vertical selecionado (Fonte: Metso, 2015) 169 


\section{SUMÁRIO}

1 INTRODUÇAO

2 OBJETIVO

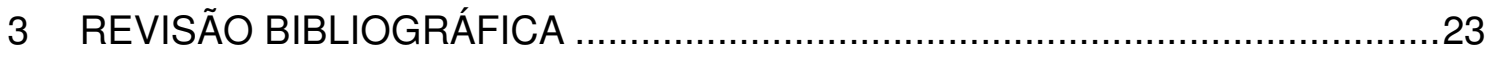

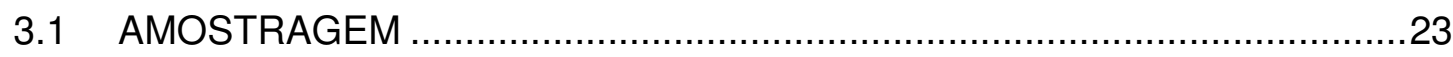

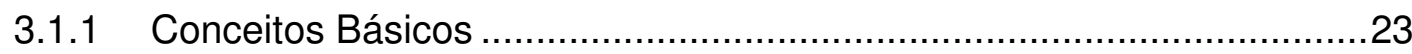

3.1.2 Breve Descrição dos Erros de Amostragem .........................................23

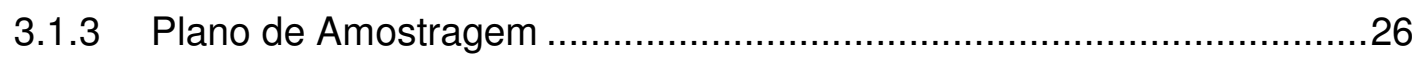

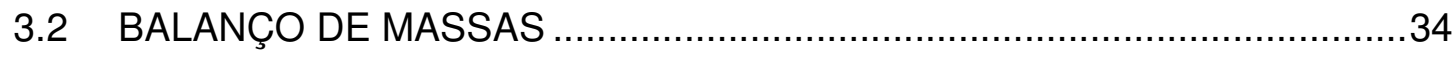

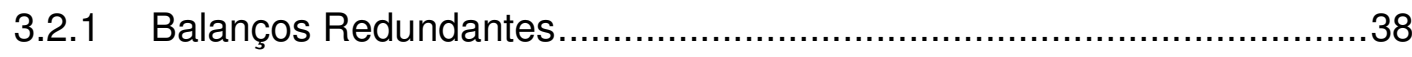

3.3 EQUIPAMENTOS E REPRESENTAÇÕES MATEMÁTICAS DE

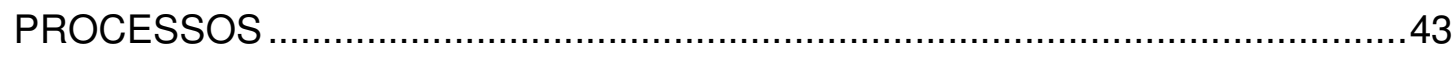

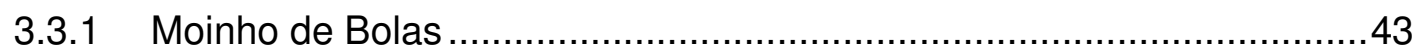

3.3.2 Ciclone

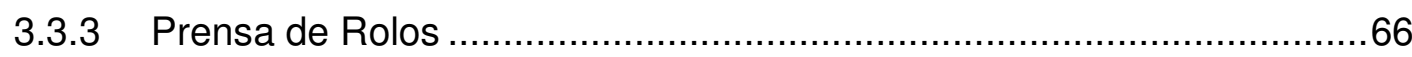

3.3.4 Moinhos Verticais de Carga Agitada......................................................

3.4 ANÁLISES DE CARACTERÍSTICAS FÍSICAS DE AMOSTRAS DE MINÉRIO 91

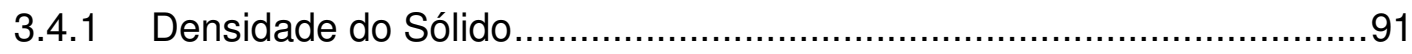

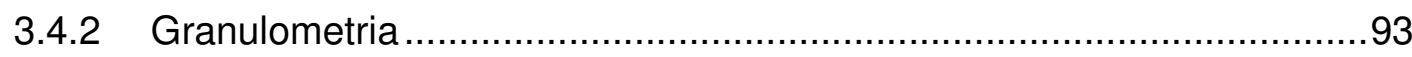

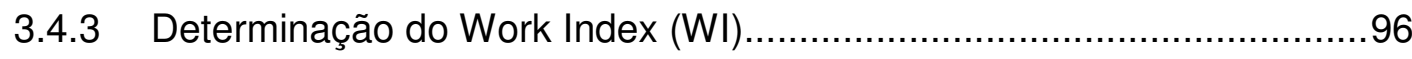

3.4.4 Ensaio de Resistência ao Impacto em Partículas Individuais ................101

3.4.5 Ensaio de Compressão de Leito de Partículas CLP .............................105

3.4.6 Ensaio de jarro para moinho de carga agitada ..................................107

4 MINERAÇÃO SERRA GRANDE ANGLOGOLD ASHANTI .............................109

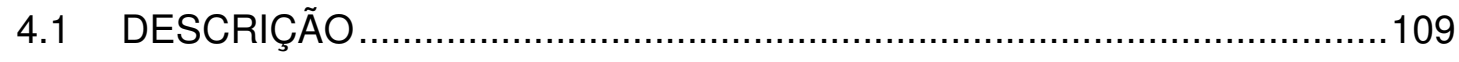


4.1.1 Operações e Processos Produtivos...................................................111

4.1.2 Consumo de Energia Elétrica de MSG ….........................................115

4.2 PRINCIPAIS CARACTERÍSTICAS DO MINÉRIO...................................117

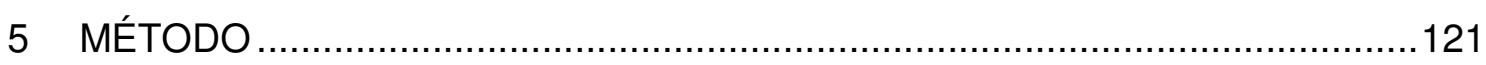

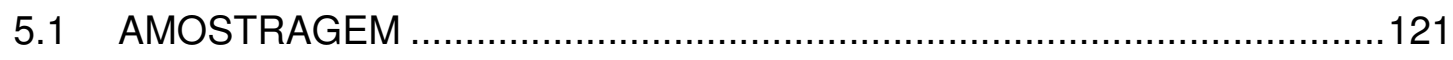

5.1.1 Planejamento de amostragem ..................................................... 121

5.1.2 Banco de dados gerado durante a amostragem................................126

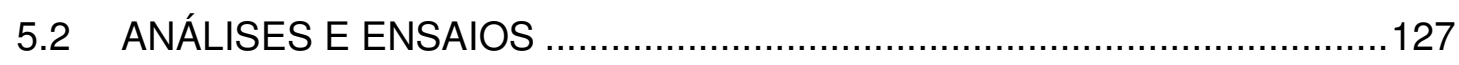

5.2.1 Determinação da Granulometria .....................................................127

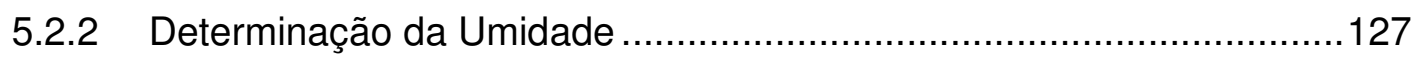

5.2.3 Determinação do Peso Específico do Minério .......................................127

5.2.4 Determinação do Wi de Bond ........................................................ 127

5.2.5 Execução do Drop Weight Test ......................................................128

5.2.6 Execução do ensaio de Leito Comprimido de Partícula .......................130

5.2.7 Execução do ensaio de Jarro Laboratorial .........................................132

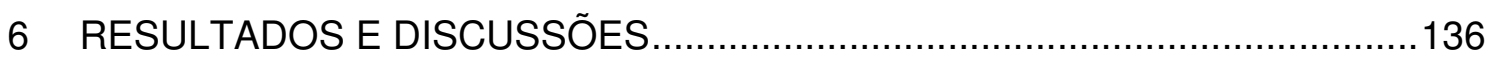

6.1 RESULTADOS DAS ANÁLISES E TESTES LABORATORIAIS ................136

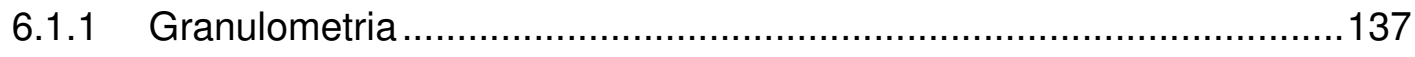

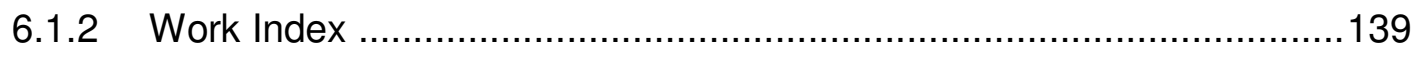

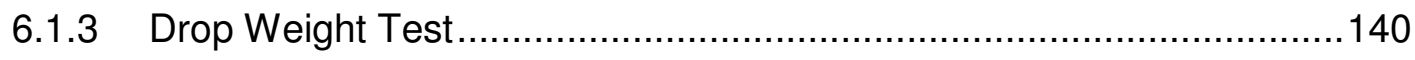

6.1.4 Compressão do Leito de Partículas ...................................................142

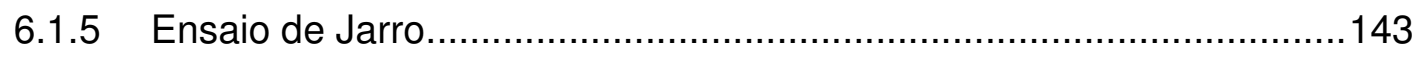

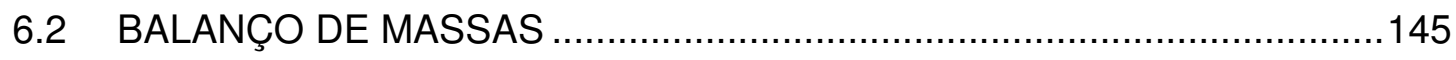

6.3 CALIBRAÇÃO DOS MODELOS SELECIONADOS ………….................147

6.4 MELHORIA DE DESEMPENHO DO CIRCUITO EXISTENTE...................148 
6.5 CENÁRIOS PARA CAPACIDADE DE 2.0 MILHÕES DE TONELADAS POR ANO 153

6.5.1 Moinho de bolas em série - Cenário 1

157

6.5.2 Moinho de bolas em paralelo - Cenário 2 ………………................162

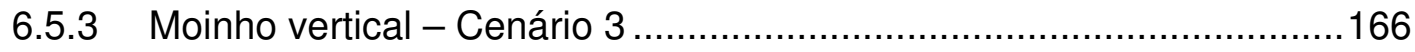

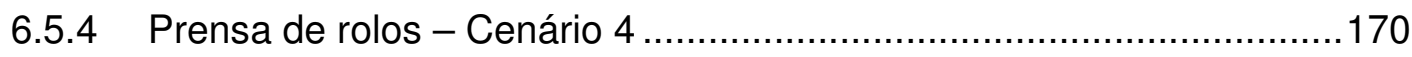

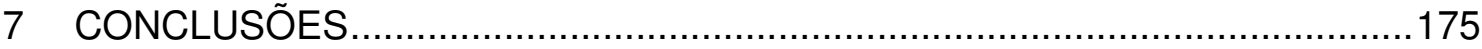

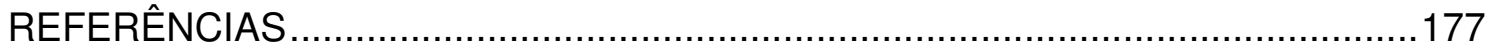

APÊNDICE 1 - FOTOGRAFIAS DE EQUIPAMENTOS E PONTOS DE TOMADA DE

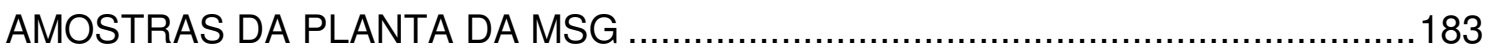

APÊNDICE 2 - PARÂMETROS MEDIDOS DURANTE PERÍODO DE AMOSTRAGEM 185

APÊNDICE 3 - RESULTADOS DOS ENSAIOS DE JARRO …............................192

APÊNDICE 4 - RESULTADOS DOS ENSAIOS DE CLP ...................................193 


\section{INTRODUÇAO}

A mineração de ouro atravessa atualmente uma forte crise em razão da queda de preço deste metal, conforme mostra o gráfico da Figura 1, onde estão lançados os valores negociados do onça de ouro no mercado de Londres desde 1968 até 2015. Os maiores valores negociados ocorreram no último trimestre de 2011 e eram aproximadamente $60 \%$ mais altos dos que os praticados atualmente.

Figura 1 - Preços históricos do ouro negociado na London Bullion Market Association (LBMA)

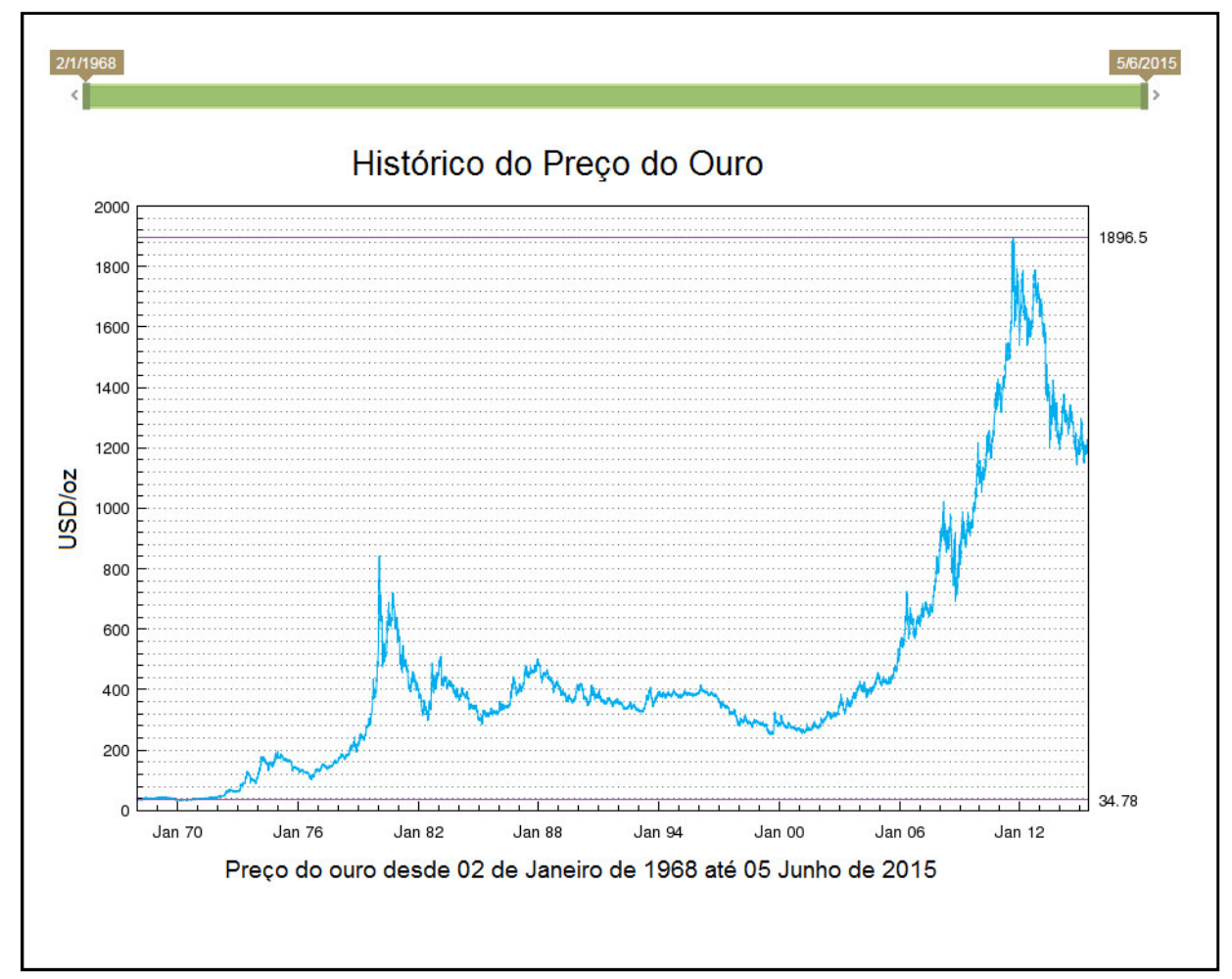

Fonte: LBMA (2015)

Projetos de várias empresas que se tornaram viáveis em razão do alto preço do ouro há quatro anos foram interrompidos pela instabilidade do preço da commodity. Algumas usinas de beneficiamento de minérios auríferos com custos altos de operação foram fechadas nos últimos anos, enquanto as usinas que permanecem em operação em todo o mundo buscam melhorias operacionais por meio de inovações, 
controle de processo e quaisquer outras ações que resultem em processo eficaz, que permita uma maior produção de ouro com menores custos.

Como a energia é comercializada no Brasil com custo elevado quando comparado a outros países (FIRJAN 2015), ela se torna um dos principais itens de custos, quase que independentemente do setor industrial.

Nesse contexto, o processo de moagem da Mineração Serra Grande (MSG) foi responsável por $16 \%$ do consumo de energia da empresa ao longo do ano de 2014 , representando um item expressivo no custo total de produção de ouro. Tal fato pode ser generalizado para outras empresas de mineração de ouro, uma vez que, nelas, a cominuição é sempre um item que representa um consumo elevado de energia elétrica. Sendo assim, há uma busca contínua pelo entendimento e otimização de sistemas de cominuição, pois neste caso pequenas melhorias podem gerar grandes oportunidades. Normalmente as melhorias de eficiência dos processos resultam em ganho de escala, como consumir menos energia mantendo a produção.

Com base nesse foco, este estudo investiga alternativas de melhoria de desempenho do circuito de moagem da MSG, mediante simulações do aumento de escala da produção. 


\section{OBJETIVO}

O objetivo deste trabalho é desenvolver um modelo matemático do processo de moagem da Mineração Serra Grande (MSG) da AngloGold Ashanti, bem como empregá-lo na simulação de cenários de expansão de sua capacidade, dos atuais 1,3 para 2,0 Mt anuais.

Para tanto, foram estudadas, planejadas e executadas etapas de amostragem no circuito industrial da MSG, seleção e calibração de modelos matemáticos existentes para o estabelecimento de uma base e para a elaboração de várias simulações do processo, de acordo com os cenários selecionados. 


\section{REVISÃo BIBLIOGRÁFICA}

\subsection{AMOSTRAGEM}

\subsubsection{Conceitos Básicos}

Seria inviável obter as principais características de uma jazida, corpo mineralizado, pilha ou fluxo de polpa, analisando individualmente todos os elementos que compõem esses universos. Portanto, para mensurar os aspectos de uma população, torna-se necessário reduzir o número de elementos a serem analisados. Para que essa redução não acarrete em mudanças significativas nas características do objeto em análise, vários conceitos foram desenvolvidos, utilizando estatística e metodologias para conservar os aspectos intrínsecos da população. Esses conceitos estão presentes na Teoria da Amostragem.

O objetivo da amostragem é, portanto, reduzir a massa de um lote, sem introduzir mudanças expressivas em suas propriedades. Porém, independentemente dos cuidados e métodos utilizados para tomar amostras, existem vários erros que são inerentes a esse processo e pode haver divergências entre os valores estimados e os de fato ocorridos. O motivo dessas variações é inerente à composição dos minérios que apresentam constituições heterogêneas e essa propriedade pode ser considerada a fonte de todos os erros de amostragem (GY, 1998).

A Teoria da Amostragem apresenta ferramentas preventivas que minimizam os erros indicando procedimentos, metodologias e equipamentos apropriados para coleta e análise de amostras (CHIEREGATI, 2007).

\subsubsection{Breve Descrição dos Erros de Amostragem}

O assunto dessa seção foi baseado nos estudos de Chieregati (2007), François-Bongarçon e Gy (2002) e Góes, Luz e Possa 2010. Existem vários erros que podem gerar diferenças entre os valores dos parâmetros medidos para amostra e os 
valores reais da população em análise. Esses erros podem ser analíticos ou de amostragem, e são identificados no texto a seguir:

Erro Global de Estimativa (OEE): é a soma do erro analítico com o erro total de amostragem, portanto representa a soma de todos os erros.

Erro Fundamental de Amostragem (FSE): é o menor erro possível de amostragem em um cenário ideal, em que todos os fragmentos tenham sido coletados com a mesma probabilidade para a composição da amostra. Cada fragmento deve ser selecionado isoladamente e em sequência. Neste caso ainda existirá a diferença entre o valor do teor da amostra e o do lote, sendo essa diferença o erro fundamental. Trata-se do único erro que não pode ser reduzido a zero, mesmo que sejam aceitas as hipóteses mais favoráveis.

Erro de Segregação e Agrupamento (GSE): são variações de constituição entre grupos de fragmentos vizinhos, diferenciados por características como densidade, dimensão, composição, forma etc., as quais podem fazer com que os fragmentos afins se agrupem ou segreguem, dificultando uma seleção com probabilidades iguais para todos os fragmentos, já que normalmente esses não são coletados individualmente.

Erro de Flutuação de Heterogeneidade (HFE): está relacionado com fatores cíclicos ou cronológicos, normalmente relacionados à atividade humana. Esse erro pode ser desmembrado em três elementos: HFE ${ }_{1}$ - erro de variação de heterogeneidade de curto prazo; $\mathrm{HFE}_{2}$ - erro de variação de heterogeneidade de longo prazo; $\mathrm{HFE}_{3}$ - erro de variação periódica de heterogeneidade. Além disso, o erro de flutuação de heterogeneidade é composto por dois erros complementares: erro de ponderação e erro de flutuação da qualidade.

Erro de Ponderação do Incremento (IWE) e Erro de Flutuação de Qualidade (QFE): ambos estão relacionados às proporcionalidades entre os incrementos amostrais e a ponderação e podem ser desprezíveis no caso em que a massa amostrada é proposicional à massa total da população analisada, ou proporcional à vazão mássica em caso de amostragem em fluxos por exemplo. Havendo grande variação dessas proporções, ocorrerá enviesamento 
da amostra, e o erro passa a ser considerável. Ambos os erros são constituídos de três componentes: aleatoriedade, não aleatoriedade e periodicidade do erro. Erro de Materialização do Incremento (IME): é a soma dos três erros subsequentes:

a. Erro de Delimitação do Incremento (IDE): associado às dificuldades para obtenção de incrementos compostos exatamente pelo formato pretendido pelo plano de amostragem.

b. Erro de Extração do Incremento (IEE): associado à representatividade do material extraído, por exemplo, durante a amostragem de uma polpa contida em um tanque sem agitação, obtém-se uma amostra somente de suas porções superficiais. Devido à sedimentação, a amostra contida na caneca coletada da superfície poderá deixar de considerar o material que decanta mais rapidamente.

c. Erro de Preparação do Incremento (IPE): associado às etapas de preparação como uma simples transferência de recipientes, misturas, pesagem, filtragem, peneiramento e todos os outros preparos de uma amostra que podem causar erros.

Erro Total de Amostragem (TSE): composto pela soma do erro de flutuação de heterogeneidade e materialização do incremento. Representa todos os erros referentes à amostragem.

Erro Analítico (AE): está correlacionado ao erro gerado pelo método de análise selecionado para determinar a característica estudada da amostra.

Na Figura 2 estão representados de maneira esquemática o erro global de estimativa e todos os outros erros que o compõem. 
Figura 2 - Representação dos erros componentes ao Overall Estimation Error (OEE) - em português: Erro Global de Estimativa

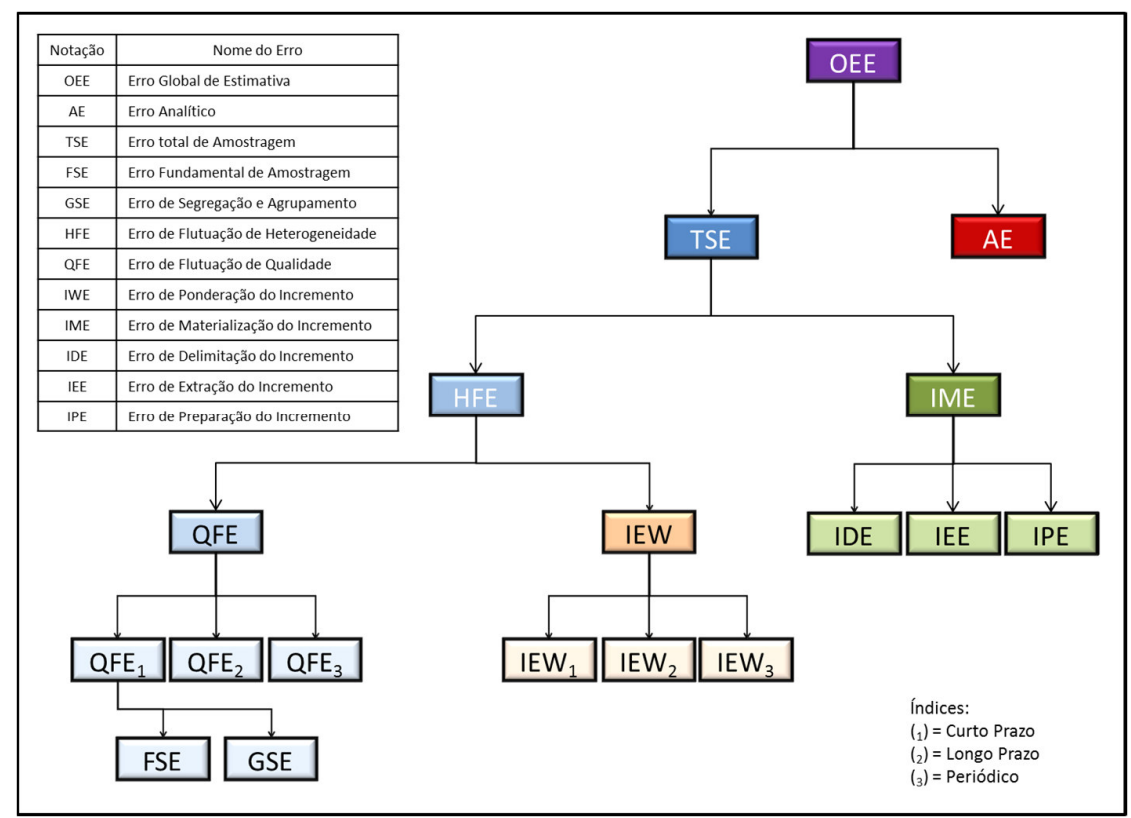

Fonte: Adaptado de PITARD, 2010 apud CHIEREGATI (2014)

Cabe ao executante da amostragem definir o quanto se está disposto a gastar para reduzir os erros aos valores requisitados. Lembrando que existem alguns erros que são, na prática, impossíveis de serem anulados.

\subsubsection{Plano de Amostragem}

A definição do plano de amostragem deve levar em consideração a precisão requerida do resultado, pois quanto maior a precisão requerida, maior o custo com o processo de amostragem. Portanto, deve sempre ser balanceada a relação de custo de amostragem com as consequências dos erros.

Também deve ser avaliado o método de retirada de amostra; em alguns casos, trabalhos experimentais podem ser necessários para identificar a melhor maneira para realizar a retirada de amostras. O método depende principalmente do tipo de material, de como ele é transportado e do objetivo da amostragem. 


\subsubsection{Tipos de amostragem}

\section{Amostragem aleatória}

A amostragem aleatória é utilizada em casos nos quais há pouca informação disponível sobre o material a ser amostrado. Convém escolher os incrementos de forma que todas as partes do material possuam a mesma probabilidade de ser amostrada. Como uma amostra verdadeiramente aleatória é difícil de ser tomada, normalmente, realiza-se uma subdivisão grosseira em áreas iguais, nas quais são selecionados incrementos.

\section{Amostragem sistemática}

$\mathrm{Na}$ amostragem sistemática, os incrementos são coletados em intervalos regulares. Esse tipo de amostragem é adequado para os casos em que o processo não seja cíclico e, portanto, não haja a possibilidade de coincidir parte do ciclo com o momento de tomada de amostras. Deve-se sempre evitar a possibilidade de um viés. Assim sendo, a retirada das amostras não deve ter relação com os ciclos de variação dos parâmetros de interesse. A amostragem sistemática terá efeitos equivalentes à amostra aleatória, podendo ser utilizada sem restrição.

\section{Amostragem Estratificada}

A amostragem estratificada considera a divisão do material em grupos distintos segundo alguma característica intrínseca. Os grupos são amostrados conforme suas massas. Esse tipo de procedimento é utilizado em muitos processos, como amostragem de vagões de trem, material em polpa onde haja sedimentação e amostra de minérios para diferentes frentes de lavra (GÓES; LUZ; POSSA, 2010).

\subsubsection{Representatividade da amostra}

Uma amostra representativa não pode ser enviesada. Essa propriedade é fácil de ser demonstrada quando existe, porém, é teoricamente impossível demonstrar sua ausência. Para uma amostra ser correta e não enviesada, todos os fragmentos do lote a ser selecionado devem possuir a mesma probabilidade de serem escolhidos (FRANÇOIS-BONGARÇON e GY, 2002).

Caso a amostra não seja enviesada e o erro de amostragem for suficientemente pequeno, ela é considerada representativa (CHIEREGATI, 2007). 


\subsubsection{Determinação da massa da amostra}

Algumas teorias foram elaboradas para determinação da massa mínima necessária para que uma amostragem representativa. Quando se comparam as massas calculadas de acordo com cada uma dessas teorias, é possível chegar a números divergentes. Normalmente, observa-se que algumas teorias menos sofisticadas são mais conservadoras e requerem uma quantidade de amostra grande, enquanto as teorias mais desenvolvidas exigem massa menor, porém, para que sejam estimadas as massas, são necessários vários parâmetros de difícil aquisição (GÓES; LUZ; POSSA, 2010).

A teoria de Pierre Gy é amplamente utilizada e difundida para se estimar uma amostra mínima e, para aplicá-la, são necessárias algumas considerações sobre a metodologia de amostragem e o material que será amostrado. Tais considerações estão listadas a seguir.

1) O material amostrado deve ser completamente homogeneizado;

2) Não deve haver erros intrínsecos das ferramentas que serão utilizadas para realizar a amostragem;

3) Não deve haver erros intrínsecos dos equipamentos de cominuição, tais como britadores ou pulverizadores de amostras;

4) Todas as partículas que compõem o lote devem ser selecionadas com equiprobabilidade

Seguindo as considerações propostas pela teoria de Gy, o erro total da amostragem será igual ao erro fundamental, representado pela equação(1) a seguir:

$$
S_{F S E}=\sqrt{d^{3} \cdot Q\left(\frac{1}{w}-\frac{1}{W}\right) l . f . h}
$$

SFSE = variância relativa do possível resultado do teor da amostra, ou estimativa do erro fundamental

d = diâmetro máximo de partícula no material amostrado, conhecido como d95 (cm)

$Q$ = fator de composição mineralógica, $\left(\mathrm{g} / \mathrm{cm}^{3}\right)$ 
$Q=x(100-x) \rho=x(100-x)\left[\frac{x}{100} \rho_{A}+\frac{(100-x)}{100} \rho_{B}\right]$

$\rho=$ média ponderada das densidades de todas as partículas, $\left(\mathrm{g} / \mathrm{cm}^{3}\right)$

$\mathrm{x}=$ teor do mineral de interesse na amostra (decimal)

$\rho_{A}=$ densidade do mineral em interesse $\left(\mathrm{g} / \mathrm{cm}^{3}\right)$

$\rho_{\text {в }}=$ densidade da ganga $\left(\mathrm{g} / \mathrm{cm}^{3}\right)$

w = massa mínima da amostra, $(\mathrm{g})$

$\mathrm{W}=$ massa do material que será amostrado $(\mathrm{g})$

I = fator de liberação do mineral

Varia de zero a um e está relacionado à liberação do mineral de interesse. Portanto, considerar o valor zero significa que o material está completamente liberado e é homogêneo, e o valor um representa materiais muito heterogêneos.

$f=$ fator de forma de partículas

Também varia de zero a um, sendo utilizado 0,1 para partículas lamelares e 1 para partículas esféricas. O valor de referência utilizado é 0,6 (NAPIER-MUNN et al.,1996).

$\mathrm{h}=$ fator de distribuição do tamanho de partículas

Recomenda-se utilizar:

$\mathrm{h}=0,25$ partícula processada para passar em uma determinada abertura de malha de peneira

$\mathrm{h}=0,5$ partícula com granulometria delimitada por malhas de peneiras sucessivas da mesma série (GÓES; LUZ; POSSA, 2010)

A equação (1) pode ser simplificada quando considerada duas premissas. De acordo com a primeira premissa, a granulometria é constante e, então, os valores de $\mathrm{Q}, \mathrm{I}, \mathrm{f}$ e h podem ser reunidos em um fator $\mathrm{C}=$ Qlfh 
A segunda premissa é que a massa do material a ser amostrado é muito grande, portanto, o fator $1 / \mathrm{W}$ tende a zero e a equação (3) pode ser assim simplificada:

$$
S_{F S E}=\sqrt{\frac{d^{3} C}{w}}
$$

A partir da equação (3) e fazendo-se algumas considerações, pode-se estimar a massa mínima da amostra para casos em que a granulometria seja o foco da amostragem e não mais o teor. Para isso, alguns termos da Fórmula de Gy são simplificados conforme a equação (4) de Barbery (1972) apud Napier-Munn et al., (1996).

$$
w=\frac{d_{m}^{3} \cdot \rho \cdot f}{s_{F S E}^{2} \cdot P}
$$

$d_{m}=$ granulometria média e pode ser calculado pela equação (5):

$$
d_{m}^{3}=\frac{d_{1}^{3}+d_{2}^{3}}{2}
$$

Onde $d_{1}$ e $d_{2}$ são os tamanhos que limitam a faixa de interesse.

$\mathrm{P}=$ proporção esperada do material na faixa granulométrica de interesse

Para a maior parte dos casos, utiliza-se como valor de referência $P=5 \%$, portanto os valores de $d_{1}$ e $d_{2}$ devem ser selecionados para $P=5 \%$.

O valor de $\mathrm{SFSE}^{2}$ é estimado a partir da precisão da estimativa e da confiança. 


$$
s_{F S E}^{2}=\frac{\emptyset}{Z}
$$

Onde:

$\Phi=$ precisão estabelecida (proporção relativa)

z = nível de confiança determinado

A Tabela 1 apresenta valores de z para diferentes níveis de confiança. Um nível de confiança de $90 \%$ normalmente é adequado.

Tabela 1 - Ordenadas da distribuição normal

\begin{tabular}{|c|c|}
\hline Nível de confiança (\%) & Z \\
\hline 50 & 0,6745 \\
\hline 80 & 1,2816 \\
\hline 90 & 1,6449 \\
\hline 95 & 1,9600 \\
\hline 99 & 2,5758 \\
\hline 99,9 & 3,2905 \\
\hline
\end{tabular}

Fonte: Napier-Munn et al. (1996)

O valor de SFSE significa que, se a proporção de material na fração grosseira é de $5 \%(P=5 \%)$ e se deseja uma precisão de $10 \%$ com $90 \%$ de confiança, os valores obtidos serão:

SFSE $=0,061$, e $P=5 \% \pm 0,5 \%$, com $90 \%$ de confiança

\subsubsection{Definição de regras rápidas e seguras para dimensionamento de amostras}

Nos casos de exploração ou amostragem inicial, é comum conhecer pouco sobre o material que se deseja amostrar, sendo que até mesmo o componente crítico é desconhecido. Contudo, para uma amostra ser representativa, é necessário que todas as classes granulométricas também o sejam.

Portanto, usando a fórmula de Gy e fazendo algumas considerações sobre os fatores de forma, densidade, fração granulométrica entre as duas malhas de 
peneiramento e a variância do erro fundamental, é possível utilizar as seguintes regras para cálculo da massa a ser amostrada (PITARD, 1993):

1) Amostra de ambiente ou exploração inicial: sugerido SFES $= \pm 5 \%$

$w \geq 10.000 d^{3}$

2) Amostra para controle de processo ou avaliação de mina: sugerido SFES $= \pm$ $1,5 \%$

$w \geq 100.000 d^{3}$

3) Investigação crítica, amostragem comercial, teste de acurácia de sistema de amostragem: sugerido SFES $= \pm 0,5 \%$

$w \geq 1.000 .000 d^{3}$

\subsubsection{Erros comuns para coleta e processamento de amostras}

A seguir, apresenta-se uma lista com os principais erros de coleta e processamento de amostras e também algumas recomendações fundamentadas nos estudos de Napier-Munn et al.(1996) e Góes, Luz e Possa (2010)

- Perda de partículas pertencentes à amostra, como material retido nos amostradores ou quarteadores.

- Contaminação da amostra na preparação por material estranho, normalmente desgaste dos equipamentos utilizados para o processamento da amostra.

- Alteração de uma característica a ser analisada, no caso de medidas de umidade, convém deixar a amostra exposta a uma fonte de calor.

- Erros não intencionais de operação, como identificação errada de amostra e mistura de frações indesejadas. 
- Erros intencionais: aumentar o teor de uma amostra com amostra rica, umidificá-la, retirar a fração grosseira ou fina etc.

- Para iniciar a amostragem, o circuito deve estar com a operação estável e o tempo de amostragem ser entre uma e duas horas sem que ocorram distúrbios no processo.

- O design dos amostradores pode causar problemas caso não seja apropriado.

- A tomada de amostra primária pode não ser representativa.

- Erros analíticos em balanças, peneiras com desgastes ou aberturas incorretas, tempo inadequado de peneiramento, calibração ou seleção de constantes incoerentes.

- Propagação de erros nos cálculos de quantidade.

- Massa menor do que a necessária estatisticamente para representar o universo amostrado.

- Atentar para a tendência de o material fino se concentrar no centro quando depositado em pilha e também de material grosseiros e concentrar na superfície quando submetido à vibração

Com tantas incertezas e fontes de erros em diversas atividades da amostra, é realmente necessário tomar os devidos cuidados e ter um bom entendimento para elaborar e executar o plano de amostragem, assim como para preparar e analisar as amostras.

O trabalho de modelagem matemática de circuitos se inicia na amostragem e, caso ela não seja representativa, todo o trabalho posterior corre o risco de não representar a realidade da usina de beneficiamento. 


\subsection{BALANÇO DE MASSAS}

O balanço de massas é uma ferramenta particularmente importante, pois, por meio dele, é possível avaliar o desempenho de uma fábrica e controlar seus processos. Essa ferramenta é utilizada para identificar as distribuições granulométricas, ou até mesmo de elemento como nos casos de metais preciosos (WILLS, 2008).

O conceito básico para compreender o balanço de massas é que a soma das vazões que alimentam um circuito dever ser igual à soma das vazões dos produtos, desde que não haja acúmulo de material no processo. Portanto, não há geração ou desaparecimento de massas durante uma operação de beneficiamento físico ou químico.

A realização de um balanço de massas para um processo em operação demanda, em muitos casos, uma campanha de amostragem. Conforme visto na seção 3.1.2, a amostragem não ocorre sem erro, por isso considera-se que a massa que entra é igual à massa que saí mais um erro (VALADÃO; MONTENEGRO; GRALERY, 2007).

Portanto, para que haja uma representação consistente dos valores, é necessário utilizar métodos matemáticos para ajuste dos dados. A utilização desses métodos não dispensa o conhecimento técnico por parte de quem formula a solução, pois é necessário analisar a coerência das respostas, que algumas vezes podem estar matematicamente corretas, porém erradas do ponto de vista do beneficiamento mineral (NUNES, 1992).

Esta seção tem o objetivo de apresentar alguns métodos matemáticos utilizados para realizar os ajustes dos dados visando ao fechamento do balanço de massa, ou seja, a obtenção de um conjunto de dados consistentes sob o ponto de vista de conservação de massas e fidelidade ao processo analisado. A teoria visa reduzir os valores dos erros aos menores possíveis e, portanto, realizar o balanço de massas consistente.

A Figura 3 representa um caso ideal de separação, onde um determinado processo separa totalmente uma espécie descrita como concentrado da outra 
representada pelo rejeito. A característica de interesse pode ser o teor de alguma substância ou elemento, a granulometria, a porcentagem de sólidos ou qualquer outro parâmetro distinguível.

Figura 3 - Separação entre duas espécies

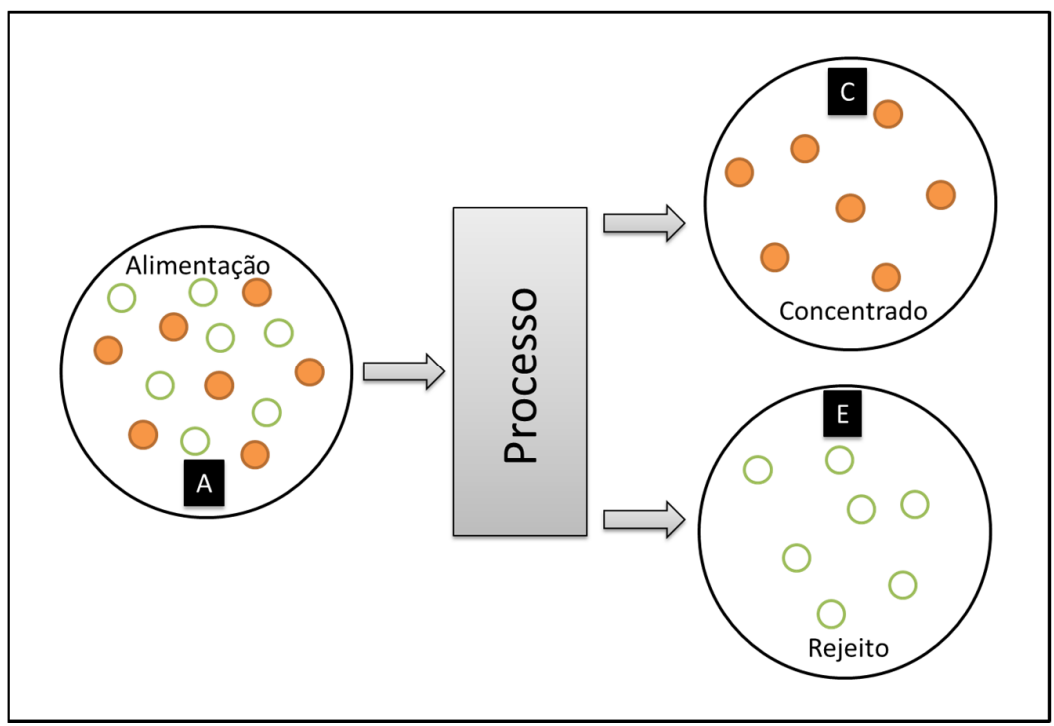

Fonte: Adaptado de VALADÃO; MONTENEGRO; GRALERY (2007)

Nos casos reais, a complexidade de uma separação aumenta, pois é praticamente impossível separar totalmente a característica de interesse (VALADÃO; MONTENEGRO; GRALERY, 2007).

Por meio da Figura 3, é possível definir algumas relações, sendo:

$\mathrm{A}=$ vazão da alimentação

$\mathrm{C}=$ vazão do concentrado

$E=$ vazão do rejeito

$a=$ característica de interesse (teor, concentração de sólidos, granulometria ou outros) de uma espécie i na alimentação

$c=$ característica de interesse da espécie i no concentrado

e $=$ característica de interesse da espécie i no rejeito

$R=$ recuperação da espécie $\mathrm{i}$ 
$\mathrm{R}_{\mathrm{c}}=$ razão de concentração

$\mathrm{Y}=$ recuperação mássica ou rendimento mássico

$\mathrm{Re}=$ razão de enriquecimento

Então:

$A=C+E$

$A a=C c+E e$

$R=\frac{C c}{A a}$

$R=\frac{c(a-e)}{a(c-e)}$

$R_{C}=\frac{A}{C}$

$Y=\frac{C}{A}=\frac{(a-e)}{(c-e)}$

$R_{e}=\frac{c}{a}$

A determinação de uma recuperação implica que existe incerteza em relação ao cálculo de $\mathrm{R}$, uma vez que poderia haver erros durante os procedimentos de determinação das características, por exemplo, nas pesagens, na análise dos teores, 
na determinação da concentração de sólidos, nas análises granulométricas e nos erros de amostragem. Portanto, usa-se do artifício da derivação parcial da equação (13) em relação aos valores de a, c, e para determinação da variação de $\mathrm{R}$.

$$
\begin{aligned}
& \frac{\partial R}{\partial a}=\frac{100 \cdot c e}{a^{2}(c-e)} \\
& \frac{\partial R}{\partial c}=\frac{100 \cdot e(a-e)}{a(c-e)^{2}} \\
& \frac{\partial R}{\partial e}=\frac{100 \cdot e(c-e)}{a(c-e)^{2}}
\end{aligned}
$$

Portanto, sendo VR a variância total associada à determinação de $R$, ela pode ser obtida pela equação (20):

$$
V R=\left(\frac{\partial R}{\partial a}\right)^{2} \cdot V a+\left(\frac{\partial R}{\partial c}\right)^{2} \cdot V c+\left(\frac{\partial R}{\partial e}\right)^{2} \cdot V e
$$

Onde: Va, Vc e Ve são as variâncias associadas à determinação de a, c, e.

Para calcular VR, as equações (17), (18) e (19) são substituídas pela (20) para se obter:

$$
V R=\frac{100^{2}}{a^{2}(c-e)^{2}} \cdot\left[\frac{c^{2} e^{2}}{a^{2}} \cdot V a+\frac{e^{2}(a-e)^{2}}{(c-e)^{2}} \cdot V c+\frac{c^{2}(c-a)^{2}}{(c-e)^{2}} \cdot V e\right]
$$

O erro é de aproximadamente $2 \sigma(\sigma=$ desvio padrão), para um intervalo de confiança de $95 \%$. 


\subsubsection{Balanços Redundantes}

O fechamento ou ajuste do balanço de massas pode ser realizado de diversas formas, utilizando-se características diferentes dos fluxos analisados. Para avaliação e monitoramento de processos industriais, normalmente os balanços de matérias são realizados com redundância, ou seja, há comparação de diferentes parâmetros analisados para o fechamento dos balanços. Dessa forma é possível realizar estimativas menos errôneas para o ajuste do balanço de massa.

A seguir é apresentado um dos métodos utilizados para o fechamento de balanço de massas redundantes, conforme descrito por Wills (2008).

Termos das equações:

$a_{k}=$ valor do componente $\mathrm{k}$ na alimentação do processo

$\mathrm{C}_{\mathrm{k}}=$ valor do componente $\mathrm{k}$ no concentrado do processo

$\mathrm{e}_{\mathrm{k}}=$ valor do componente $\mathrm{k}$ no rejeito do processo

$r_{k}=$ resíduo referente ao erro de fechamento do balanço

$\mathrm{k}$ = parâmetro, valor varia de 1 a n

$$
A a_{k}-C c_{k}-E e_{k}=r_{k}
$$

Assumindo-se que:

$$
A=1
$$

Então:

$$
E=A-C=1-C
$$


Substituindo a equação (22) pela (24):

$$
a_{k}-C c_{k}-(1-C) e_{k}=r_{k}
$$

ou:

$$
\left(a_{k}-e_{k}\right)-C\left(c_{k}-e_{k}\right)=r_{k}
$$

O objetivo desse método é encontrar o valor de $\mathrm{C}$ que minimize a soma dos quadrados dos resíduos referentes ao erro de fechamento. Ou seja, minimizar a função S da equação (27).

$$
S=\sum_{k=1}^{n}\left(r_{k}\right)^{2}
$$

Substituindo-se (27) por (25):

$$
S=\sum_{k=1}^{n}\left(a_{k}-e_{k}\right)^{2}+C^{2} \sum_{k=1}^{n}\left(c_{k}-e_{k}\right)^{2}-2 C \sum_{k=1}^{n}\left(a_{k}-e_{k}\right)\left(c_{k}-e_{k}\right)
$$

Para obter o mínimo da função $S$, é necessário derivá-la em relação a $C$ e igualar a zero:

$$
\frac{d S}{d C}=0=2 C_{a j} \sum_{k=1}^{n}\left(c_{k}-e_{k}\right)^{2}-2 \sum_{k=1}^{n}\left(a_{k}-e_{k}\right)\left(c_{k}-e_{k}\right)
$$


onde:

$\mathrm{C}_{\mathrm{aj}}=$ melhor estimativa para o valor de $\mathrm{C}$

Rearranjando a equação (29):

$$
C_{a j}=\frac{\sum_{k=1}^{n}\left(a_{k}-e_{k}\right)\left(c_{k}-e_{k}\right)}{\sum_{k=1}^{n}\left(c_{k}-e_{k}\right)^{2}}
$$

Ajustando os valores dos componentes de acordo com os fluxos de massa existentes:

$$
a_{k a j}-C_{a j} c_{k a j}-\left(1-C_{a j}\right) e_{a j}=0
$$

onde akaj, Ckaj, ekaj são valores ajustados do componente k, portanto:

$$
\left(a_{k}-a_{k c r}\right)-C_{a j}\left(c_{k}-c_{k c r}\right)-\left(1-C_{a j}\right)\left(e_{k}-e_{k c r}\right)=0
$$

onde akcr, Ckcr, ekcr são valores das correções que serão realizadas.

Reescrevendo a equação (25):

$$
a_{k}-C_{a j} c_{k}-\left(1-C_{a j}\right) e_{k}=r_{k}
$$

Subtraindo a equação (32) da (33):

$$
r_{k}=a_{k c r}-C_{a j} c_{k c r}-\left(1-C_{a j}\right) e_{k c r}
$$

A função $S_{c r}$ deve ser minimizada com a utilização da técnica dos mínimos quadrados. 


$$
S_{c r}=\sum_{k=1}^{n}\left(\left(a_{k c r}\right)^{2}+\left(c_{k c r}\right)^{2}+\left(e_{k c r}\right)^{2}\right)
$$

Monta-se então a função $L$ de Lagrange para se obter a minimização dos desvios, conforme a equação (36):

$L=\sum_{k=1}^{n}\left(\left(a_{k c r}\right)^{2}+\left(c_{k c r}\right)^{2}+\left(e_{k c r}\right)^{2}\right)+2 \sum_{k=1}^{n} \lambda_{k}\left(r_{k}-a_{k c r}+C_{a j} c_{k c r}+\left(1-C_{a j}\right) e_{k c r}\right)$

Para minimizar os desvios, a função $L$ deve ser deriva parcialmente em relação a cada uma das incógnitas e igualada a zero:

$$
\begin{aligned}
& \frac{\partial L}{\partial a_{k c r}}=2 a_{k c r}-2 \lambda_{k}=0 \\
& a_{k c r}=\lambda_{k} \\
& \frac{\partial L}{\partial c_{k c r}}=2 c_{k c r}+2 \lambda_{k} C_{a j}=0 \\
& c_{k c r}=-\lambda_{k} C_{a j}
\end{aligned}
$$

$$
\frac{\partial L}{\partial e_{k c r}}=2 e_{k c r}+2 \lambda_{k}\left(1-C_{a j}\right)=0
$$

$$
e_{k c r}=-\lambda_{k}\left(1-C_{a j}\right)
$$




$$
\frac{\partial L}{\partial \lambda_{k}}=2\left(r_{k}-a_{k c r}+C_{a j} c_{k c r}+\left(1-C_{a j}\right) e_{k c r}\right)=0
$$

Substituindo-se os valores de akcr, Ckcr, ekcr, na equação (44):

$$
r_{k}=\lambda_{k}\left(1+\left(C_{a j}\right)^{2}\left(1-C_{a j}\right)^{2}\right)=h \lambda_{k}
$$

onde:

$$
h=\left(1+\left(C_{a j}\right)^{2}\left(1-C_{a j}\right)^{2}\right)
$$

portanto:

$$
a_{k c r}=\frac{r_{k}}{h}
$$

$$
\begin{aligned}
& c_{k c r}=-\frac{r_{k}}{h} C_{a j} \\
& e_{k c r}=-\frac{r_{k}}{h}\left(1-C_{a j}\right)
\end{aligned}
$$

Para utilização do método descrito, deve-se:

1) Determinar o valor de $C_{a j}$ pela equação (30).

2) Calcular h pela equação (45).

3) Calcular rk pela equação (33).

4) Calcular o valor das correções que devem ser aplicadas a $a_{k c r}, C_{k c r}$, ekcr pelas equações (46), (47) e (48). 


\subsection{EQUIPAMENTOS E REPRESENTAÇÕES MATEMÁTICAS DE PROCESSOS}

Esta seção descreve brevemente as características fundamentais e também as principais representações matemáticas que são utilizadas para dimensionamento e simulação de moinhos de bolas, ciclones, prensas de rolos e moinhos de carga agitada por impelidor.

Devido ao grande número de trabalhos desenvolvidos com o objetivo de criar modelos que representassem operações unitárias de equipamentos de cominuição, torna-se impraticável relacionar todos os modelos existentes para descrever um mesmo processo. Portanto, serão explicitados os mais conhecidos e aqueles que foram utilizados na realização deste trabalho para descrever cada um dos equipamentos.

\subsubsection{Moinho de Bolas}

De acordo com Beraldo (1987), moinhos de bolas são fabricados de acordo com faixas amplas de relação comprimento $x$ diâmetro. Esse equipamento é aplicado para moagem a seco ou a úmido, em estágios primário, secundário ou remoagem. Moinho de bolas é, portanto, extremamente versátil para a cominuição em diferentes faixas de granulometria. Sua ilustração é apresentada na Figura 4. 
Figura 4 - Representação de moinho de bolas

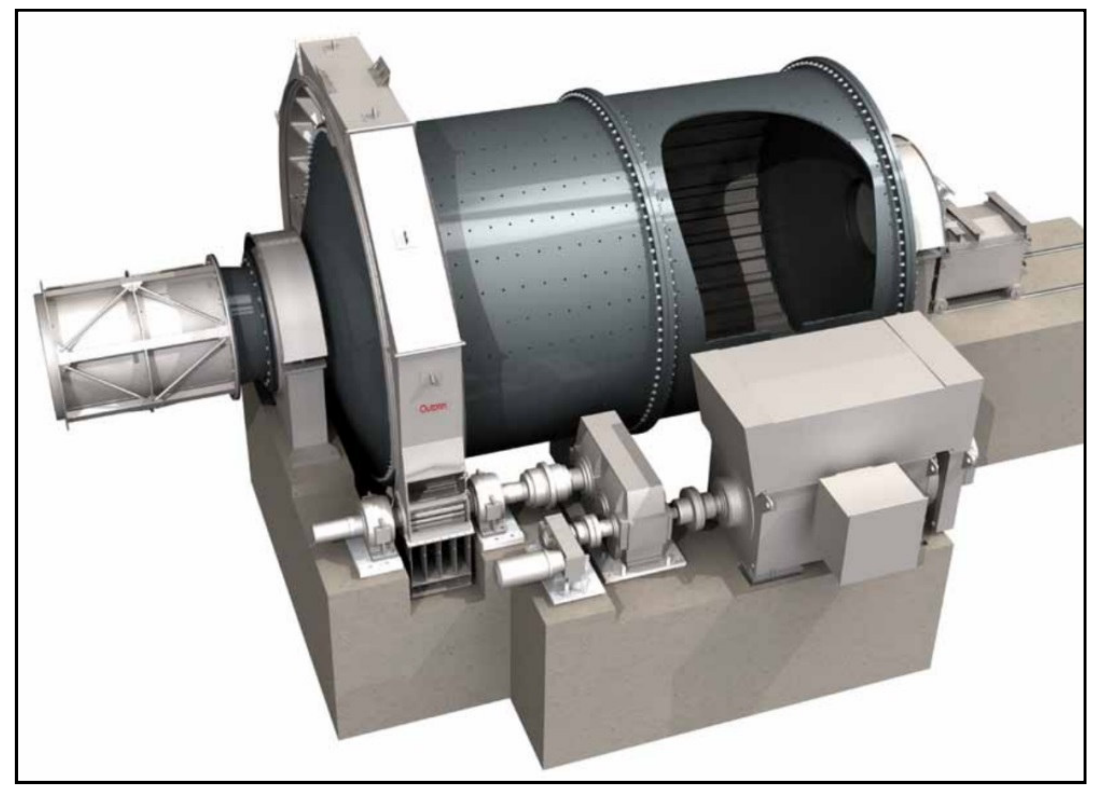

Fonte: Outotec (2012)

Apesar de o moinho de bolas apresentar grande variedade nos tipos de acionamento, material/perfil de revestimentos, dimensões, rotação etc., a concepção de seu funcionamento é relativamente simples. Nesse caso, um corpo tubular preenchido por esferas, normalmente metálicas, que, quando entra em rotação, movimenta a carga de bolas juntamente com o minério em seu interior, promovendo assim, quebras das partículas basicamente pelos mecanismos de atrição e impacto (BERALDO,1987).

\subsubsection{Modelos matemáticos para moagem em moinhos de bolas}

Napier-Munn e Lynch (1991) descreveram o status da modelagem e simulação computacional para processos de tratamento de minérios. Na conclusão do estudo, os autores listam três elementos vitais, mencionados a seguir, que tornaram as ferramentas de simulação uma realidade.

1) Modelos realísticos do processo

2) Interfaces amigáveis dos simuladores

3) Computadores acessíveis com hardwares, nos quais pudessem ser executados os simuladores 
Em particular, os itens 2 e 3 citados propiciaram o desenvolvimento de modelos mais realistas de processos (item 1), mais complexos do ponto de vista matemático, com a utilização de maiores números de variáveis e interações, ao mesmo tempo em que os cálculos eram realizados com maior rapidez e facilidade, pois os computadores eram acessíveis e os resultados muito mais coerentes com a realidade. O número de usuários de computadores aumentou e difundiu esse conhecimento, o que fez com que os circuitos de cominuição existentes pudessem ser simulados, comprovando-se a efetividade dos modelos propostos. Atualmente não resta dúvida sobre o desenvolvimento que esse tipo de ferramenta trouxe para a eficiência operacional das indústrias e assertividade no dimensionamento de novos equipamentos.

\subsection{Modelos empíricos}

No passado houve várias tentativas empíricas de se criar um modelo para moagem de bolas, que relacionasse o tamanho do material da alimentação com tamanho do material do produto por meio da energia aplicada e de constantes referentes ao tipo de material. Alguns desses modelos foram e continuam sendo usados para uma estimativa primária do comportamento da moagem. Os principais autores dessas teorias foram Kick, Rittinger e Bond (KICK 1865; RITTINGER; 1867 e BOND, 1952 apud CHAVES, 2003). Os três modelos podem, no entanto, ser generalizados segundo a equação (49) demonstrada por Walker (1937), que se segue.

$$
d E=K \cdot d x / x^{n}
$$

Onde:

$\mathrm{dx}=$ variação diferencial do tamanho da partícula

$\mathrm{dE}=$ diferencial de energia necessário para gerar um diferencial de tamanho dx

$\mathrm{K}=$ constante referente ao material

$\mathrm{n}=$ constante dependente do fator $\mathrm{K}$ 
De acordo com Delboni, Sampaio e Lima (2010), o método de Bond é representado pela equação (50), mencionada a seguir, fundamentada no método desenvolvido por Bond e no índice de trabalho:

$$
E=10 W i\left[\frac{1}{\sqrt{P_{80}}}-\frac{1}{\sqrt{F_{80}}}\right]
$$

onde:

$\mathrm{E}=$ energia $(\mathrm{kWh} / \mathrm{st})$

WI = Work index ou Índice de trabalho

$\mathrm{P}_{80}=$ tamanho em $\mu \mathrm{m}$ em que passam $80 \%$ da massa do produto

$\mathrm{F}_{80}=$ tamanho em $\mu \mathrm{m}$ em que passam $80 \%$ da massa da alimentação

Por meio da equação (50), é possível estimar a quantidade de energia necessária para a moagem do material na condição requerida para o processo. Para isso, deve-se quantificar o Wi do material pelo método de Bond.

Alguns fatores são necessários para corrigir eventuais desvios na aplicação do modelo de Bond, uma vez que Bond estabeleceu condições padrão para aplicação do método por ele criado. Entre tais fatores de correção $E F_{i}$ propostos por Rowland (1986) destacam-se os referentes à moagem a seco, circuito aberto, diâmetro do moinho, alimentação com material muito grosseiro e geração de produto muito fino. Esses fatores serão apresentados na seção 3.3.1.2.

\subsection{Modelo do Misturador Perfeito ou Perfect Mixing Model (PMM)}

O modelo do misturador perfeito (PMM) proposto por Withen (1976) apud Delboni (2003) será aqui descrito com detalhes, pois este foi selecionado para emprego no presente trabalho.

Há na literatura especializada modelos de três naturezas, quais sejam, modelos empíricos, modelos fenomenológicos e modelos fundamentais. Uma classe importante de modelos fenomenológicos é o modelo de balanço populacional. 
Tanto o Perfect Mixing Model - PMM como o modelo cinético são derivações do modelo de balanço populacional e, portanto, de natureza fenomenológica. Tais modelos incluem essencialmente dois grupos de parâmetros. Enquanto o primeiro grupo representa as características específicas de fragmentação das partículas, o segundo grupo de parâmetros inclui a cinética de fragmentação que ocorre no equipamento, este último estimado de forma indireta, sendo, portanto, tratado como uma composição de fenômenos físicos. Tais modelos são baseados na previsão das características do produto pelas características da alimentação sem descrever mecanisticamente os princípios físicos que ocorrem no interior de moinhos, por isso mesmo conhecidos como Black Box Models (GOMES, 2014).

Os modelos fenomenológicos não são, portanto, baseados na energia consumida, representando, assim, uma evolução no uso de fenômenos de quebra de partículas individuais e suas combinações no arcabouço do balanço populacional. Trata-se, portanto, de um enfoque diferente das associações entre energia consumida e características do produto, como nos denominados modelos energéticos.

O PMM é embasado no equilíbrio da massa contida em cada uma das frações granulométricas que compõem a carga interna do moinho. Com base nesse princípio, é estabelecido o balanço de massas para cada uma das faixas granulométricas que entram e saem da carga do moinho. A título de exemplo, para determinada faixa granulométrica, o fluxo de entrada é composto pelo material da alimentação nova do moinho e pelo material que estava dentro do moinho com granulometria acima e que foi quebrado, gerando partículas na granulometria considerada. Já o fluxo de saída da mesma fração granulométrica da carga é composto pelo produto do moinho e pelo material que sai da faixa considerada, porém permanecendo na carga do moinho.

A cinética de cominuição é representada por três funções (BERALDO, 1987).

- Função Taxa de Quebra (Breakage Rate): representa a velocidade de quebra do material na granulometria de alimentação.

- Função Quebra (Appearance Function): representa a distribuição granulométrica gerada pela quebra de uma partícula maior.

- Função Classificação: representa uma seleção que possa ocorrer durante a moagem de partículas mais grossas e a liberação das partículas finas. Esta 
função não apresenta efeito significativo na moagem de bolas, mas tem influência relevante na moagem de barras.

Conforme descrito por Delboni (DELBONI, 2003), o PMM considera que o produto do moinho está relacionado com a massa dentro do moinho através de uma taxa de descarga di para cada faixa granulométrica como mostra a equação (51).

$$
p_{i}=d_{i} s_{i}
$$

onde:

$\mathrm{p}_{\mathrm{i}}=$ vazão do produto descarregado pelo moinho da fração granulométrica $\mathrm{i}$

$\mathrm{Si}=$ massa da fração granulométrica i no moinho

$\mathrm{d}_{\mathrm{i}}=$ taxa de descarga do material da fração granulométrica i

O balanço de massa para cada faixa é descrito por:

$$
f_{i}-p_{i}\left(1+\frac{r_{i}}{d_{i}}\left(1-a_{i i}\right)\right)+\sum_{j=1}^{i-1} a_{i j}\left(\frac{r_{i}}{d_{i}}\right) p_{i}=0
$$

Onde:

$f_{i}=$ vazão de alimentação da fração granulométrica i do moinho

$r_{i}=$ taxa de quebra do material na fração i

$a_{i j}=$ appearence function ou função quebra

Esse modelo é bastante utilizado, pois permite ajuste para moinhos de diversos tamanhos e condições de operação. Geralmente, o ajuste tem por base uma amostragem, na qual são determinadas as distribuições de alimentação e produto do moinho $\left(\mathrm{f}_{\mathrm{i}}, \mathrm{p}_{\mathrm{i}}\right)$, assim como a determinação da função quebra ( $\mathrm{aij}_{\mathrm{ij}}$ ) por meio do ensaio padronizado de laboratório. A calibração do modelo consiste, portanto na determinação da função taxa de quebra $\left(r_{i} / d_{i}\right)$, a qual torna-se assim característica do 
moinho amostrado que, após normalização, permite comparações com diversas outras operações de moinho de bolas, quaisquer que sejam as suas dimensões.

Para realizar essa normalização, é necessário dividir os parâmetros $r_{i} / d_{i}$ pelo tempo de residência médio das partículas no interior do moinho como indica a equação (53):

$$
\frac{r_{i}}{d_{i}^{*}}=\frac{\left(\frac{r_{i}}{d_{i}}\right)}{\left(\frac{D^{2} L}{4 Q}\right)}
$$

onde:

$\mathrm{D}=$ diâmetro interno do moinho $(\mathrm{m})$

$L=$ comprimento interno do moinho $(m)$

$\mathrm{Q}=$ vazão volumétrica da alimentação do moinho $\left(\mathrm{m} / \mathrm{h}^{3}\right)$

Portanto, de posse da função de taxa de quebra normalizada $\left(r / d^{*}\right)$ para um circuito, torna-se possível simular cenários para mudanças como diâmetro do moinho, grau de enchimento, velocidade de rotação, variação de Wi e diâmetro de bolas (DELBONI, 2003).

Para realizar as simulações, considera-se que:

$$
\left(\frac{r_{i}}{d_{i}^{*}}\right)_{S I M}=(\text { FATOR DE ESCALA })\left(\frac{r_{i}}{d_{i}^{*}}\right)_{A J U S}
$$

Cálculo dos fatores de escala para diferentes parâmetros:

Efeito do Diâmetro (D) do moinho

$$
F_{A}=\sqrt{\frac{D_{S I M}}{D_{A J U S}}}
$$


Efeito do Grau de Enchimento (GE) do moinho

$$
F_{B}=\left[\frac{\left(1-G E_{S I M}\right)}{\left(1-G E_{A J U S}\right)} \frac{\left(G E_{S I M}\right)}{\left(G E_{A J U S}\right)}\right]
$$

Efeito da Velocidade do moinho (Vel) em porcentagem da velocidade crítica

$$
F_{C}=\left(\frac{V e l_{S I M}}{V e l_{A J U S}}\right)
$$

O fator de correção da equação (57) é valido para variações de velocidade do moinho entre os limites de $55 \%$ e $78 \%$ da velocidade crítica do moinho.

Efeito da variação do Wi do minério

$$
F_{D}=\left(\frac{W I_{A J U S}}{W I_{S I M}}\right)^{0,8}
$$

Efeito do diâmetro de bolas $\left(D_{b}\right)$

$$
X_{\text {max }}=K D_{b}^{2}
$$

onde:

$X_{\max }=$ tamanho de partícula no qual ocorre a máxima taxa de quebra $(\mathrm{mm})$

$\mathrm{K}=$ constante (aproximadamente $4,4 \times 10^{-4} \mathrm{~mm}^{-1}$ )

$\mathrm{D}_{\mathrm{b}}=$ diâmetro das bolas $(\mathrm{mm})$

$r / d^{*} a D b^{2}$ para $x>x_{\max }$

$r / d^{*} a 1 / D_{b}^{2}$ para $x<X_{\max }$ 
Sendo assim, os fatores de correção são os seguintes:

para $x>x_{\max }$

$$
F_{E}=\left(\frac{D_{b S I M}}{D_{b \text { AJUS }}}\right)^{2}
$$

e para $x<x_{\max }$

$$
F_{E}=\left(\frac{\left(D_{b \operatorname{SIM}^{-1}}\right)}{\left(D_{b \text { AJUS }}{ }^{-1}\right)}\right)^{2}
$$

\subsubsection{Modelo Energético de Moinhos de Bolas - Método de Bond-Rowland}

O dimensionamento de moinhos de bolas pode ser feito de diferentes maneiras, com base no consumo energético da moagem (BERALDO, 1987). Entre os diferentes métodos apresentados para realizar o dimensionamento, o mais comum se baseia no modelo de Bond equação (50), onde, a partir da informação da granulometria de alimentação e do produto e de posse do Wi do minério, é possível estimar a energia específica para realizar a moagem. A energia calculada se refere à vazão de alimentação nova do circuito, bem como a potência requerida para o acionamento do eixo do pinhão do moinho. Isso significa que não inclui as perdas de energia que ocorrem nos redutores, motores e em outros componentes (DELBONI; SAMPAIO; LIMA, 2010).

Por ser um método que utiliza correlações empíricas para uma determinada condição industrial padrão, utilizam-se fatores de correção conforme propostos por Rowland (1982), para aplicações diferentes daquelas consideradas como padrão. Os resultados são úteis para estimativas preliminares de dimensionamento de moinhos de bolas nas condições previstas por Bond-Rowland para emprego do equipamento. A equação (62) é, portanto, a equação (50) acrescida dos fatores de correção descritos a seguir. 


$$
E=10 W i\left[\frac{1}{\sqrt{P_{80}}}-\frac{1}{\sqrt{F_{80}}}\right] . E F i
$$

\section{$E F_{1}-$ Moagem a seco}

Fator igual a 1,3 referente às ineficiências da moagem a seco

\section{$E F_{2}-$ Circuito aberto}

A moagem em circuito aberto consome mais energia quando comparada com circuito fechado. O fator de correção está descrito na Tabela 2, cuja referência é, portanto, a porcentagem passante na malha de controle.

Tabela 2 - Fator de ineficiência para circuitos abertos

\begin{tabular}{|c|c|}
\hline $\begin{array}{c}\text { Controle do produto \% } \\
\text { passante na }(\text { malha de } \\
\text { referência em } \mu \mathrm{m})\end{array}$ & Fator $\mathrm{EF}_{2}$ \\
\hline 50 & 1,035 \\
\hline 60 & 1,05 \\
\hline 70 & 1,10 \\
\hline 80 & 1,20 \\
\hline 90 & 1,40 \\
\hline 92 & 1,46 \\
\hline 95 & 1,57 \\
\hline 98 & 1,70 \\
\hline
\end{tabular}

Fonte: Delboni; Sampaio; Lima (2010)

$\mathrm{EF}_{3}-$ Fator do diâmetro

Segundo Rowland, o aumento do diâmetro do moinho eleva a eficiência de moagem conforme apresentado na Tabela 3. 
Tabela 3 - Fatores de eficiência do diâmetro do moinho

\begin{tabular}{|c|c|c|}
\hline $\begin{array}{c}\text { Diâmetro do moinho interno } \\
\text { à carcaça }(\mathrm{m})\end{array}$ & $\begin{array}{c}\text { Diâmetro do moinho interno } \\
\text { ao revestimento }(\mathrm{m})\end{array}$ & Fator $\mathrm{EF}_{3}$ \\
\hline 0,914 & 0,79 & 1,25 \\
\hline 1,00 & 0,88 & 1,23 \\
\hline 1,22 & 1,10 & 1,17 \\
\hline 1,52 & 1,40 & 1,12 \\
\hline 1,83 & 1,79 & 1,075 \\
\hline 2,00 & 1,82 & 1,060 \\
\hline 2,13 & 1,98 & 1,042 \\
\hline 2,44 & 2,29 & 1,014 \\
\hline 2,59 & 2,44 & 1,000 \\
\hline 2,74 & 2,59 & 0,992 \\
\hline 2,90 & 2,74 & 0,977 \\
\hline 3,00 & 2,85 & 0,970 \\
\hline 3,05 & 2,90 & 0,966 \\
\hline 3,02 & 3,05 & 0,956 \\
\hline 3,35 & 3,20 & 0,948 \\
\hline 3,51 & 3,35 & 0,939 \\
\hline 3,66 & 3,51 & 0,931 \\
\hline 3,81 & 3,66 & 0,923 \\
\hline 3,96 & 3,81 & 0,914 \\
\hline$>3,96$ & $>3,81$ & 0,914 \\
\hline
\end{tabular}

Fonte: Delboni; Sampaio; Lima (2010)

\section{$\mathrm{EF}_{4}$ - Fator de oversize}

Fator aplicado quando o tamanho da maior partícula é superior à referência estipulada por Bond, esta última definida por Fo.

$$
F o=4.000\left(\frac{13}{W i}\right)^{0,5}
$$

E a relação de redução $R_{r}$ definido por:

$$
R_{r}=\frac{F_{80}}{P_{80}}
$$

O fator $\mathrm{EF}_{4}$ é calculado pela equação (65):

$$
E F_{4}=\frac{R_{r}+(W i-7)\left(\frac{F_{80}-F o}{F o}\right)}{R_{r}}
$$


$\mathrm{EF}_{5}-$ Material fino

Quando o valor de $\mathrm{P}_{80}$ está abaixo de $74 \mu \mathrm{m}$, deve-se usar a equação (66).

$$
E F_{5}=\frac{P_{80}+10,3}{1,145 P_{80}}
$$

$\mathrm{EF}_{6}$ - Relação de redução em moinho de barras

Esse fator não será descrito, pois não tem aplicação para este trabalho.

$\mathrm{EF}_{7}$ - Baixa relação de redução em moinho de bolas

Aplica-se a equação (67) quando a relação de redução for menor que 6.

$$
E F_{7}=\frac{R_{r}-1,22}{R_{r}-1,35}
$$

$\mathrm{EF}_{8}$ - Moagem em moinho de barras

Esse fator não será descrito, pois não tem aplicação para este trabalho.

Tendo calculado o consumo de energia pela equação (62), é possível selecionar um moinho de bolas que seja capaz de fornecer a potência requerida utilizando-se, por exemplo, catálogos de fornecedores de equipamentos. A Figura 5 e a Tabela 4 foram extraídas do catálogo da Metso, empresa finlandesa que fornece equipamentos industriais para beneficiamento de minérios. Os parâmetros apresentados para a Tabela 4 são para moinhos com descarga por overflow operando em $76 \%$ da velocidade crítica, em moagem secundária em circuito fechado a úmido com carga de bolas entre 35 e $40 \%$ 
Figura 5 - Referência dos pontos onde são medidas as dimensões do diâmetro (D) e comprimento (L) dos moinhos de bolas

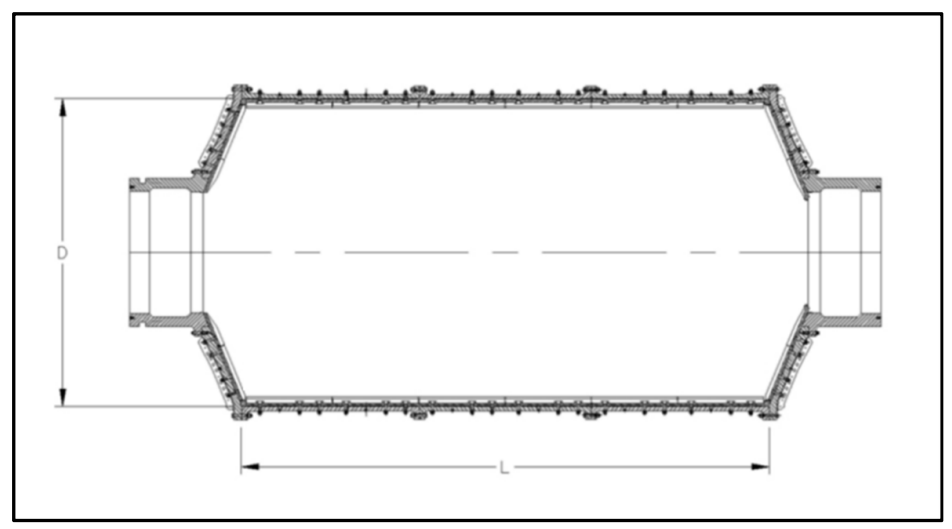

Fonte: Metso (2015)

Tabela 4 - Informações técnicas de parâmetros de moinhos de bolas

\begin{tabular}{|c|c|c|c|}
\hline $\begin{array}{c}\text { Dimensão D x L } \\
(\text { pé})\end{array}$ & $\begin{array}{c}\text { Dimensão D x L } \\
(\mathrm{m})\end{array}$ & $\begin{array}{c}\text { Potência Aprox. } \\
(\mathrm{hp} / \mathrm{kW})\end{array}$ & $\begin{array}{c}\text { Potência Motor } \\
(\mathrm{hp} / \mathrm{kW})\end{array}$ \\
\hline $9^{\prime} \times 12^{\prime}$ & $(2,7 \times 3,7)$ & $388 / 290$ & $450 / 335$ \\
\hline $9^{\prime} \times 14^{\prime}$ & $(2,7 \times 4,2)$ & $455 / 340$ & $500 / 373$ \\
\hline $95^{\prime} \times 15^{\prime}$ & $(2,9 \times 4,6)$ & $564 / 420$ & $600 / 447$ \\
\hline $10^{\prime} \times 15^{\prime}$ & $(3,0 \times 4,6)$ & $596 / 445$ & $700 / 522$ \\
\hline $10.5^{\prime} \times 15^{\prime}$ & $(3,2 \times 4,6)$ & $734 / 547$ & $800 / 597$ \\
\hline $10.5^{\prime} \times 17^{\prime}$ & $(3,2 \times 5,2)$ & $836 / 623$ & $900 / 671$ \\
\hline $11^{\prime} \times 17^{\prime}$ & $(3,3 \times 5,2)$ & $944 / 704$ & $1000 / 746$ \\
\hline $11.5^{\prime} \times 18^{\prime}$ & $(3,5 \times 5,5)$ & $1125 / 839$ & $1250 / 932$ \\
\hline $13^{\prime} \times 17^{\prime}$ & $(3,9 \times 5,2)$ & $1460 / 1089$ & $1500 / 1119$ \\
\hline $13^{\prime} \times 19^{\prime}$ & $(3,9 \times 5,8)$ & $1637 / 1220$ & $1750 / 1305$ \\
\hline $14^{\prime} \times 18^{\prime}$ & $(4,2 \times 5,5)$ & $1877 / 1400$ & $2000 / 1491$ \\
\hline $14^{\prime} \times 20^{\prime}$ & $(4,2 \times 6,0)$ & $2091 / 1559$ & $2250 / 1677$ \\
\hline $15^{\prime} \times 19^{\prime}$ & $(4,6 \times 5,8)$ & $2372 / 1769$ & $2500 / 1864$ \\
\hline $15.5^{\prime} \times 21^{\prime}$ & $(4,7 \times 6,4)$ & $2861 / 2133$ & $3000 / 2237$ \\
\hline $16.5^{\prime} \times 21^{\prime}$ & $(5,0 \times 6,4)$ & $3362 / 2507$ & $3000 / 2237$ \\
\hline $16.5^{\prime} \times 24^{\prime}$ & $(5,0 \times 7,3)$ & $3854 / 2873$ & $4000 / 2983$ \\
\hline $16.5^{\prime} \times 27^{\prime}$ & $(5,0 \times 8,2)$ & $4346 / 3240$ & $4500 / 3356$ \\
\hline $16.5^{\prime} \times 30^{\prime}$ & $(5,0 \times 9,1)$ & $4838 / 3608$ & $5000 / 3728$ \\
\hline $16.5^{\prime} \times 33^{\prime}$ & $(5,0 \times 10,0)$ & $5330 / 3975$ & $5500 / 4101$ \\
\hline $18^{\prime} \times 29^{\prime}$ & $(5,5 \times 8,8)$ & $5847 / 4360$ & $6000 / 4474$ \\
\hline $18^{\prime} \times 31.5^{\prime}$ & $(5,5 \times 9,6)$ & $6360 / 4743$ & $6000 / 4474$ \\
\hline $18^{\prime} \times 33.5^{\prime}$ & $(5,5 \times 10,2)$ & $6771 / 5049$ & $7000 / 5220$ \\
\hline
\end{tabular}

Fonte: Adaptado de Metso (2015) 


\subsubsection{Ciclone}

Ciclone ou hidrociclone é um equipamento amplamente utilizado como classificador em circuitos de moagem, tendo influência significativa no desempenho e na eficiência da operação de moagem. Alterações nas condições estruturais ou de operação do ciclone podem ser responsáveis pelo aumento de capacidade ou pelas alterações nas granulometrias do produto da moagem. O resultado da classificação afeta também a eficiência nos processos posteriores de beneficiamento como flotação, lixiviação e outros processos hidrometalúrgicos. Devido a isso, o entendimento e estudo desse equipamento é fundamental (LYNCH, 1975).

A Figura 6 apresenta uma ilustração dos principais componentes e fluxos do ciclone. O equipamento é composto basicamente por um corpo metálico com uma câmara de alimentação seguida de uma seção cilíndrica que se afunila em uma seção cônica. O ciclone é alimentado com polpa de minério pelo inlet, entrada lateral e tangencial ao corpo do equipamento. O material alimentado pode sair por dois pontos: pelo apex, que é localizado no final da seção cônica e por onde flui o material grosseiro ou underflow, ou pelo vortex, que é localizado na parte superior do equipamento e por onde flui o material classificado fino ou overflow.

Figura 6 - Principais componentes e fluxos do ciclone

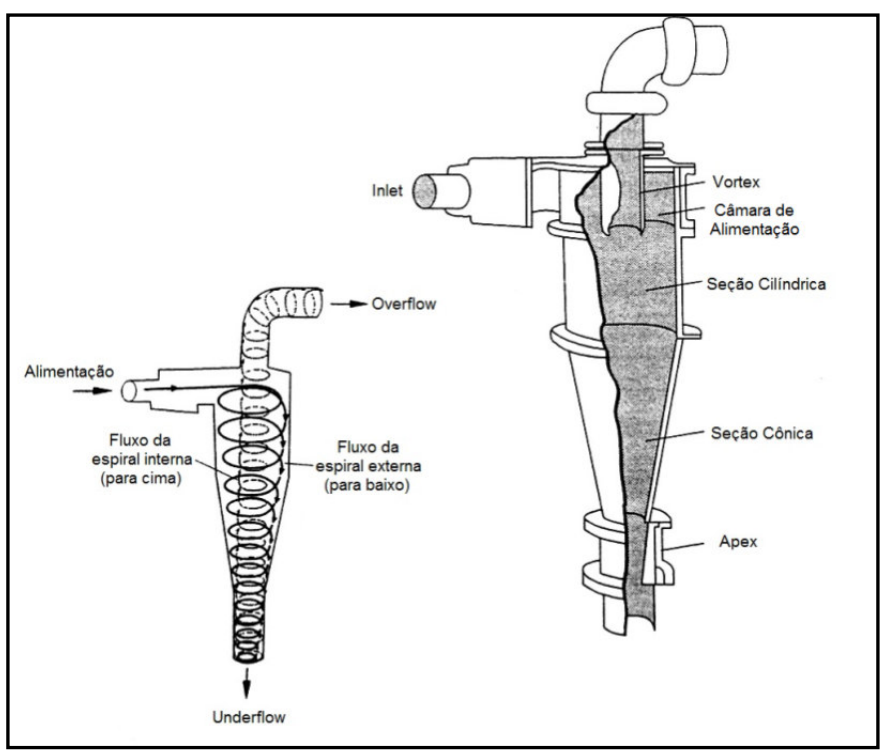

Fonte: Adaptado de Napier-Munn et al. (1996) 
O resultado da classificação pode ser avaliado pelas curvas de partição do sistema que apresentam, para cada tamanho de partícula que alimentam ciclone, a fração que segue para o underflow.

A curva de partição é um recurso útil para quantificar e comparar o desempenho da classificação de ciclones. Em geral, as curvas de partição decrescem com o tamanho das partículas e tendem a alcançar um valor chamado by-pass ou curtocircuito (FINCH, 1983).

Uma curva de partição típica, denominada curva real, é mostrada na Figura 7, onde o eixo das ordenadas apresenta a porcentagem do material alimentado que sai no underflow, e na abscissa, o tamanho de partícula.

Figura 7 - Curva de partição típica para ciclone

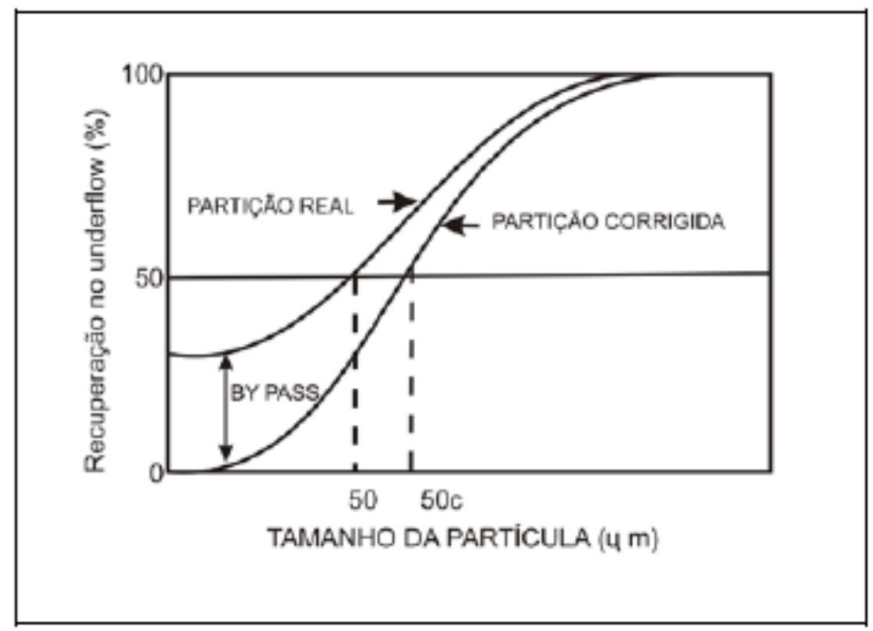

Fonte: Correia (2010)

A curva de partição real é obtida a partir de dados experimentais. O parâmetro d50 representa o diâmetro em que $50 \%$ do material alimentado no ciclone é encaminhado ao overflow.

Parte das partículas finas flui pelo underflow, pois são arrastadas pelo fluxo de água, entre outros fatores. Esse fenômeno é conhecido como by-pass ou curto-circuito e impede que o processo de classificação em ciclones forneça uma separação perfeita. 
Para a determinação da curva de partição corrigida, também mostrada na Figura 7, em que hipoteticamente não ocorreria o fenômeno de by-pass, considera-se que, se $R_{f}$ corresponde à fração de água da alimentação que sai no underflow, uma porcentagem $\mathrm{R}_{\mathrm{f}}$ de todos os tamanhos de partículas é arrastada para o underflow. Com essas considerações, é possível calcular uma curva corrigida que fornecerá o d50c para o sistema (KELSALL, 1953).

A curva de partição é calculada pela equação (68) a seguir:

$$
\beta_{(i)}=\frac{U \cdot u_{(i)}}{A \cdot a_{(i)}}
$$

Sendo:

$\beta=$ Partição

$\mathrm{i}=$ malha granulométrica

$\mathrm{U}, \mathrm{A}=$ vazão mássica de sólidos do underflow e na alimentação respectivamente

$u_{(i)}, a_{(i)}=$ porcentagem retida simples em peso na malha $\mathrm{i}$ do underflow e na alimentação respectivamente

Utilizando a teoria proposta por Kelsall (1953), os pontos para curva de partição corrigida podem ser calculados como descrito a seguir (PLITT, 1976):

$$
\beta_{(i)_{c}}=\frac{\beta_{(i)}-R_{f}}{1-R_{f}}
$$

Para calcular a recuperação de fluido para o underflow:

$$
R_{f}=\frac{R_{v}-R_{s} \phi}{1-\phi}
$$


Sendo que, para calcular a partição volumétrica em termos da razão entre vazões, utiliza-se a equação:

$$
R_{v}=\frac{S}{S+1}
$$

A razão entre vazões é definida como:

$$
S=\frac{\text { Vazão volumétrica do underflow }}{\text { Vazão volumétrica do overflow }}
$$

onde:

$\phi=$ fração volumétrica de sólidos na alimentação da polpa

$\mathrm{R}_{\mathrm{s}}=$ recuperação de sólidos para o underflow

Por meio de um artifício matemático, que considera a divisão dos valores das abscissas da curva de partição corrigida pelo diâmetro mediano da partição $\left(\mathrm{d}_{50 c}\right)$, obtém-se a curva padrão de partição.

Segundo Plitt (1976) a curva padrão para determinado material é independente de parâmetros do ciclone e das condições operacionais. Portanto, é possível, por meio dos testes de bancada, prever dimensões de um equipamento em escala industrial. (LYNCH, 1965 apud PLITT, 1976).

A curva padrão tem mais de uma parametrização a equação (73) é a formulação de Plitt, e tem por base a distribuição de Rosin-Rammler:

$$
\beta_{(i)_{\text {padrão }}}=1-e^{\left[-0,693\left(\frac{d_{i}}{d_{50}}\right)^{m}\right]}
$$


Onde $m$ está relacionado com a inclinação da curva de partição.A fórmula de Whiten para cálculo de eficiência (NAPIER-MUNN et al.,1996) foi utilizada por Nageswararao e está representada na equação (74), mencionada a seguir:

$$
E_{0 a i}=C\left[\frac{e^{\alpha}-1}{e^{\alpha d_{i} / d_{50 c}}+e^{\alpha}-2}\right]
$$

Onde:

$E_{0 a i}=$ recuperação para o overflow para partículas de diâmetro $i$

$\mathrm{C}=$ partição de água para o overflow

A = parâmetro de inclinação da curva de partição

O modelo de Nageswararao é tratado com detalhes na seção 3.3.2.1.2.

\subsubsection{Modelos para ciclones}

Existem dois modelos matemáticos principais que têm sido utilizados na maior parte dos programas computacionais para modelagem e simulação de ciclones. Esses modelos foram desenvolvidos por Plitt (1976) e Nageswararao (1978), com base em extensas campanhas de ensaios. Ambos dependem de relações empíricas entre as variáveis selecionadas. Apesar de existir semelhanças entre os modelos, há também divergências em suas estruturas e variáveis envolvidas que, algumas vezes, podem levar a resultados diferentes em simulações para projetos similares.

O modelo de Plitt é empregado nos simuladores comerciais ModSim e Usimpac, enquanto o modelo de Nageswararao é a base para o simulador JKSimMet.

\subsection{Modelo de Plitt}

No estudo de Plitt (1976), é apresentado um conjunto de quatro equações que integram o seu modelo matemático. Na sequência, estão descritas as equações principais e suas variáveis.

Variáveis: 
- Alimentação do Ciclone, A (L/min)

- Diâmetro mediano de separação corrigido, d50c $(\mu \mathrm{m})$

- Razão volumétrica, S

- Inclinação da curva de partição, m

- Diâmetro do ciclone $\mathrm{D}_{\mathrm{c}}(\mathrm{cm})$

- Diâmetro do vortex, $D_{0}(\mathrm{~cm})$

- Diâmetro do apex, Du (cm)

- Diâmetro de entrada, $D_{i}(\mathrm{~cm})$

- Altura livre do vortex, $\mathrm{h}(\mathrm{cm})$

- Pressão no ciclone expressa em relação à alimentação, $\mathrm{H}(\mathrm{m})$

- Pressão no ciclone, $\mathrm{P}(\mathrm{kPa})$

- Fração volumétrica de sólidos na alimentação, $\phi(\%)$

- Densidade do líquido, $\rho\left(\mathrm{g} / \mathrm{cm}^{2}\right)$

- Densidade do sólido, $\rho_{s}\left(\mathrm{~g} / \mathrm{cm}^{2}\right)$

Para previsão do d $_{50 c}, \mathrm{~S}, \mathrm{P}$ e $\mathrm{m}$ de Plitt (1976), as seguintes relações foram propostas:

$$
d_{50_{c}}=\frac{50,5 D_{c}^{0,46} D_{i}^{0,6} D_{o}^{1,21} e^{(0,063 \phi)}}{D_{u}^{0,71} h^{0,37} A^{0,45}\left(\rho_{s}-\rho\right)^{0,5}}
$$




$$
\begin{aligned}
& S=\frac{1,9\left(D_{u} / D_{o}\right)^{3,31} h^{0,54}\left(D_{u}^{2}+D_{o}^{2}\right)^{0,36} e^{(0,0054 \phi)}}{H^{0,24} D_{c}^{1,11}} \\
& P=\frac{1,88 A^{1,78} e^{(0,0055 \phi)}}{D_{c}^{0,37} D_{i}^{0,94} h^{0,28}\left(D_{u}^{2}+D_{o}^{2}\right)^{0,87}} \\
& m=1,94 e^{\left(-1,58 R_{v}\right)}\left(\frac{D_{c}^{2} h}{A}\right)^{0,15}
\end{aligned}
$$

O modelo de Plitt tem várias aplicações como análise e diagnóstico de processo por meio das variáveis de $d_{50}, m$ e $R_{f}$, bem como é utilizado para dimensionamento de ciclones.

\subsection{Modelo de Nageswararao}

O estudo de Nageswararao (1978) apresenta o método utilizado para desenvolver o seu modelo para ciclones. Esse método foi baseado nos trabalhos pioneiros de Lynch e Rao (1975) e é definido por variáveis de projeto de operação e variáveis dependentes.

A consideração do campo de força centrífuga dentro do ciclone é definida pelo fator $\mathrm{P} /\left(\rho_{\mathrm{s}} g \mathrm{D}_{\mathrm{c}}\right)$. Também é apresentado no modelo o efeito do movimento diferencial das partículas sólidas representado pelo fator $\lambda$.

A seguir é apresentada a lista de variáveis consideradas para o modelo de Nageswararao:

- Diâmetro do ciclone $D_{c}$

- Diâmetro do vortex pelo diâmetro do ciclone, $D_{0} / D_{c}$

- Diâmetro do Apex pelo diâmetro do ciclone, $D_{u} / D_{c}$

- Diâmetro de entrada pelo diâmetro do ciclone, $D_{i} / D_{c}$

- Comprimento da seção cilíndrica do vortex pelo diâmetro do ciclone, $L_{c} / D_{c}$

- Ângulo do Cone, $\theta$ 
Para previsão do $d_{50 c}, R_{f}, R_{v}$ e $A$ do modelo de Nageswararao, as seguintes relações foram propostas:

$$
d_{50_{c}}=K_{D_{o}}\left(\frac{D_{i}}{D_{c}}\right)^{-0,5}(\theta)^{0,15}\left(\frac{L_{c}}{D_{c}}\right)^{0,2} D_{c}^{0,35}\left(\frac{D_{o}}{D_{c}}\right)^{0,52}\left(\frac{D_{u}}{D_{c}}\right)^{-0,47} \lambda^{0,93}\left(\frac{P}{\rho_{p} g D_{c}}\right)^{-0,22}
$$

Pela constante KDo, é possível calibrar a equação (79), desde que se disponha da curva de partição, características do minério como granulometria e peso específico e demais variáveis de geometria e operação do ciclone considerado.

$$
\begin{aligned}
& R_{f}=K_{W_{o}}\left(\frac{D_{i}}{D_{c}}\right)^{-0,5}(\theta)^{-0,24}\left(\frac{L_{c}}{D_{c}}\right)^{0,22}\left(\frac{D_{o}}{D_{c}}\right)^{-1,19}\left(\frac{D_{u}}{D_{c}}\right)^{2,40} \lambda^{0,27}\left(\frac{P}{\rho_{p} g D_{c}}\right)^{-0,53} \\
& R_{v}=K_{V_{o}}\left(\frac{D_{i}}{D_{c}}\right)^{-0,25}(\theta)^{-0,24}\left(\frac{L_{c}}{D_{c}}\right)^{0,22}\left(\frac{D_{o}}{D_{c}}\right)^{-0,94}\left(\frac{D_{u}}{D_{c}}\right)^{1,83}\left(\frac{P}{\rho_{p} g D_{c}}\right)^{-0,31} \\
& Q=K_{Q_{o}}\left(\frac{D_{i}}{D_{c}}\right)^{0,45}(\theta)^{-0,1}\left(\frac{L_{c}}{D_{c}}\right)^{0,2} D_{c}^{2}\left(\frac{P}{\rho_{p}}\right)^{0,5}\left(\frac{D_{o}}{D_{c}}\right)^{0,68}
\end{aligned}
$$

\subsubsection{Seleção de Ciclones}

Para selecionar a dimensão adequada do ciclone para determinado processo, é recomendável recorrer a catálogos de equipamentos fornecidos por fabricantes tradicionais do mercado, que assim auxiliam na obtenção de informações sobre as suas dimensões comerciais e as faixas de atuação.

A Figura 8 contém uma indicação da faixa de operação de ciclones fabricados pela WEIR. Essas informações são utilizadas para obter um indicativo sobre o equipamento a ser usado em cada aplicação. 
Figura 8 - Faixa de operação de ciclones Cavex

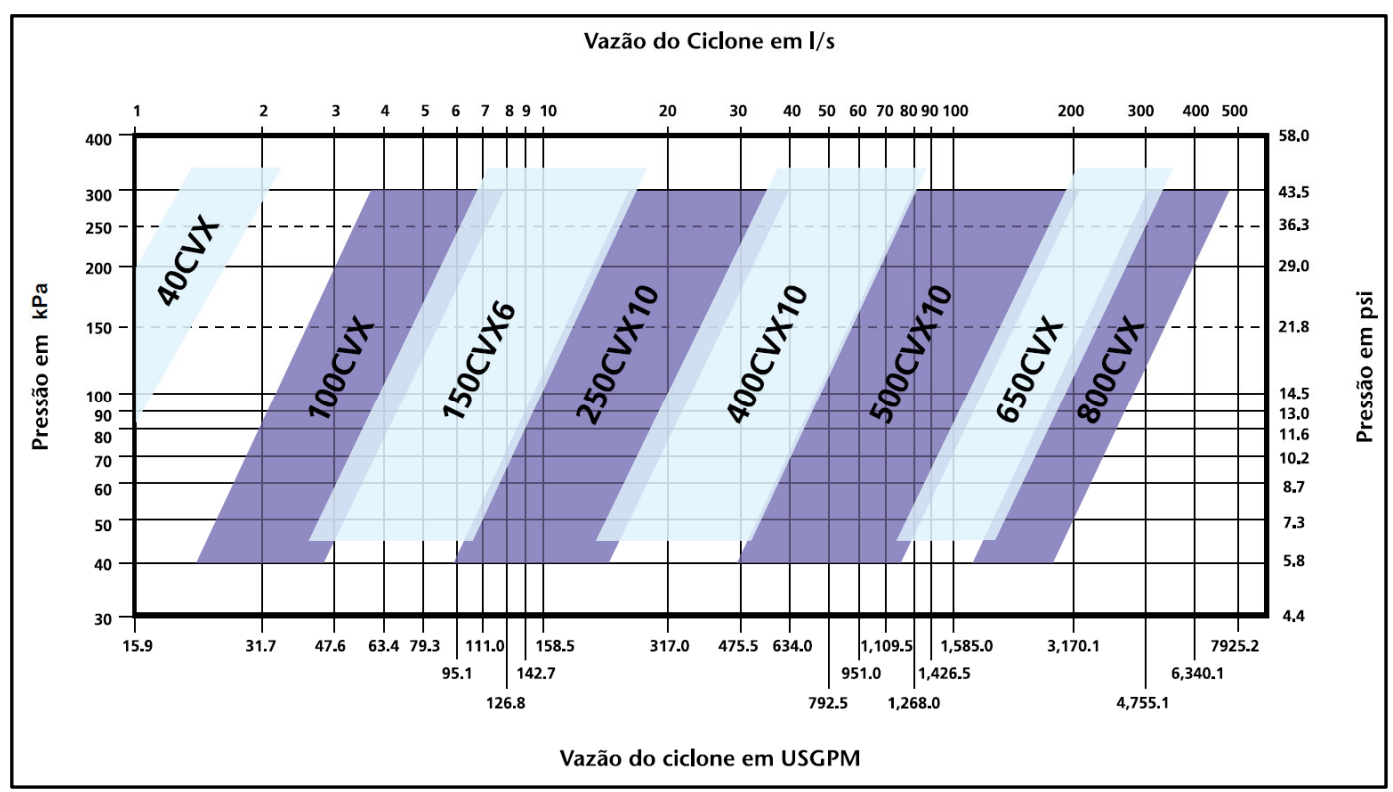

Fonte: Weir (2011)

Ainda a título de exemplo, após identificar-se a melhor opção para determinada aplicação, utiliza-se a Tabela 5 para se estimar as demais dimensões do ciclone, quais sejam, área do orifício de entrada, diâmetro do vortex, diâmetro do apex, inclinação do cone, altura livre, altura total, além do peso do equipamento. Essas características são também fundamentais para as operações desses equipamentos, conforme os dois modelos matemáticos apresentados. 
Tabela 5 - Dimensões ciclones comerciais fabricados pela Weir

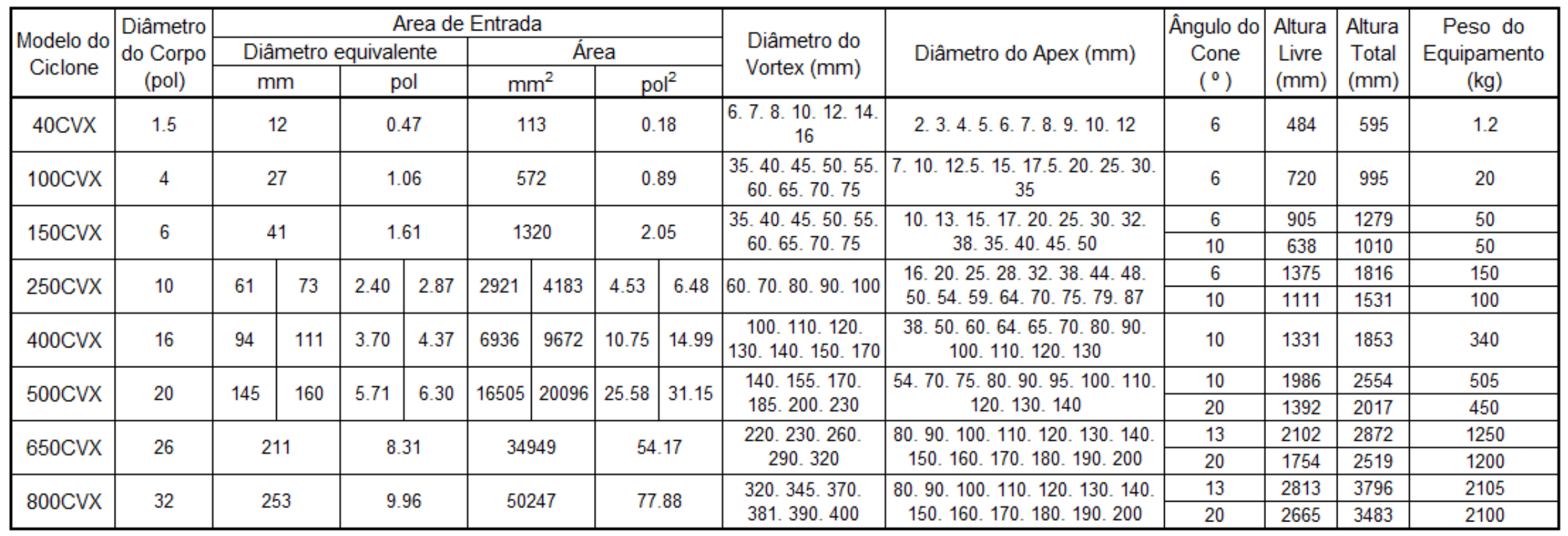

Fonte: Adaptado de Weir (2011) 


\subsubsection{Prensa de Rolos}

Prensa de rolos (PR) ou High Pressure Grinding Rolls (HPGR) é uma tecnologia relativamente nova quando comprada às normalmente utilizadas para cominuição nas indústrias de processamento mineral, principalmente quando se trata de rochas de tenacidade alta.

A prensa de rolos foi inventada em 1988 pelo professor alemão Klaus Schönert (1988), como consequência de sua pesquisa de fratura de rochas. Inicialmente, a HPGR foi largamente utilizada na Europa pela indústria de moagem de clínquer, enquanto uma das primeiras aplicações para indústria mineral foi no processamento de minério de diamante, uma vez que o equipamento oferece certo grau de seletividade para liberação do diamante da rocha encaixante. Entretanto, o atrativo principal para utilização da prensa de rolos é a alta razão de redução alcançada, bem como o consumo relativamente baixo de energia específica quando comparada a diversas outras tecnologias de cominuição.

A aplicação potencial para o equipamento inclui a preparação do material para moagem, substituindo, assim, as etapas de britagem terciária e moagem em moinho de barras. Devido as microtrincas geradas nos fragmentos processados por esse equipamento, a capacidade do moinho de bolas aumenta, enquanto o consumo de energia específica diminui (KELLERWESSEL, 1993).

A prensa de rolos é constituída por dois rolos paralelos que giram em sentido contrário, montados sobre uma estrutura metálica como mostrado na Figura 7. Enquanto um rolo é fixo, o outro pode movimentar-se no plano horizontal, de forma a aproximar-se ou afastar-se do rolo fixo. 
Figura 9 - Representação de uma seção de um HPGR, incluindo o sistema hidráulico de compressão dos rolos

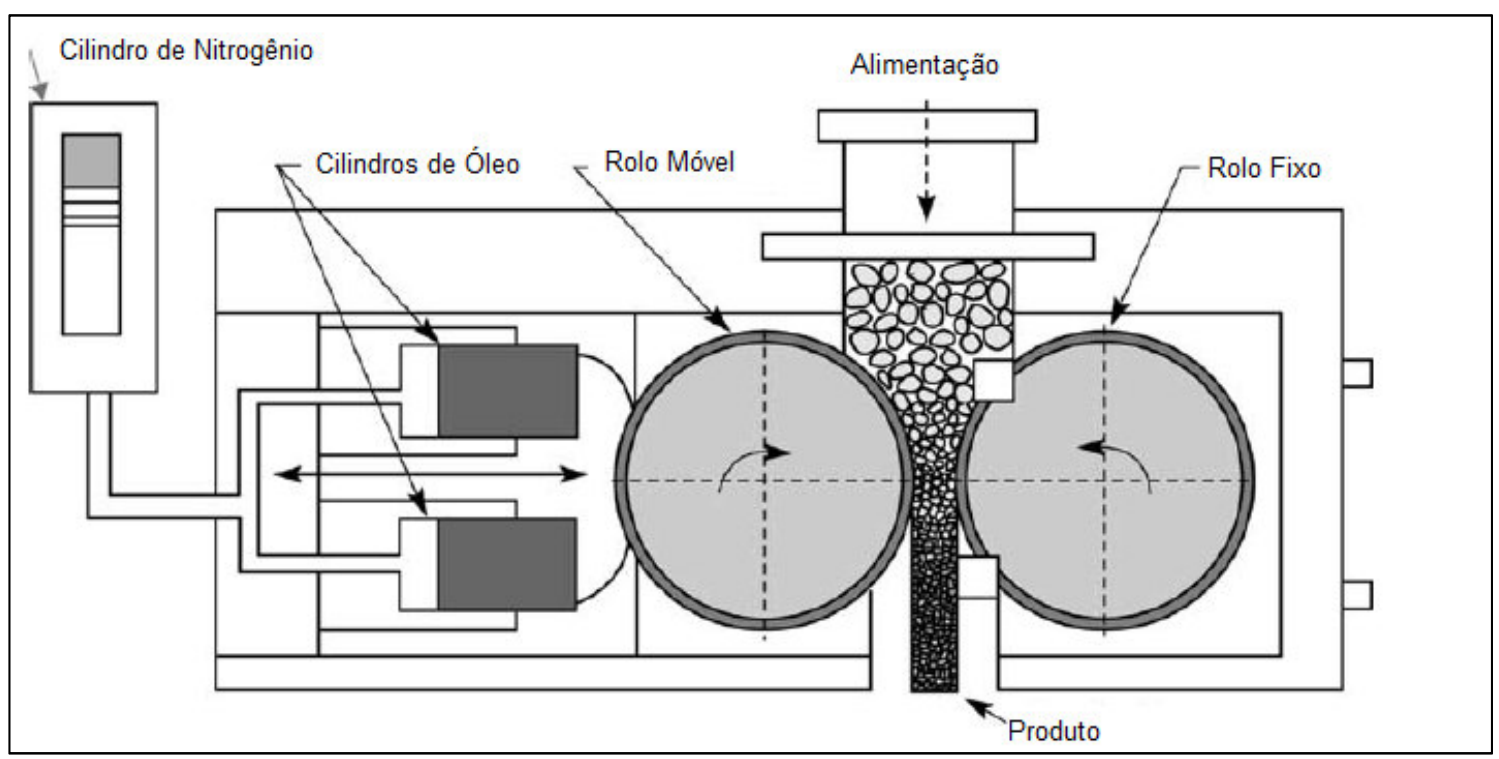

Fonte: Adaptado de Napier-Munn et al.(1996)

A cominuição ocorre principalmente por compressão das partículas na zona próxima ao plano horizontal que contém os centros dos dois rolos. Nas zonas superiores a esse plano, também ocorre cominuição, porém em magnitude decrescente à medida que dele elas se afastam.

O cilindro hidráulico é configurado para imprimir uma pressão determinada no leito de partículas, de forma que ele seja comprimido em até $70 \%$ de seu volume inicial. Essa pressão que normalmente está acima de $50 \mathrm{MPa}$ controla a granulometria do produto (NAPIER-MUNN et al., 1996).

A capacidade do equipamento é determinada principalmente pelas:

- Características dos rolos
- Dimensões
- Velocidade de rotação
- Perfis de revestimento dos rolos

- Características do material
- Granulometria de alimentação
- Tenacidade do material
- Fricção da partícula 
Wang (2013) demonstrou que circuitos que incluem HPGR em etapa anterior à moagem em moinho de bolas podem gerar redução de energia entre 23 e $30 \%$ quando comparada a circuitos de moagem SAG ou AG.

\subsubsection{Teoria e estrutura do modelo da Prensa de Roloso}

O modelo de Morrell/Tondo/Shi (DANIEL; MORREL, 2004) para prensa de rolos é composto por três partes: previsão da granulometria do produto, sua alimentação e consumo de energia. Esses três módulos combinados compõem o modelo integrado para previsão do produto de um HPGR, sendo representado pela Figura 10.

Figura 10 - Estrutura esquemática do modelo de HPGR

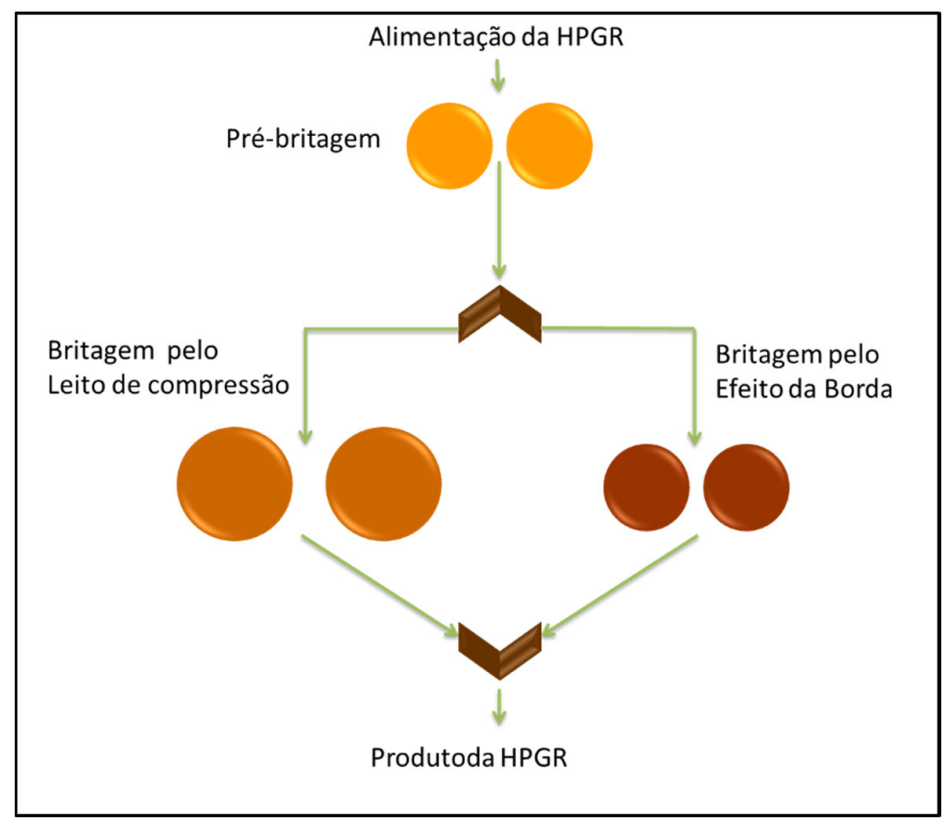

Fonte: Adaptado de Daniel; Morrel (2004)

\subsection{Modelo da granulometria do produto}

O modelo de granulometria do produto é também composto por três partes que definem o processo separadamente, sendo que essas partes combinadas produzem o resultado final. $O$ modelo de redução de tamanho assume que existem três mecanismos de quebra independentes no HPGR (MORRELL; SHI e TONDO, 1997 apud DANIEL; MORREL, 2004). Os três subprocessos (ou zonas de quebra dentro do britador) são definidos na sequência. 


\section{Zona de pré-britagem}

Partículas maiores que um tamanho crítico $\left(\mathrm{x}_{\mathrm{c}}\right)$ serão quebradas diretamente na superfície dos rolos, como ocorre em um britador de rolos convencional. O produto dessa pré-britagem segue para uma região de leito de compressão que se forma entre os rolos. Assim, a interface entre a compressão e a zona de pré-britagem é definida como a abertura crítica $\left(x_{c}\right)$, sendo ela expressa pela equação (83), mencionada a seguir:

$$
x_{c}=0,5\left\{\left(D+x_{g}\right)-\left[\left(D+x_{g}\right)^{2}-\frac{4 \rho_{g} D x_{g}}{\rho_{c}}\right]^{0,5}\right\}
$$

Onde

$\mathrm{D}=$ diâmetro do rolo em $(\mathrm{m})$

$\mathrm{X}_{\mathrm{g}}=$ abertura de trabalho $(\mathrm{m})$

$\rho_{g}=$ densidade da partícula $\left(\mathrm{t} / \mathrm{m}^{3}\right)$

$\rho_{c}=$ densidade do leito compactado $\left(t / m^{3}\right)$

\section{Zona do efeito de borda}

A quebra de partículas nas bordas dos rolos é diferente da quebra no centro. Tal fenômeno tem sido explicado pelo gradiente de pressão em decorrência da largura dos rolos e da falta de confinamento do minério em suas bordas (WATSON e BROOKS;1994 apud DANIEL; MORREL 2004). Esse efeito de borda define a proporção de partículas grosseiras que se encontram no produto da HPGR.

O modelo assume uma mudança no perfil de pressão na borda dos rolos, onde o material é cominuído em partículas individuais assim como na zona de pré-britagem. Assume-se que não há quebra de partículas em leito comprimido nessa zona, enquanto, na realidade, uma mudança gradual de pressão é susceptível de ser encontrada. 
A interface que define o limite entre a zona de compressão e o efeito de borda é representada matematicamente pela fração da alimentação que é submetida à cominuição de partículas individuais. Essa fração é representada pela equação (84) (MORRELL; SHI e TONDO, 1997 apud DANIEL; MORREL, 2004).

$$
f=\gamma \frac{x_{g}}{L}
$$

Sendo

$f$ = fração do material da alimentação que é cominuído na região da borda

$Y=$ é o fator de separação, específico do minério

$x_{g}=$ Abertura de trabalho $(m)$

$\mathrm{L}=$ comprimento dos rolos $(\mathrm{m})$

\section{Zona de leito comprimido}

O limite da zona de compressão é algum ponto entre as bordas dos rolos, definido por $f / 2$. $L$, onde $L$ é o comprimento dos rolos e $f$ é a fração definida pela equação (84), estendendo-se ascendentemente entre a área de menor abertura $\left(\mathrm{x}_{\mathrm{g}}\right)$ e a área delimitada pela abertura crítica $\left(x_{c}\right)$, dada pela equação (83). A zona de compressão é considerada a mais importante para efeito de cominuição no HPGR, pois é nessa região onde ocorre a maioria dos processos de fragmentação.

\subsection{Modelo de alimentação}

Para um determinado teste, a vazão de alimentação $\left(Q_{m}\right.$, em $\left.t / h\right)$ é determinada dividindo-se a massa da amostra processada pelo tempo de processamento, conforme mostra a equação (85).

$$
Q_{m}=3,6 \frac{\text { Massa de amostra para o teste }(\mathrm{kg})}{\text { Tempo de processamento }(\mathrm{s})}
$$


O modelo prevê a alimentação usando a equação (86), também expresso em toneladas por hora $(\mathrm{t} / \mathrm{h})$.

$$
Q_{c}=3600 u L \rho_{g} x_{g} c
$$

Onde:

$\mathrm{u}=$ velocidade tangencial dos rolos $(\mathrm{m} / \mathrm{s})$

$\mathrm{L}=$ comprimento dos rolos $(\mathrm{m})$

$\mathrm{x}_{\mathrm{g}}=$ abertura de trabalho $(\mathrm{m})$

$\rho_{g}=$ densidade da partícula $\left(\mathrm{t} / \mathrm{m}^{3}\right)$

$\mathrm{C}=$ fator de correção

\subsection{Modelo da potência consumida}

A potência consumida $(\mathrm{kW})$ por um HPGR pode ser calculada diretamente pelo produto da energia específica de cominuição $\left(E_{c s}\right)$, medida durante ensaios de laboratório em (kWh/t), e a vazão de alimentação (t/h) no HPGR simulado. A previsão da potência consumida é, portanto, relacionada diretamente à acurácia da previsão da vazão de alimentação.

A energia específica medida experimentalmente $\left(E_{c s}\right)$ é calculada a partir da soma da energia consumida no eixo ( $\left.P_{\text {shaft }}\right)$ com a energia consumida em vazio ( $P_{\text {no- }}$ load), dividida pela vazão de alimentação medida $\left(Q_{m}\right)$ como na equação (87).

$$
E_{c S}=\frac{\left(P_{\text {no-load }}+P_{\text {shaft }}\right)}{Q_{m}}
$$

A energia em vazio é a energia consumida para manter o equipamento funcionando sem alimentação. 
A energia consumida no eixo ( $\left.P_{\text {shaft }}\right)$ é calculada pela medida experimental do torque $(\tau)$ nos rolos multiplicada pela velocidade tangencial dos rolos expressa pela equação (88), que se segue.

$$
P_{\text {shaft }}=\frac{2 \tau u}{D}
$$

Onde:

$$
\begin{aligned}
& \tau=\text { torque do eixo }(\mathrm{Nm}) \\
& \mathrm{u}=\text { velocidade circunferencial em }(\mathrm{m} / \mathrm{s}) \\
& \mathrm{D}=\text { diâmetro dos rolos }(\mathrm{m}) \\
& P_{\text {shaft }}=\text { energia consumida pelo eixo }(\mathrm{kWh} / \mathrm{t})
\end{aligned}
$$

\subsubsection{Seleção de Prensa de Rolos}

Vários parâmetros são relevantes para realizar o dimensionamento da prensa de rolos. Esta seção traz alguns dos principais critérios para o dimensionamento e seleção do equipamento.

\subsection{Condições de alimentação}

O tamanho máximo de partícula da alimentação (top size), a distribuição granulométrica e a umidade são os principais parâmetros para garantir o sucesso da operação com prensa de rolos (KLIMOWSKY, 2002).

O tamanho máximo de alimentação de partículas depende do tipo de superfície do rolo, do tamanho da abertura entre rolos e das propriedades do minério a ser alimentado, sobretudo a dureza. As restrições em relação à granulometria de alimentação são reguladas por questões mecânicas e não por considerações de processo. Um parâmetro importante para essa análise é a relação entre top size e abertura entre rolos $\left(x_{\max } / \mathrm{s}\right)$. Em geral, recomenda-se trabalhar em valores entre 1,0 a 1,5 para assegurar uma boa eficiência de cominuição e evitar flutuações de performance causadas por poucos fragmentos que estejam acima do tamanho máximo. 
O tamanho da abertura entre os rolos está correlacionado com as propriedades dos minérios e também com o diâmetro do rolo. A Figura 11 apresenta o tamanho da abertura entre os rolos como uma função do diâmetro do rolo para diferentes tipos de minério. A relação recomendada entre $\mathrm{x} \max / \mathrm{s}$ é determinada pelo tipo de superfície do rolo e pela dureza específica do minério.

Figura 11 - Sugestão de distância entre rolos para diferentes diâmetros e diferentes minérios

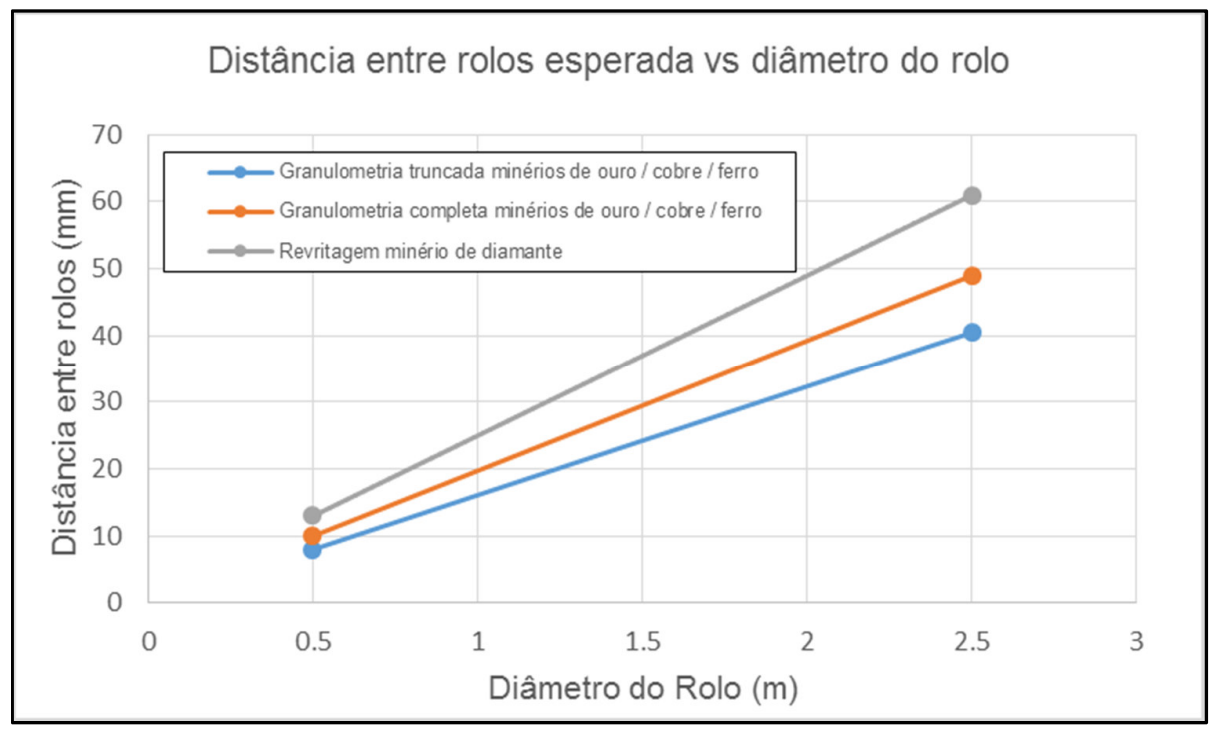

Fonte: Adaptado de Klimowsky (2002)

Como indicação de Klimowsky (2002), a relação $x_{\max } / \mathrm{s}$ deve ser menor do que 1 para minérios duros com resistência à compressão acima de $250 \mathrm{Mpa}$ e, para minérios com resistência abaixo de $100 \mathrm{Mpa}$, é aceitável que seja maior que 1,5.

Para a distribuição granulométrica, recomenda-se que a alimentação seja feita com a faixa granulométrica completa, afim de evitar desgastes excessivos nos rolos, pois, para alimentações escalpadas, a abrasão dos rolos aumenta drasticamente. A retirada de finos pode ajudar nos casos de minérios com baixa resistência à compressão ou minérios que se prendem às superfícies com facilidade e incrustem os equipamentos com finos.

A umidade da alimentação pode representar um problema significativo para rolos de superfícies lisas, pois causa deslizamento do material por diminuir o atrito 
entre os rolos e o leito de partículas, o que compromete a taxa de alimentação do equipamento. Para os casos em que os rolos são pinados, ocorrem menos deslizamentos. No entanto, o excesso de umidade deve ser evitado para que não seja comprometida a capacidade de alimentação do equipamento.

A velocidade de rotação dos rolos é um fator muito importante para determinar o custo de investimento da prensa de rolos. Quanto maior a velocidade dos rolos, menor o custo de investimento, pois rolos menores em velocidades maiores apresentam capacidades de alimentação equivalentes a rolos maiores com velocidades menores. Também para velocidades relativamente mais altas, a caixa de transmissão será menor por haver menos torque para o movimento dos rolos.

Entretanto, caso a velocidade exceda ao máximo recomendado, haverá deslizamento do leito de partículas, aumento do desgaste dos rolos e diminuição da vazão de alimentação do equipamento. Outro ponto relevante refere-se à vida útil do revestimento dos rolos, por ser diretamente proporcional ao número absoluto de ciclos da zona de compressão.

De forma geral, uma diretriz relatada por Klymowsky (2002) sugere que, para alimentações grosseiras, a velocidade tangencial máxima do rolo (umax) não deve exceder 1,35 vezes a raiz quadrada do diâmetro do rolo (D).

$$
u_{\max }\left(\frac{m}{s}\right) \leq 1,35 \cdot \sqrt{D}(m)
$$

A equação (89) leva em consideração a aceleração do material na superfície do rolo. No caso de rolos com mais de 2,0 m de diâmetro, eles operam com sucesso em condições de velocidade acima da sugerida pela diretriz. Entretanto, convém considerar rolos com diâmetros acima de 1,7 m - equação (90).

$$
u_{\max }\left(\frac{m}{s}\right) \leq D(m)
$$


A relação entre a velocidade tangencial $\left(u_{\max }\right)$ e o diâmetro do rolo é apresentada na Figura 12.

Figura 12 - Sugestão para velocidade tangencial máxima do rolo para diferentes diâmetros

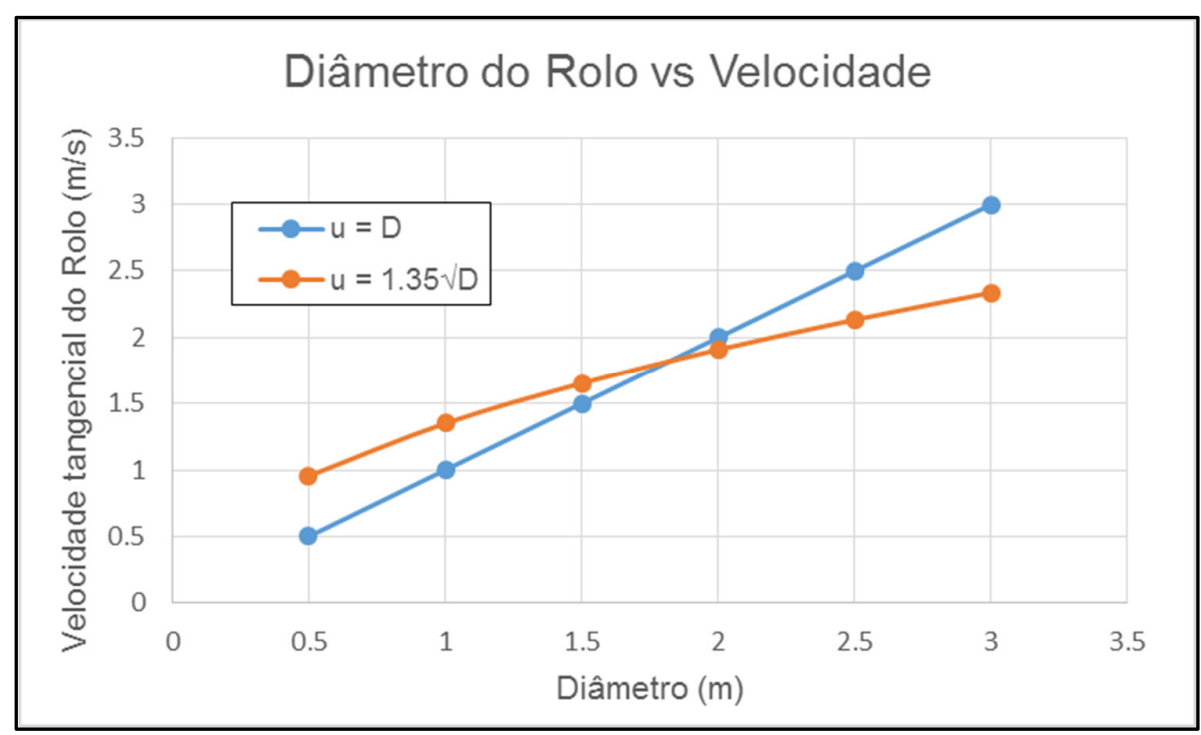

Fonte: Adaptado de Klymowsky (2002)

Os principais fatores que influenciam no desempenho da prensa de rolos estão divididos em grupos e relatados na planilha elabora por Oliveira (2016). Em sua dissertação de mestrado, este autor apresentou uma campanha experimental em planta piloto de prensa de rolos conduzida em 18 ensaios para diferentes cenários, considerando circuito fechado com peneira, circuito com recirculação parcial do produto e recirculação do produto das bordas. 
Tabela 6 - Fatores que influenciam a capacidade das prensas de rolos

\begin{tabular}{|l|l|}
\hline Fatores que influenciam a capacidade da PR & Grau de influência \\
\hline 1. Relacionados ao equipamento: & \\
Tipo de superfície dos rolos & Alto \\
Pressão específica & Baixo \\
Velocidade de rotação dos rolos & Moderado \\
Razão L/D & Baixo \\
\hline 2. Relacionados ao minério: & \\
Peso específico & Alto \\
Resistência à compressão & Alto \\
Umidade da alimentação & Moderado \\
Distribuição granulométrica da alimentação & Alto \\
\hline 3. Relacionada à condição de alimentação: & \\
Nível e fluidez de material no silo & Alto \\
Segregação da alimentação & Alto \\
\hline
\end{tabular}

Fonte: Oliveira (2016)

A granulometria do produto da prensa de rolos pode ser tão fina ou até mais fina que o produto da moagem de barras ou bolas. Isso pode ser observado na Figura 13 a partir do experimento de Morsky et al. (1995). Neste trabalho, foi utilizada a mesma granulometria de alimentação para moinho de bolas, barras e HPGR e aplicou-se a mesma energia específica ( $4 \mathrm{kWh} / \mathrm{t})$ para os diferentes processos. Neste mesmo trabalho, a fração abaixo da faixa de $100 \mu \mathrm{m}$ para HPGR é maior quando comparada aos produtos dos moinhos. 
Figura 13 - Granulometria do produto do moinho de Barras, moinho e bolas e HPGR

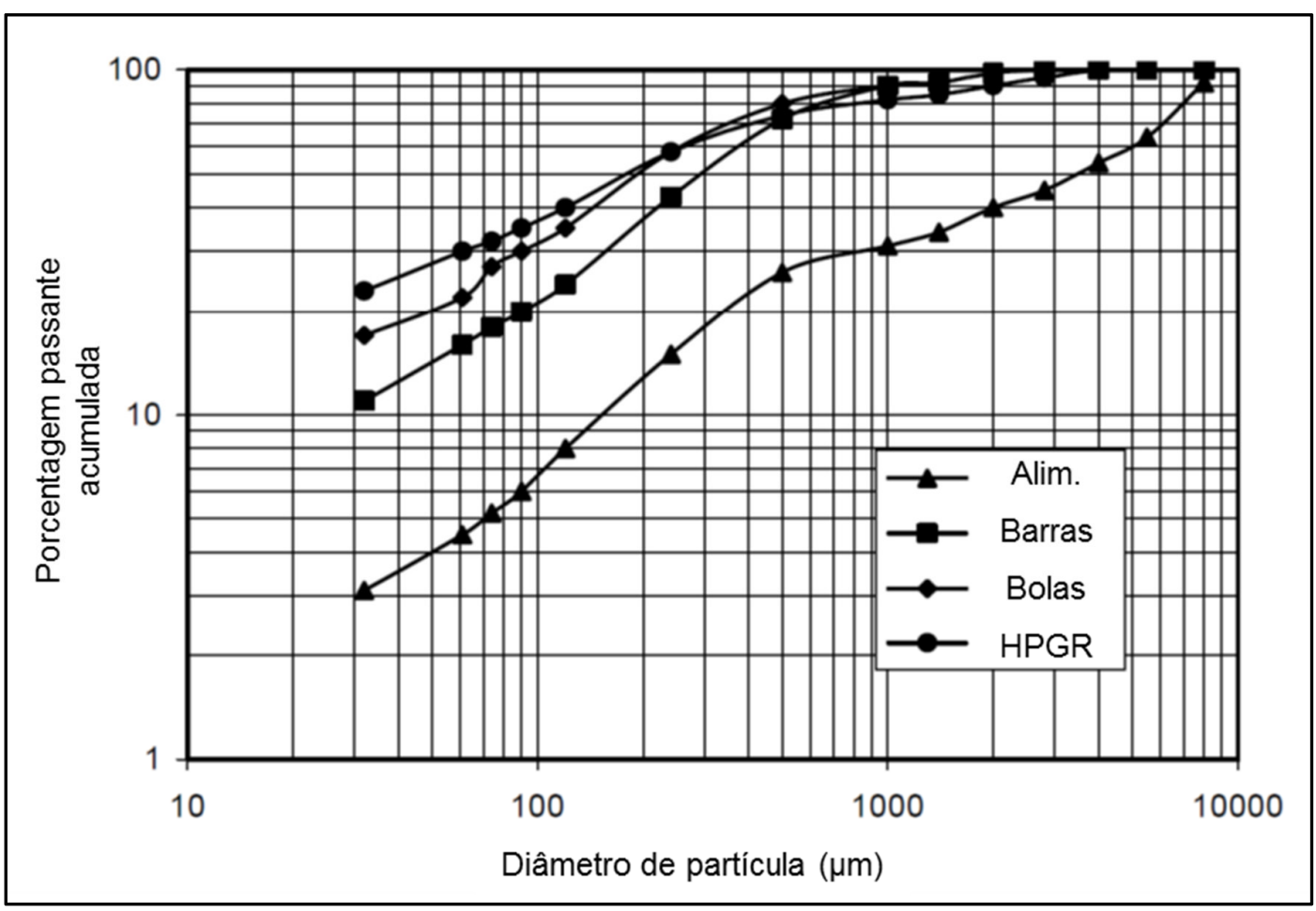

Fonte: Adaptado de Morsky (1995)

3.3.3.2.2 Força específica de cominuição, energia específica e potência necessária.

A granulometria do produto do HPGR é função da força aplicada nos rolos. Quanto maior a força aplicada nos rolos, mais fino será o produto e também maior será potência necessária para manter tal força. Como resultado, o consumo de energia específica será crescente conforme a granulometria mais fina do produto.

Na linguagem específica da indústria a força ou força específica aplicada aos rolos é dada em $\mathrm{N} / \mathrm{mm}^{2}$, muito embora esta não seja uma definição correta. É comum que a melhor eficiência operacional ocorra em valores entre 1 a 2,5 N/mm² para minérios com baixa resistência à compressão e, entre 3 a $4,5 \mathrm{~N} / \mathrm{mm}^{2}$, para minérios mais tenazes.

Na prática, a aplicação da força de cominuição é limitada pelo material da superfície do rolo, podendo atingir, para a indústria do cimento, valores entre 7 a 8 $\mathrm{N} / \mathrm{mm}^{2}$. Entretanto, as boas práticas de engenharia limitam a força de cominuição entre 4 a $4,5 \mathrm{~N} / \mathrm{mm}^{2}$. 
Em aplicações industriais, a energia específica de cominuição $\left(E_{c s}\right)$ varia normalmente entre 1 e $3 \mathrm{kWh} / \mathrm{t}$, dependendo também das características do material e da superfície dos rolos. Materiais friáveis e úmidos podem demandar mais do que 3 $\mathrm{kWh} / \mathrm{t}$ devido à baixa vazão mássica específica. Já materiais duros absorvem de 1,5 a 2,0 kWh/t em níveis elevados de força de cominuição. A potência do motor do HPGR pode, também, ser calculada de acordo com a equação (91) (KLIMOWSKY, 2002).

$$
P_{\text {req }}=E_{c s} \cdot M=E_{c s} \cdot m \cdot D \cdot L \cdot u
$$

$$
\begin{aligned}
& \text { Preq = Potência total requerida do motor }(\mathrm{KW}) \\
& M=\text { Vazão mássica }(\mathrm{t} / \mathrm{h}) \\
& \mathrm{D}=\text { Diâmetro do rolo }(\mathrm{m}) \\
& \mathrm{u}=\text { Velocidade do rolo }(\mathrm{m} / \mathrm{s}) \\
& E_{c s}=\text { Consumo específico de energia }(\mathrm{kWh} / \mathrm{t}) \\
& m=\text { Vazão mássica específica }\left(\mathrm{t} . \mathrm{s} / \mathrm{m}^{3} \mathrm{~h}\right) \\
& L=\text { Comprimento do rolo }(\mathrm{m})
\end{aligned}
$$

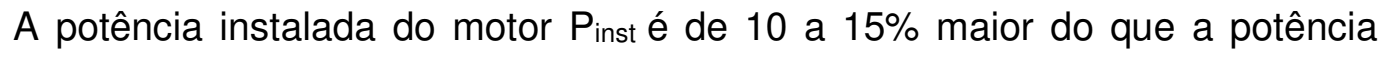
requerida, valor este relacionado às perdas de energia.

\subsection{Dimensionando prensa de rolos}

O dimensionamento de prensas de rolos requer ensaios laboratoriais e, se possível, ensaios em escala piloto para determinar parâmetros específicos do equipamento e do minério processado.

Os resultados desses ensaios permitem determinar a densidade do leito compactado, a densidade das partículas, a capacidade específica, a energia específica, a força específica, entre outros.

Neste trabalho, não foram realizados ensaios em escala piloto para dimensionamento do equipamento. A abordagem adotada teve por base dados e informações de banco de dados sobre os parâmetros do equipamento e, para 
descrever as características do minério, foram executados ensaios de Drop Weight test (DWT) e Compressão de Leito de Partículas (CLP). As seções 3.4.4 e 3.4.5 contêm informações, respectivamente sobre procedimentos e funções dos ensaios.

Os resultados do ensaio CLP estabelecem uma relação entre energia aplicada e fragmentação resultante, de forma análoga ao tratamento de dados do ensaio DWT. A principal diferença entre os ensaios CLP e DWT consiste na forma de transmissão de energia do equipamento ao minério. Assim, enquanto a transmissão de energia no ensaio CLP é por compressão, no ensaio DWT a energia é transmitida por impacto.

Ambos os ensaios geram resultados que auxiliam na identificação da energia requerida para obtenção do produto desejado (NAPIER-MUNN et al., 1996).

De posse dos valores de energia específica e da capacidade específica é possível selecionar a partir de informações de fornecedores o equipamento que melhor atende ao processo. À título de exemplo, a Tabela 7 apresenta modelos de equipamentos fabricados pela Metso. 
Tabela 7 - Parâmetros para seleção de Prensa de Rolos industriais
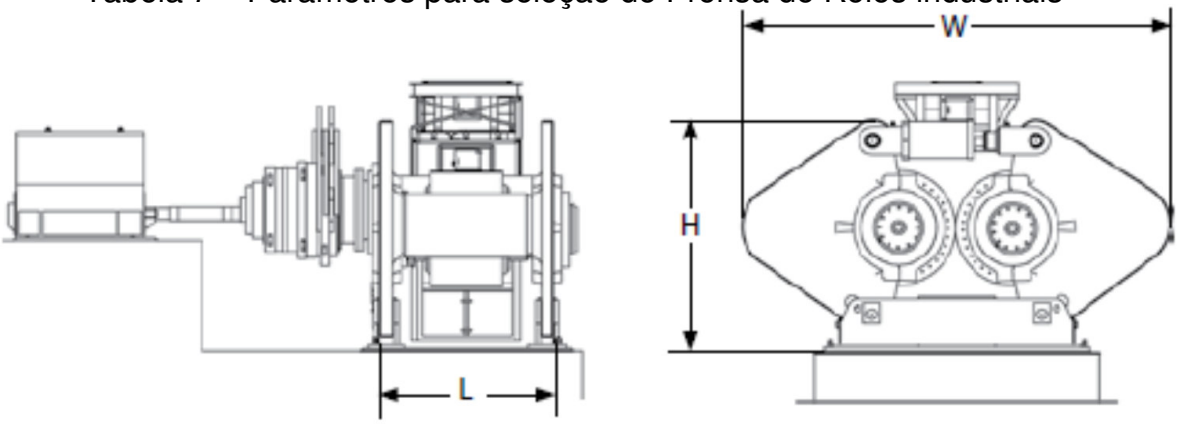

\begin{tabular}{|c|c|c|c|c|c|c|c|c|c|c|}
\hline \multirow{2}{*}{$\begin{array}{l}\text { Parâmetro } \\
\text { equipamento }\end{array}$} & \multirow{2}{*}{ Un, } & \multicolumn{9}{|c|}{ Modelos HRC ${ }^{\text {TM }}$} \\
\hline & & 800 & 1000 & 1200 & 1450 & 1700 & 2000 & 2400 & 2600 & 3000 \\
\hline Diâmetro do rolo & $(\mathrm{mm})$ & 730 & 1000 & 1200 & 1450 & 1700 & 2000 & 2400 & 2600 & 3000 \\
\hline Comprimento do rolo & $(\mathrm{mm})$ & 500 & 625 & 750 & 900 & 1000 & 1500 & 4650 & 4750 & 2000 \\
\hline Potência máxima instalada & kW & $2 \times 132$ & $2 \times 260$ & $2 \times 440$ & $2 \times 650$ & $2 \times 900$ & $2 \times 1900$ & $2 \times 3000$ & $2 \times 3700$ & $2 \times 5700$ \\
\hline Potência máxima instalada & hp & $2 \times 177$ & $2 \times 349$ & $2 \times 590$ & $2 \times 872$ & $2 \times 12027$ & $2 \times 2548$ & $2 \times 4023$ & $2 \times 4962$ & $2 \times 7644$ \\
\hline Velocidade nominal do rolo & RPM & 28,8 & 25,8 & 23,5 & 21,4 & 19,1 & 19,1 & 19,1 & 19,1 & 19,1 \\
\hline Velocidade tangencial do rolo & $(\mathrm{m} / \mathrm{s})$ & 1,2 & 1,4 & 1,5 & 1,6 & 1,7 & 2,0 & 2,4 & 2,6 & 3,0 \\
\hline $\begin{array}{l}\text { Tamanho máximo de } \\
\text { alimentação* }\end{array}$ & $(\mathrm{mm})$ & 20 & 25 & 30 & 26 & 43 & 50 & 60 & 65 & 75 \\
\hline Capacidade típica** & $(\mathrm{t} / \mathrm{h})$ & $72-145$ & $127-253$ & $200-399$ & $318-636$ & $434-867$ & $900-1800$ & $1426-2851$ & $1775-3549$ & $2700-5400$ \\
\hline Altura $\mathrm{H}$ & $(\mathrm{mm})$ & 2400 & 2700 & 2200 & 3556 & 3730 & 5309 & 6646 & 6030 & 6937 \\
\hline Largura L & $(\mathrm{mm})$ & 3700 & 3520 & 1610 & 2050 & 3690 & 6079 & 3630 & 6030 & 6937 \\
\hline Comprimento W & $(\mathrm{mm})$ & 2700 & 3500 & 4400 & 5196 & 6240 & 9512 & 9092 & 9380 & 10800 \\
\hline
\end{tabular}

Fonte: Metso (2015) 


\subsection{Fluxogramas para utilização de Prensa de Rolos}

Existem diferentes possibilidades para se configurar circuitos utilizando prensa de rolos, cada um conforme o respectivo objetivo específico, sendo eles: aumento da capacidade, melhoria das recuperações metalúrgicas, cominuição seletiva ou aumento de eficiência energética (MORLEY, 2006). Além dessas perspectivas, cada circuito influencia na implantação e no custo operacional.

Para este estudo, apenas três alternativas foram analisadas, as quais estão representadas na Figura 14. Os circuitos são alimentados pelo produto de uma britagem terciária.

Figura 14 - Possibilidade de circuitos para uso de prensa de rolos

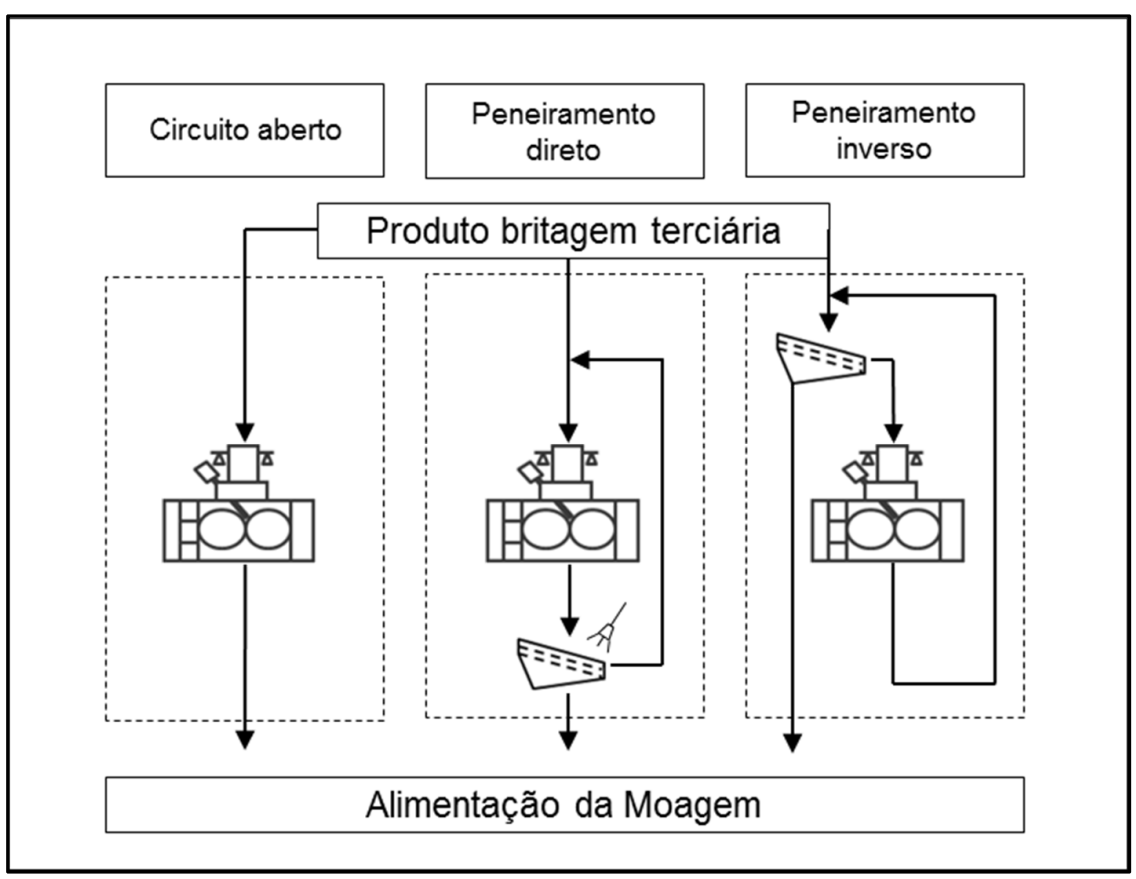

Fonte: Adaptado de Morley (2006)

A primeira alternativa representa um circuito aberto que é alimentado de forma direta, sem que haja classificação do produto. Trata-se do circuito passagem simples. Esse caso apresenta como principal vantagem o menor desgaste dos rolos e a sua simplicidade, pois não emprega peneiras. Em contrapartida, neste tipo de circuito há 
pouco controle sobre a granulometria do produto, o que pode ocasionar problemas operacionais na etapa posterior, geralmente de moagem.

A segunda alternativa ilustrada na Figura 14, denominada peneiramento direto, considera que o produto da prensa de rolos seja peneirado, sendo o undersize o produto final e o oversize recirculado para realimentação da prensa de rolos. Nessas condições, o controle da granulometria do produto é considerado muito bom. Em aplicações industriais o feito é efetuado a úmido, o que causa problemas na alimentação da prensa de rolos caso o oversize apresente umidade relativamente elevada.

A terceira alternativa consiste no circuito de peneiramento inverso, em que a prensa de rolos é alimentada indiretamente pelo oversize de uma peneira, o produto da prensa de rolos recirculado para alimentação da peneira, cujo undersize é o produto final da operação. A principal vantagem desse circuito é o emprego de prensa de rolos com menores dimensões, pois parte da alimentação é desviada para o produto final. Entretanto, a alimentação truncada para esse equipamento resulta em desgaste mais rápido do revestimento dos rolos (VAN DER MEER, 2011).

\subsubsection{Vantagens indicadas para uso de Prensa de Rolos}

Um dos benefícios potenciais da utilização de HPGR é a diminuição da energia especifica para a etapa subsequente de moagem. Nestes casos, a prensa de rolos geraria microtrincas fragilizando assim o material encaminhado à moagem.

Algumas publicações indicam resultados de redução do índice de Bond para moinhos de bolas na ordem de 10 a 25\% quando comparado a produtos obtidos a partir de circuitos dotados de britagens convencionais (DANIEL, 2007 e NORGATE; WELLER, 1994).

A Figura 15 apresenta duas fotografias: (a) de um fragmento gerado a partir de uma britagem convencional; (b) outro fragmento com várias microfraturas provocadas pelo processamento com prensa de rolos. 
Figura 15 - Fotografia da evidência de geração de microfraturas: (a) britagem convencional;

(b) produto de prensa de rolos

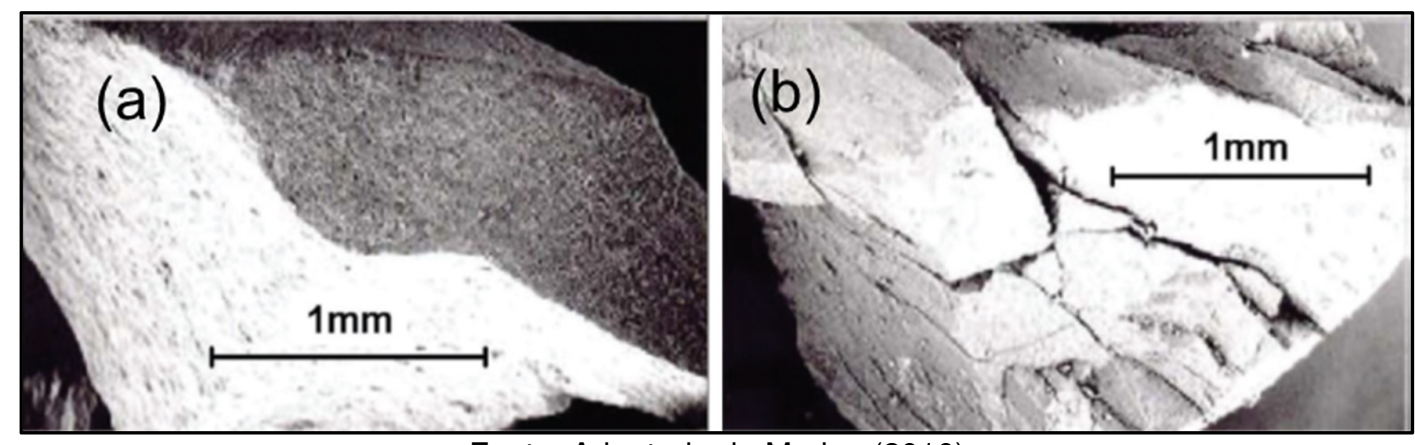

Fonte: Adaptado de Morley (2010)

Para Klymowsky (2006), as principais vantagens de HPGR na indústria de cimento são aumento de capacidade produtiva, redução de custos operacionais, pouco espaço necessário para instalação do equipamento e elevada vida útil dos rolos. Para a indústria de beneficiamento de minérios diamantíferos, o principal benefício é o aumento na recuperação e liberação do mineral de interesse.

Baum (2011) apresenta melhorias na recuperação de lixiviação de cobre, como apresentado na Figura 16. O mesmo autor indica benefícios também na flotação e concentração densitária de minerais de cobre mediante emprego de prensas de rolos. 
Figura 16 - Comparação de cinética de lixiviação de cobre entre britagem convencional com britador cônico e cominuição com HPGR

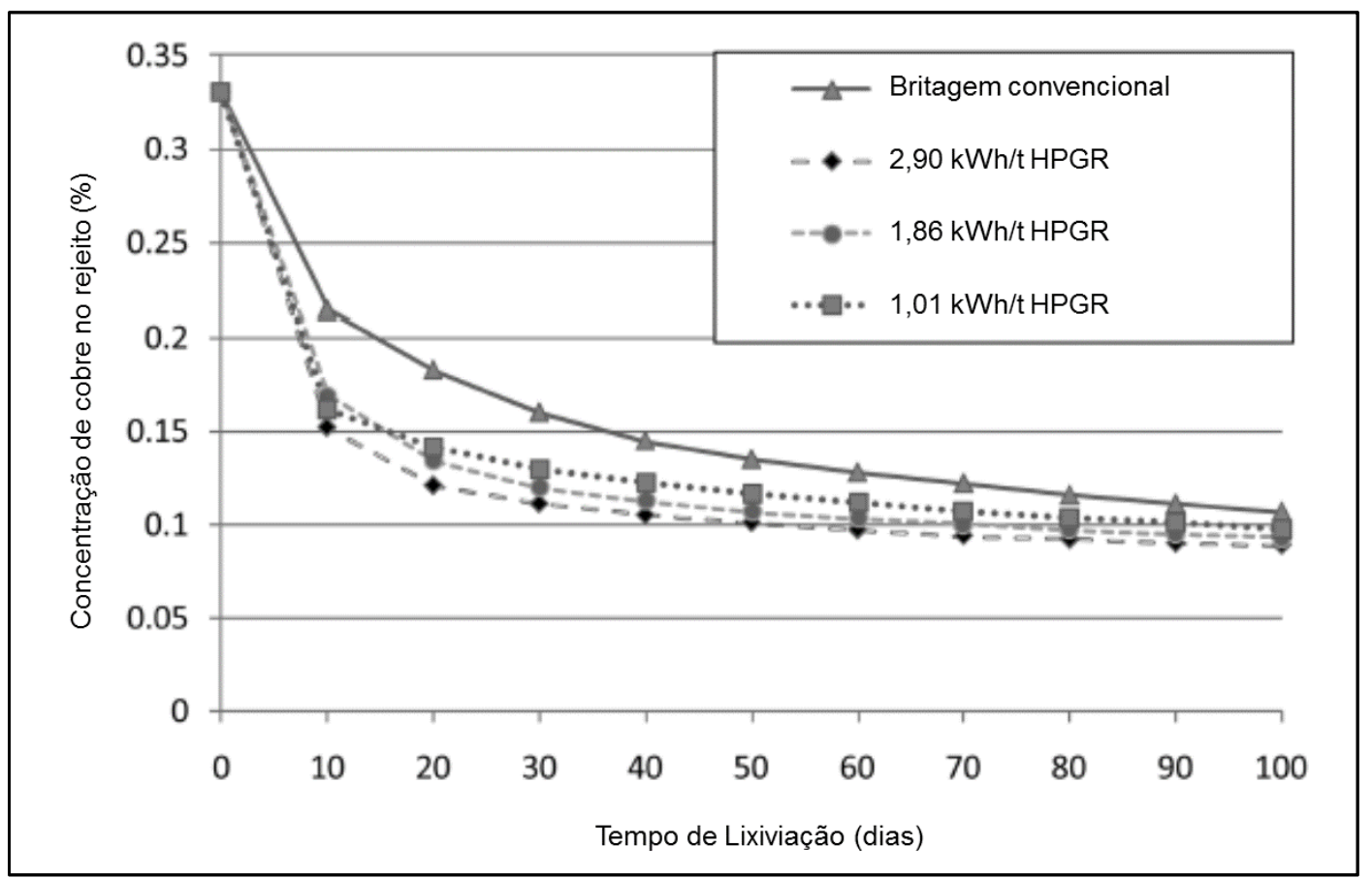

Fonte: Adaptado de Baum (2011)

\subsubsection{Moinhos Verticais de Carga Agitada}

Existe uma extensa variedade de moinhos de carga agitada, utilizados em usinas de beneficiamento de minérios na maioria das vezes para realizar remoagem ou moagens finas e ultrafinas. No entanto, não se descarta a possibilidade de seu uso para moagens mais grosseiras, como demonstrado por Shi et al. (2009). Alguns detalhes sobre esses equipamentos, operação e comparação com moinhos de bolas são apresentados a seguir.

\subsubsection{Moinho vertical com carga agitada por impelidor}

Moinhos verticais são utilizados principalmente para remoagem de minérios de cobre, ferro e ouro, trazendo várias vantagens quando comparados a moinhos tubulares de carga cadente. Destaca-se como principal vantagem o consumo de energia até $30 \%$ mais baixo. Além disso, moinhos verticais apresentam alta disponibilidade relativa e baixos custos com manutenção. Apesar de tantos pontos 
favoráveis, o equipamento é pouco usual nas operações do Brasil e, devido ao desenvolvimento relativamente recente, ainda existem poucas informações publicadas sobre dimensionamento, operação, processo e otimização desses equipamentos, sendo quase nenhuma em língua portuguesa (BERGERMAN, 2013).

Moinhos verticais são compostos por impelidores constituídos de materiais resistentes ao atrito causado pelo minério a ser moído. Tais impelidores funcionam como um agitador que irá girar para causar o movimento da carga e a quebra das partículas, enquanto o corpo do moinho permanece estático. Dessa forma, o equipamento transfere energia para carga de forma mais eficiente do que os tradicionais moinhos de tubulares horizontais.

Os primeiros moinhos desse tipo foram dimensionados com intenção de realizar uma limpeza superficial de partículas. Entretanto, com a necessidade de moagens mais finas, o equipamento se tornou uma opção adequada para produtos por exemplo com $\mathrm{P}_{80}$ entre 15 e $40 \mu \mathrm{m}$. Embora haja muitas evidências da utilização de moinhos de bolas convencionais para moagem fina, mediante a utilização de corpos moedores de menor diâmetro, esse tipo de moinho tem baixa eficiência para transferir a energia para a carga (NAPIER-MUNN et al., 1996).

Moinhos verticais podem ser utilizados para moagem a seco ou a úmido. A Figura 17 apresenta dois modelos de moinhos verticais: Tower Mill e Sala Agitated Mill (SAM). 
Figura 17 - Exemplo de moinhos verticais com cargas agitadas por impelidores:

a. Tower mil; b. Sala Agitated Mill (SAM)

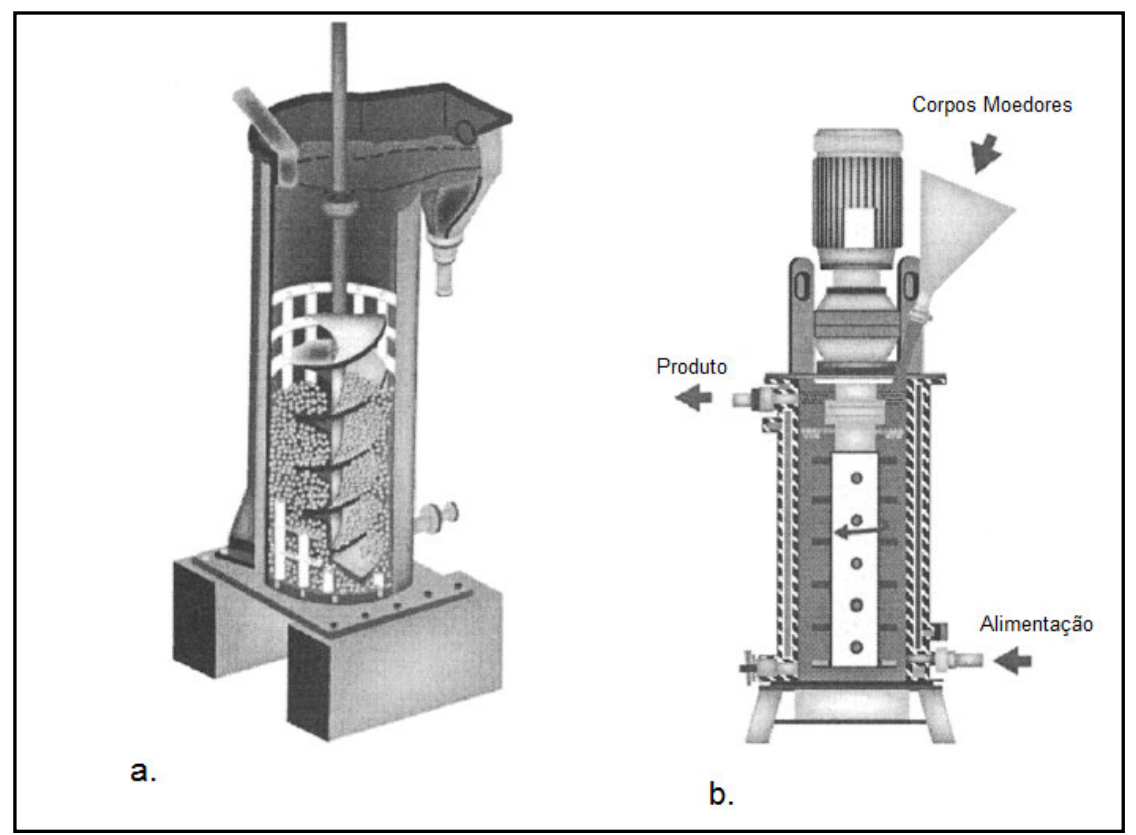

Fonte: Adaptado de Jankovic (2001)

\subsubsection{Principais parâmetros de operação para moagem em moinhos verticais de carga agitada}

Dentre os muitos parâmetros que afetam a moagem em moinhos verticais por impelidor, este subcapítulo descreve os considerados principais, quais sejam, diâmetro e condições dos corpos moedores, densidade da polpa e velocidade do impelidor.

No estudo de laboratório realizado por Jankovic (2001) foram variados os principais parâmetros de operação e analisados os efeitos para moinhos Tower, Sala, Netzch e Pin Mill. Nesse mesmo estudo foi verificado que corpos moedores usados produzem produtos mais finos se comparados a corpos moedores novos com as mesmas dimensões. Isso ocorre porque parte da energia consumida pela cominuição é utilizada para desgastar as irregularidades dos corpos moedores quando novos, processo este que consome energia. Corpos moedores usados já estão com o formato mais desgastado e, com menor quantidade de saliências, apresentam maior superfície para moagem e assim moem melhor. 
O efeito do diâmetro dos corpos moedores pode gerar uma pequena diferença na granulometria do produto, porém produz grande diferença na eficiência da moagem. No estudo de Jankovic (2001), foi explicitado que, para definir o diâmetro dos corpos moedores mais eficientes, é realmente necessário realizar testes, pois grandes variações são percebidas entre os tipos de moinho e também entre a granulometria de alimentação e de produto do material.

A velocidade do impelidor também pode alterar significativamente os resultados da moagem, cujo aumento leva à melhoria da eficiência de moagem e, para corpos moedores mais grosseiros, esse efeito se torna ainda mais evidente.

A densidade da polpa gera implicações no consumo de energia para a moagem. Para esse caso, quanto maior a porcentagem de sólidos, maior a eficiência de moagem.

Jankovic (2001) conclui que, os parâmetros analisados apresentam forte influência na moagem em moinho vertical de carga agitada por impelidores e, como as correlações entre essas características não são desprezíveis, o efeito de apenas uma variável não pode ser generalizado.

\subsubsection{Comparação entre moinho horizontal e moinho vertical para moagem grosseira}

Um estudo comparativo realizado por SHI et al.(2009) utilizou quatro tipos diferentes de moinho horizontal e vertical e sete tipos diferentes de amostra de minério, que foram alimentados com granulometria variando de $3,35 \mathrm{~mm}$ até $150 \mu \mathrm{m}$ para atingir produtos com $\mathrm{P}_{80}$ mais finos do que $100 \mu \mathrm{m}$. Nesse mesmo estudo, foi determinada a eficiência de moagem em moinho de bolas de Bond e em um moinho vertical com carga agitada por impelidor. As amostras empregadas foram dois minérios de chumbo-zinco (GC2 e GHB) e o minério de ouro com silicatos (SMT). O teste para o moinho de Bond foi conduzido para abertura de peneira de $125 \mu \mathrm{m}$ para (GC2), $106 \mu \mathrm{m}$ para (GHB) e $75 \mu \mathrm{m}$ para (SMT), com a carga circulante de $250 \%$. Os testes com o moinho vertical de laboratório foram conduzidos a úmido, com $72 \%$ de sólidos. 
A eficiência energética foi comparada com base na medida de energia consumida pelos motores de ambos os moinhos, descontada a energia necessária para rodar o equipamento em vazio. A Tabela 8 apresenta um resumo dos resultados.

Tabela 8 - Comparação dos parâmetros entre moinho de bolas de Bond e moinho vertical de carga agitada por impelidor para moagem grosseira em laboratório para diferentes minérios

\begin{tabular}{|l|c|c|c|c|c|c|c|}
\hline Tipo de Minério & un. & \multicolumn{2}{|c|}{ GC2 } & \multicolumn{2}{c|}{ GHB } & \multicolumn{2}{c|}{ SMT } \\
\hline Moinho & & Bolas & Impelidor & Bolas & Impelidor & Bolas & Impelidor \\
\hline Work Index - Laboratório & $\mathrm{kWh/t}$ & \multicolumn{2}{|c|}{11,9} & \multicolumn{2}{|c|}{15,4} & \multicolumn{2}{|c|}{15,9} \\
\hline F80 & $\mu \mathrm{m}$ & 1968 & 2287 & 2000 & 1999 & 2017 & 2065 \\
\hline P80 & $\mu \mathrm{m}$ & 84 & 73 & 83 & 78 & 49 & 52 \\
\hline Abertura da peneira & $\mu \mathrm{m}$ & 125 & 125 & 106 & 106 & 75 & 75 \\
\hline Energia específica & $\mathrm{kWh} / \mathrm{t}$ & 11,6 & 8,7 & 16,9 & 10,6 & 23,8 & 17,4 \\
\hline
\end{tabular}

Fonte: SHI, et al. (2009)

O mesmo estudo conclui que, para moagem grosseira, houve redução em média de $30 \%$ no consumo de energia, mediante a substituição de moinho de bolas por moinho vertical com impelidor. A Figura 10 apresenta um gráfico onde estão lançadas as distribuições granulométricas dos produtos obtidos.

Outra importante vantagem relatada no mesmo estudo de Shi é que o tempo de residência da moagem no moinho vertical foi menor. 
Figura 18 - Curvas de Distribuição granulométrica do Moinho de bolas de Bond e Moinho vertical com carga agitada por impelidor

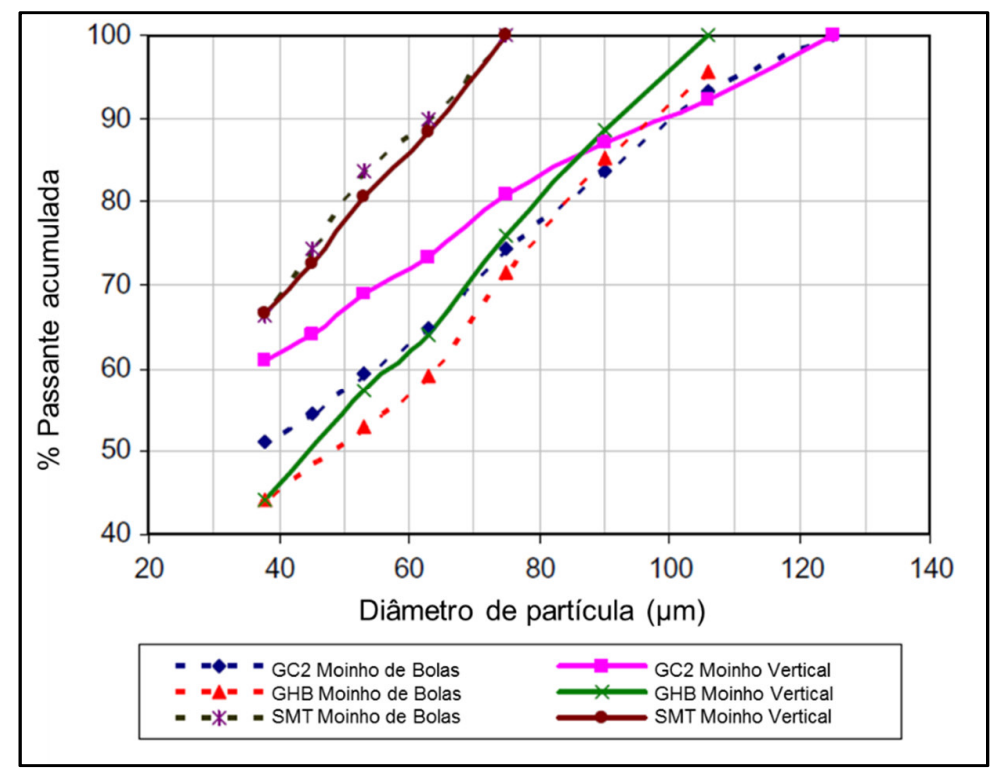

Fonte: Adaptado de SHI et al. (2009)

\subsubsection{Dimensionamento de Moinho de Carga Agitada}

Para realizar dimensionamento de moinhos de carga agitada por impelidores, foi desenvolvido por Bergerman (2013) um método baseado em ensaio de moagem em jarro laboratorial. Os resultados do ensaio de bancada foram correlacionados pelo mesmo autor a resultados industriais.

O estudo realizado por Bergerman (2013) foi realizado testando seis amostras de diferentes usinas e contemplou mais de 130 ensaios, demonstrando boa aderência entre os resultados dos ensaios de laboratório e os respectivos obtidos em ambiente industrial.

O objetivo da aplicação desse ensaio é estimar a energia específicarequerida para cominuição de determinada amostra, com base nos valores de granulometria medidos para alimentação e produto da moagem.

Portanto, determina-se a granulometria de alimentação, tempo de moagem e granulometria do produto. Para calcular a potência utilizada em moinhos de 
laboratório menores que 2,44 m, utiliza-se a equação (92), desenvolvida por Rowland (1982).

$$
k W b=6,3 \cdot D^{0,3} \cdot \operatorname{sen}\left(51-22\left(\frac{2,44-D}{2,44}\right)\right) \cdot\left(3,2-3 V_{p}\right) \cdot C_{s} \cdot\left(1-\frac{0,1}{2^{\left(9-10 C_{s}\right)}}\right)
$$

onde:

$k W b=$ Potência no eixo do pinhão; (kW/t de corpos moedores)

$\mathrm{D}=$ Diâmetro do moinho interno ao revestimento $(\mathrm{m})$

$V_{p}=$ Fração do volume do moinho preenchido por corpos moedores

$\mathrm{C}_{\mathrm{s}}=$ Fração da velocidade crítica

Tendo a energia específica e a capacidade estipulada pelo projeto, pode-se utilizar informações de fornecedores para auxiliar a seleção dos equipamentos comerciais que atendam às requisições do processo. A Figura 19 e a Tabela 9 foram extraídas de catálogo da Metso, empresa que fornece equipamentos industriais para beneficiamento de minérios

Figura 19 - Referências geométricas de moinhos verticais da série VTM da Metso

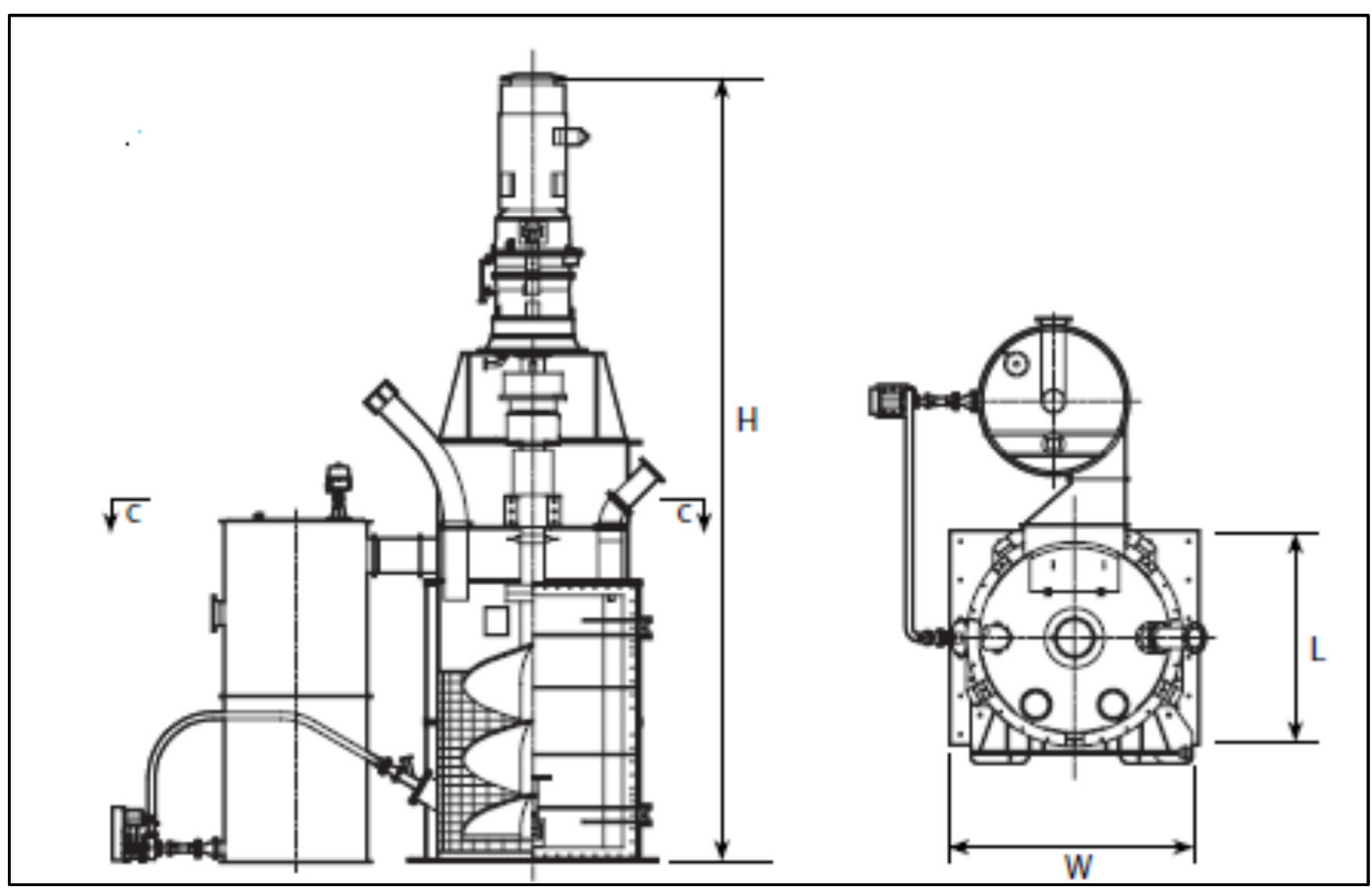

Fonte: Metso (2015) 
Tabela 9 - Informações técnicas de parâmetros de moinhos verticais da série VTM da Metso

\begin{tabular}{|l|c|c|c|c|c|}
\hline \multicolumn{1}{|c|}{ Modelo } & $\begin{array}{c}\mathrm{H} \\
\mathrm{mm}(\mathrm{pol})\end{array}$ & $\begin{array}{c}\mathrm{L} \\
\mathrm{mm}(\mathrm{pol})\end{array}$ & $\begin{array}{c}\mathrm{W} \\
\mathrm{mm}(\mathrm{pol})\end{array}$ & $\begin{array}{c}\text { Potência do } \\
\text { motor } \\
\mathrm{kW} / \mathrm{hp}\end{array}$ & $\begin{array}{c}\text { Peso (vazio) } \\
\text { ton }\end{array}$ \\
\hline VTM-15-WB & $7.060(278)$ & $1.520(60)$ & $1.320(52)$ & $11 / 15$ & 5,5 \\
\hline VTM-20-WB & $7.180(283)$ & $1.520(60)$ & $1.320(52)$ & $15 / 20$ & 5,9 \\
\hline VTM-40-WB & $7.460(294)$ & $1.780(70)$ & $1.520(60)$ & $30 / 40$ & 8,2 \\
\hline VTM-60-WB & $7.600(299)$ & $1.780(70)$ & $1.520(60)$ & $45 / 60$ & 8,8 \\
\hline VTM-75-WB & $7.900(311)$ & $1.960(77)$ & $1.700(67)$ & $56 / 75$ & 12,5 \\
\hline VTM-125-WB & $9.270(365)$ & $2.670(105)$ & $2.310(91)$ & $93 / 125$ & 17,9 \\
\hline VTM-150-WB & $9.780(385)$ & $2.670(105)$ & $2.310(91)$ & $112 / 150$ & 19,6 \\
\hline VTM-200-WB & $9.780(385)$ & $2.670(105)$ & $2.310(91)$ & $150 / 200$ & 20,5 \\
\hline VTM-250-WB & $9.650(380)$ & $3.660(144)$ & $3.180(125)$ & $186 / 250$ & 33,8 \\
\hline VTM-300-WB & $9.650(380)$ & $3.660(144)$ & $3.180(125)$ & $224 / 300$ & 35,7 \\
\hline VTM-400-WB & $11.320(446)$ & $3.910(154)$ & $3.380(133)$ & $298 / 400$ & 52,7 \\
\hline VTM-500-WB & $12.070(475)$ & $3.860(152)$ & $3.780(149)$ & $373 / 500$ & 66,1 \\
\hline VTM-650-WB & $12.270(483)$ & $3.250(128)$ & $3.860(152)$ & $485 / 650$ & 82,6 \\
\hline VTM-800-WB & $13.460(530)$ & $3.560(140)$ & $4.060(160)$ & $597 / 800$ & 100,4 \\
\hline VTM-1000-WB & $13.460(530)$ & $3.660(144)$ & $4.270(168)$ & $746 / 1000$ & 116,1 \\
\hline VTM-1250-WB & $13.460(530)$ & $4.090(161)$ & $4.520(178)$ & $932 / 1250$ & 125,4 \\
\hline
\end{tabular}

Fonte: Metso (2015)

\subsection{ANÁLISES DE CARACTERÍSTICAS FÍSICAS DE AMOSTRAS DE MINÉRIO}

\subsubsection{Densidade do Sólido}

A determinação da densidade de amostras de minério pode ser realizada com auxílio de balão de vidro com fundo chato ou picnômetro, equipado com tampa, também de vidro, pela qual passa um canal capilar, conforme ilustrado na Figura 20. 
Figura 20 - Picnômetros utilizados no laboratório de processo da Mineração Serra Grande

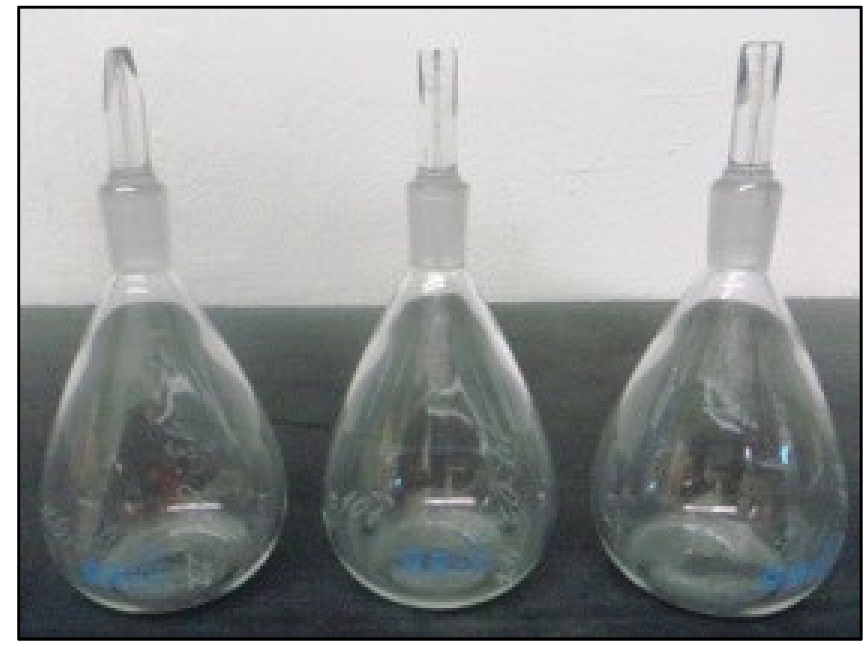

Fonte: Acervo pessoal do autor

O procedimento a seguir descrito (SAMPAIO; DA SILVA, 2007) foi utilizado para quantificar a densidade das amostras selecionadas de minério.

1) Pesar o picnômetro limpo seco e vazio, sendo que, para secar, se utiliza estufa a $100^{\circ} \mathrm{C}$, com resfriamento em dessecador. $O$ valor medido representa o $A_{1}$;

2) Preencher o picnômetro completamente com água até que transborde. Colocar a tampa, secar a água na parte externa do vidro e pesar. $\mathrm{O}$ valor medido representa o $\mathrm{A}_{4}$;

3) Após esses procedimentos, determina-se a densidade da água utilizando-se o volume do picnômetro e o valor da massa do picnômetro cheio menos a massa dele vazio;

4) Adicionar a amostra de minério no picnômetro e pesar para obter o valor de $A_{2}$.A massa da amostra pode ser, portanto, obtida pela diferença $A_{1}-A_{2}$.

5) Adicionar água para obter o valor de $A_{3}$.

Com base nos procedimentos antes descritos, utiliza-se a equação (93) para determinar a densidade de uma amostra (SAMPAIO; DA SILVA, 2007): 


$$
d_{s}=\frac{\left(A_{2}\right)-\left(A_{1}\right)}{\left(A_{4}+A_{2}\right)-\left(A_{1}+A_{3}\right)}
$$

Onde:

ds = densidade de sólidos

$A_{1}=$ massa do picnômetro vazio, limpo e seco

$A_{2}=$ massa do picnômetro mais amostra

$A_{3}=$ massa do picnômetro mais amostra, mais água

$A_{4}=$ massa do picnômetro mais água

O volume do picnômetro varia de acordo com a aplicação requerida. Para realizar o ensaio, é necessário uma balança de precisão. Recomenda-se a realização em duplicata do ensaio para obter boa reprodutibilidade.

Deve-se garantir que não haja formação de bolhas no sólido imerso. Para tanto, pode ser necessário aquecer o líquido até a sua ebulição, expulsando os gases presentes. Além disso, recomenda-se agitar o picnômetro com água e amostra, antes do aquecimento e após o resfriamento.

A obtenção do valor da densidade do minério é importante para se realizarem simulações, pois essa característica determina as estimativas de vazões volumétricas e, consequentemente, parâmetros como pressões de ciclone e carga circulante de circuitos de moagem.

\subsubsection{Granulometria}

As informações de granulometria do minério nas etapas do processamento são normalmente utilizadas para balizar a operação de processos de cominuição, além de se constituir em índices para controle de processos. Em muitas aplicações, peneiramentos ou classificações são utilizados para desaguar ou concentrar minerais. 
Para simulações de processo e calibração de modelos, a granulometria dos vários fluxos do circuito estudado é primordial. Em circuitos industriais, é necessário realizar amostragem para determinação de granulometrias e, com base nelas, executar balanços de massas e estabelecimentos de parâmetros para calibração dos modelos empregados.

Para etapa da determinação da granulometria do material, é importante utilizar os conceitos da teoria da amostragem, para que o material seja representativo do fluxo em análise.

Uma vez tomada a amostra, deve-se homogeneizar e reduzir a massa. Os métodos mais comuns para esta operação são quarteamento em pilha, pilha alongada ou quarteador Jones (SAMPAIO; DA SILVA, 2007).

Devem ser utilizadas padronizações para definir a série adequada de peneiras para se realizar o peneiramento na determinação da granulometria. As séries mais comuns são Tyler e a série da American Society for Testingand Materials (ASTM), que é uma opção conhecida e usual. A duas séries estão apresentadas no Apêndice 2.

O ensaio para determinação da granulometria de uma amostra pode ser efetuado a seco ou a úmido, em peneirador vibratório ou manualmente, como representado na Figura 21. 
Figura 21 - (a) Série de peneiras em peneirador vibratório; (b) peneiramento manual

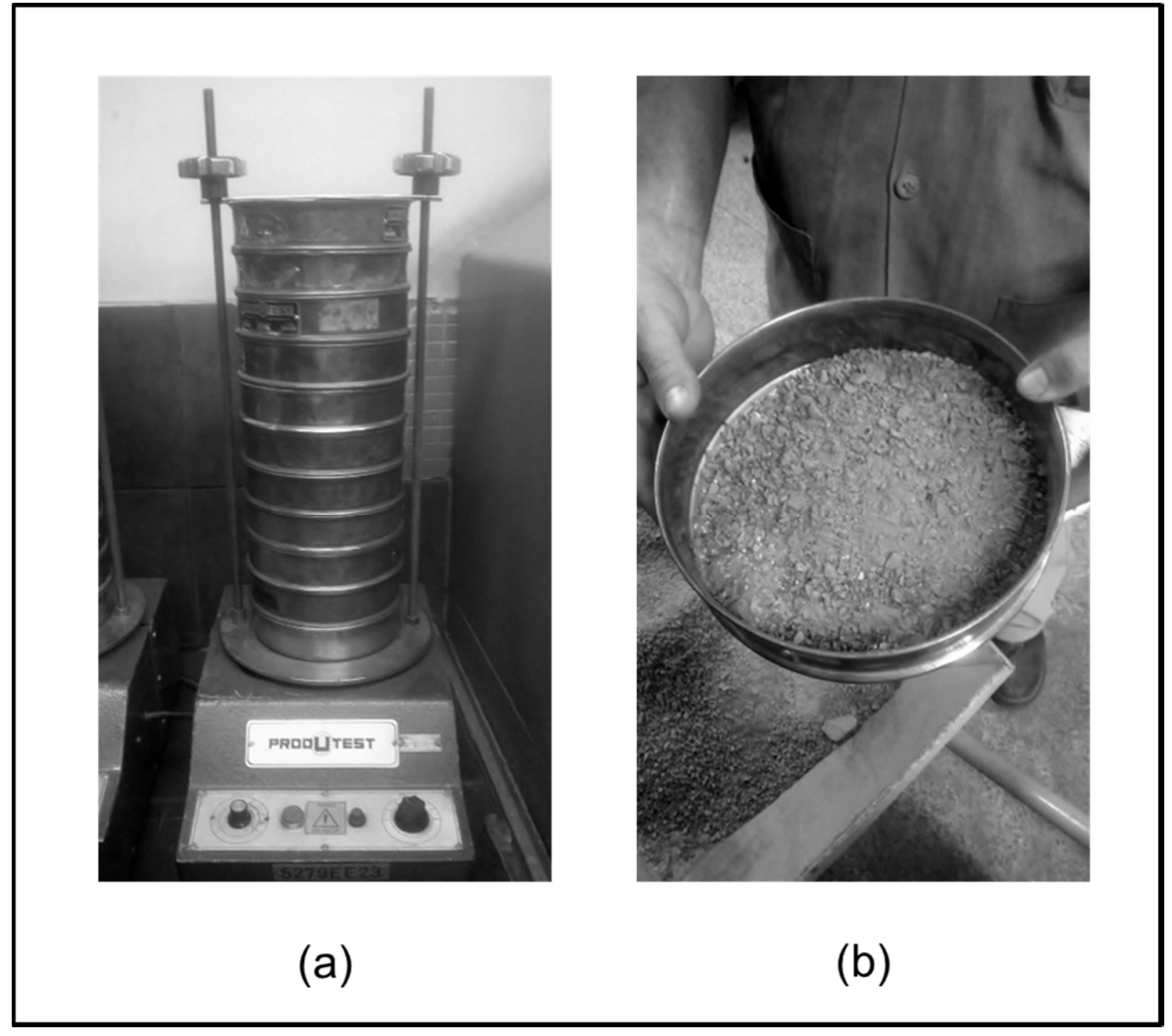

Fonte: Acervo de fotos do autor

O procedimento de peneiramento realizado no laboratório da Serra Grande, é relativamente simples e deve tem como pontos de atenção a preparação da amostra, garantindo que as partículas estejam desagregadas. A massa de material alimentado na primeira peneira não deve ser elevada, para não haver entupimento das malhas da peneira. Nos casos de peneiramento a úmido, é importante não permitir vazões exageradas de água. 


\subsubsection{Determinação do Work Index (WI)}

O Work index (Wi), índice de trabalho ou índice de moabilidade, é um parâmetro definido por Bond para identificar a resistência de um material à cominuição. Numericamente o Wi representa, de acordo com Bond, o trabalho necessário, em $\mathrm{kWh}$, para moagem de uma tonelada curta de material com tamanho infinito, até o tamanho final de um $\mathrm{P}_{80}$ de $100 \mu \mathrm{m}$.

Bond desenvolveu três diferentes métodos para determinar o Wi, um para moinho de bolas, um para moinho de barras e outro para impacto. Para efeito deste estudo, descreve-se na sequência apenas o roteiro para determinação do Wi para moinhos de bolas.

\subsubsection{Determinação do Wi para moagem de bolas}

O ensaio de Wi para moagem em moinhos de bolas é realizado a seco em um moinho padrão, conforme ilustrado na Figura 22 (ABNT - NBR 11376). O moinho possui comprimento e diâmetro de $0,305 \mathrm{~m}$ ou 12 polegadas, revestimento liso e gira a 70 rotações por minuto. Suas extremidades são arredondas e o equipamento contém um contador automático de giros com comando de parada.

A carga moedora é composta por 285 bolas de aço, com peso total de 20,125 $\mathrm{kg}$ e peso específico de $7,83 \mathrm{~g} / \mathrm{cm}^{3}$, com distribuição específica de diâmetros, conforme descrita na Tabela 10, que se segue. 
Figura 22 - Representação gráfica do moinho de bolas utilizado para ensaio Wi de Bond

\begin{tabular}{|l|l}
\hline \multicolumn{2}{|c|}{ Representação gráfica do circuito fechado de moagem } \\
$\mathrm{M}=$ Alimentação nova (adicionada) \\
$\mathrm{Y}=$ Produto, que é descartado \\
$\mathrm{CC}=$ Carga circulante
\end{tabular}

Fonte: Barbato e Sampaio (2007)

Tabela 10 - Especificação da carga moedora do ensaio Wi de Bond

\begin{tabular}{|c|c|}
\hline Número de Bolas & Diâmetro em $(\mathrm{mm})$ \\
\hline 43 & 36,5 \\
\hline 67 & 30,2 \\
\hline 10 & 25,4 \\
\hline 71 & 19,1 \\
\hline 94 & 15,9 \\
\hline
\end{tabular}

Fonte: Barbato e Sampaio (2007) 
O ensaio, conforme proposto por Bond, é realizado até a carga circulante atingir $250 \%$ e se estabilizar nesse valor.

O procedimento do ensaio é descrito sucintamente conforme Barbato (2007).

Em condições normais, utilizam-se cerca de 15 a $30 \mathrm{~kg}$ de amostra, sendo que se recomenda a realização de ensaios em duplicata.

1) Britar de 15 a $30 \mathrm{~kg}$ da amostra em circuito fechado em peneira de $3,36 \mathrm{~mm}$. Homogeneizar a amostra em pilha prismática em bancada para retirar as alíquotas a serem utilizadas no ensaio;

2) Preencher uma proveta de $1000 \mathrm{~mL}$ até $700 \mathrm{~mL}$ com o minério. Essa proveta deverá ser batida contra uma superfície revestida de borracha para compactar o material. Realizar o procedimento em triplicata e considerar o valor do peso médio da amostra como o valor de $\mathrm{M}$ da alimentação total;

3) Realizar a análise granulométrica da alimentação utilizando a série de Tyler $\sqrt{2}$, e determinar o F80 da alimentação;

4) Definir a massa passante do material de alimentação na abertura de malha de classificação determinada para o teste (Am);

5) Utilizar a carga de bolas da Tabela 10 para preencher o moinho adicionando também a massa de mineiro determinada anteriormente. No primeiro ciclo, o número de rotações deve ser previamente definido, de acordo com as características do minério;

6) Descarregar todo o material presente no moinho, separar minério de bolas e peneirar material moído para determinar:

MAR = massa retida na malha do ensaio

MAP = massa passante na malha do ensaio

$M A L=$ massa líquida passante na malha do ensaio

A fração nova de minério a ser adicionado no ciclo seguinte corresponde ao valor passante em (Am) e deve ser retirada diretamente da pilha de homogeneização;

7) Para se calcular o valor da massa passante líquida (MAL), utilizar a equação (94): 
$(M A L)=(M A)-(M A P)$

8) Carregar o moinho com a alimentação nova, mais a carga de bolas e mais a massa retida na malha do teste. Os ciclos serão repetidos até que a massa passante na malha do teste seja igual à massa da alimentação nova. Esse acontecimento indica o equilíbrio do sistema;

9) Para determinar a massa passante em Am, contida na alimentação nova, utilizar como base a análise granulométrica realizada no item (3);

10)Calcular o valor da massa a ser adicionada no sistema (AAR) pela equação (95):

$A A R=\frac{\text { Alimentação Inicial }}{1+\text { Carga Circulante }}$

11)Determinar o valor do desvio correspondente ao ciclo pela equação (96):

Desvio $=(M A P)-(A A R)$

12) Determinar a moabilidade pela equação (97):

$M o b=\frac{(M A L)}{\left(N_{R}\right)}$

13) Calcular o número de rotações $\left(\mathrm{N}_{R}\right)$ pela equação $(98)$ : 


$$
\left(N_{R}\right)=\frac{(A A R)-(M A)}{M o b}
$$

Para equação (98), o valor de (MA) se refere ao ciclo seguinte;

14)Repetir as operações descritas até que a moagem atinja equilíbrio ou o valor de moabilidade inverta a tendência de crescimento ou de decréscimo em três ciclos. A confirmação de que o sistema entrou em equilíbrio é calculado pela média aritmética dos três últimos valores de moabilidade, sendo que a diferença entre o maior e o menor valor deve ser inferior a 5\% em relação ao valor médio.

15)Após alcançar o equilíbrio, realizar granulometria da fração passante em Am para o último ciclo e determinar o $\mathrm{P}_{80}$ do produto;

16) Calcular o valor de WI de acordo com a equação (99):

$$
W i=\frac{44,5}{A m^{0,23} \cdot M o b^{0,82} \cdot\left(\frac{10}{\sqrt{P_{80}}}-\frac{10}{\sqrt{F_{80}}}\right)} \cdot 1,1
$$

Onde:

$\mathrm{Am}=$ abertura da malha de peneiramento do ensaio $(\mu \mathrm{m})$;

$\mathrm{Wi}=$ índice de moabilidade para moagem $(\mathrm{kWh} / \mathrm{t})$;

$\mathrm{P}_{80}=$ abertura da peneira pela qual passam80\% da massa do produto $(\mu \mathrm{m}) ;$

$F_{80}=$ abertura da peneira pela qual passam $80 \%$ da massa da alimentação $(\mu \mathrm{m})$;

Mob = média dos três últimos valores de moabilidade no estado de equilíbrio;

1,102 = fator de conversão de tonelada curta para tonelada métrica.

A Tabela 11 apresenta um modelo para o acompanhamento dos ciclos do teste de determinação de WI para moinhos de bola 
Tabela 11 - Modelo de tabela para acompanhamento dos ciclos do teste de determinação do WI para moagem de bolas

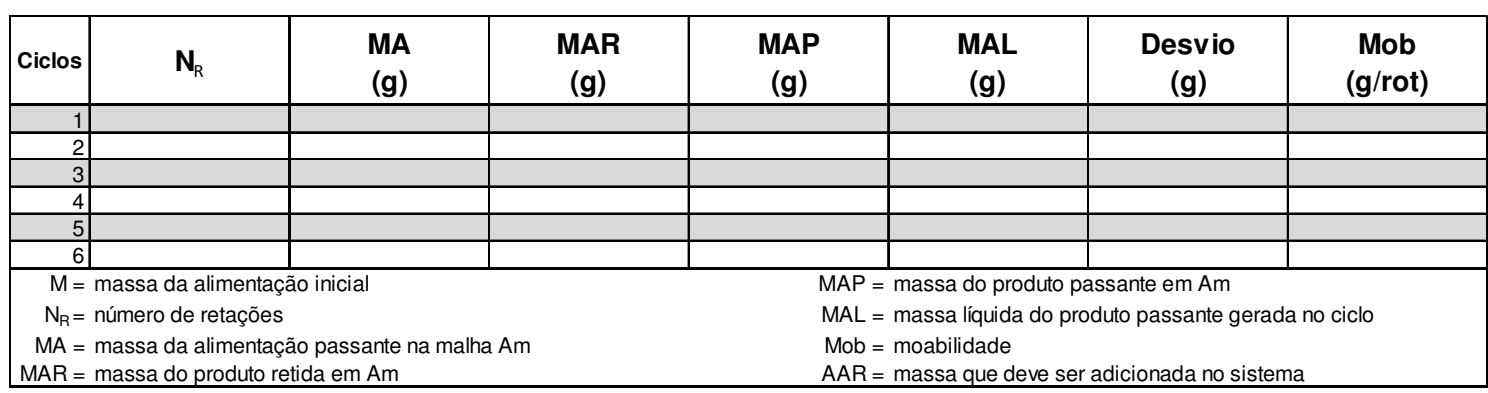

Fonte: Adaptada de Barbato; Sampaio (2007)

\subsubsection{Ensaio de Resistência ao Impacto em Partículas Individuais}

Os ensaios de resistência ao impacto foram desenvolvidos para identificar o comportamento de quebra do minério quando é submetido a diferentes energias. Essa correlação pode ser expressa como o grau de quebra para determinado nível de energia ou como a função quebra.

Existem dois ensaios para identificar a função quebra, são eles:

- Drop Weight Test (DWT)

- Duplo Pêndulo

Ambos os ensaios foram desenvolvidos pelo Julius Kruttschnitt Mineral Research Centre (JKMRC). O ensaio de Duplo Pêndulo apresenta algumas restrições, pois demanda muito tempo para sua realização e não é representativo para determinados valores de energia e tamanho de partículas. Além disso, nesse ensaio, há imprecisões no cálculo da energia de quebra decorrente da concepção do equipamento. Para eliminar essas questões, foi desenvolvido o DWT, realizado no equipamento denominado célula de impacto, que oferece maior precisão para a realização do ensaio. Após um período de transição, o ensaio DWT substituiu o ensaio Duplo Pêndulo (NAPIER-MUNN et al.,1996). 


\subsubsection{Drop Weight Test (DWT)}

O ensaio é realizado no equipamento representado na Figura 23, que consiste em um peso de aço montado em duas guias metálicas e confinado a em uma cabine acrílica que permite a visão do movimento de queda do peso. Um sistema elétrico é utilizado para suspender o peso até a altura desejada. Quando o peso atinge a altura especificada, é acionado um sistema que permite que o peso caia em queda livre, de forma a impactar o fragmento alocado em sua base. A estrutura do equipamento é robusta para suportar as condições requisitadas pelo ensaio.

Figura 23 - Ilustração simplificada do Drop Weight Tester ou Célula de Impacto

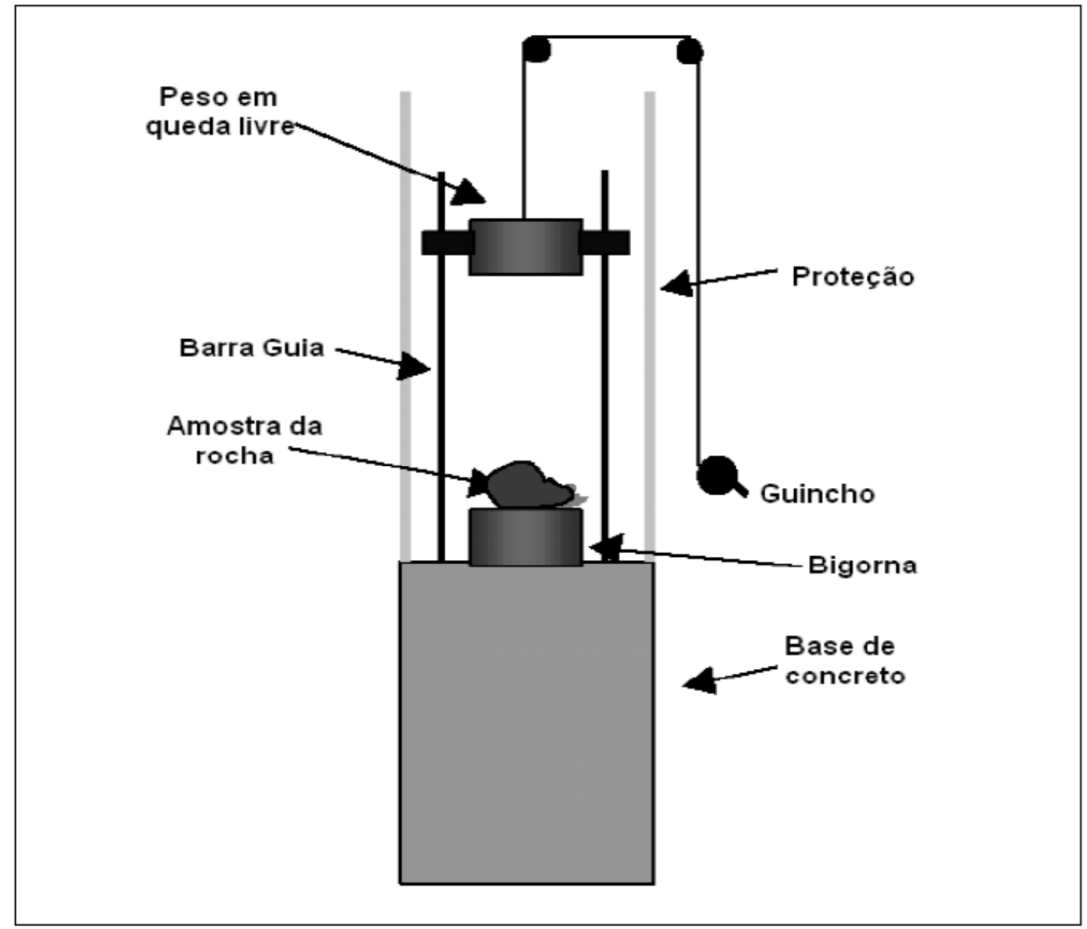

Fonte: Delboni; Sampaio; Lima (2010)

O equipamento permite que sejam montados vários pesos diferentes e que o peso seja liberado em qualquer altura requisitada. Dessa forma, é possível gerar quantidade de energia em uma faixa ampla com a variação de tais parâmetros.

No ensaio, emprega-se fragmentos com tamanhos entre 10 e $50 \mathrm{~mm}$, além de anéis de chumbo com pesos entre $20 \mathrm{~kg}$ e $50 \mathrm{~kg}$ e alturas de queda entre 5 e $100 \mathrm{~cm}$. 
Sob tais condições, o equipamento pode gerar energias específicas de quebra entre 0,01 e $50 \mathrm{kWh} / \mathrm{t}$.

O procedimento consiste em selecionar fragmentos em diferentes faixas de tamanho, formando lotes que, então, são submetidos ao impacto do peso com a energia específica variante para cada lote. As quebras dos fragmentos ocorrem de forma individual.

No fim de cada quebra, é medida a diferença entre as alturas inicial e final do peso e o produto é recolhido. Pela equação (100), é possível calcular a energia utilizada em cada ciclo da Célula de Impacto.

$$
E_{i}=M \cdot g \cdot\left(h_{i}-h_{f}\right)
$$

Onde:

$E_{i}=$ energia utilizada para fragmentação

$\mathrm{M}=$ massa do peso

$\mathrm{g}$ = aceleração da gravidade

$h_{i}=$ altura inicial

$h_{f}=$ altura final

Portanto, com o valor da energia utilizada, pode-se calcular o valor da energia específica pela equação (101). Para isso, é necessário considerar que a $E_{i}$ foi inteiramente empregada para quebra do fragmento.

$$
E_{c s}=E_{i} / m
$$

Onde:

$E_{c s}=$ energia específica de cominuição

m = massa média da partícula 


\subsubsection{Relação Entre Fragmentação e Energia Aplicada}

Após a realização das quebras, as partículas fragmentadas de cada lote são reunidas e encaminhadas ao peneiramento em série de malhas padronizadas. A partir das distribuições granulométricas obtidas, são calculados os valores do parâmetro normalizado correspondente. Trata-se do parâmetro $t_{10}$, que representa a porcentagem passante na malha igual a $10 \%$ do tamanho médio das partículas contidas no respectivo lote. De posse dos 15 conjuntos de valores de energia aplicada e fragmentação correspondente, parametriza-se a relação entre ambos pela equação (96), que se segue.

$$
t_{10}=A\left(1-e^{-\left(b E_{C S}\right)}\right)
$$

Onde:

$\mathrm{t}_{10}=$ porcentagem passante na malha que equivale à $1 / 10$ do tamanho inicial do fragmento

$E_{c s}=$ energia específica de cominuição $(\mathrm{kWh} / \mathrm{t})$

$\mathrm{A}$ e $\mathrm{b}=$ parâmetros relacionados à resistência à fragmentação do minério

Figura 24 representa a função que descreve a fragmentação normalizada de um minério em relação à energia específica aplicada. Essa função tem um rápido crescimento inicial determinado pelo parâmetro $b$, tendendo posteriormente a um valor assintótico, estabelecido pelo parâmetro A.

Figura 24 - Representação da fragmentação em decorrência da energia específica aplicada 


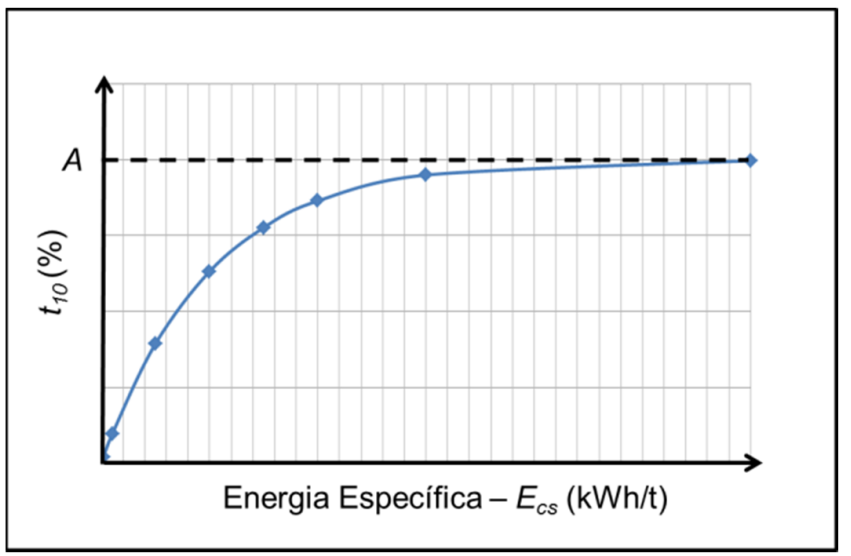

Fonte: Gerado pelo autor

Característicos da amostra de minério submetido ao ensaio, os valores de $\mathrm{A}$ e b são inversamente proporcionais à resistência à quebra por impacto. $O$ Índice de Quebra do material é determinado por $A^{*} b$ e representado pela sigla IQ. Esse índice pode ser utilizado para classificar o material em relação à resistência ao impacto.

Apesar dos procedimentos de DWT e Wi serem utilizados para estabeleceras características do minério quando submetidos a processo de cominuição, os índices Wi e IQ não se correlacionam (CHIEREGATI, 2001).

\subsubsection{Ensaio de Compressão de Leito de Partículas CLP}

O ensaio de CLP assemelha-se com o DWT, sendo a principal diferença a forma de transferir energia do equipamento às partículas de minério. O CLP utiliza a compressão das partículas em um leito para realizar a quebra aplicando diferentes níveis de energia, enquanto o DWT transfere energia para a fragmentação por meio do impacto.

O procedimento para realizar o ensaio de CLP não é padronizado como o ensaio de Bond ou DWT, pode, portanto, ser executado utilizando-se diferentes prensas ou equipamentos de compressão, desde que seja possível determina a força aplicada.

O objetivo do teste é identificar a matriz de quebra do material assim como correlacionar diferentes energias aplicadas a diferentes granulometrias de produtos. 
O método consiste inicialmente em dispor de forma regular uma monocamada de minério na faixa granulométrica estipulada no fundo de um pistão metálico de paredes resistentes.

Aplica-se uma força por meio da prensa e mede-se o deslocamento do pistão. Alguns equipamentos podem realizar este procedimento de forma automática, tal qual o equipamento mostrado na Figura 25, cujo produto é uma curva que indica a energia dispendida para o teste.

Figura 25 - Unidade hidráulica e câmera de compressão utilizada em CLP

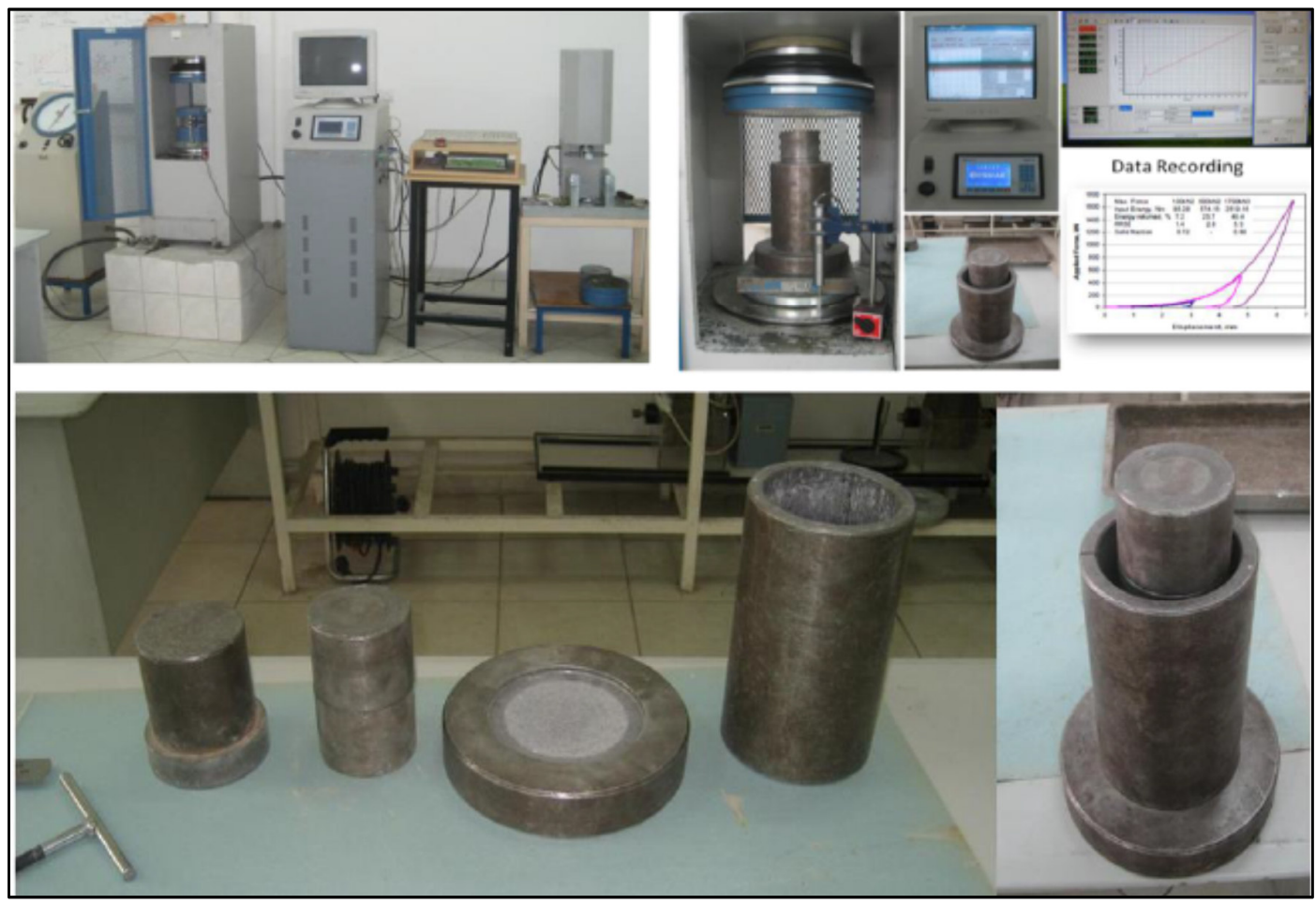

Fonte: Oliveira (2016)

Com base na energia e na massa de minério utilizada no ensaio, determina-se a energia específica de cominuição ( $\left.E_{c s}\right)$

O ensaio também pode ser realizado com prensa manual, nesse caso a medida de deslocamento do êmbolo do cilindro é realizada com uso de paquímetro. 
Para cada ensaio constrói-se uma curva como a apresentada na Figura 26. A área hachurada é utilizada para cálculo da energia empregada.

Figura 26 - Resultado de testes de CLP deslocamento do êmbolo versus força aplicada

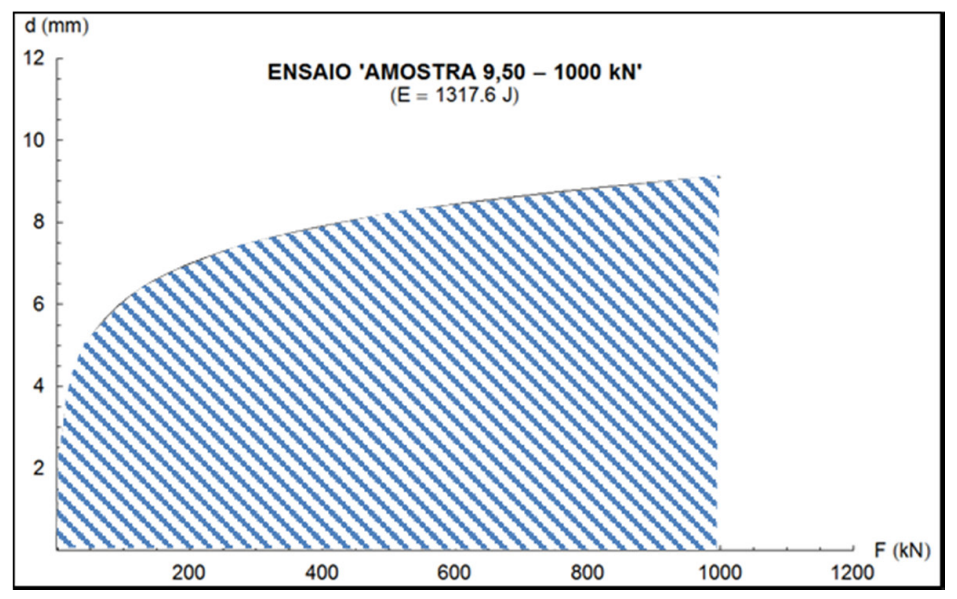

Fonte: Obtida em testes realizados para este estudo

Ao término da aplicação da força, a amostra é peneirada para determinação da fragmentação ocorrida e gerar a matriz de quebra do minério. $O$ tratamento dos dados resultantes do ensaio é semelhante ao descrito para o ensaio DWT, utilizando-se, entretanto, equação (102), esta última modificada com a inserção do termo x, que representa a média geométrica do intervalo.

$$
t_{10}=A\left(1-e^{-\left(b E_{c S .} \cdot x\right)}\right)
$$

Os resultados do teste CLP são os valores de $A$ e $b$ obtidos a partir da equação (103), bem como da matiz de quebra do material. Esses valores são utilizados para a simulação do modelo da HPGR.

\subsubsection{Ensaio de jarro para moinho de carga agitada}


O ensaio de jarro foi desenvolvido para estimar o consumo de energia em moinhos verticais industriais (BERGERMAN, 2013).

O procedimento adotado para execução de ensaios de moagem em jarros seguiu aquele descrito por Bergerman (2013), incluindo um jarro de aço carbono, com revestimento interno liso 8" de diâmetro e 10" de comprimento disposto uma mesa de rolos, de forma a rotação em $71,3 \%$ da velocidade crítica.

O enchimento do jarro foi adotado em $40 \%$ de corpos moedores de aço cromo de $12,7 \mathrm{~mm}$ de diâmetro e polpa do minério, esta última com $50 \%$ de sólidos em peso, massa de minérios $913 \mathrm{~g}$ e massa de água $913 \mathrm{~g}$. 


\section{MINERAÇÃO SERRA GRANDE ANGLOGOLD ASHANTI}

\subsection{DESCRIÇÃO}

Situada no município de Crixás, estado de Goiás, a usina de beneficiamento da unidade Serra Grande processa minério proveniente de quatro minas, sendo três subterrâneas e uma a céu aberto, denominadas: Mina III, Mina Nova, Mina Palmeiras e Open Pit. A Figura 27 apresenta o mapa e fotografia de satélite da usina.

Figura 27 - Localização da Mineração Serra Grande no estado de Goiás

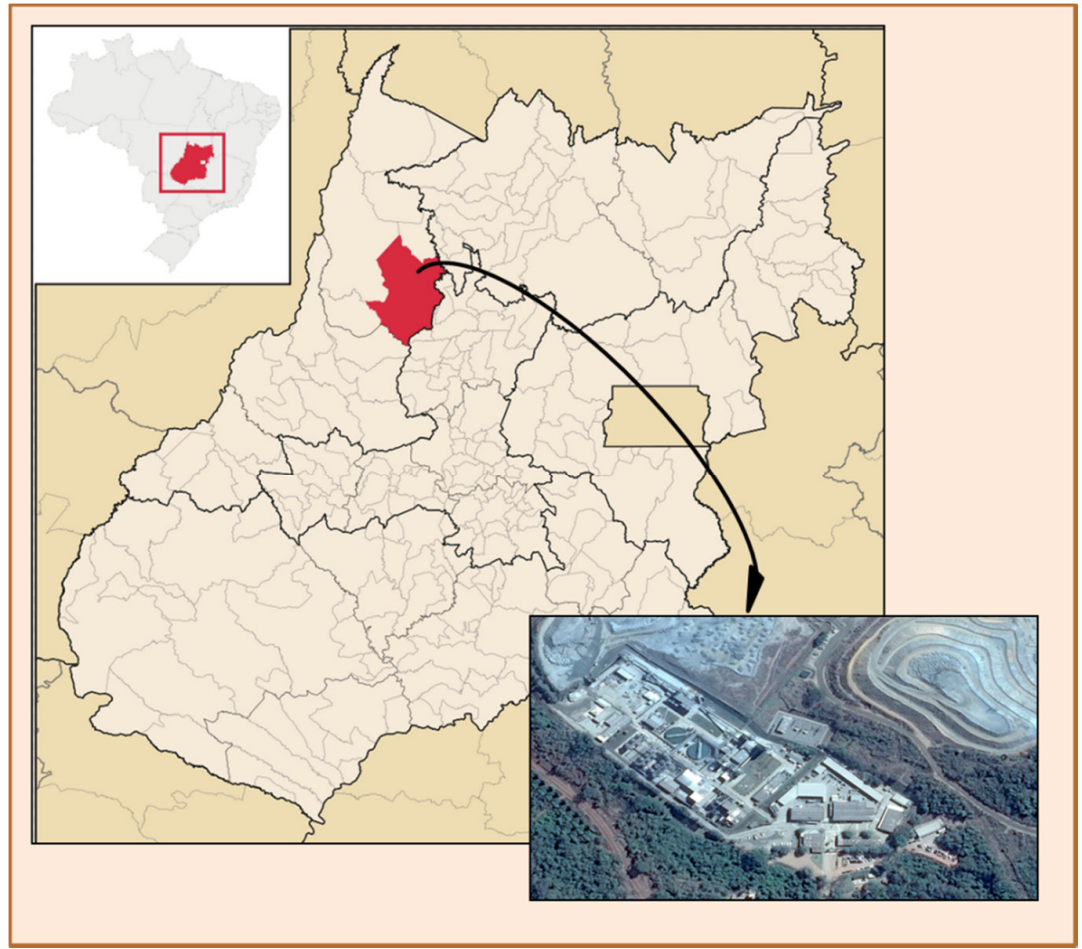

Fontes: Google Maps e Wikipedia. Adaptado pelo autor

A usina de beneficiamento mineral da Mineração Serra Grande (MSG) iniciou suas atividades em outubro de 1989, com apenas um moinho e capacidade para tratar $1.200 \mathrm{t} / \mathrm{dia}$. Atualmente a usina tem capacidade para tratar aproximadamente 3.600 t/dia. 
Para atingir a capacidade atual, foi realizada em 2008/2009 uma expansão com adição de mais um moinho ao circuito. Nesse caso, porém, o aumento da capacidade não se deveu apenas em razão da adição de novos equipamentos, mas também devido à realização de vários estudos e trabalhos de otimização. Entre eles, destacam-se os projetos no sistema de bombeamento, a mudança nas baterias de ciclones, na maior carga de bolas dos moinhos, a instalação de diafragma nos moinhos e a automação da moagem, além de projetos em outras áreas da usina. Considera-se, portanto, que, em termos práticos, as possibilidades de aumento da capacidade da moagem estão praticamente esgotadas e, para qualquer acréscimo de produção, deve-se avaliar a instalação de novos equipamentos em diversas áreas.

A Figura 28 apresenta o histórico de produção da usina da MSG, junto ao valor do teor médio de ouro alimentado no ano.

Figura 28 - Histórico da produção da usina e dos teores de alimentação

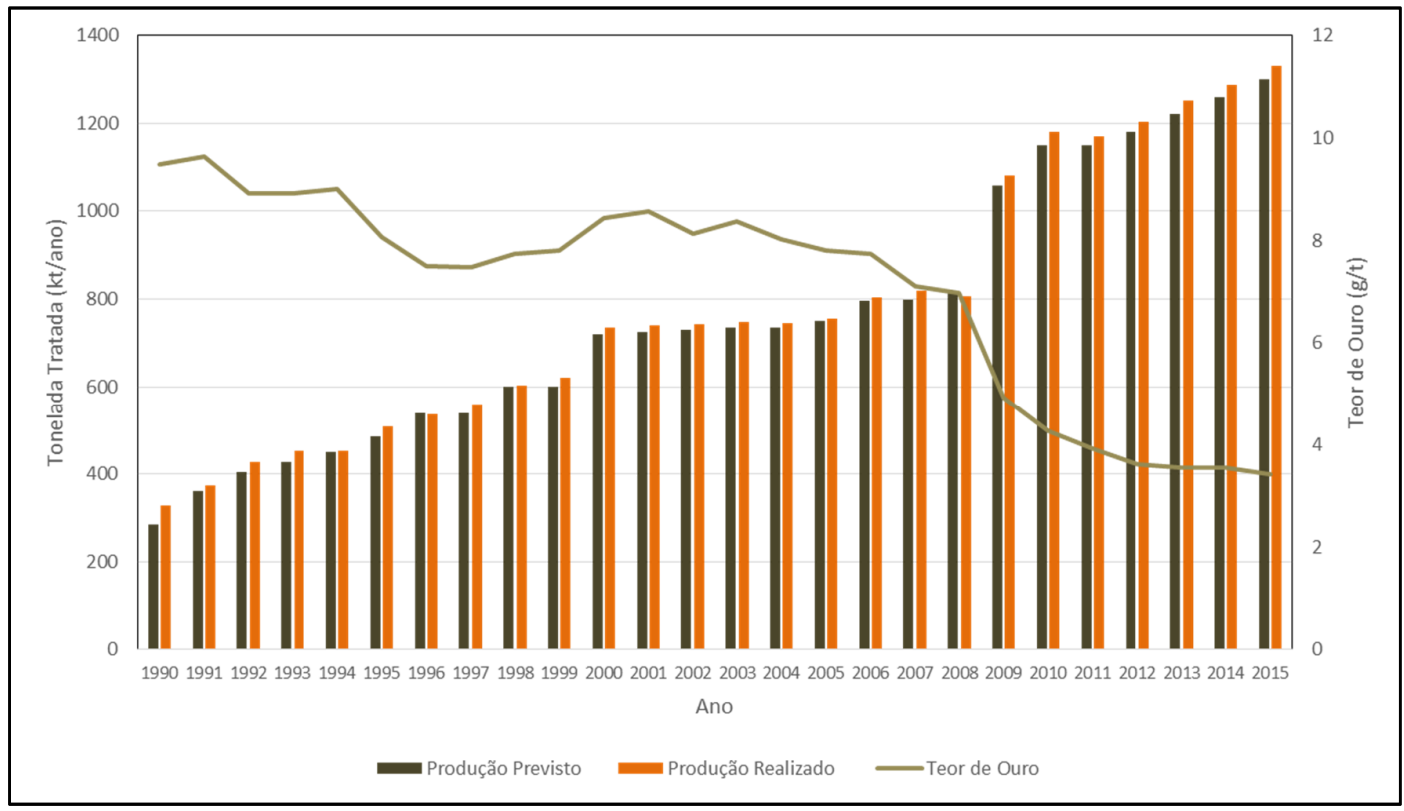

Fonte: Banco de dados da MSG

Pelo gráfico da Figura 18, fica explícito o efeito dos trabalhos de otimização, pois a cada ano a produção foi aumentada. Outro ponto que pode ser observado é que o teor de ouro da alimentação da planta diminuiu, mediante a progressiva exaustão de corpos mais ricos. 
Atualmente, uma das possibilidades para melhorar o desempenho e diminuir o custo operacional por onça produzida é uma nova expansão da capacidade, o que traria ganhos de escala e melhoria da eficiência operacional.

\subsubsection{Operações e Processos Produtivos}

O processo atual de produção da MSG inicia-se com a britagem e moagem do minério. Parte da carga circulante dos moinhos (underflow dos ciclones) alimenta o circuito de concentração densitária, enquanto o overflow dos ciclones segue para o espessamento. $O$ underflow do espessador segue para a lixiviação em tanques com cianeto de sódio, depois filtragem, clarificação da solução e precipitação com zinco (processo Merrill Crowe). O rejeito sólido proveniente desse processo é bombeado em forma de polpa para a barragem de rejeitos. Portanto, a produção final de ouro da usina é proveniente de dois circuitos paralelos: Merrill Crowe e densitário. A Figura 29 apresenta o fluxograma atual da usina de Serra Grande. 
Figura 29 - Fluxograma de Processo da Mineração Serra Grande

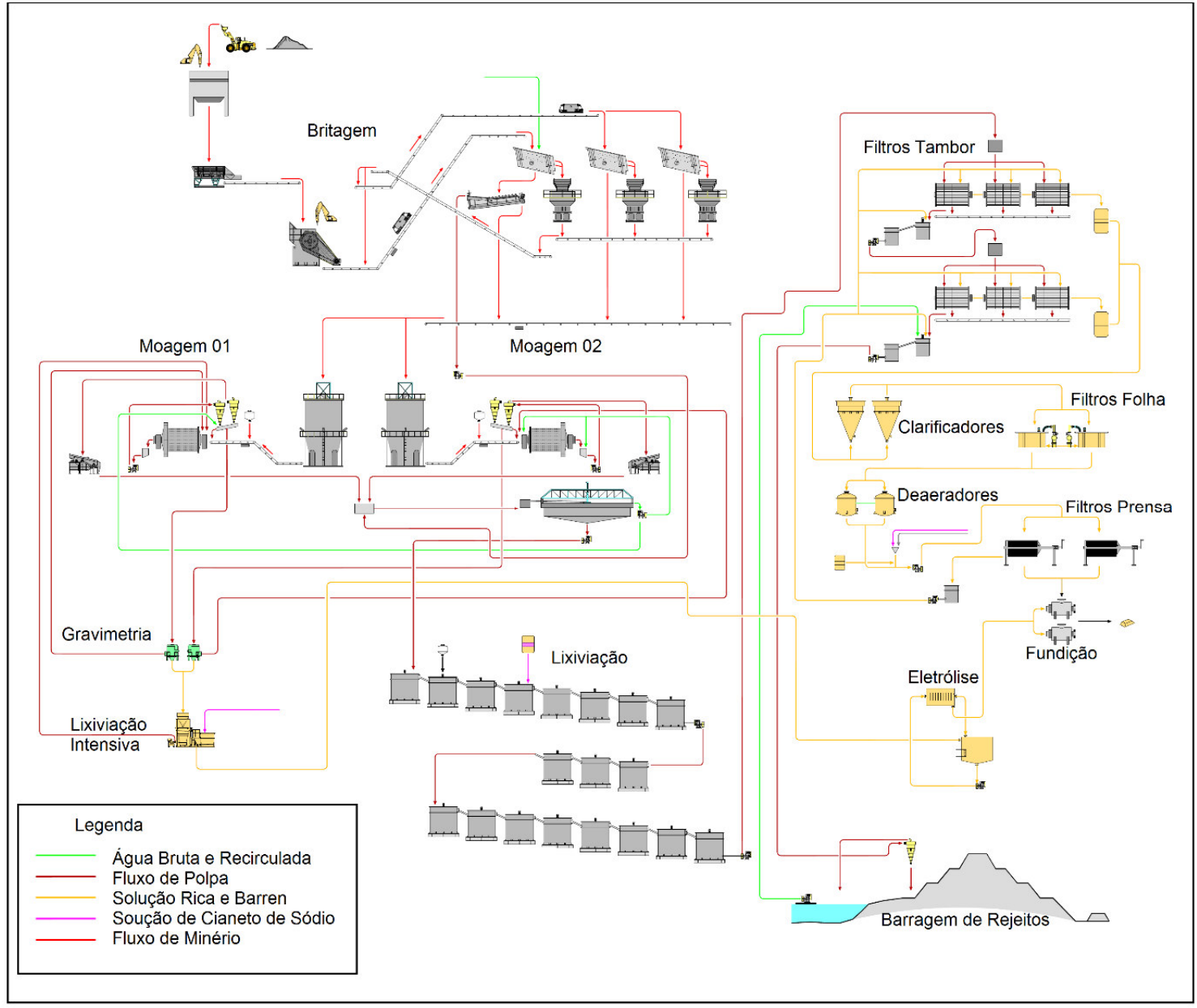

Fonte: Banco de dados da MSG

\subsubsection{Descrição operacional do circuito de moagem}

O minério britado contido no interior do respectivo silo é retomado por meio de transportadores de correia até o ponto de alimentação dos moinhos. Na estrutura do transportador de correia está instalada uma balança que indica a vazão horária de alimentação dos moinhos e totaliza a massa de minério processado. Para identificação da umidade do minério, é realizada amostragem manual na correia.

A amostragem do minério para realizar o balanço metalúrgico é feita a cada 6 minutos por um amostrado automático, compondo uma amostra que será analisada por turno. As amostras são fechadas diariamente nos seguintes horários: $5 \mathrm{~h}, 13 \mathrm{~h}$ e $21 \mathrm{~h}$. 
Também antes da alimentação do moinho, o minério recebe automaticamente adição de cal virgem, dosado conforme o valor do $\mathrm{pH}$ medido no primeiro tanque da lixiviação. $\mathrm{O}$ valor de referência para o $\mathrm{pH}$ é próximo a 11. A cal virgem é de grande importância, pois evita a formação do gás cianídrico $(\mathrm{HCN})$, componente tóxico que pode causar a morte de seres humanos, mesmo se inalado em baixas concentrações, melhora o desempenho do espessamento, etapa subsequente à moagem, e auxilia na oxidação do ferro, reduzindo o consumo de cianeto.

Em cada um dos dois circuitos paralelos de moagem há um moinho de bolas que opera em configuração fechada e a úmido com ciclones. O moinho MO-01 possui diâmetro nominal de 12' e 17' de comprimento nominal e é dotado de revestimento em aço, motor de $1800 \mathrm{HP}$, operando com $74 \%$ da respectiva velocidade crítica (17 rpm). Analogamente, o moinho MO-02 possui diâmetro nominal de 9' de diâmetro por 11,4 ' de comprimento, girando a $78 \%$ da respectiva velocidade crítica (19,3 rpm).

Os dois moinhos possuem diafragmas, o que possibilita a operação com grau de enchimento de $45 \%$. O Work Index dos minérios alimentados na usina varia de 8,5 a $14 \mathrm{kWh} / \mathrm{t}$. A potência de operação do MO-01 tem como valor de referência $1.050 \mathrm{~kW}$, com vazão de alimentação de $115 \mathrm{t} / \mathrm{h}$, enquanto o MO-02 opera com potência de 400 kW e produção de $45 \mathrm{t} / \mathrm{h}$. Os corpos moedores utilizados são esferas de aço de 63 $\mathrm{mm}$ de diâmetro $\left(2^{1 / 2 "}\right)$.

O moinho MO-01 opera com três ciclones, permanecendo dois em stand-by. Já o moinho MO-02 opera com dois ciclones, um em stand-by.

A polpa da descarga dos moinhos é diluída para valores em torno de 54 a $62 \%$ de sólidos na caixa da bomba que alimenta os ciclones, cujo overflow apresenta 25 a $35 \%$ de sólidos e underflow 75 a $80 \%$ de sólidos.

O overflow dos ciclones, produto final das moagens, passa por uma peneira vibratória que retém materiais grosseiros vindos da mina, como restos de explosivos, madeira e estopins. A fração passante na peneira segue para o espessador primário para concentrar a polpa em $58 \%$ de sólidos. Parte do underflow retorna aos moinhos, constituindo a carga circulante, enquanto cerca de $20 \%$ do fluxo é direcionado para as caixas de passagem e bombeada para os concentradores centrífugos Knelson XD30. O concentrado da gravimetria, conforme denominação local, segue para a 
lixiviação intensiva em um equipamento $A C A C I A$, enquanto o rejeito da gravimetria retorna para os moinhos por outra caixa de passagem e sistema de bombeamento. $O$ overflow do espessador primário é empregado para a diluição da polpa que alimenta os moinhos. O produto final das moagens tem por referência o $\mathrm{P}_{80}$ aproximado de 106 $\mu \mathrm{m}$, sendo que a granulometria típica do minério que alimenta os moinhos é $100 \%$ menor que $5 / 16 "$.

Desde dezembro de 2014, as moagens contam com sistema de controle e automação. Há equipamentos para medida de parâmetros operacionais, como densidade dos fluxos de overflow e alimentação dos ciclones, vazões de água para diluição da alimentação da moagem e diluição do produto da moagem, nível das caixas de passagem do produto da moagem, velocidade de rotação da bomba que alimenta os ciclones e pressão de operação da bateria dos ciclones e outros dados.

As informações obtidas pelos sensores alimentam um programa computacional que simula a granulometria do produto. Na sequência, outro programa realiza análises on-line para decisões de mudanças do set point de operação, visando aumentar a eficiência da moagem.

Apesar de o sistema de automação indicar aumento potencial da capacidade de produção, isso não ocorre em razão, entre outras causas, da baixa disponibilidade dos instrumentos.

O fluxograma da Figura 30 representa o processo para ambos os moinhos de bolas da usina da MSG, com circuitos independentes para todos os equipamentos, com exceção do espessador que, portanto, é o mesmo para ambos os moinhos de bolas MO-01 e MO-02. 
Figura 30 - Fluxograma do circuito de uma linha individual de moagem da MSG

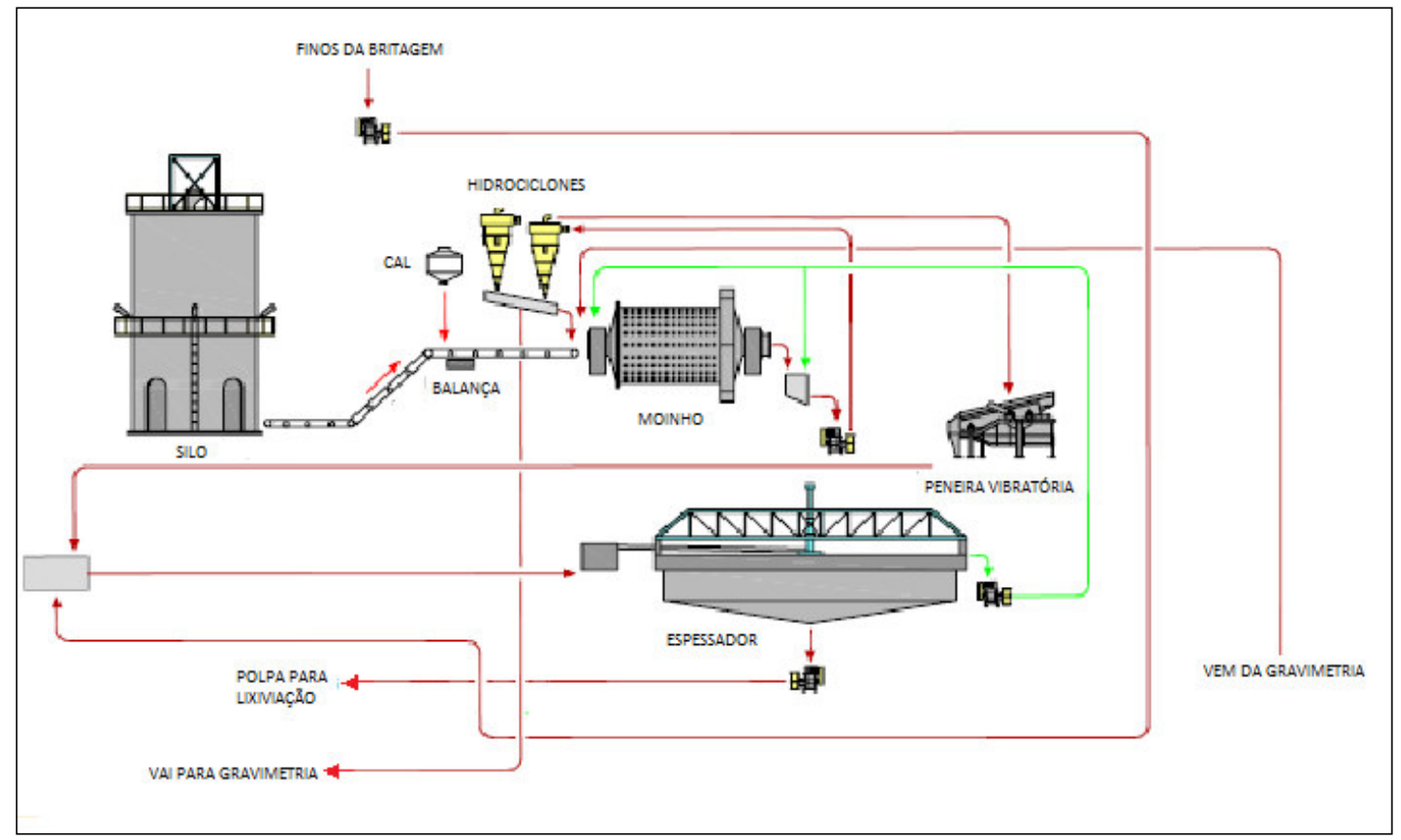

Fonte: Banco de dados da MSG

\subsubsection{Consumo de Energia Elétrica de MSG}

Ao longo do ano de 2014, o consumo médio mensal de energia da MSG foi $7427 \mathrm{MWh}$, sendo 48,2\% referentes à operação da usina e16\% correspondentes à moagem. Os valores de consumo das principais áreas são apresentados na Tabela 12 e Figura 31. 
Tabela 12 - Consumo de energia das principais áreas da MSG

\begin{tabular}{|l|r|r|r|}
\hline \multicolumn{2}{|c|}{ Consumo de Energia MSG } \\
\hline \multicolumn{2}{|c|}{} & MWh/mês \\
\hline Áreas da MSG & $3.579,53$ \\
\hline Planta Metalúrgica & $1.266,79$ \\
\hline Mina III & 900,26 \\
\hline Mina Pequizão & 640,56 \\
\hline Mina Palmeiras & 531,39 \\
\hline Adm./Desenvolvimento & 260,56 \\
\hline Mina Nova & 143,94 \\
\hline Geologia / Exploração & 103,82 \\
\hline Manutenção/ Escritórios & $7.426,86$ \\
\hline Total & \multicolumn{2}{c|}{ Consumo de Energia Metalurgia } \\
\hline \multicolumn{2}{|l|}{ Área da Planta Metalúrgica } & MWh/mês \\
\hline Moagem & $1.152,80$ \\
\hline Ar Comprimido & 751,86 \\
\hline Britagem & 411,80 \\
\hline Filtragem & 390,23 \\
\hline Bombeamento Rejeito & 170,82 \\
\hline Lixiviação & 158,51 \\
\hline Precipitação & 139,57 \\
\hline Espessamento & 116,40 \\
\hline
\end{tabular}

Fonte: Banco de dados da MSG

Figura 31 - Percentual de consumo energético das principais áreas da MSN

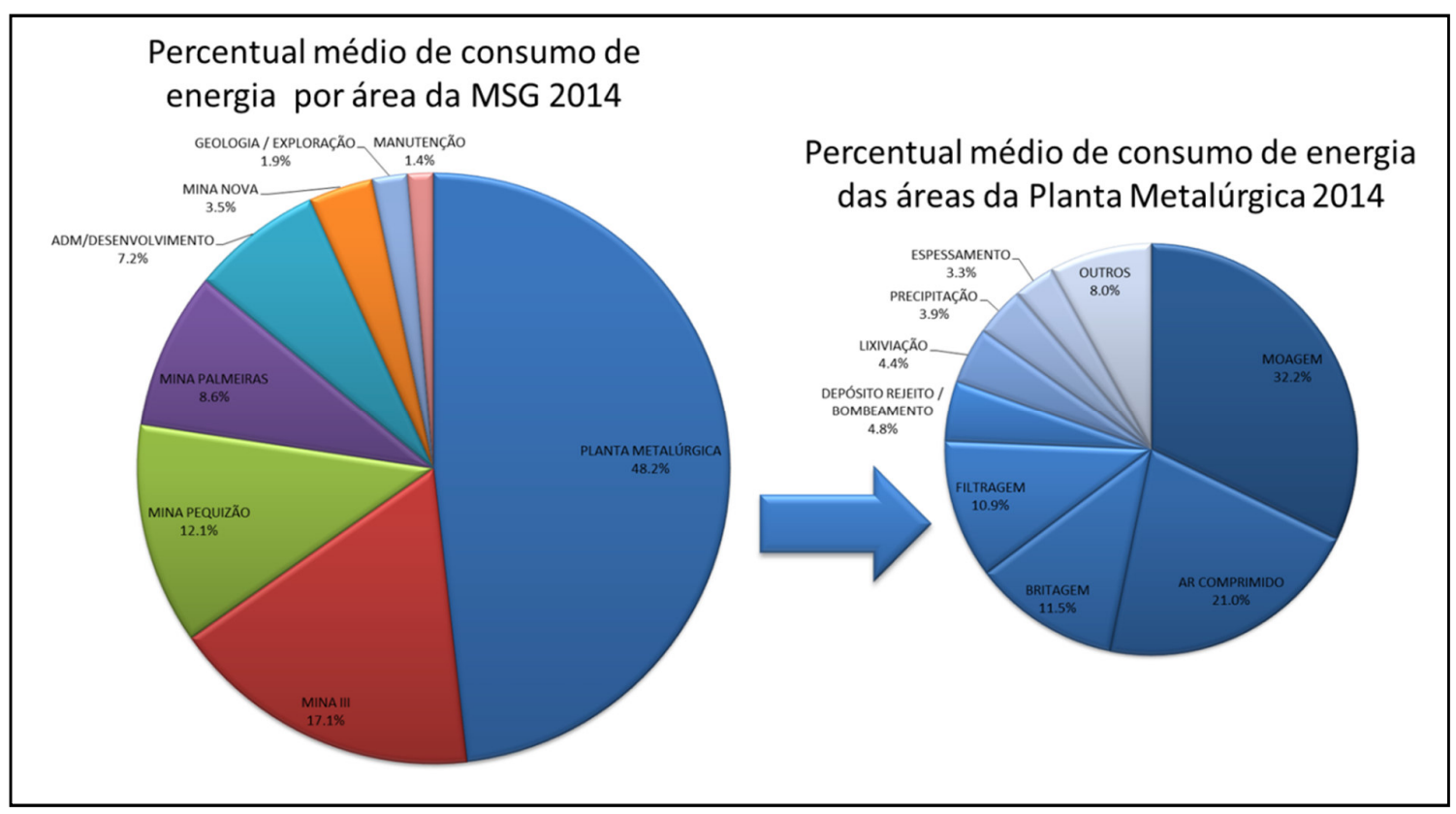

Fonte: Banco de dados da MSG

Apesar de o objetivo do trabalho não contemplar a otimização dos circuitos de moagem, julgou-se importante apresentar dados do consumo de energia do circuito atual, para efeito de comparação entre os cenários simulados. 


\subsection{PRINCIPAIS CARACTERÍSTICAS DO MINÉRIO}

A jazida da MSG está localizada no greenstone belt de Crixás, alvo de diversos estudos geológicos desde o final da década de 1970.

Greenstone belts são constituídos por sequências de rochas vulcânicas e sedimentares afetadas por metamorfismo de baixo grau e, em geral, com idade arqueana e paleoproterozoica, distribuídas nos escudos pré-cambrianos do globo. Grande parte do território brasileiro é formado por escudos pré-cambrianos que contêm sequências do tipo greenstone belt, com depósitos cujas reservas somam quase 1.000 toneladas de ouro. Na região de Crixás, o ouro é associado a formações ferríferas sulfetadas (pirrotita e arsenopirita) em veios de quartzo e disseminado em xistos carbonosos e máficos (JOST et al., 2001). Essa variabilidade de litotipos pode ser percebida visualmente, conforme mostra a Figura 32 que assim apresenta os principais minérios processados pela MSG, assim como rochas encaixantes.

Figura 32 - Principais minérios e rochas encaixantes presentes nas minas da MSG

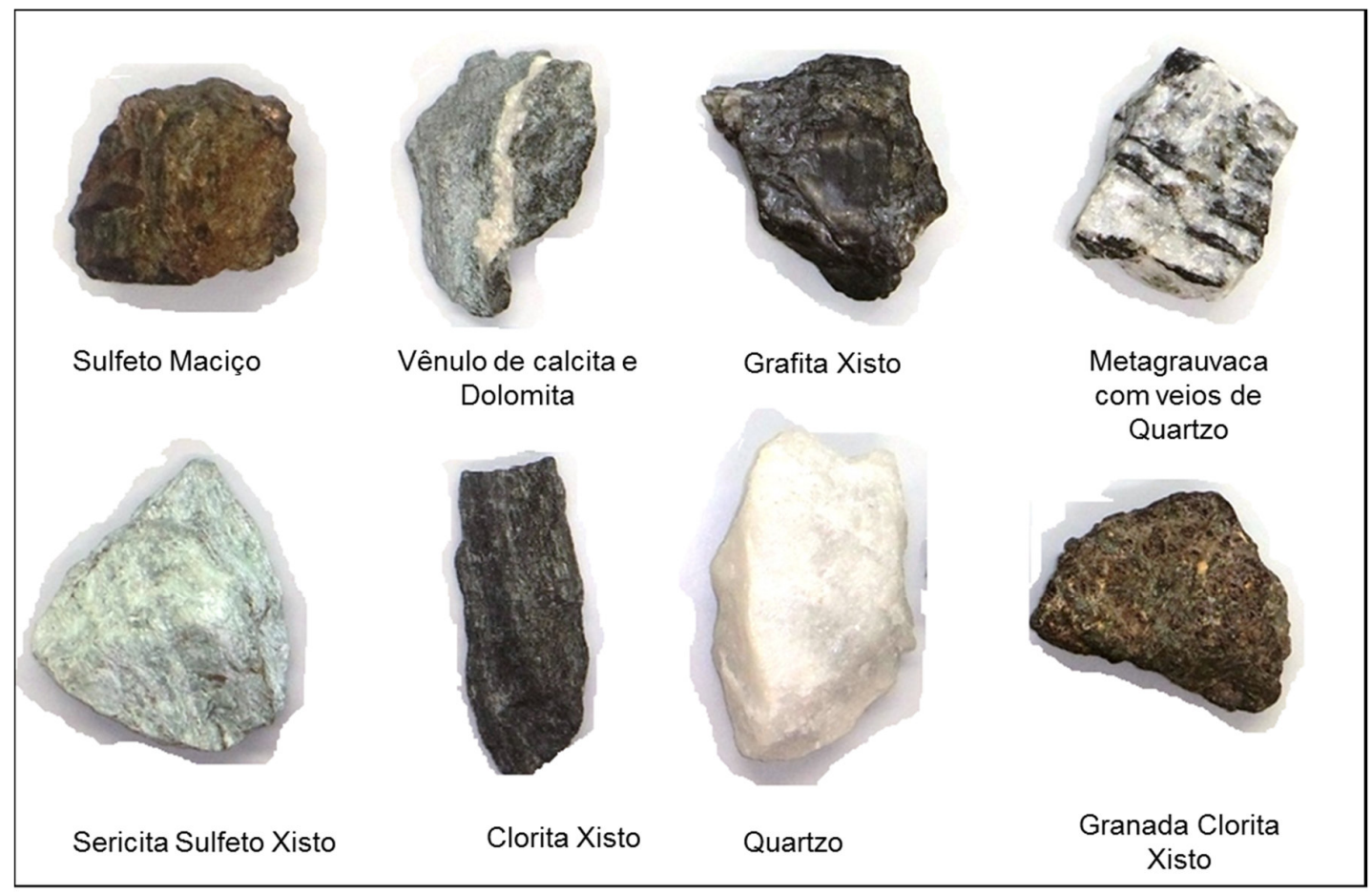

Fonte: Acervo de fotos do autor 
Apesar da grande diferença mineralógica entre os vários minérios da jazida da MSG, as pilhas que alimentam a usina são formadas em função apenas do teor de ouro, conforme a seguinte classificação:

- Pilha 1 - acima de $4,00 \mathrm{~g} / \mathrm{t}$

- Pilha 2 - entre 3,00 até $3,99 \mathrm{~g} / \mathrm{t}$

- Pilha 3 - entre 2,50 até $2,99 \mathrm{~g} / \mathrm{t}$

- Pilha 4 - entre 2,00 até $2,49 \mathrm{~g} / \mathrm{t}$

- Pilha 5 - entre 1,50 até $1,99 \mathrm{~g} / \mathrm{t}$

- Pilha 6 - abaixo de $1,49 \mathrm{~g} / \mathrm{t}$

Em trabalho realizado por Viana, (2013) oito diferentes amostras provenientes de quatro minas foram analisadas quimicamente e submetidas a ensaios de cominuição e lixiviação em escala de laboratório. Os resultados das análises químicas se encontram na Tabela 13. 
Tabela 13 - Resultados da concentração dos elementos químicos em cada uma das amostras

\begin{tabular}{|c|c|c|c|c|c|c|c|c|c|}
\hline Elemento & Unidade & $\begin{array}{l}\text { Amostra 1- } \\
\text { Palmeiras }\end{array}$ & $\begin{array}{l}\text { Amostra 2- } \\
\text { Palmeiras }\end{array}$ & $\begin{array}{c}\text { Amostra 3- } \\
\text { Pequizão }\end{array}$ & $\begin{array}{l}\text { Amostra 4- } \\
\text { Mina Nova }\end{array}$ & $\begin{array}{l}\text { Amostra 5- } \\
\text { Pequizão }\end{array}$ & $\begin{array}{c}\text { Amostra 6- } \\
\text { Mina III }\end{array}$ & \begin{tabular}{|l|} 
Amostra 7- \\
Mina Nova
\end{tabular} & $\begin{array}{l}\text { Amostra 8- } \\
\text { Mina Nova }\end{array}$ \\
\hline $\mathrm{Au}$ & $\mathrm{ppb}$ & 4.690 & 11.389 & 14.072 & 12.789 & 4.909 & 4.260 & 567 & 17.177 \\
\hline $\mathrm{S}$ & $\%$ & 3,67 & 3,39 & 1,76 & 4,45 & 1,6 & 1,44 & 1,52 & 0,04 \\
\hline $\mathrm{Ag}$ & $\mathrm{ppm}$ & 0,68 & 0,1 & $<0,02$ & $<0,02$ & $<0,02$ & $<0,02$ & $<0,02$ & $<0,02$ \\
\hline $\mathrm{Al}$ & $\%$ & 10,19 & $>15$ & 6,97 & 7,7 & 6,84 & 7,59 & 6,65 & 0,29 \\
\hline As & ppm & 3 & 6 & 767 & $>10.000$ & 983 & 348 & 721 & 326 \\
\hline $\mathrm{Ba}$ & ppm & 244 & 489 & 661 & 650 & 1.212 & 3.079 & 2.109 & 51 \\
\hline $\mathrm{Be}$ & $\mathrm{ppm}$ & 2,5 & 2,2 & 0,9 & 1,5 & 1 & 0,7 & 1,4 & $<0,1$ \\
\hline $\mathrm{Bi}$ & $\mathrm{ppm}$ & 0,34 & 0,13 & 0,08 & 1,26 & 0,17 & 0,07 & 0,29 & 0,08 \\
\hline $\mathrm{Ca}$ & $\%$ & 2,06 & 0,16 & 2,75 & 2,26 & 2,59 & 7,18 & 5,85 & 0,94 \\
\hline $\mathrm{Cd}$ & ppm & 0,36 & 0,03 & 0,52 & 0,56 & 1,52 & 0,71 & 1,39 & 0,14 \\
\hline $\mathrm{Ce}$ & ppm & 18,3 & 26,37 & 55,66 & 46,53 & 74,02 & 84,89 & 58,98 & 3,78 \\
\hline Co & ppm & 60,2 & 38,7 & 8,8 & 69,5 & 10,3 & 8,6 & 23,5 & 0,7 \\
\hline $\mathrm{Cr}$ & $\mathrm{ppm}$ & 660 & 893 & 30 & 168 & 30 & 22 & 103 & $<1$ \\
\hline Cs & ppm & $<5$ & $<5$ & $<5$ & $<5$ & $<5$ & $<5$ & $<5$ & $<5$ \\
\hline $\mathrm{Cu}$ & ppm & 340,2 & 188 & 39,8 & 28 & 32,3 & 32,9 & 111,5 & 3,7 \\
\hline $\mathrm{Fe}$ & $\%$ & $>15$ & 9,63 & 4,6 & 14,14 & 3,88 & 5,33 & 6,34 & 1,07 \\
\hline $\mathrm{Ga}$ & ppm & 17,3 & 27,6 & 11,4 & 15,7 & 11,7 & 12,3 & 13,3 & 0,6 \\
\hline $\mathrm{Ge}$ & ppm & $<0,01$ & $<0,01$ & $<0,01$ & $<0,01$ & $<0,01$ & $<0,01$ & $<0,01$ & $<0,01$ \\
\hline $\mathrm{Hf}$ & ppm & $<0,02$ & $<0,02$ & $<0,02$ & 0,88 & 1,1 & 1,11 & 0,44 & $<0,02$ \\
\hline $\ln$ & ppm & 0,17 & 0,14 & 0,04 & 0,48 & 0,06 & 0,07 & 0,09 & $<0,02$ \\
\hline $\mathrm{K}$ & $\%$ & 1,06 & 4,3 & 1,11 & 3,2 & 1,61 & 1,13 & 3,28 & 0,07 \\
\hline $\mathrm{La}$ & ppm & 7,4 & 8,6 & 29,2 & 22,7 & 38,4 & 43,1 & 33,7 & 2 \\
\hline $\mathrm{Li}$ & $\mathrm{ppm}$ & 32 & 93 & 24 & 45 & 22 & 20 & 41 & $<1$ \\
\hline $\mathrm{Lu}$ & ppm & 0,12 & 0,13 & 0,14 & 0,3 & 0,28 & 0,34 & 0,25 & 0,02 \\
\hline $\mathrm{Mg}$ & $\%$ & 1,23 & 0,18 & 1,25 & 1,57 & 1,29 & 2,59 & 2,26 & 0,36 \\
\hline $\mathrm{Mn}$ & $\%$ & 0,09 & 0,05 & 0,08 & 0,12 & 0,07 & 0,1 & 0,18 & 0,06 \\
\hline Mo & ppm & 0,36 & 0,58 & 0,99 & 1,02 & 1,77 & 0,44 & 1,62 & 0,46 \\
\hline $\mathrm{Na}$ & $\%$ & 3,67 & 3,78 & 4,11 & 0,74 & 3,41 & 4,53 & 0,46 & 0,03 \\
\hline $\mathrm{Nb}$ & $\mathrm{ppm}$ & 61,7 & 50,4 & 7,6 & 13,6 & 10,8 & 12,9 & 9,7 & 0,5 \\
\hline $\mathrm{Ni}$ & ppm & 197,1 & 212,7 & 20,9 & 117,1 & 27,3 & 32,7 & 78 & 3,3 \\
\hline $\mathrm{P}$ & ppm & 156 & 77 & 302 & 427 & 366 & 3503 & 622 & 67 \\
\hline $\mathrm{Pb}$ & ppm & 8,1 & 5,3 & 6,5 & 8,4 & 5,2 & 4,1 & 11,5 & 1,8 \\
\hline $\mathrm{Rb}$ & ppm & 10,4 & 57,6 & 27,4 & 91,5 & 38,8 & 23,6 & 75,6 & 2,4 \\
\hline $\mathrm{S}$ & $\%$ & 2,67 & 2,37 & 0,92 & 3,74 & 0,71 & 0,65 & 0,74 & 0,04 \\
\hline $\mathrm{Sb}$ & ppm & 0,71 & 0,98 & 0,75 & 28,72 & 0,86 & 0,58 & 0,76 & 0,44 \\
\hline Sc & $\mathrm{ppm}$ & 79,4 & 105,8 & 14,6 & 40,4 & 14,5 & 22,7 & 22,3 & 0,9 \\
\hline $\mathrm{Se}$ & ppm & 2 & 2 & $<2$ & 6 & 3 & $<2$ & 3 & $<2$ \\
\hline $\mathrm{Sn}$ & ppm & 2,9 & 2,9 & 2,1 & 3,2 & 2,3 & 2,2 & 3 & 0,9 \\
\hline $\mathrm{Sr}$ & ppm & 151,5 & 209,6 & 194,4 & 129,4 & 119,3 & 167,8 & 154,6 & 15,6 \\
\hline $\mathrm{Ta}$ & ppm & 0,49 & 16,3 & 2,23 & 4,12 & 2,41 & 3 & 2,1 & 0,19 \\
\hline $\mathrm{Tb}$ & ppm & 0,54 & 0,54 & 0,42 & 0,75 & 0,63 & 0,79 & 0,58 & 0,07 \\
\hline $\mathrm{Te}$ & $\mathrm{ppm}$ & 0,56 & 0,78 & 0,26 & 3,41 & 0,38 & 0,56 & 1,72 & 0,15 \\
\hline Th & ppm & 0,7 & 0,4 & 3,5 & 3,7 & 4,9 & 5,2 & 4,1 & $<0,2$ \\
\hline $\mathrm{Ti}$ & $\%$ & 0,65 & 1,05 & 0,16 & 0,6 & 0,13 & 0,22 & 0,37 & $<0,01$ \\
\hline $\mathrm{TI}$ & ppm & 0,04 & 0,15 & 0,13 & 0,45 & 0,2 & 0,12 & 0,43 & $<0,02$ \\
\hline $\mathrm{U}$ & ppm & 0,3 & 0,2 & 1 & 1,2 & 1,9 & 1,2 & 1,9 & 0,1 \\
\hline $\mathrm{V}$ & ppm & 329 & 549 & 67 & 218 & 60 & 67 & 133 & 6 \\
\hline W & $\mathrm{ppm}$ & 6 & 36,4 & 5,4 & 9,6 & 3,9 & 8,9 & 8 & 0,5 \\
\hline $\mathrm{Y}$ & ppm & 8,2 & 6,8 & 9,9 & 17,2 & 16,5 & 21,8 & 16,6 & 1,5 \\
\hline $\mathrm{Yb}$ & ppm & 1,1 & 1,3 & 1 & 2,2 & 1,7 & 2,2 & 1,6 & 0,01 \\
\hline$Z n$ & ppm & 90 & 26 & 27 & 70 & 57 & 27 & 46 & 4 \\
\hline $\mathrm{Zr}$ & ppm & 18,9 & 16,6 & 64 & 77,4 & 130,2 & 165,3 & 95,5 & 1,9 \\
\hline
\end{tabular}

Fonte: Viana (2013) 
Além das características químicas, que influenciam fortemente 0 processamento hidrometalúrgico, há grandes variações nos aspectos físicos das amostras, como densidade, Wi e abrasividade, conforme apresentadas na Tabela 14, em estudo realizado para seis minérios em 2012 e relatado por Viana (2013).

Tabela 14 - Variações das características físicas dos minérios das diferentes minas da MSG

\begin{tabular}{|c|c|c|c|c|}
\hline Amostra & $\begin{array}{c}\text { Densidade } \\
\text { aparente }\left(\mathrm{g} / \mathrm{cm}^{3}\right)\end{array}$ & $\begin{array}{c}\text { Peso específico } \\
\left(\mathrm{g} / \mathrm{cm}^{3}\right)\end{array}$ & Wi (kWh/st) & $\mathrm{Ai}$ \\
\hline $1001-\mathrm{MN}$ & 1,66 & 2,75 & 13,6 & 0,307 \\
\hline $1002-\mathrm{CPO} 4$ & 1,68 & 2,61 & 13,7 & 0,383 \\
\hline $1003-\mathrm{MIII}$ & 1,65 & 2,68 & 8,5 & 0,311 \\
\hline $1004-\mathrm{PZ}$ & 1,70 & 2,57 & 13,4 & 0,225 \\
\hline $1005-\mathrm{OP}$ & 1,66 & 2,53 & 13,2 & 0,181 \\
\hline $1006-\mathrm{MP}$ & 1,75 & 3,04 & 11,4 & 0,148 \\
\hline
\end{tabular}

Fonte: Banco de dados da MSG 


\section{MÉTODO}

\subsection{AMOSTRAGEM}

\subsubsection{Planejamento de amostragem}

A campanha de amostragem conduzida pelo autor deste estudo no circuito de moagem da MSG foi fundamentada na teoria da amostragem, para que as tomadas de amostra fossem representativas dos fluxos do circuito selecionado. A partir das análises das amostras foram gerados os dados e as informações necessárias para a realização do balanço de massas e das calibrações dos modelos

A campanha de amostragem foi planejada em decorrência dos pontos que deveriam ser amostrados, conforme apresentados na Tabela15, assim como dos parâmetros que deveriam ser monitorados no período da amostragem.

Tabela15 - Local onde foram coletadas as amostras e tipo de procedimento

\begin{tabular}{|l|l|}
\hline Procedimento & Ponto de amostragem \\
\hline Manual & Produto do britador primário \\
\hline Automático & Alimentação nova do moinho de bolas \\
\hline Manual & Descarga dos moinhos \\
\hline Automático & Alimentação da bateria de ciclones \\
\hline Automático & Overflow da bateria de ciclones \\
\hline Manual & Underflow da bateria de ciclones \\
\hline
\end{tabular}

A amostragem foi executada com participação ativa do autor em 30 de janeiro de 2015, durante o período compreendido entre 17 h e 19 h.

Algumas amostras foram tomadas manualmente e outras com auxílio de amostradores automáticos instalados na planta. Os fluxos da alimentação nova dos dois moinhos foram coletados, em intervalos regulares a cada $6 \mathrm{~min}$, por amostradores corta fluxo de trajetória retilínea, apresentados na Figura 33, que cortam o fluxo do minério em queda livre após a correia transportadora. Os cortadores contam 
com aberturas das facas maiores do que três vezes o tamanho da maior partícula, coerentes, portanto, com a teoria da amostragem. As amostras coletadas por esse equipamento são normalmente utilizadas para análise do teor de ouro da alimentação do circuito. Como a reconciliação raramente diverge de mais ou menos $5 \%$, tais amostras são consideradas representativas para o teor e, consequentemente, para a granulometria.

Figura 33 - Fotografias dos amostradores da alimentação nova dos Moinhos MO-01 e MO-02

\begin{tabular}{|c|c|c|}
\hline Amostrador - Alimentação do MO-01 & Amostrador - Alimentação do MO-02 \\
\hline & & \\
\hline & & \\
\hline & & \\
\hline & & \\
\hline & & \\
\hline
\end{tabular}




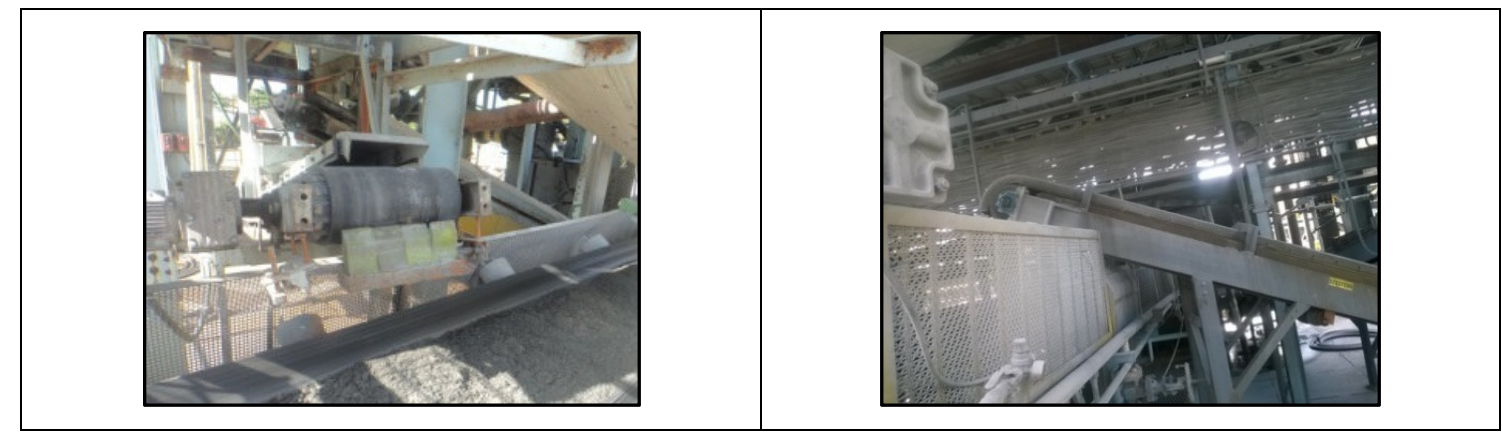

Fonte: Acervo de fotos do autor

Os fluxos de alimentação e do overflow da bateria de ciclones foram coletados pelo Opt Density apresentado na Figura 34, equipamento este que efetua medida das densidades de polpa e permite obter amostras de polpa durante a operação da moagem mediante um sistema automático que alimenta o equipamento. Como opção pode-se também alimentar baldes compondo uma amostra incremental com ciclos estipulados pelo operador.

No caso específico da amostragem conduzida pelo autor, os intervalos de amostragem foram também regulares a cada 6 min. O equipamento inclui também uma tomada de fluxo para medida automática da densidade do underflow. Entretanto, esse fluxo entope com facilidade, pois a polpa é muito grossa e espessa, enquanto o ponto de alimentação dos mangotes acumula partículas que impedem que o fluxo possa ser amostrado automaticamente. Em razão desses impedimentos, a amostragem do underflow dos ciclones foi efetuada de forma manual. 
Figura 34 - OptDensity- Medidor automático das densidades de alimentação e overflow da bateria de ciclones

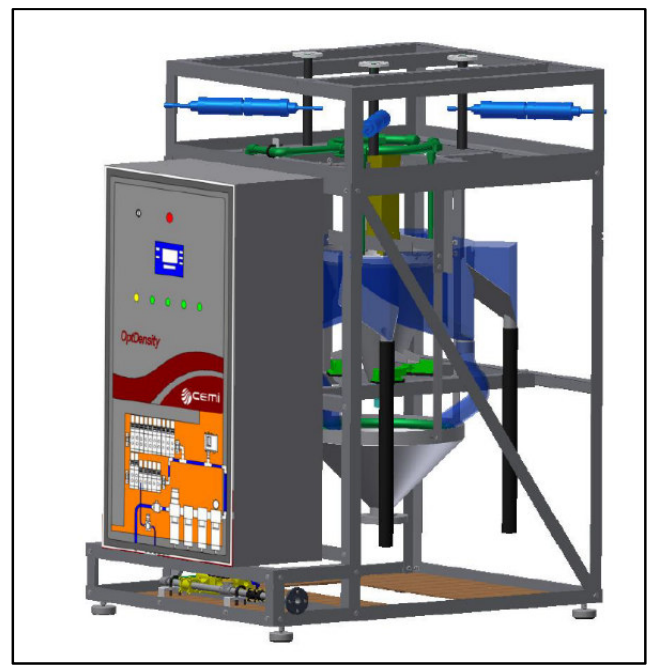

Fonte: Cemi (2015)

Os fluxos de underflow dos ciclones e descarga dos moinhos foram amostrados manualmente em intervalos regulares de $20 \mathrm{~min}$ cada. Os incrementos eram compostos por aproximadamente três litros de polpa, sendo que cada litro foi coletado individualmente. Primeiro se coletava a amostra da descarga do moinho e, na sequência, a amostra do underflow.

Os amostradores estão ilustrados na Figura 35, assim como dois pontos onde os mesmos foram utilizados.

Embora os amostradores utilizados não fossem exatamente iguais aos apresentados no desenho da Figura 35, procurou-se aproximá-los ao máximo do desenho proposto. Ambos os amostradores foram considerados adequados para realizar uma amostragem representativa. 
Figura 35 - Amostradores utilizados para fazer amostragem no circuito da MSG

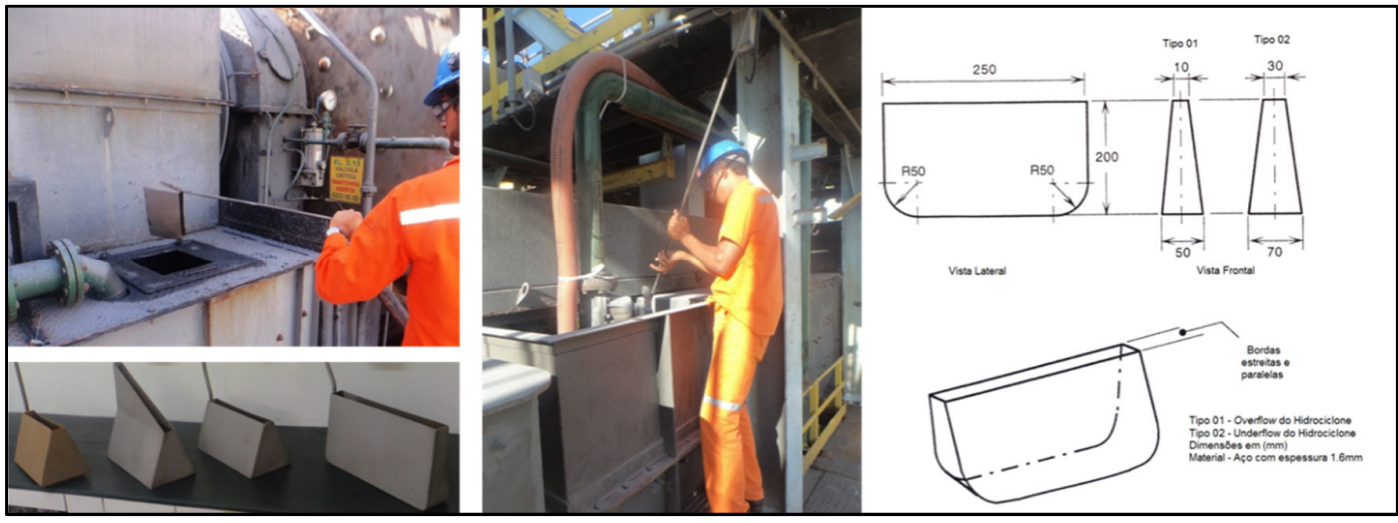

Fontes: Acervo de fotos do autor e Napier-Munn et al. (1996). Adaptado pelo autor

Após a tomada das amostras, o material foi enviado ao laboratório de processos da MSG, onde as amostras foram preparadas para a realização dos peneiramentos e ensaios para determinação de densidade do minério e de umidade da alimentação nova do moinho. No Apêndice 1 são apresentadas fotos adicionais do circuito e dos respectivos pontos de amostragem.

Além dos pontos já citados foi amostrado parte do produto do britador primário. Para tanto foi necessária a parada do transportador de correia, de forma que se fizesse um corte do material e coleta de aproximadamente $150 \mathrm{~kg}$ dessa amostra. Tal amostra foi acondicionada em tambores e posteriormente remetida ao Laboratório de Simulação e Controle LSC da Escola Politécnica da USP (EPUSP), para a realização dos ensaios DWT.

Amostras com aproximadamente $50 \mathrm{~kg}$ das alimentações novas dos dois moinhos foram enviadas em tambores para a realização dos ensaios Wi no mesmo LSC. 


\subsubsection{Banco de dados gerado durante a amostragem}

Ao longo da amostragem, além da tomada de amostras, foram obtidos dados do processo, oriundos de instrumentos para o sistema supervisório. Os parâmetros selecionados são apresentados na Tabela 16, enquanto o Apêndice 3 apresenta os gráficos gerados pelas informações coletadas.

Tabela 16 - Parâmetros monitorados e gravados durante amostragem dos dois moinhos

\begin{tabular}{|l|}
\hline Principais parâmetros das Moagens 01 e 02 \\
\hline Alimentação nova \\
\hline Vazão de água na caixa de bomba de descarga dos moinhos de bolas \\
\hline Densidade da polpa na alimentação dos ciclones \\
\hline Densidade da polpa do overflow dos ciclones \\
\hline Pressão de operação dos ciclones \\
\hline Potência registrada nos motores dos moinhos de bolas \\
\hline Nível dos silos \\
\hline
\end{tabular}

Atualmente os dois circuitos de moagem da MSG são equipados com sistema de automação e controle da operação. Esse sistema consiste em supervisionar as variáveis do processo medidas por instrumentos e, na sequência, tomar decisões com base em lógica fuzzy.

Durante a amostragem, as vazões de alimentação e velocidade de rotação das bombas de alimentação dos ciclones foram monitoradas, assim como a pressão de operação dos ciclones, a potência consumida pelos moinhos, a velocidade de rotação dos moinhos, o nível das caixas de bomba de descarga dos moinhos, as vazões de água para caixa de alimentação da moagem, além de outras informações menos relevantes. 


\subsection{ANÁLISES E ENSAIOS}

\subsubsection{Determinação da Granulometria}

Para determinar a granulometria foi utilizada a combinação de peneiramento a seco e a úmido. Cada amostra foi inicialmente quarteada a seco por amostrador rotativo automático, do qual foi obtida uma alíquota para peneiramento a úmido na malha de 400 Tyler $(0,038 \mathrm{~mm})$. Seguiu-se a secagem da fração retida em $400 \# \mathrm{e}$ peneiramento nas peneiras 6,$35 ; 4,75 ; 3,36 ; 2,36 ; 1,70 ; 1,18 ; 0,850 ; 0600 ; 0,425$; 0,$300 ; 0,212 ; 0,150 ; 0,106 ; 0,075 ; 0,053 \mathrm{~mm}$.

\subsubsection{Determinação da Umidade}

Análise de umidade das amostras de alimentação nova dos moinhos incluiu inicialmente o quarteamento em amostrador rotativo automático, seguida da pesagem da alíquota quarteada e secagem em estufa a $200^{\circ} \mathrm{C}$. Após a secagem, a amostra foi novamente pesada para calcular a porcentagem de água contida nela. O procedimento foi realizado em triplicata.

\subsubsection{Determinação do Peso Específico do Minério}

Os procedimentos foram executados também em triplicata, conforme descrito na Seção 3.4.1.

\subsubsection{Determinação do Wi de Bond}

As amostras chegaram ao LSC-EPUSP em 19 de fevereiro de 2015, e parte dos ensaios foram realizados na primeira semana de março. 
O ensaio de Wi foi executado no LSC-EPUSP, conforme procedimento descrito na seção 3.4.3.1, empregando a malha de fechamento de 100\# Tyler. Fotografias obtidas durante a execução do ensaio são apresentadas na Figura 36.

Figura 36 - Fotografias da realização do ensaio de Wi

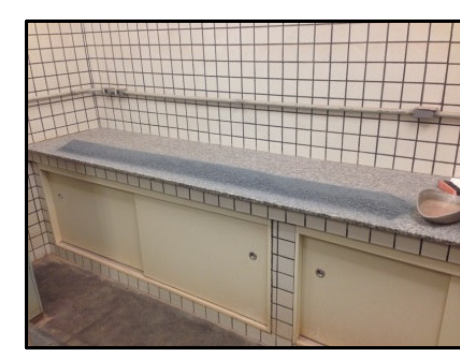

Pilha alongada da amostra

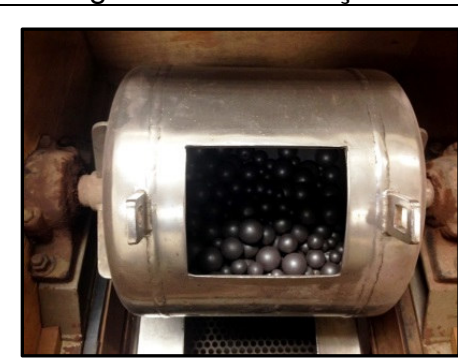

Moinho de Bond LSC/USP

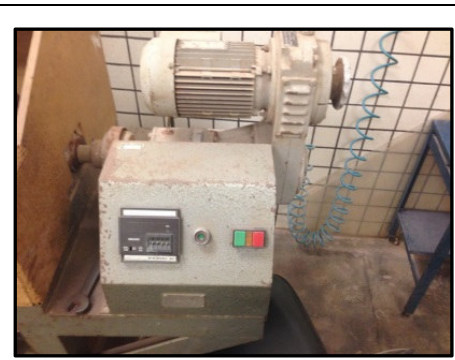

Sistema de acionamento de contador de revoluções

Fonte: Acervo de fotos do autor

\subsubsection{Execução do Drop Weight Test}

O ensaio DW foi realizado nos laboratórios do LSC-EPUSP, segundo os procedimentos descritos na seção 3.4.4.1 desta dissertação. A Tabela 17 apresenta as faixas de granulometria das partículas empregadas na formação de cada lote, bem como a energia estipulada para fragmentação de cada lote. Após a pesagem, de cada lote, foram calculadas a massa de queda e as respectivas alturas de queda para gerar as energias especificadas. As fotografias da Figura 37 foram tiradas durante os procedimentos. 
Tabela 17 - Tamanho de partículas e energias estipuladas para os lotes de amostra na realização do DWT

\begin{tabular}{|c|c|c|}
\hline Lote & Tamanho $(\mathrm{mm})$ & Ecs $(\mathrm{kWh} / \mathrm{t})$ \\
\hline 1 & $63,0 \times 53,0$ & 0,40 \\
\hline 2 & $63,0 \times 53,0$ & 0,25 \\
\hline 3 & $63,0 \times 53,0$ & 0,10 \\
\hline 4 & $45,0 \times 37,5$ & 1,00 \\
\hline 5 & $45,0 \times 37,5$ & 0,25 \\
\hline 6 & $45,0 \times 37,5$ & 0,10 \\
\hline 7 & $31,5 \times 26,5$ & 2,50 \\
\hline 8 & $31,5 \times 26,5$ & 1,00 \\
\hline 9 & $31,5 \times 26,5$ & 0,25 \\
\hline 10 & $22,4 \times 19,0$ & 2,50 \\
\hline 11 & $22,4 \times 19,0$ & 1,00 \\
\hline 12 & $22,4 \times 19,0$ & 0,25 \\
\hline 13 & $16,0 \times 13,2$ & 2,50 \\
\hline 14 & $16,0 \times 13,2$ & 1,00 \\
\hline 15 & $16,0 \times 13,2$ & 0,25 \\
\hline
\end{tabular}


Figura 37 - Fotografias obtidas durante a realização do ensaio DWT

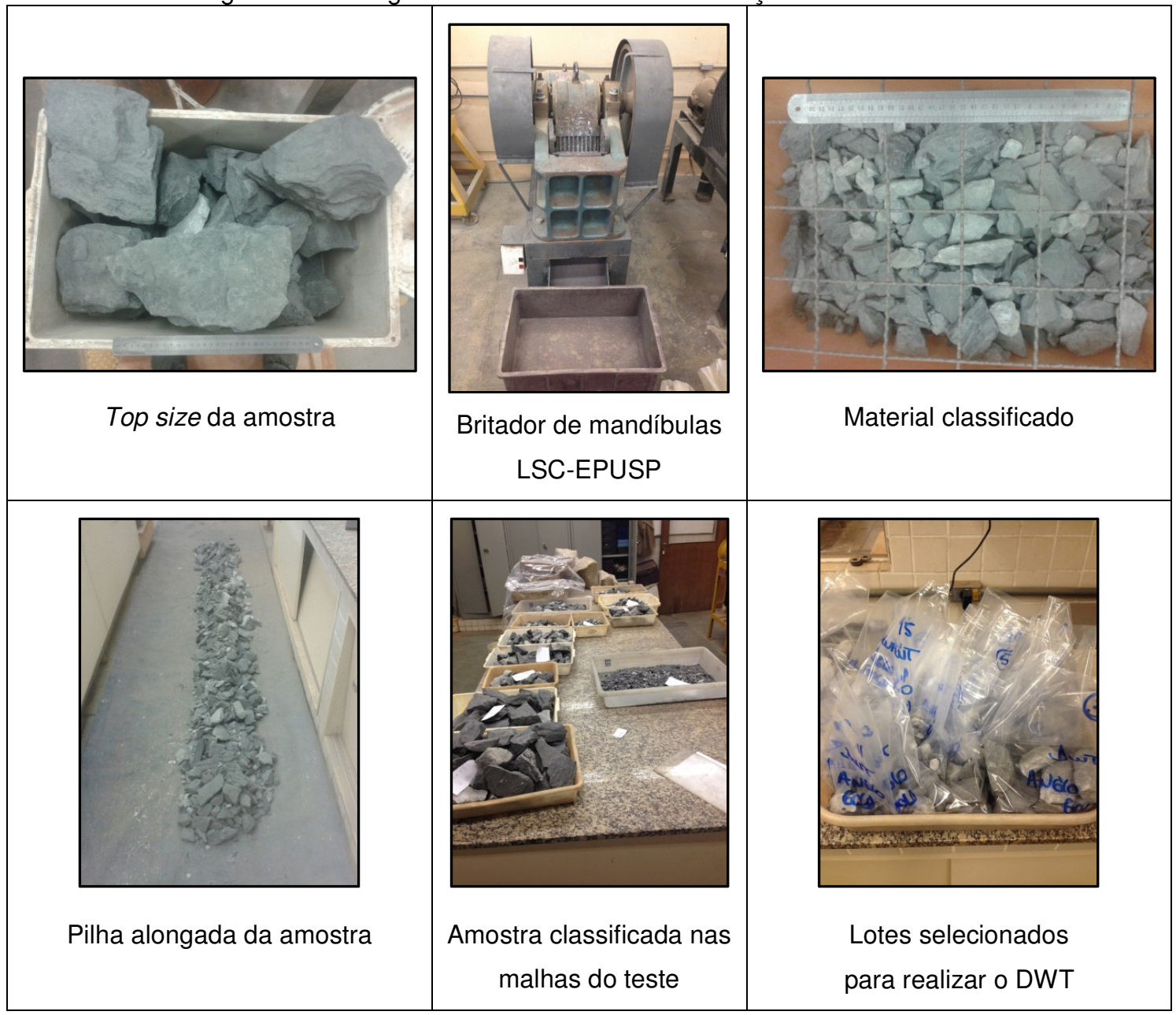

Fonte: Acervo de fotos do autor

\subsubsection{Execução do ensaio de Leito Comprimido de Partícula}

O ensaio de leito comprimido foi realizado conforme procedimento descrito na seção 3.4.5, e o preparo da amostra consistiu em tomar $15 \mathrm{~kg}$ do produto previamente tomado da britagem primária de MSG e britar o material em laboratório para abertura de $12,7 \mathrm{~mm}$.

O produto da britagem de laboratório foi peneirado em três diferentes frações: (a): $-12,7 \mathrm{~mm}+9,5 \mathrm{~mm}$; (b) -9,5 mm +6,35 mm; (c) -6,35 mm +4,75 mm. Essas faixas representam as alternativas de alimentação de uma HPGR antes da moagem de 
MSG. Foi, portanto, medida a densidade aparente e, depois, tomadas três alíquotas representativas de cada fração.

Para determinar a massa de cada alíquota, foi necessário calcular o diâmetro médio das partículas e, então, estimar o volume ocupado pelo material para formar uma monocamada de fragmentos.

O material devidamente amostrado foi espalhado no pistão de teste de forma a uniformizar a ocupação das partículas.

Após o preenchimento, posicionou-se o pistão e tomou-se o respectivo valor da altura inicial. Aplicou-se então força sobre o pistão e mediu-se novamente o deslocamento quando aplicada força de $10 \mathrm{kN}$ assim como deslocamento ao final dos testes quando aplicada a força máxima de cada ciclo.

Cada fração granulométrica foi submetida a três diferentes níveis de força: 250, 500 e $1000 \mathrm{kN}$.

A Figura 38 apresenta fotografias do cilindro utilizado para o teste, amostras separadas, medição com paquímetro da distância entre a tampa e a borda do pistão e a prensa para realizar o ensaio de CLP. 
Figura 38 - Fotografias obtidas durante o ensaio de CLP

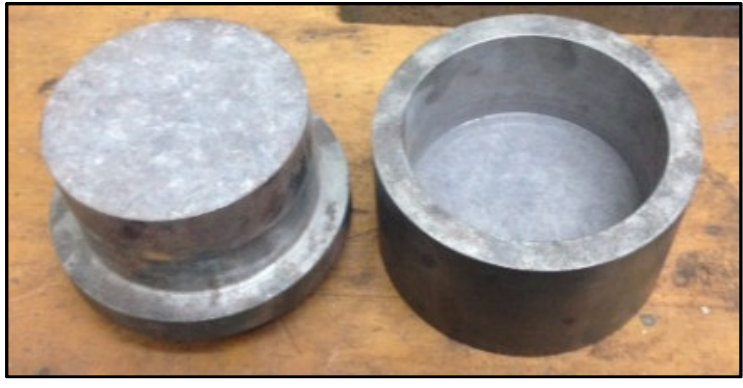

Pistão para ensaio CLP

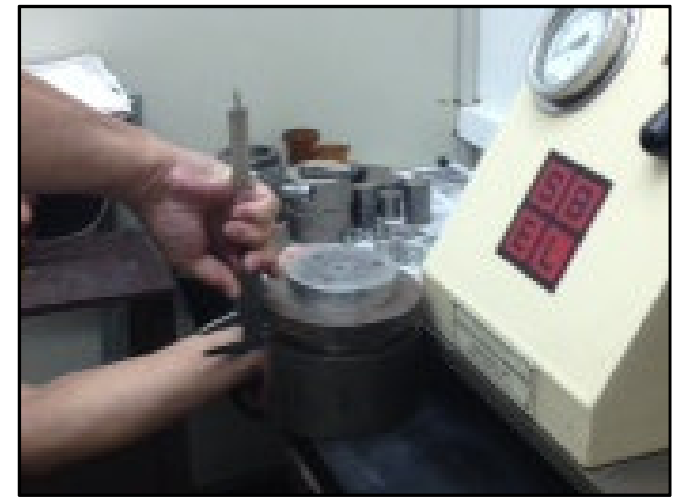

Medição do deslocamento do êmbolo

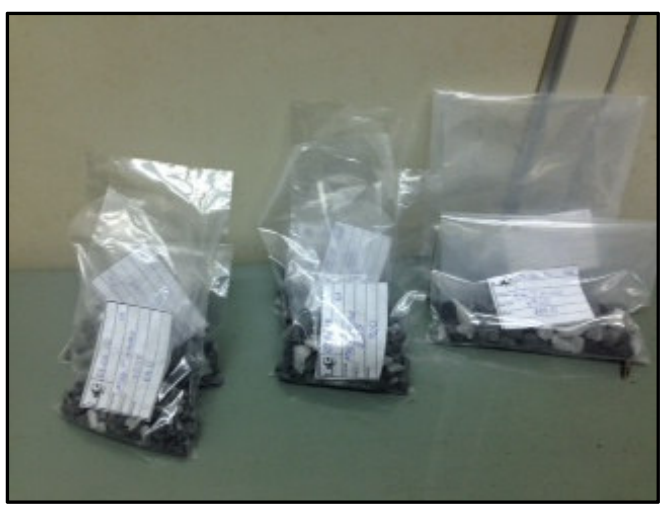

Frações de minério separadas para ensaio

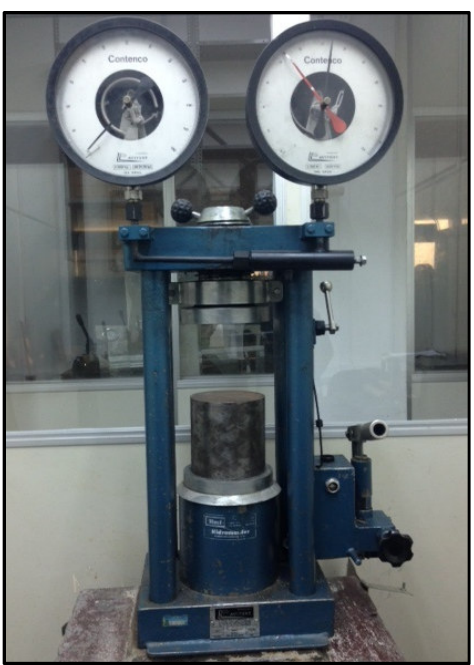

Prensa para ensaio CLP

Fonte: Acervo de fotos do autor

\subsubsection{Execução do ensaio de Jarro Laboratorial}

O ensaio de jarro foi realizado com o objetivo de estimar a potência requerida por moinho vertical para realizar cominuição conforme cenário selecionado para as simulações. Essa perspectiva é apresentada de forma detalhada na seção 6.5.3.

O procedimento foi realizado conforme descrito pela seção 3.4.6, porém a preparação da amostra apresentou algumas particularidades. Foi necessário construir 
a curva de moagem dos minérios para adequar a granulometria da amostra à alimentação do jarro.

Utilizando parte da amostra tomada no produto do britador primário de MSG iniciaram-se os procedimentos de cominuição do minério para gerar a curva de moagem.

O ensaio de jarro foi realizado em jarro de ferro fundido, com revestimento liso, diâmetro interno de 8" e altura interna de 10". Foram utilizados 15,87 $\mathrm{kg}$ de corpos moedores de 12,7 mm. Os materiais são apresentados na Erro! Fonte de referência não encontrada. e os resultados do ensaio de testes na seção 6.1.5.

Figura 39 - Corpos moedores de 12,7 mm e moinho 8" x 10"
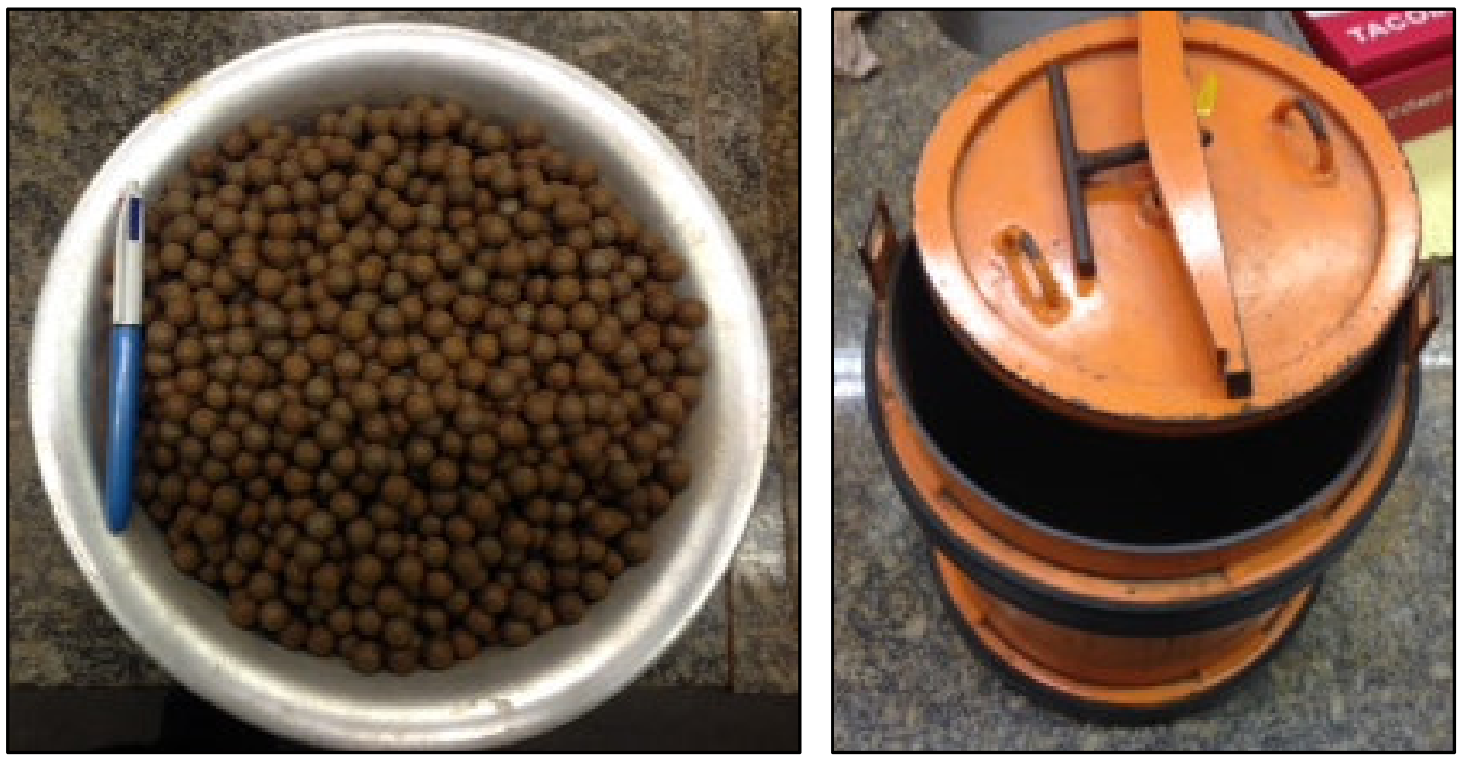

Fonte: Acervo de fotos do autor

Foram realizadas moagens individuais para 15, 30, 45 e 60 minutos. Após o fim de cada moagem, o material foi peneirado a úmido, formando a família de curvas apresentada na Figura 40.

A curva denominada Objetivo foi obtida por simulações e representa a granulometria estimada, que alimenta o circuito em série. 
Não foi possível, em laboratório, gerar material com a mesma característica granulométrica à simulada, porém a parte mais grosseira da curva mostrou-se razoavelmente semelhante, com valor de $\mathrm{P}_{80}=165 \mu \mathrm{m}$, conforme mostra a Figura 41 . Por esse motivo, o tempo de 60 min de moagem foi considerado ótimo para gerar a amostra do ensaio de jarro.

Figura 40 - Curvas granulométricas dos produtos das moagens

para adequação do $\mathrm{P}_{80}$ da alimentação do ensaio de jarro

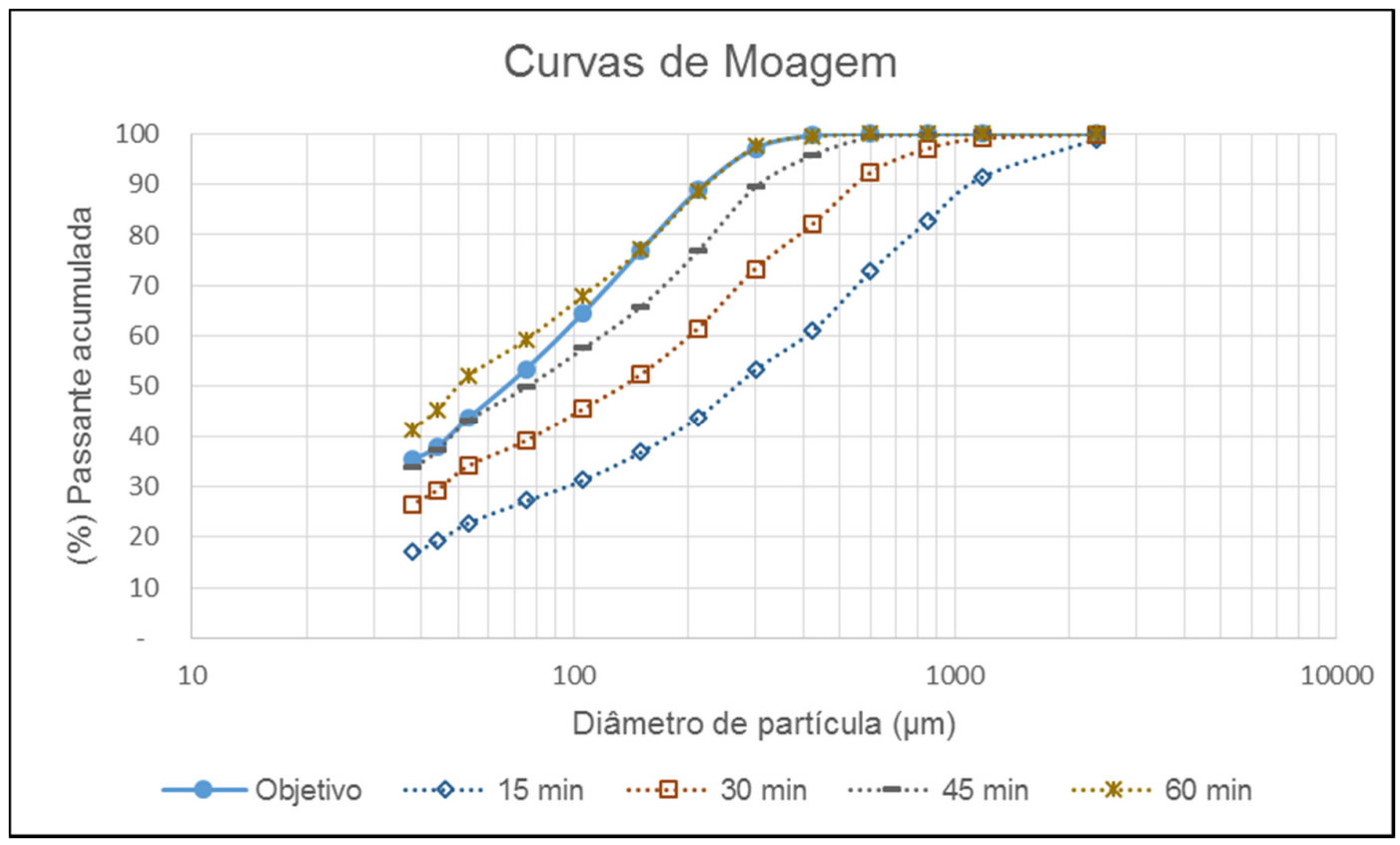

Fonte: Elaborado pelo autor 
Figura 41 - Curva de moagem correlacionando o $\mathrm{P}_{80}$ com o tempo de moagem

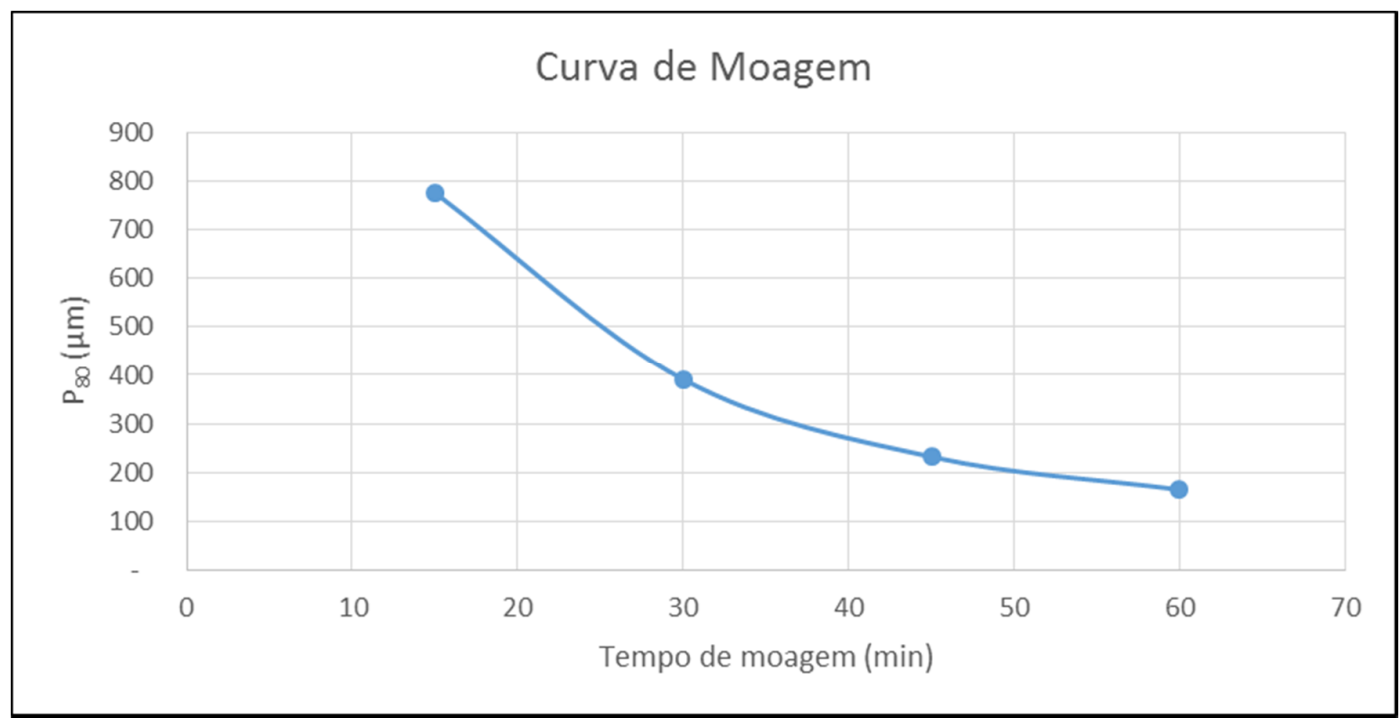

Fonte: Elaborado pelo autor 


\section{RESULTADOS E DISCUSSÕES}

\subsection{RESULTADOS DAS ANÁLISES E TESTES LABORATORIAIS}

A amostragem planejada ocorreu no prazo previsto, segundo os procedimentos previamente estabelecidos. Os principais parâmetros de geometria dos equipamentos e respectivas condições de operação do circuito de moagem estão listados nas Tabela 18 e 19.

Tabela 18 - Dados obtidos durante a amostragem

\begin{tabular}{|l|c|c|c|}
\hline \multicolumn{1}{|c|}{ Parâmetros } & Unidade & MO_01 & MO_02 \\
\hline Vazão de alimentação nova & $\mathrm{t} / \mathrm{h}$ & 114,9 & 42,0 \\
\hline $\begin{array}{l}\text { Vazão de água na caixa da bomba de } \\
\text { polpa }\end{array}$ & $\mathrm{m}^{3}$ & 110 & 50 \\
\hline $\begin{array}{l}\text { Densidade da polpa da alimentação dos } \\
\text { ciclones }\end{array}$ & $\mathrm{t} / \mathrm{m}^{3}$ & 1,54 & 1,47 \\
\hline $\begin{array}{l}\text { Densidade da polpa do overflow dos } \\
\text { ciclones }\end{array}$ & $\mathrm{t} / \mathrm{m}^{3}$ & 1,25 & 1,18 \\
\hline Pressão de operação dos ciclones & $\mathrm{Bar}$ & 0,71 & 0,58 \\
\hline $\begin{array}{l}\text { Potência consumida nos motores dos } \\
\text { moinhos de bolas }\end{array}$ & $\mathrm{kW}$ & 1.061 & 406 \\
\hline Diâmetro nominal interno & $\mathrm{m}$ & 3,48 & 2,57 \\
\hline Comprimento nominal interno & $\mathrm{m}$ & 5,34 & 3,74 \\
\hline $\begin{array}{l}\text { Nível dos silos de alimentação da } \\
\text { moagem }\end{array}$ & $\%$ & 72,2 & 39,5 \\
\hline
\end{tabular}

Tabela 19 - Dados dimensionais dos ciclones

\begin{tabular}{|l|c|c|c|}
\hline \multicolumn{1}{|c|}{ Parâmetro } & Unidade & HC_01 & HC_02 \\
\hline Diâmetro do ciclone - Dc & $\mathrm{m}$ & 0,508 & 0,508 \\
\hline Diâmetro do inlet - Di & $\mathrm{m}$ & 0,152 & 0,152 \\
\hline Diâmetro do vortex - Do & $\mathrm{m}$ & 0,173 & 0,188 \\
\hline Diâmetro do apex $-\mathrm{Du}$ & $\mathrm{m}$ & 0,112 & 0,102 \\
\hline Comprimento livre da seção cilíndrica - Lc & $\mathrm{m}$ & 0,381 & 0,381 \\
\hline Ângulo do cone $-\theta$ & $\underline{0}$ & 10 & 10 \\
\hline
\end{tabular}


Os parâmetros informados nas Tabela 18 e 19 são em parte as médias dos valores medidos durante as duas horas de amostragem. As dimensões do ciclone e moinho foram obtidas nos manuais dos respectivos equipamentos.

A umidade do minério alimentado no Moinho 01 foi 2,1\% e, no Moinho 02, 3,2\%. O valor do peso específico do minério foi medido em 2,73.

\subsubsection{Granulometria}

Os resultados das análises de granulometria obtidos para os fluxos de ambas as linhas de moagem estão listados na Tabela 20 e Tabela 21, assim como na Figura 42 e Figura 44.

Figura 42 - Gráfico da granulometria dos fluxos amostrados para a linha de moagem 01

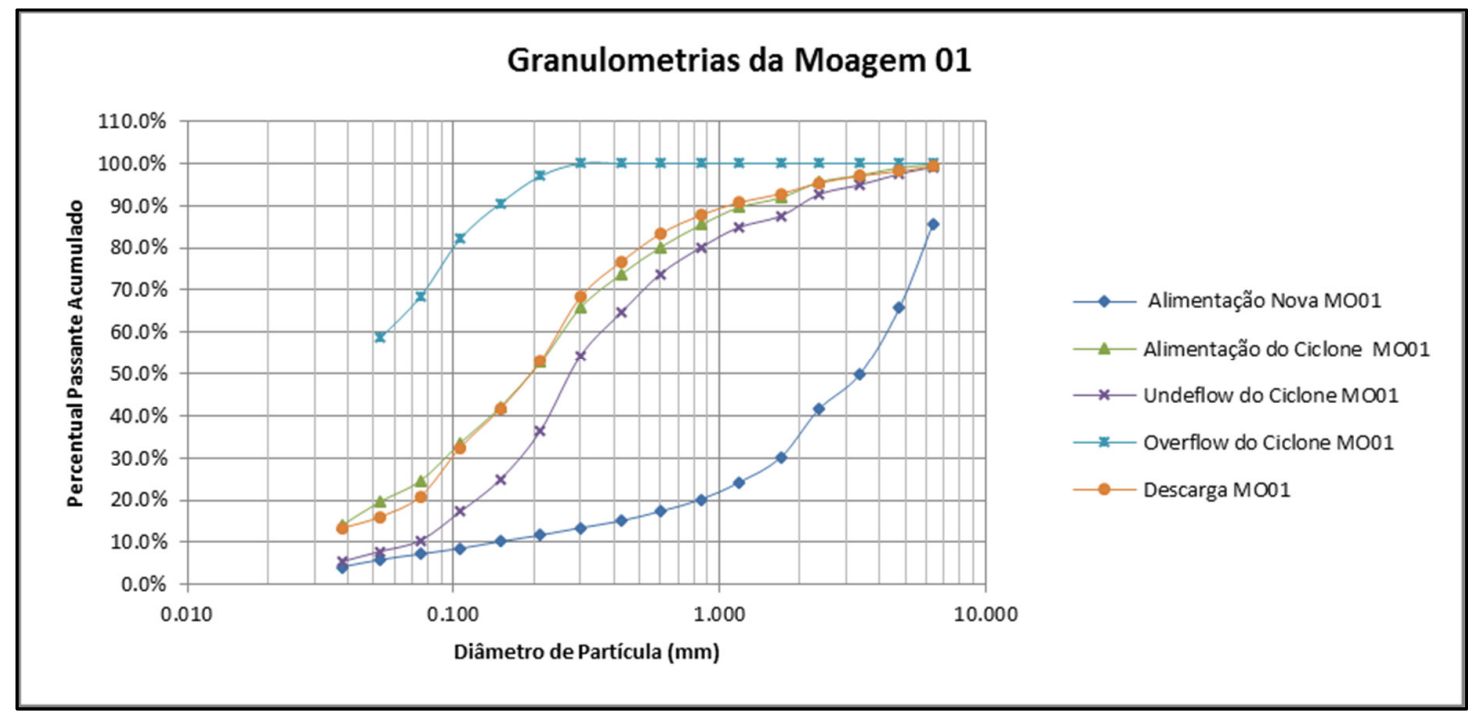

Fonte: Gerado pelo autor 
Tabela 20 - Percentual retido passante para os fluxos amostrados na linha de moagem do Moinho 01

\begin{tabular}{|c|c|c|c|c|c|}
\hline \multicolumn{6}{|c|}{ Porcentagem Passante Acumulada- Moinho - 01 } \\
\hline $\begin{array}{c}\text { Malha } \\
(\mathrm{mm})\end{array}$ & $\begin{array}{c}\text { Alimentação } \\
\text { Nova }\end{array}$ & $\begin{array}{c}\text { Alimentação } \\
\text { Ciclone }\end{array}$ & $\begin{array}{c}\text { Underflow } \\
\text { Ciclone }\end{array}$ & $\begin{array}{c}\text { Overflow } \\
\text { Ciclones }\end{array}$ & $\begin{array}{c}\text { Descarga } \\
\text { Moinho }\end{array}$ \\
\hline 6,35 & 85,8 & 99,8 & 99,2 & 100,0 & 99,3 \\
\hline 4,75 & 65,8 & 99,0 & 97,5 & 100,0 & 98,2 \\
\hline 3,36 & 49,8 & 97,2 & 94,9 & 100,0 & 97,1 \\
\hline 2,36 & 41,5 & 95,6 & 92,7 & 100,0 & 95,4 \\
\hline 1,70 & 30,2 & 91,9 & 87,6 & 100,0 & 92,9 \\
\hline 1,180 & 24,2 & 89,6 & 84,9 & 100,0 & 90,7 \\
\hline 0,850 & 20,2 & 85,5 & 80,1 & 100,0 & 87,8 \\
\hline 0,600 & 17,4 & 80,2 & 73,9 & 100,0 & 83,4 \\
\hline 0,425 & 15,1 & 73,7 & 64,6 & 100,0 & 76,7 \\
\hline 0,300 & 13,5 & 65,8 & 54,4 & 100,0 & 68,4 \\
\hline 0,212 & 11,8 & 52,7 & 36,5 & 97,0 & 53,1 \\
\hline 0,150 & 10,3 & 42,2 & 25,0 & 90,6 & 41,7 \\
\hline 0,106 & 8,6 & 33,6 & 17,3 & 82,2 & 32,5 \\
\hline 0,075 & 7,3 & 24,6 & 10,5 & 68,5 & 20,9 \\
\hline 0,053 & 5,9 & 19,7 & 7,9 & 58,6 & 16,1 \\
\hline 0,038 & 4,2 & 14,1 & 5,5 & 44,7 & 13,4 \\
\hline
\end{tabular}

Figura 43 - Gráfico da granulometria dos fluxos amostrados para a linha de moagem 02

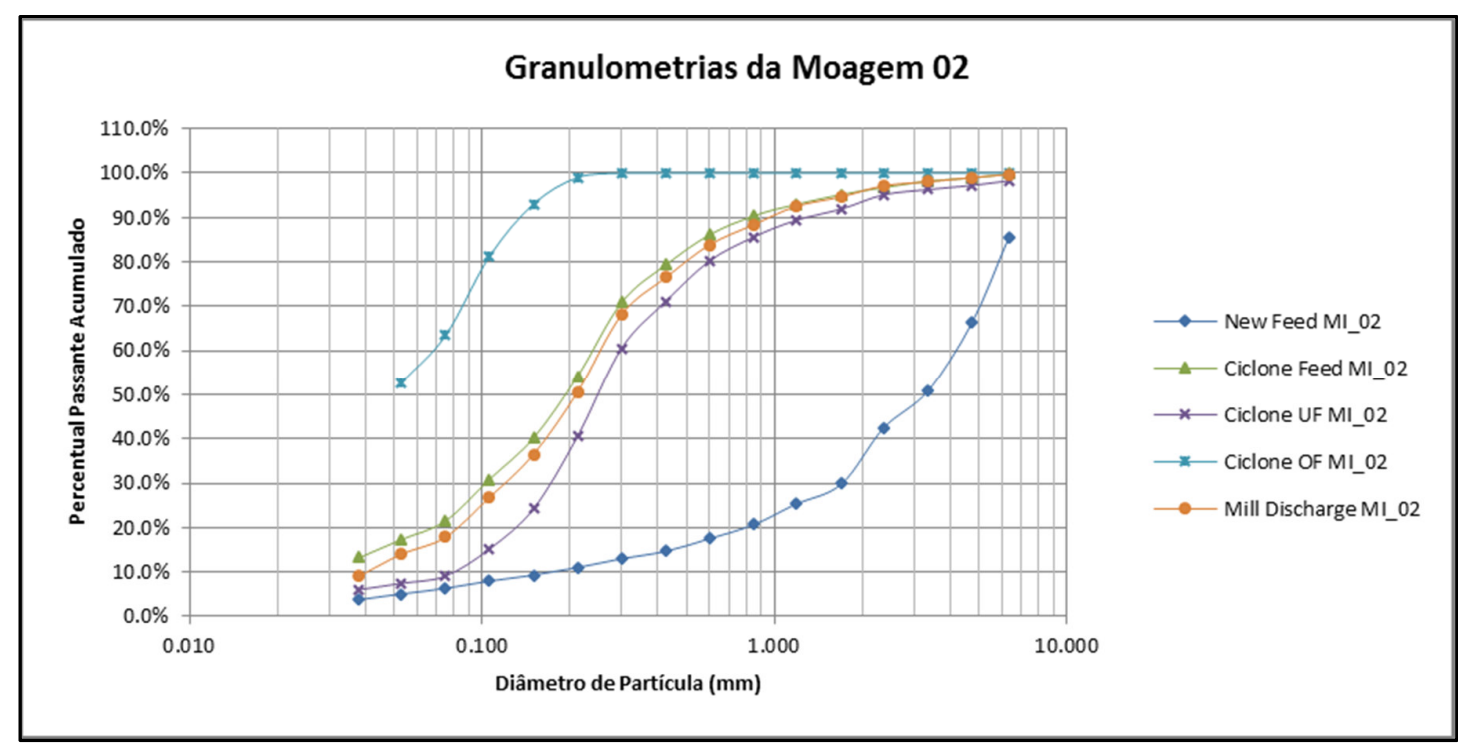

Fonte: Gerado pelo autor 
Tabela 21 - Percentual retido passante para os fluxos amostrados na linha de moagem do Moinho 02

\begin{tabular}{|c|c|c|c|c|c|}
\hline \multicolumn{7}{|c|}{ Moinho - 02 \% Passante Acumulada } \\
\hline $\begin{array}{c}\text { Malha } \\
(\mathrm{mm})\end{array}$ & $\begin{array}{c}\text { Alimentação } \\
\text { Nova }\end{array}$ & $\begin{array}{c}\text { Alimentação } \\
\text { Ciclone }\end{array}$ & $\begin{array}{c}\text { Underflow } \\
\text { Ciclone }\end{array}$ & $\begin{array}{c}\text { Overflow } \\
\text { Ciclone }\end{array}$ & $\begin{array}{c}\text { Descarga } \\
\text { do moinho }\end{array}$ \\
\hline 6,35 & 85,6 & 99,9 & 98,3 & 100,0 & 99,7 \\
\hline 4,75 & 66,4 & 98,9 & 97,3 & 100,0 & 99,0 \\
\hline 3,36 & 50,9 & 98,2 & 96,3 & 100,0 & 98,0 \\
\hline 2,36 & 42,4 & 96,7 & 95,1 & 100,0 & 97,1 \\
\hline 1,70 & 29,9 & 95,2 & 91,9 & 100,0 & 94,7 \\
\hline 1,180 & 25,3 & 92,9 & 89,3 & 100,0 & 92,5 \\
\hline 0,850 & 20,7 & 90,4 & 85,6 & 100,0 & 88,4 \\
\hline 0,600 & 17,5 & 86,1 & 80,2 & 100,0 & 83,9 \\
\hline 0,425 & 14,7 & 79,3 & 71,1 & 100,0 & 76,5 \\
\hline 0,300 & 13,0 & 70,8 & 60,5 & 100,0 & 68,1 \\
\hline 0,212 & 11,0 & 54,1 & 40,5 & 99,0 & 50,6 \\
\hline 0,150 & 9,3 & 40,2 & 24,3 & 93,0 & 36,5 \\
\hline 0,106 & 8,0 & 30,9 & 15,2 & 81,3 & 26,8 \\
\hline 0,075 & 6,4 & 21,5 & 9,1 & 63,4 & 17,8 \\
\hline 0,053 & 5,1 & 17,3 & 7,5 & 52,7 & 14,0 \\
\hline 0,038 & 3,8 & 13,3 & 6,1 & 38,3 & 9,1 \\
\hline
\end{tabular}

\subsubsection{Work Index}

Os valores medidos e calculados durante o ensaio para determinação do WI estão listados na Tabela 22, 23 e 24, que se seguem.

Tabela 22 - Valores medidos e calculados durante o teste de Wi

\begin{tabular}{|c|c|c|c|c|c|c|c|c|c|c|}
\hline \multirow[t]{3}{*}{ Período } & $\begin{array}{c}\text { Número } \\
\text { de } \\
\text { Rotações }\end{array}$ & $\begin{array}{c}A \\
\text { Massa Retida } \\
\text { na Malha Teste }\end{array}$ & \begin{tabular}{|c|}
$B$ \\
Massa Passante \\
Malha Teste
\end{tabular} & $\begin{array}{c}\text { C } \\
\text { Massa } \\
\text { Reposta }\end{array}$ & \begin{tabular}{|c|}
$D$ \\
Massa Passante \\
na Malha Teste \\
Utilizada da \\
Alimentação
\end{tabular} & \begin{tabular}{|c}
$E$ \\
Massa Passante \\
na Malha Teste \\
Gerada no \\
Período
\end{tabular} & $\begin{array}{c}F \\
\text { Gramas por } \\
\text { Revolução }\end{array}$ & $\begin{array}{c}G \\
\text { Massa da } \\
\text { alimentação } \\
\text { nova }\end{array}$ & $\begin{array}{c}\text { Revoluções } \\
\text { para o } \\
\text { Próximo } \\
\text { Período }\end{array}$ & \begin{tabular}{|c|} 
Media de \\
Gramas por \\
Revolução dos \\
Três Últimos \\
Períodos
\end{tabular} \\
\hline & (rev.) & & & $\begin{array}{c}\text { (B do período } \\
\text { anterior) }\end{array}$ & & $(B-D)$ & $(E /$ rev. $)$ & $(M O-A)$ & $(Z-D) / F)$ & \\
\hline & & (g) & (g) & (g) & (g) & (g) & (g) & (g) & (rev.) & \\
\hline \begin{tabular}{|l|} 
Inicial \\
\end{tabular} & - & - & 1503,0 & - & & - & - & - & & - \\
\hline 1 & 30 & 1049,60 & 453,4 & 453,40 & 372,74 & 80,66 & 2,689 & 1503,0 & 30 & - \\
\hline 2 & 118 & 1114,60 & 388,4 & 388,40 & 112,44 & 275,96 & 2,339 & 453,4 & 118 & - \\
\hline 3 & 142 & 1103,00 & 400,0 & 400,00 & 96,32 & 303,68 & 2,139 & 388,4 & 142 & - \\
\hline 4 & 154 & 1090,50 & 412,5 & 412,50 & 99,20 & 313,30 & 2,034 & 400,0 & 154 & - \\
\hline 5 & 161 & 1074,00 & 429,0 & 429,00 & 102,30 & 326,70 & 2,029 & 400,0 & 161 & - \\
\hline 6 & 159 & 1074,00 & 429,0 & 429,00 & 106,39 & 322,61 & 2,029 & 412,5 & 159 & - \\
\hline 7 & 159 & 1074,00 & 429,0 & 429,00 & 106,39 & 322,61 & 2,029 & 429,0 & 159 & - \\
\hline 8 & 159 & 1074,00 & 429,0 & 429,00 & 106,39 & 322,61 & 2,029 & 429,0 & 159 & 2,029 \\
\hline
\end{tabular}


Tabela 23 - Parâmetros obtidos para o cálculo de Wi

\begin{tabular}{|l|c|c|}
\hline Parâmetro & Valor & Unidade \\
\hline Abertura da malha do teste & $\mathbf{1 4 9}$ & $\mu \mathrm{m}$ \\
\hline Densidade aparente & $\mathbf{2 , 1 5}$ & $\mathrm{t} / \mathrm{m}^{3}$ \\
\hline Fração da alimentação passante na malha do teste & $\mathbf{2 4 , 8}$ & $\%$ \\
\hline Produto Ideal & $\mathbf{4 2 9}$ & $\mathrm{G}$ \\
\hline F80 da Alimentação do Teste & $\mathbf{1 7 5 0}$ & $\mu \mathrm{m}$ \\
\hline P80 da fração passante na malha teste no último período & $\mathbf{1 1 8}$ & $\mu \mathrm{m}$ \\
\hline Média dos últimos três valores de gramas por revolução & $\mathbf{2 , 0 2 9}$ & $\mathrm{g} / \mathrm{revol}$ \\
\hline
\end{tabular}

Tabela 24 - Distribuição granulométrica da alimentação e do produto do ensaio para determinação do Wi

\begin{tabular}{|c|c|c|}
\hline \multirow[b]{2}{*}{$\begin{array}{l}\text { Malha } \\
(\mathrm{mm})\end{array}$} & \multicolumn{2}{|c|}{ Porcentagem passante acumulada } \\
\hline & $\begin{array}{l}\text { Alimentação } \\
\text { do ensaio }\end{array}$ & $\begin{array}{l}\text { Produto da } \\
\text { Malha teste do } \\
\text { último período }\end{array}$ \\
\hline 3,33 & 100,00 & - \\
\hline 2,38 & 94,76 & - \\
\hline 1,68 & 77,17 & - \\
\hline 1,19 & 66,70 & - \\
\hline 0,84 & 48,32 & - \\
\hline 0,59 & 42,77 & - \\
\hline 0,42 & 36,86 & - \\
\hline 0,297 & 33,07 & - \\
\hline 0,212 & 29,52 & - \\
\hline 0,149 & 24,79 & 100,00 \\
\hline 0,105 & 20,60 & 75,28 \\
\hline 0,074 & 16,81 & 58,75 \\
\hline 0,053 & 12,17 & 42,34 \\
\hline 0,044 & 9,48 & 31,61 \\
\hline$d_{80}(\mathrm{~mm})$ & 1,75 & 0,12 \\
\hline
\end{tabular}

O valor calculado a partir do ensaio de Wi realizado foi 11,6 kWh/sht.

\subsubsection{Drop Weight Test}

A partir das amostras tomadas na correia transportadora do produto da britagem primária foi realizado o ensaio de DWT. Figura 44 apresenta os resultados obtidos em termos das curvas tn vs t10. A matriz de quebra do minério está descrita 
na Tabela 25 e os valores calculados para as constantes A e b da equação (102) estão apresentados na Tabela 26.

Figura 44 - Curva $t_{n}$ versus $t_{10}$ para o minério de MSG

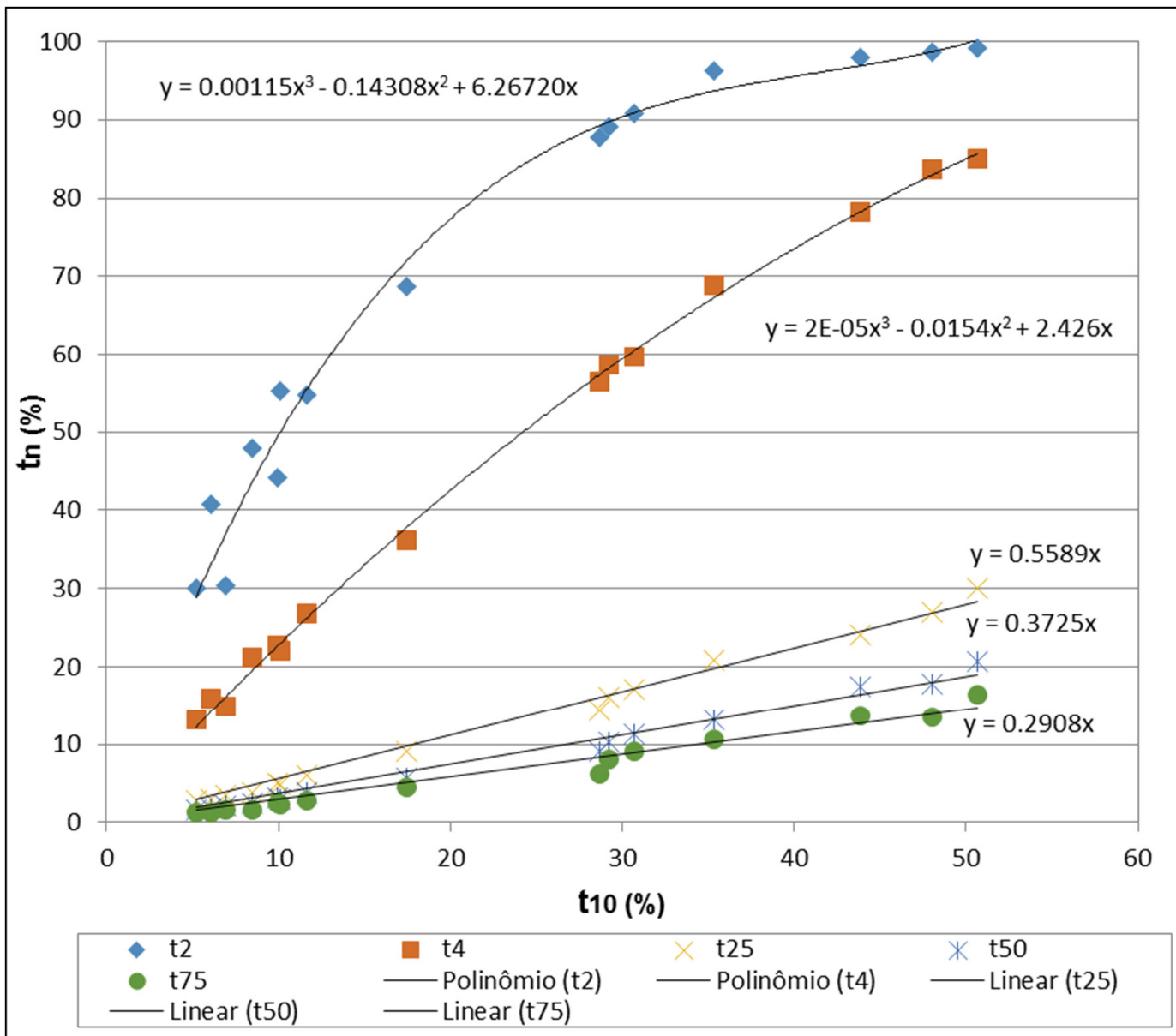

Fonte: Gerado pelo autor

Tabela 25 - Matriz quebra para ensaio de DWT

\begin{tabular}{|c|c|c|c|c|c|}
\hline $\mathbf{t 1 0}$ & $\mathbf{t 7 5}$ & $\mathbf{t 5 0}$ & $\mathbf{t 2 5}$ & $\mathbf{t 4}$ & $\mathbf{t 2}$ \\
\hline $\mathbf{1 0}$ & 2.9 & 3.7 & 5.6 & 22.7 & 49.5 \\
\hline $\mathbf{2 0}$ & 5.8 & 7.5 & 11.2 & 42.5 & 77.3 \\
\hline $\mathbf{3 0}$ & 8.7 & 11.2 & 16.8 & 59.4 & 90.4 \\
\hline
\end{tabular}


Tabela 26 - Valores estimados de A, b e IQ para ensaio de DWT

\begin{tabular}{|c|c|}
\hline A & 54,38 \\
\hline b & 0,84 \\
\hline IQ & 45,42 \\
\hline
\end{tabular}

\subsubsection{Compressão do Leito de Partículas}

A partir das amostras tomadas na correia transportadora do produto da britagem primária, foram realizados os procedimentos de adequação do material, seguidos da execução do ensaio de compressão do leito de partículas. Os resultados dos parâmetros $A$ e b para as três diferentes frações granulométricas, que compõem a curva representada pela equação (103), são apresentados na Tabela 27, enquanto as matrizes de quebra do material são descritas na Tabela 28.

Tabela 27 - Parâmetros A, b e IQ para os três ensaios de CLP

\begin{tabular}{|c|c|c|c|}
\hline $\begin{array}{c}\text { Faixa de } \\
\text { tamanho }(\mathbf{m m})\end{array}$ & A & b & IQ \\
\hline $\mathbf{- 6 , 3 5 + 4 , 7 5}$ & 27.96 & 1.44 & 40.25 \\
\hline $\mathbf{- 9 , 5 0 + 6 , 3 5}$ & 36.38 & 0.91 & 33.11 \\
\hline $\mathbf{- 1 2 , 7 + 9 , 5 0}$ & 37.43 & 1.02 & 38.15 \\
\hline
\end{tabular}

Tabela 28 - Matriz quebra para os três ensaios de CLP

\begin{tabular}{|c|c|c|c|c|c|c|}
\hline $\begin{array}{c}\text { Faixa de tamanho } \\
(\mathbf{m m})\end{array}$ & $\mathbf{t}_{\mathbf{1 0}}$ & $\mathbf{t}_{\mathbf{7 5}}$ & $\mathbf{t}_{\mathbf{5 0}}$ & $\mathbf{t}_{\mathbf{2 5}}$ & $\mathbf{t}_{\mathbf{4}}$ & $\mathbf{t}_{\mathbf{2}}$ \\
\hline \multirow{4}{*}{$\mathbf{6 , 3 5 + 4 , 7 5}$} & 10 & 3.32 & 4.29 & 6.30 & 17.37 & 31.75 \\
\cline { 2 - 7 } & 20 & 6.86 & 8.82 & 12.90 & 32.61 & 55.83 \\
\cline { 2 - 7 } & 30 & 10.59 & 13.44 & 19.12 & 45.96 & 72.08 \\
\cline { 2 - 7 } & 50 & 18.04 & 22.68 & 31.41 & 72.65 & 100.00 \\
\hline \multirow{4}{*}{$\mathbf{9 , 5 0 + 6 , 3 5}$} & 10 & 3.36 & 4.23 & 5.98 & 18.73 & 35.40 \\
\cline { 2 - 7 } & 20 & 6.93 & 8.77 & 12.33 & 36.64 & 66.82 \\
\cline { 2 - 7 } & 30 & 11.06 & 14.00 & 19.27 & 50.71 & 80.85 \\
\cline { 2 - 7 } & 50 & 18.97 & 23.68 & 31.77 & 77.57 & 100.00 \\
\hline \multirow{4}{*}{$\mathbf{1 2 , 7 + 9 , 5 0}$} & 10 & 3.50 & 4.37 & 6.25 & 18.93 & 31.49 \\
\cline { 2 - 7 } & 20 & 7.00 & 8.74 & 12.50 & 37.87 & 62.97 \\
\cline { 2 - 7 } & 30 & 11.69 & 14.24 & 19.53 & 54.43 & 81.50 \\
\cline { 2 - 7 } & 50 & 20.04 & 25.02 & 34.10 & 88.23 & 100.00 \\
\hline
\end{tabular}




\subsubsection{Ensaio de Jarro}

A Figura 45 traz a curva granulométrica da alimentação dos ensaios de jarro, enquanto a curva objetivo representa o valor estimado para o produto final da moagem. Também são apresentadas na mesma Figura 45 as curvas granulométricas para os produtos dos ensaios de 3, 5 e 10 min de moagem.

Figura 45 - Curvas granulométricas dos produtos dos ensaios de jarro

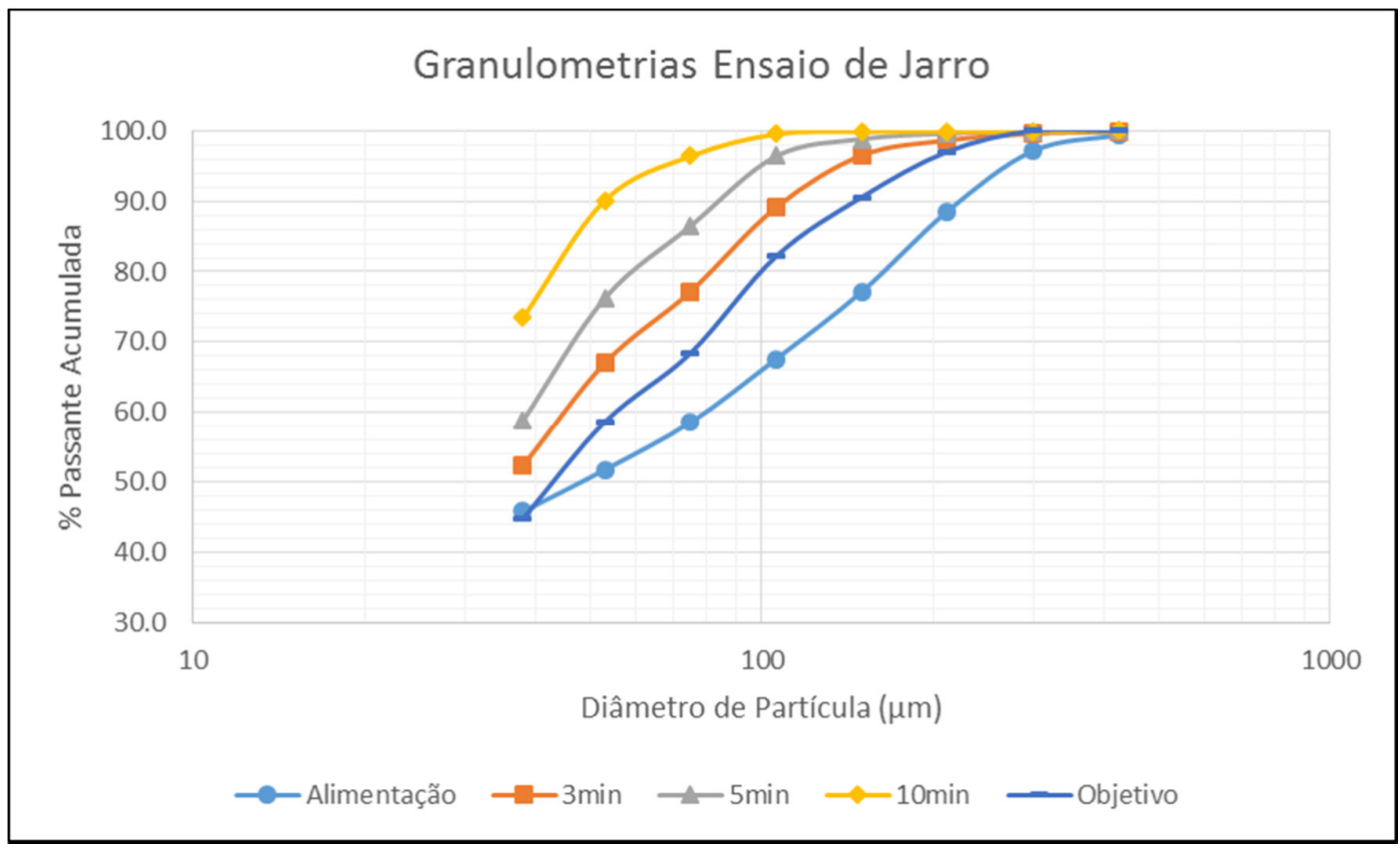

Fonte: Gerado pelo autor

A equação (104), utilizada para o cálculo da energia específica de moagem, tem como base a equação (92) proposta por Rowland para o cálculo da potência consumida pelo moinho. No entanto, considera o tempo de operação do ensaio, a massa de corpos moedores e a massa de minério (BERGERMAN, 2013).

$E=\frac{6,3 \cdot D^{0,3} \cdot \operatorname{sen}\left(51-22\left(\frac{2,44-D}{2,44}\right)\right) \cdot\left(3,2-3 V_{p}\right) \cdot C_{s} \cdot\left(1-\frac{0,1}{\left.2^{(9-10} C_{s}\right)}\right) \cdot t \cdot m_{b}}{m_{m} 60}$

O resultado dos cálculos de energia específica consumida durante cada ensaio de jarro e os parâmetros utilizados são apresentados na Tabela 29. 
Tabela 29 - Parâmetros para cálculo de energia específica para o ensaio de jarro

\begin{tabular}{|c|l|c|c|c|c|}
\hline Fator & \multicolumn{1}{|c|}{ Significado } & Und. & $3 \mathrm{~min}$ & $5 \mathrm{~min}$ & $10 \mathrm{~min}$ \\
\hline $\mathrm{E}$ & $\begin{array}{l}\text { Energia específica consumida } \\
\text { durante o ensaio de jarro }\end{array}$ & $\mathrm{kWh} / \mathrm{t}$ & 2,54 & 6,78 & 13,57 \\
\hline $\mathrm{D}$ & $\begin{array}{l}\text { Diâmetro do moinho interno ao } \\
\text { revestimento }\end{array}$ & $\mathrm{m}$ & \multicolumn{3}{|c|}{0,2032} \\
\hline $\mathrm{V}_{\mathrm{p}}$ & $\begin{array}{l}\text { Fração do volume interno do } \\
\text { moinho ocupado pelas bolas }\end{array}$ & & \multicolumn{3}{|c|}{0,4} \\
\hline $\mathrm{C}_{\mathrm{s}}$ & Fração da velocidade crítica & & \multicolumn{3}{|c|}{0,76} \\
\hline $\mathrm{t}$ & Tempo de operação do Jarro & $\mathrm{min}$ & 3 & 5 & 10 \\
\hline $\mathrm{mb}_{\mathrm{b}}$ & Massa de bolas & $\mathrm{kg}$ & \multicolumn{3}{|c|}{15,87} \\
\hline $\mathrm{m}_{\mathrm{m}}$ & Massa de minério & $\mathrm{kg}$ & \multicolumn{3}{|c|}{0,913} \\
\hline
\end{tabular}

A Figura 46 apresenta, para cada um dos ensaios, a energia específica versus o $\mathrm{P}_{80}$ dos produtos. Essa curva é útil para este estudo, pois, por meio dela, estima-se a energia específica necessária para gerar produtos de diferentes $\mathrm{P}_{80}$, partindo de uma alimentação com $\mathrm{F}_{80}=165 \mu \mathrm{m}$.

Figura 46 - Gráfico da energia específica consumida em cada ensaio de jarro versus o $\mathrm{P}_{80}$ do produto

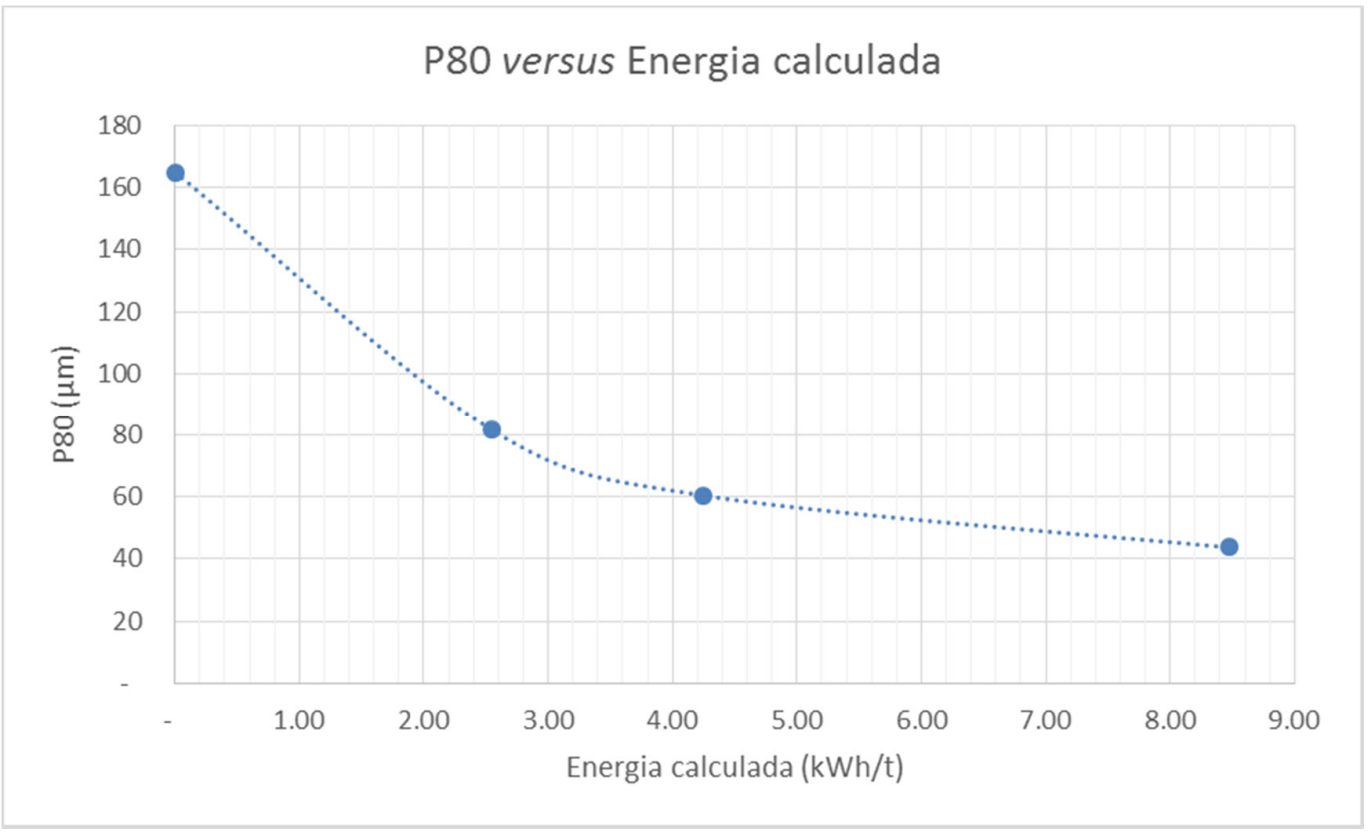

Fonte: Gerado pelo autor 


\subsection{BALANÇO DE MASSAS}

Os dados obtidos na amostragem e aqueles resultantes de ensaios de caracterização foram utilizados para efetuar o balanço de massas, que foi conduzido como auxílio do simulador de processos JKSimMet, versão 6.0.

A Figura 47 e a Figura 48 incluem valores de granulometrias para cada fluxo. Neste caso os pontos representam valores experimentais, enquanto as linhas são resultados dos ajustes após o balanço de massa. Em função da aderência observada entre valores experimentais e calculados, a amostragem foi considerada adequada.

Figura 47 - Comparação das granulometrias entre os dados experimentais e os dados do balanço de massa para o Moinho 01

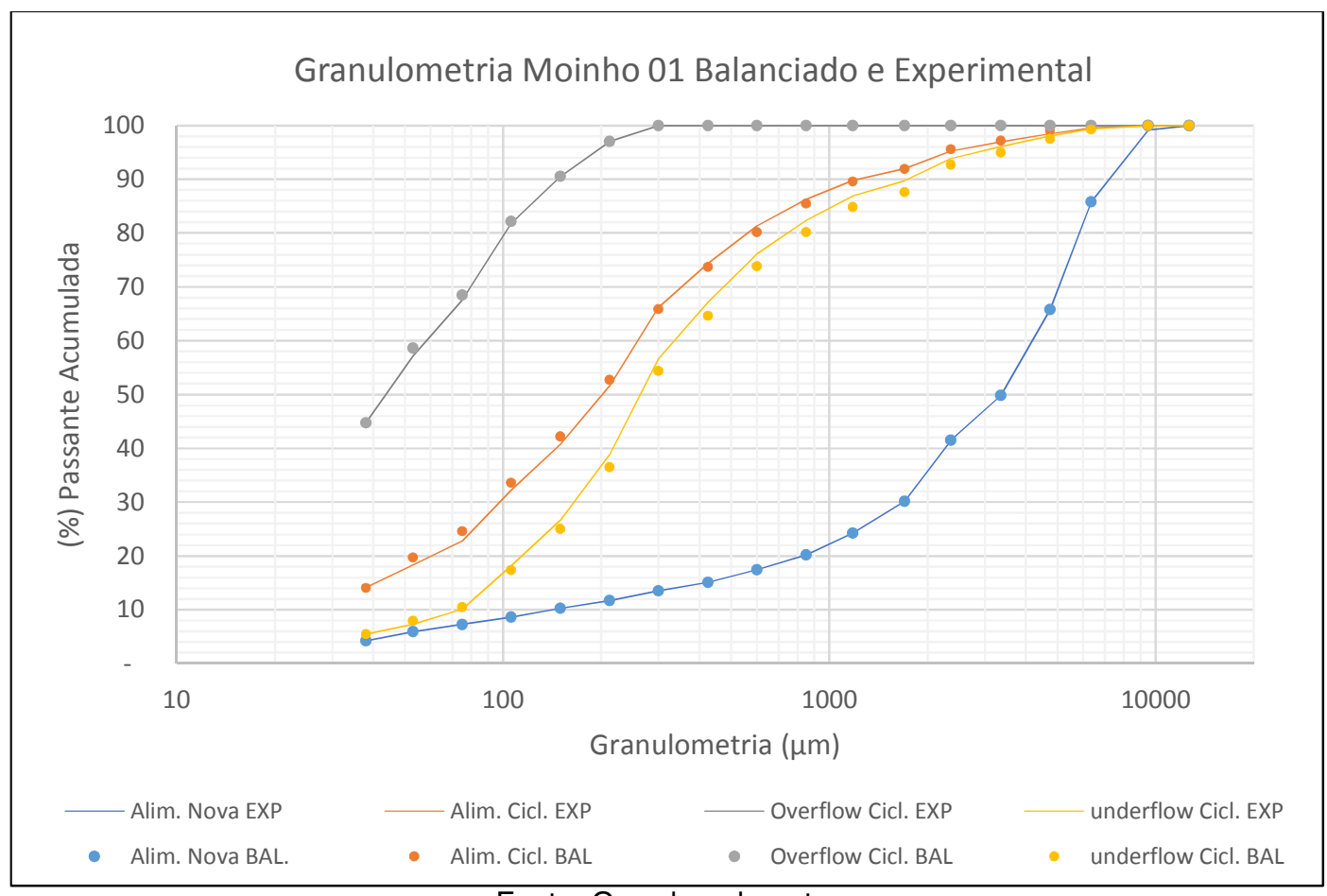

Fonte: Gerado pelo autor 
Figura 48 - Comparação das granulometrias entre os dados experimentais e os dados do balanço de massa para o Moinho 02

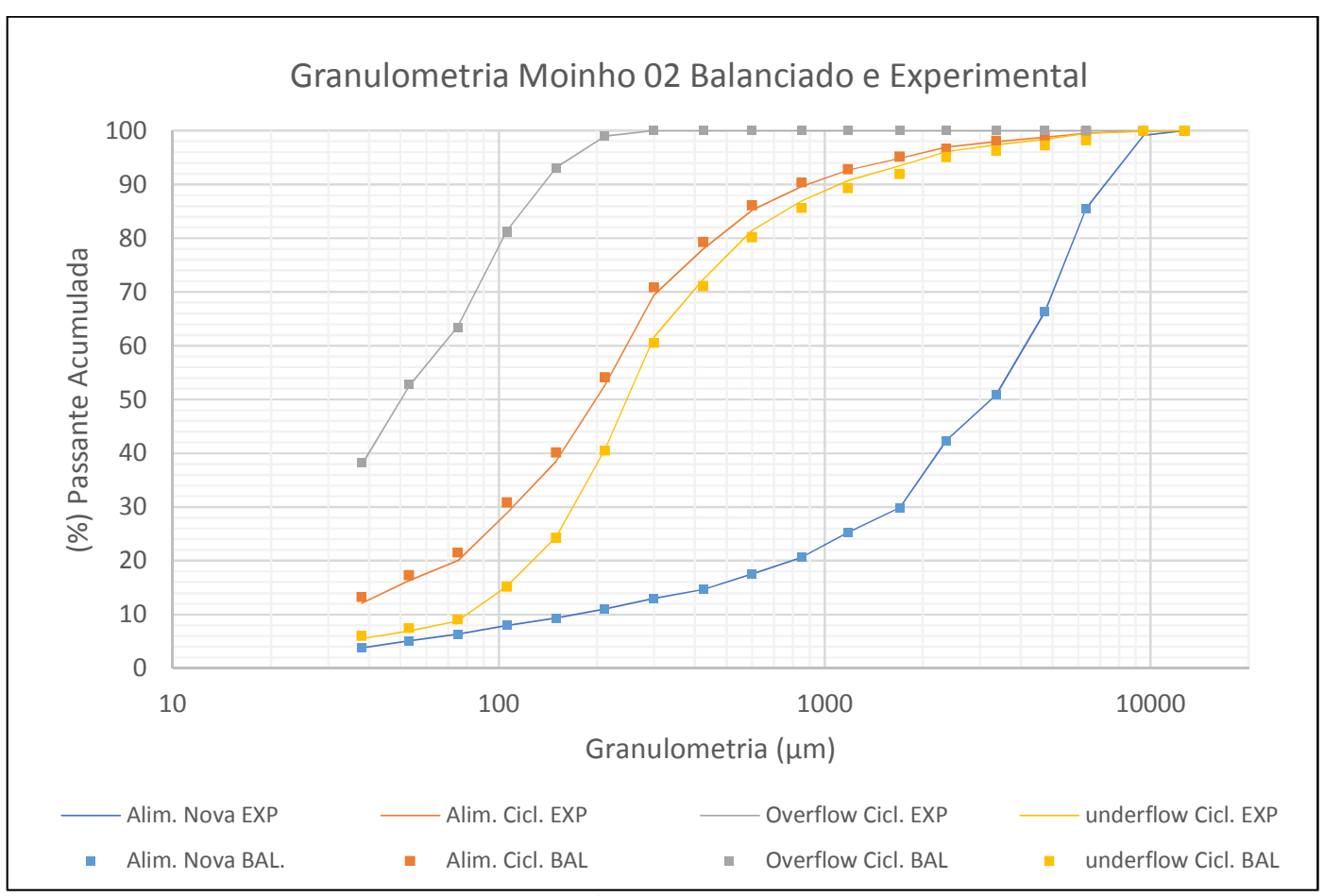

Fonte: Gerado pelo autor

O JKSimMet, versão 6.0utiliza recurso para gerar um gráfico que compara os dados experimentais versus os dados do balanço de massa. A Figura 49 mostra no primeiro quadro todos os parâmetros medidos e, no segundo, a ampliação da zona mais populosa. 
Figura 49 - Dados do balanço de massa versus dados experimentais
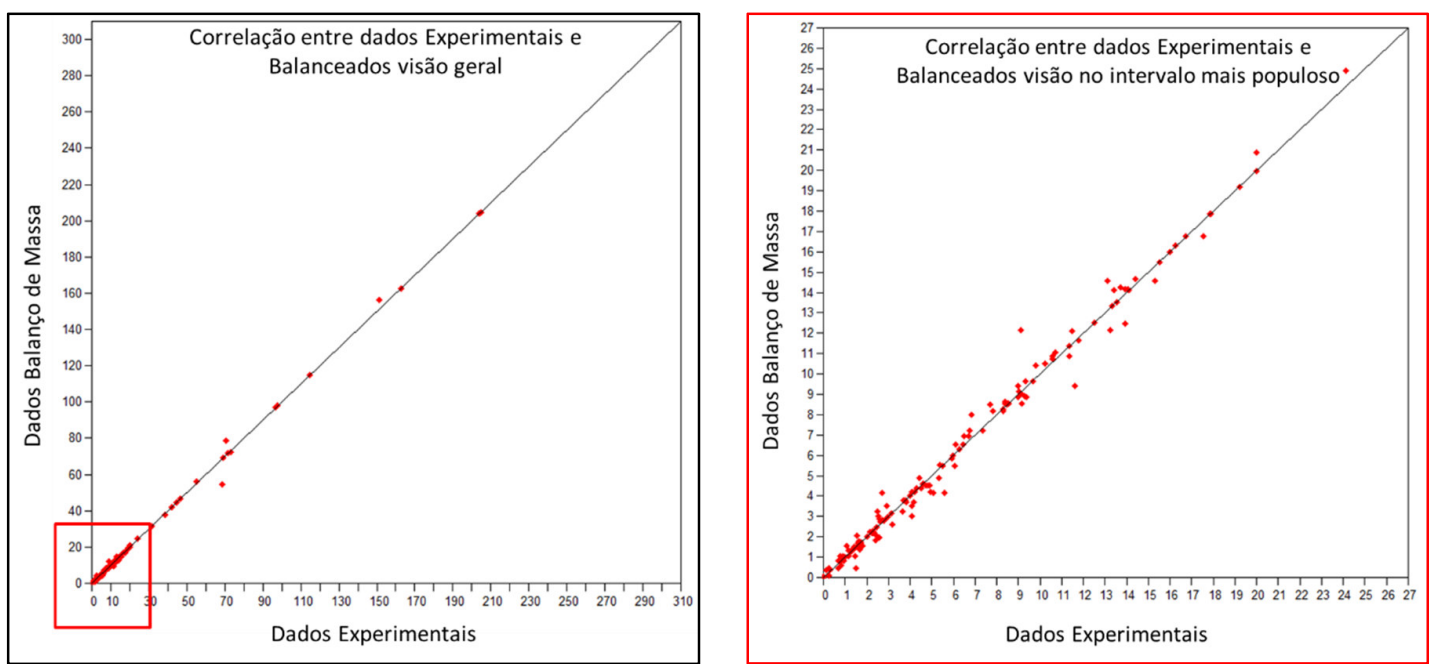

Fonte: Gerado pelo autor

\subsection{CALIBRAÇÃO DOS MODELOS SELECIONADOS}

Após o fechamento do balanço de massas foi realizada a calibração dos modelos matemáticos de processo, mediante emprego de um módulo específico para esse fim do simulador JKSimMet.

O modelo do misturador perfeito de Whiten foi utilizado para representar o processo de moagem nos moinhos de bolas, cujos detalhes podem ser consultados na seção 3.3.1.1.1. O modelo de Nageswararao foi empregado para representar o processo de classificação que ocorre nos ciclones, conforme descrição contida na seção 3.3.2.1.2.

A Tabela 30 traz os valores calibrados da função cinética de quebra $\left(r / d^{*}\right)$. Os valores calculados das constantes dos ciclones são apresentados na Tabela 31.

Tabela 30 - Valores calibrados para definição das curvas de $\ln \left(r / d^{*}\right)$

\begin{tabular}{|c|c|c|c|}
\hline \multirow{2}{*}{ Nó } & \multirow{2}{*}{ Tamanho } & \multicolumn{2}{|c|}{$\operatorname{In}(r / d *)$} \\
\cline { 3 - 4 } & & MO_01 & MO_02 \\
\hline 1 & 0,2 & 1.674 & 1.503 \\
\hline 2 & 1,5 & 3.712 & 3.966 \\
\hline 3 & 15,0 & 5.232 & 5.733 \\
\hline
\end{tabular}


Tabela 31 - Valores das constantes do modelo de Nageswararao calibrado

\begin{tabular}{|c|c|c|}
\hline Constantes do modelo de Nageswararao & HC_01 & HC_02 \\
\hline Constante do $\mathrm{d}_{50}-\left(\mathrm{K}_{\mathrm{D} 0}\right)$ & $8.144 \mathrm{e}-005$ & $7.891 \mathrm{e}-005$ \\
\hline Constante da Vazão - (KQ0) & 511 & 602 \\
\hline Constante da partição do volume - (Kv1) & 7.15 & 9.11 \\
\hline Constante da partição de água - v (Kw1) & 10.66 & 14.44 \\
\hline Inclinação da Curva - ( $\alpha)$ & 2.01 & 2.81 \\
\hline
\end{tabular}

\subsection{MELHORIA DE DESEMPENHO DO CIRCUITO EXISTENTE}

Como exercício, após balanço de massa e calibração do modelo, alguns parâmetros de processo foram avaliados como forma de identificar oportunidades de melhoria de desempenho do circuito em operação.

Nesse sentido foram simuladas diferentes condições de densidade da polpa para alimentação dos ciclones, também variações dos diâmetros de alimentação de corpos moedores e variações para os diâmetros de vortex e apex das baterias de ciclones.

Essas avaliações foram feitas previamente no simulador JKSimMet para, posteriormente, testar as mudanças no circuito em operação. É imprescindível informar que grandes ganhos em conhecimentos relacionados ao comportamento do circuito de moagem foram adquiridos, pois, na busca de melhorar as condições operacionais, vários testes foram realizados com o auxílio do software.

Em função dos resultados dos balanços de massas identificou-se grandes desvios nas indicações dos medidores de vazão de água.

Sendo assim, foram realizadas a manutenção e calibração dos instrumentos, que assim passaram a indicar valores coerentes com os calculados no balanço.

Com essas informações e com o contato mais frequente na planta, foi verificado que a densidade da polpa, que alimentava os ciclones apresentava grande amplitude de variação, assim como a carga circulante.

As variações de densidade ocorriam, pois, a filosofia do controle do moinho era baseada em adicionar água na caixa para o controle do nível, e não para o controle 
da densidade. Enquanto que a velocidade da bomba permanecia constante. Essa metodologia resulta em grandes variações de densidade e consequentemente pressão de operação dos ciclones, carga circulante e granulometria.

A execução do controle da operação poderia ser a chave dessa questão, uma vez que a densidade da polpa era um parâmetro que variava livremente, e a operação se baseava no nível da caixa da bomba para abrir ou fechar as válvulas de água, mantendo a velocidade das bombas de polpa, que alimentam os ciclones, constante e, portanto, com grande variação da pressão de operação dos ciclones e da carga circulante.

Com o emprego do modelo calibrado e tendo ciência da sensibilidade da operação quanto às variações constantes de densidade, foi possível comprovar a necessidade de haver maior controle da densidade da polpa. Portanto, buscou-se restabelecer o funcionamento da malha de controle automática, que interligava o nível da caixa do produto da moagem com a velocidade de rotação da bomba de polpa que alimenta os ciclones.

A malha de controle estava desabilitada, pois o medidor de nível que era utilizado na caixa não era adequado e apresentava medidas de nível incorretas, tendo variações repentinas e dificuldade para limpeza, manutenção e calibração.

Além disso, as válvulas de controle demandavam manutenção frequente e também estavam desabilitadas, pois não correspondiam ao acionamento via PLC.

Diante do cenário exposto foram amplamente discutidos e selecionados medidores de níveis adequados para instalação na caixa dos dois moinhos. Também foi discutido um plano de manutenção para as válvulas automáticas. Essas iniciativas eram necessárias para que o controle automático do nível da caixa voltasse a funcionar.

Com os novos instrumentos instalados e os antigos devidamente recuperados foi possível restabelecer o funcionamento da malha de controle. Durante a sintonia da malha foi identificada uma trava no PLC da planta para que o limite de rotação da bomba não ultrapassasse $70 \%$ da velocidade crítica de operação da bomba. Porém, essa condição não foi considerada adequada, uma vez que limitaria um dos 
principais equipamentos periféricos da moagem e, consequentemente, a possibilidade de moer com maior intensidade.

Apesar do receio de utilizar a bomba com sua capacidade máxima na operação, as simulações do circuito só mostravam ganhos mediante maior capacidade de bombeamento, além de que o controle automático seria capaz de evitar cavitações ou transbordo da caixa.

Utilizando simulações foi possível mostrar a estabilidade do circuito de moagem ao se adotar $55 \%$ de sólidos na alimentação dos ciclones para ambos os circuitos. Dessa forma, haveria ganhos de capacidade de aproximadamente $4 \%$, uma vez que o Moinho 01 passaria a processar $120 \mathrm{t} / \mathrm{h}$ enquanto o circuito $243,5 \mathrm{t} / \mathrm{h}$, sem que fossem alteradas as granulometrias dos produtos dos circuitos calibrados, como apresentado na Figura 50.

Pelo simulador foi identificado que haveria aumento da pressão dos ciclones e também da carga circulante, porém, como a malha de controle estaria habilitada e as bombas de polpa estariam aptas a aumentar as velocidades de rotação, esses parâmetros estariam controlados.

Outros parâmetros de operação foram também variados na simulação para verificar se haveria possíveis ganhos. Alteraram-se modelos e dimensões de ciclones, porém não foram identificadas possibilidades que aumentassem significativamente a capacidade de produção do circuito. Estas observações confirmaram vários estudos já realizados nessa área, na tentativa de otimizar a operação dos ciclones.

O principal aspecto observado com auxílio das simulações foi a sensibilidade de desempenho em função da variação do diâmetro do apex. O material utilizado atualmente é poliuretano e que se desgasta rapidamente, o que implica a variação gradual do corte do ciclone. Partindo de uma peça nova, em 15 dias de operação já apresentava diâmetro fora do especificado. Porém, como o circuito opera com ciclones reserva, não foi necessário parar a operação para substituição de apex.

O apex novo do Moinho 01 tem diâmetro de $100 \mathrm{~mm}$ e é substituído ao atingir diâmetro aproximado de $120 \mathrm{~mm}$. Essa variação de $20 \%$ influencia no corte do ciclone, porém é compensado pelo aumento da velocidade de rotação da bomba. 
No estudo descrito foi possível identificar ganhos de qualidade do produto e identificados aumentos de produção mediante utilização de apex cerâmico. Embora resista mais ao desgaste decidiu-se não realizar testes industriais em função da possibilidade de recirculação de corpos moedores.

Outro ponto avaliado pela simulação foi a diminuição do diâmetro dos corpos moedores de 2,5" para 2,0". Neste caso o benefício potencial foi o aumento da capacidade de alimentação do circuito de aproximadamente 3\%. Em função do maior consumo associado a corpos moedores de menor diâmetro a MSG decidiu conduzir um estudo independente de custo/benefício.

O resultado de produção da moagem esperado para o ano de 2015 era de 1,28 MTPA. Entretanto, com o auxílio de iniciativas conjuntas das chefias de processo, manutenção e produção foi possível produzir 1,33 MTPA - aumento de 3,9\%, em parte alcançado por meio das simulações acima descritas. 
Figura 50 - Circuito original e otimizado por simulação no software JKSimMet

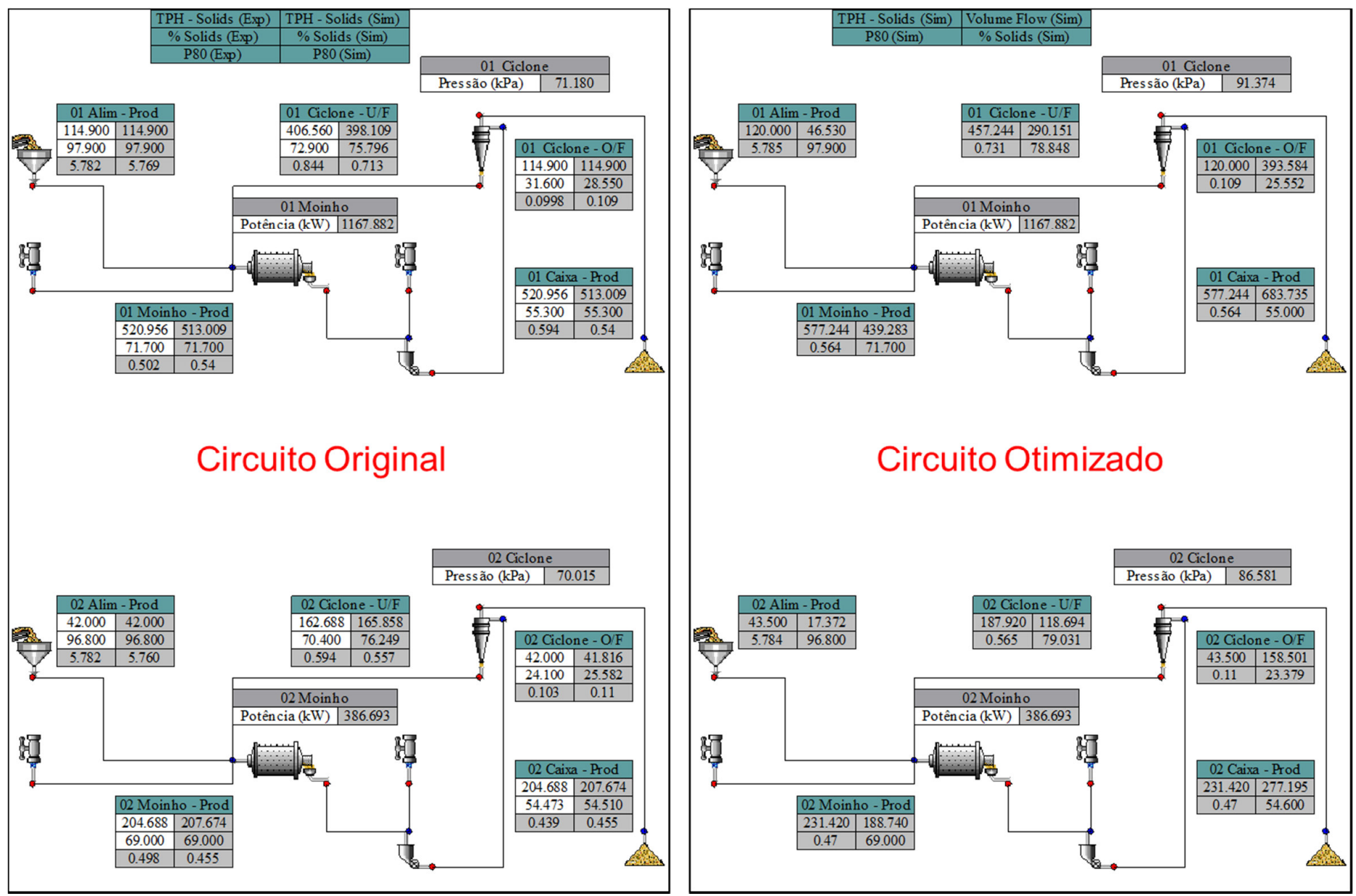

Fonte: Gerado pelo autor 


\subsection{CENÁRIOS PARA CAPACIDADE DE 2.0 MILHÕES DE TONELADAS POR ANO}

Neste capítulo são propostos quatro circuitos diferentes, mediante a inserção de novos equipamentos, para se obter aumento da capacidade de produção da moagem de MSG de aproximadamente $55 \%$, passando dos atuais 1,3 para 2,0 milhões de toneladas processadas por ano.

Os cenários estudados por intermédio de simulações foram os seguintes:

1. Moinho de bolas em série

2. Moinho de bolas em paralelo

3. Moinho vertical

4. Prensa de rolos

Para todos os casos foram realizadas simulações com utilização do software JKSimMet, versão 6.0. Outras teorias e práticas foram também levados em consideração, complementando assim as simulações.

As alternativas 1. (Moinho de bolas em série) e 2. (Moinho de bolas em paralelo) são comumente utilizados em expansões para operação de moagem em plantas de beneficiamento de minérios.

O circuito 3. (Moinho vertical) inclui o uso do moinho vertical para uma alimentação com $\mathrm{F}_{80}$ de aproximadamente $165 \mu \mathrm{m}$, gerando um produto com $\mathrm{P}_{80}$ de $109 \mu \mathrm{m}$, portanto, em uma faixa granulométrica não usual para sua operação e com baixa razão de redução.

Da mesma forma é pouco comum a proposta de utilizar a prensa de rolos para o circuito 4, pois a alimentação contaria com $F_{80}$ de $5,8 \mathrm{~mm}$ e o produto com $\mathrm{P}_{80}$ de 2,5 mm. Normalmente, prensas de rolos trabalham em faixas granulométricas mais grosseiras enquanto moinhos verticais geram produtos mais finos. Há, portanto, riscos de os resultados não serem representativos para simulações e dimensionamento dos equipamentos. Caso sejam selecionadas, tais alternativas deverão ser objeto de campanhas piloto para comprovação de resultados.

Muito embora fora da faixa de operação industrial corrente, as propostas simuladas usaram como base as faixas de operação da prensa de rolos e do moinho 
vertical previstas pela empresa Metso, conforme descritas no respectivo manual (METSO, 2015), conforme mostra a Figura 51.

Figura 51 - Faixa granulométrica de atuação de equipamentos utilizados para moagem

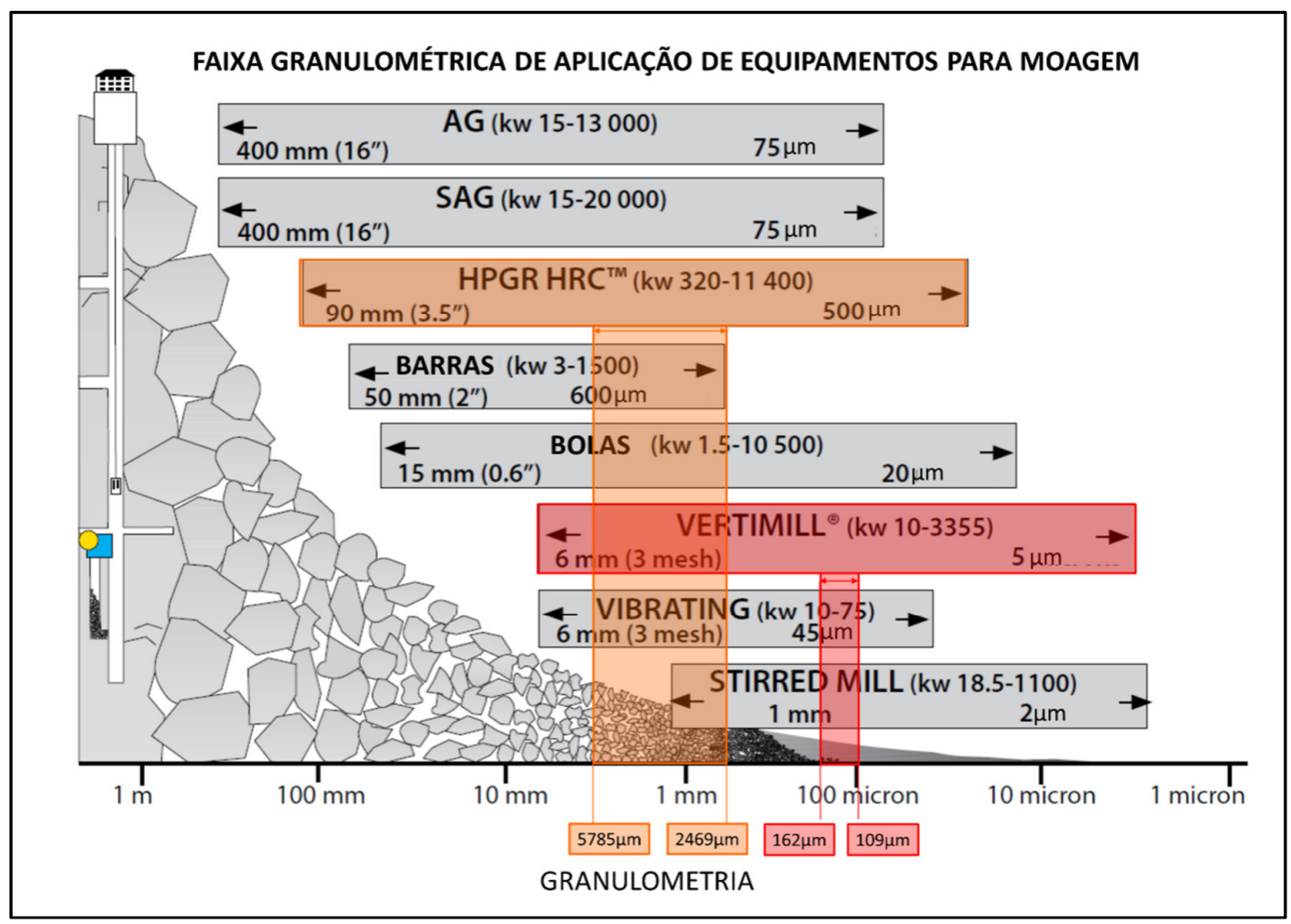

Fonte: Adaptado de Metso (2015)

Para realizar as simulações e dimensionar os equipamentos, diversas premissas foram necessárias, conforme descrições detalhadas contidas nos subcapítulos de cada cenário.

As curvas granulométricas de alimentação dos circuitos foram baseadas nas mesmas apresentadas nas Figura 42 e Figura 43 ou na média delas, quando aplicadas.

Para atingir a capacidade anual de a2.0 milhões de toneladas por ano, a vazão de alimentação total dos circuitos foi estipulada em $243 \mathrm{t} / \mathrm{h}$ e o rendimento operacional da moagem de $94 \%$, o que resulta em 8.234 horas de operação por ano.

Em todos os cenários buscou-se atingir P80 próximo a $109 \mu \mathrm{m}$ como produto final da moagem. 
A primeira estimativa realizada para identificação do consumo de energia pelos novos equipamentos considerou uma abordagem convencional, mediante o cálculo do WI operacional de Bond pela equação (62), com base nos parâmetros apresentados na Tabela 32.

A Tabela 32 indica também os fatores Rr e F0 estimados para calcular o fator de correção EF4, conforme equação...

Tabela 32 - Parâmetros para o dimensionamento do consumo Global de energia da moagem para o cenário 2,0 mtpa

\begin{tabular}{|l|c|c|}
\hline \multicolumn{1}{|c|}{ Parâmetros de entrada } & un. & Valores \\
\hline Alimentação & $\mathrm{t} / \mathrm{h}$ & 243 \\
\hline $\mathrm{Wi}$ & $\mathrm{kWh} / \mathrm{st}$ & 11,6 \\
\hline $\mathrm{F}_{80}$ & $\mu \mathrm{m}$ & 5769 \\
\hline $\mathrm{P}_{80}$ & $\mu \mathrm{m}$ & 109 \\
\hline $\mathrm{R}_{\mathrm{r}}$ & & 52,9 \\
\hline $\mathrm{F}_{0}$ & $\mu \mathrm{m}$ & 4235 \\
\hline
\end{tabular}

A Tabela 33 apresenta os fatores de correção de Rowland para a equação (62). Tabela 33 - Fatores de correção de Rowland para o dimensionamento da energia global do circuito

\begin{tabular}{|l|l|c|}
\hline \multicolumn{2}{|c|}{ Fatores para correção } & Valores \\
\hline$E F_{1}$ & Moagem a seco & Não se aplica \\
\hline$E F_{2}$ & Circuito aberto & Não se aplica \\
\hline$E F_{3}$ & Diâmetro & Não se aplica \\
\hline$E F_{4}$ & Oversize & 1,031 \\
\hline$E F_{5}$ & Material fino & Não se aplica \\
\hline$E F_{6}$ & Relação de redução para moinho de barras & Não se aplica \\
\hline$E F_{7}$ & Baixa relação de redução & Não se aplica \\
\hline$E F_{8}$ & Moagem em moinho de barras & Não se aplica \\
\hline
\end{tabular}

A Tabela 34 apresenta os resultados para estimativa do consumo de energia do circuito. Com base na equação (62), a potência requerida para executar a cominuição do material seria de $2.179 \mathrm{~kW}$ que, descontadas as potências dos moinhos existentes de 1168 kW e 387 kW, respectivamente para o Moinho 1 e Moinho 
2, resulta em $624 \mathrm{~kW}$ adicionais necessários para se atingir a capacidade total do circuito de 2 mtpa.

Tabela 34 - Resultados do dimensionamento do consumo de energia para moagem de 2,0 mtpa

\begin{tabular}{|l|c|c|}
\hline \multicolumn{1}{|c|}{ Resultados } & un. & Valores \\
\hline Energia específica requerida nos moinhos & $\mathrm{kWh} / \mathrm{t}$ & 8,97 \\
\hline Potência requerida dos moinhos & $\mathrm{kW}$ & 2179 \\
\hline Moinho 01 & $\mathrm{kW}$ & 1168 \\
\hline Moinho 02 & $\mathrm{kW}$ & 387 \\
\hline Novo equipamento & $\mathrm{kW}$ & 624 \\
\hline
\end{tabular}

Os cálculos acima descritos foram utilizados apenas para efeitos comparativos, pois não consideram as particularidades de cada circuito simulado. 


\subsubsection{Moinho de bolas em série - Cenário 1}

Este cenário considera a inclusão de um moinho de bolas para operar em série junto aos dois moinhos já existentes, de forma a atingir a vazão total do circuito de $243 \mathrm{t} / \mathrm{h}$. A Figura 52 apresenta o fluxograma selecionado para esta proposta.

A princípio, o aumento de vazão para cada moinho existente foi considerado proporcional às potências instaladas, quais sejam, $73 \%$ da alimentação total para 0 moinho 01 e $27 \%$ para o moinho 02. Desta forma o modelo do moinho 01 foi alimentado com $178 \mathrm{t} / \mathrm{h}$ e o do moinho 02 com $65 \mathrm{t} / \mathrm{h}$.

Figura 52 - Proposta de circuito para a simulação considerando moinho de bolas em série junto aos já instalados na usina da MSG

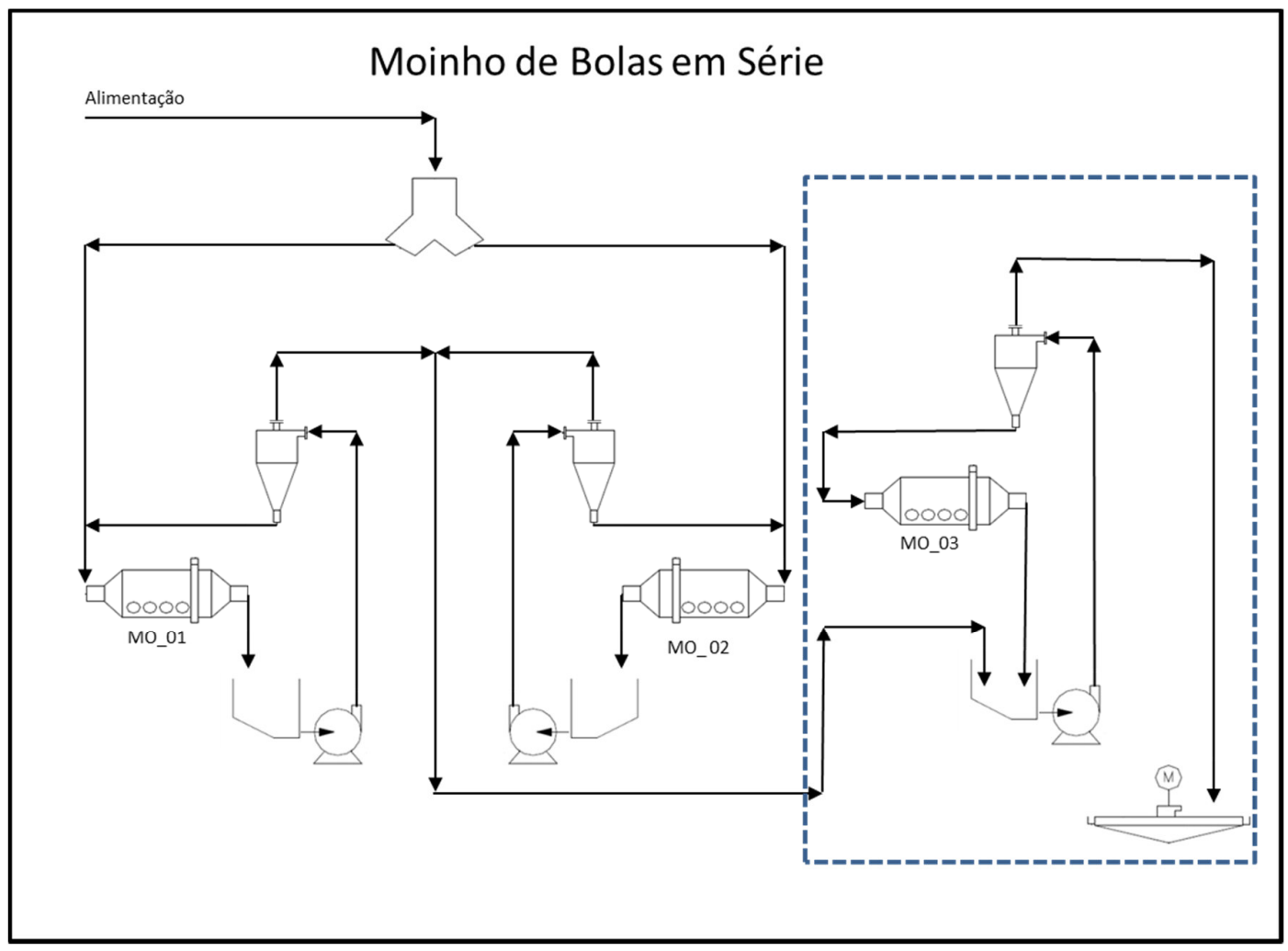

Fonte: Gerado pelo autor

Com acréscimo das vazões do circuito de moagem sem quaisquer alterações nos equipamentos periféricos, a simulação resultou no aumento expressivo da carga 
circulante e da pressão de operação dos ciclones. Para tanto decidiu-se ajustar as condições de operação da classificação do circuito utilizando como referência a Tabela 5 para a seleção dos ciclones. Vários equipamentos foram simulados para realizar a simulação em ambos os moinhos, até que se encontrasse aqueles que oferecessem uma condição adequada de classificação com valores coerentes de pressão, de concentração de sólidos dos fluxos de descarga dos ciclones e de cargas circulantes próximas às existentes em cada circuito.

Durante as simulações foi observado que não era possível manter a vazão de alimentação dividida proporcionalmente entre os dois moinhos existentes, pois os primeiros resultados indicaram que o moinho 02 tem percentualmente maior capacidade para expansão do que o moinho 01, por isso foi necessário adequar a alimentação conforme a disponibilidade dos equipamentos. O moinho 01 foi alimentado com $71,6 \%$ da alimentação total ou $174 \mathrm{t} / \mathrm{h}$, enquanto o moinho 02 com $28,4 \%$ ou $69 \mathrm{t} / \mathrm{h}$.

Os resultados obtidos para essa etapa do dimensionamento indicaram produtos mais grosseiros dos moinhos 01 e 02, passando de $109 \mu \mathrm{m}$ para $162 \mu \mathrm{m}$. Logo, o trabalho que o moinho em série realiza na simulação é remoer o produto das duas moagens existentes, assegurando que o produto final do circuito apresente $P_{80}$ de 109 $\mu \mathrm{m}$.

O novo moinho foi então adicionado ao fluxograma considerando um circuito inverso de moagem, onde a alimentação nova do moinho em série passava primeiro pela bateria de ciclones, antes de alimentar o equipamento. Neste caso, as frações mais finas seriam produto da moagem, enquanto as frações mais grosseiras alimentariam o terceiro moinho.

Para o terceiro moinho terceiro moinho considerou-se médias aritméticas do Moinho 1 e Moinho 2 da função cinética de quebra $\ln \left(r / d^{*}\right)$, cujos valores seguem descritos na Tabela 35. 
Tabela 35 - Valores utilizados como referência de $\ln \left(r / d^{*}\right)$ para o moinho em série

\begin{tabular}{|c|c|c|}
\hline \multirow{2}{*}{ Nó } & \multirow{2}{*}{ Tamanho } & $\ln (r / d *)$ \\
\cline { 3 - 3 } & & MO_Série \\
\hline 1 & 0,2 & 1.588 \\
\hline 2 & 1,5 & 3.839 \\
\hline 3 & 15,0 & 5.482 \\
\hline
\end{tabular}

Para as constantes do modelo de Nageswararao também foram consideradas como referência as médias dos valores das constantes dos dois circuitos de classificação previamente calibrados. Os valores das constantes dos ciclones assim calculadas são apresentados na Tabela 36 .

Tabela 36 - Valores utilizados como referência para as constantes do modelo de Nageswararao

\begin{tabular}{|l|c|}
\hline Constantes do modelo de Nageswararao & HC_Série \\
\hline Constante do d50 - $\left(\mathrm{K}_{\mathrm{D} 0}\right)$ & $8.02 \mathrm{E}-05$ \\
\hline Constante da Vazão - $\left(\mathrm{K}_{\mathrm{Q} 0}\right)$ & 556 \\
\hline Constante da partição do volume - $\left(\mathrm{K}_{\mathrm{v} 1}\right)$ & 8.13 \\
\hline Constante da partição de água - v $\left(\mathrm{K}_{\mathrm{w} 1}\right)$ & 12.55 \\
\hline Inclinação da Curva - $(\alpha)$ & 2.41 \\
\hline
\end{tabular}

Para dar início às simulações do moinho de bolas em série utilizou-se um equipamento de 3,2 $\mathrm{m}$ de diâmetro e 4,6 $\mathrm{m}$ de comprimento, em função da necessidade de fornecer $624 \mathrm{~kW}$ (Tabela 34). A seleção do equipamento foi baseada na Tabela 4.

O modelo misturador perfeito selecionado teve por base grau de enchimento de $35 \%$ com corpos moedores de $60 \mathrm{~mm}$ e peso específico de 7,80 , rotação igual a $70 \%$ da velocidade crítica e Wi de 11,6 kWh/st.

O resultado das simulações indicou que o equipamento selecionado geraria potência de $618 \mathrm{~kW}$, para um produto final do circuito de moagem com $\mathrm{P}_{80}$ de $105 \mu \mathrm{m}$, mediante ajustes no sistema de classificação, conforme mostra a Figura 53.

A Tabela 39 apresenta as dimensões e parâmetros selecionados, conforme definidos pelas simulações conduzidas pelo autor, como os mais recomendados para operação da bateria de ciclones do moinho em paralelo. 
Tabela 37 - Dimensões e parâmetros para operação dos ciclones para cenário de moinho em paralelo

\begin{tabular}{|l|c|c|}
\hline Parâmetro & Un. & Valor \\
\hline Número de ciclones & & 4 \\
\hline Diâmetro do corpo & $(\mathrm{m})$ & 0,508 \\
\hline Diâmetro de Entrada (Dc) & $(\mathrm{m})$ & 0,160 \\
\hline Diâmetro Vortex (Do) & $(\mathrm{m})$ & 0,230 \\
\hline Diâmetro Apex Spigot (Du) & $(\mathrm{m})$ & 0,100 \\
\hline Altura do Cilindro (Lc) & $(\mathrm{m})$ & 0,568 \\
\hline Cone (Theta) & $(\stackrel{\circ}{)})$ & 10 \\
\hline Pressão de operação & $\mathrm{kPa}$ & 58 \\
\hline
\end{tabular}

A Tabela 38 apresenta as dimensões e os parâmetros definidos pelo autor como os mais recomendados para operação do moinho selecionado.

Tabela 38 - Dimensões e parâmetros para operação do moinho de bolas para cenário de moinho em paralelo

\begin{tabular}{|l|c|c|}
\hline Parâmetro & Un. & Valor \\
\hline Diâmetro interno & $(\mathrm{m})$ & 3.2 \\
\hline Comprimento interno & $(\mathrm{m})$ & 4.6 \\
\hline Fração crítica da velocidade de rotação & $(\%)$ & 70 \\
\hline Enchimento corpos moedores & $(\%)$ & 35 \\
\hline Diâmetro de corpos moedores & $(\mathrm{mm})$ & 60 \\
\hline Potência do motor estimada & $(\mathrm{hp})$ & 1000 \\
\hline
\end{tabular}


Figura 53 - Fluxograma do circuito simulado para cenário 1. Moinho de bolas em série

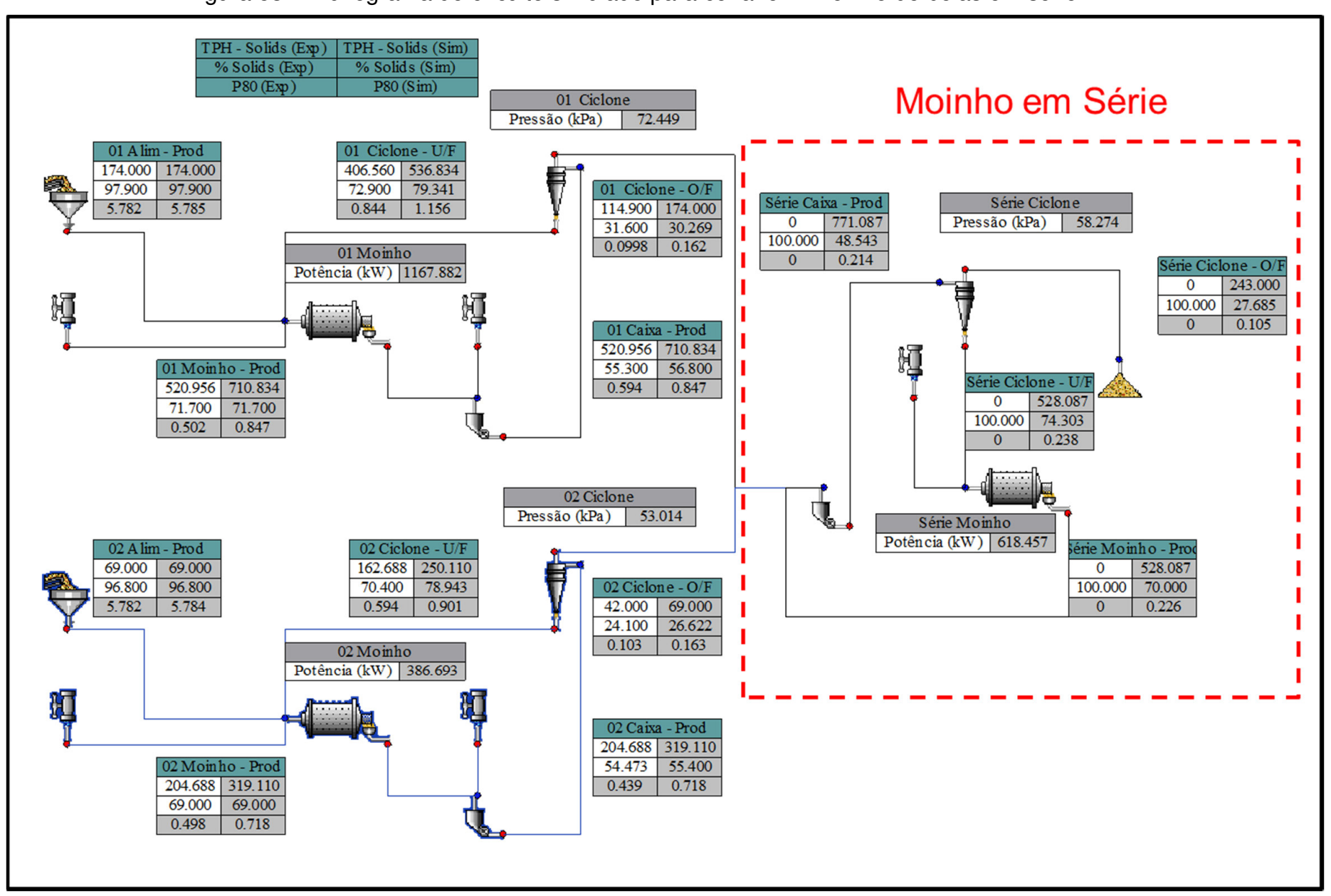

Fonte: Gerado pelo autor 


\subsubsection{Moinho de bolas em paralelo - Cenário 2}

Este cenário considerou a inclusão de um terceiro moinho de bolas em paralelo aos moinhos existentes para atingir a vazão total de $243 \mathrm{t} / \mathrm{h}$ no circuito de moagem. A Figura 54 apresenta o fluxograma do circuito selecionado para este cenário.

Nesse caso considerou-se que as vazões de alimentação dos moinhos 01 e 02 permaneceriam as mesmas em relação ao Caso Base. Assim, a capacidade estipulada para o terceiro moinho seria de $83 \mathrm{t} / \mathrm{h}$ para atingir a vazão total estipulada para o circuito.

Figura 54 - Circuito selecionado para simulação de uma terceira linha de moagem na usina da MSG

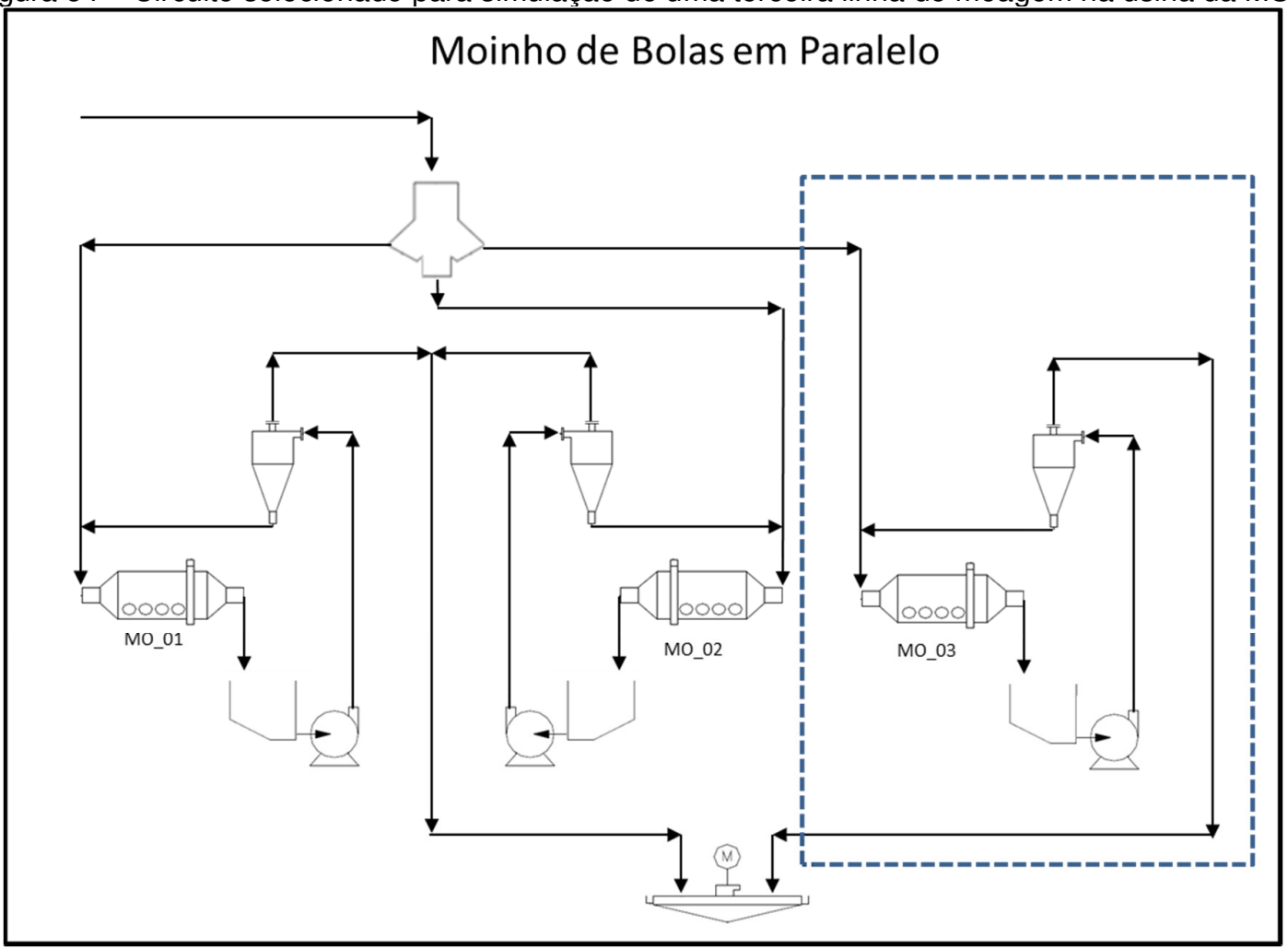

Fonte: Gerado pelo autor

A alimentação do novo equipamento em paralelo foi simulada de forma direta, com curva granulométrica do fluxo de alimentação igual à média das granulometrias das alimentações dos moinhos 01 e 02 . De forma análoga ao cenário do moinho em série, as constantes dos modelos para o terceiro moinho e ciclones foram calculadas 
como as médias das constantes obtidas para os equipamentos existentes, cujos resultados estão apresentados na Tabela 35 e Tabela 36.

Para identificar a bateria de ciclones que melhor atendia à classificação, foram realizadas simulações com diferentes modelos da Tabela 5.

A estimativa inicial para o consumo de energia foi baseada no resultado apresentado na Tabela 34. Assim, para início das simulações foi considerado o mesmo equipamento apresentado para a alternativa de moagem em série, ou seja, moinho de bolas com 3,2 $\mathrm{m}$ de diâmetro e 4,6 m de comprimento. $\mathrm{O}$ modelo de misturador perfeito selecionado foi baseado em grau de enchimento de $35 \%$ com corpos moedores de $60 \mathrm{~mm}$ e peso específico de 7,80 , rotação igual a $70 \%$ da velocidade crítica e Wi de 11,6 kWh/st.

O equipamento selecionado atendeu à capacidade estipulada de $83 \mathrm{t} / \mathrm{h}$ com potência de $618 \mathrm{~kW}$. A curva granulométrica do produto obtido pelas simulações para o equipamento está muito próxima daquelas dos produtos gerados pelos moinhos 01 e 02, conforme apresentadas na Figura 55.

Figura 55 - Curvas granulométricas dos produtos das moagens 01,02 e terceiro moinho em paralelo

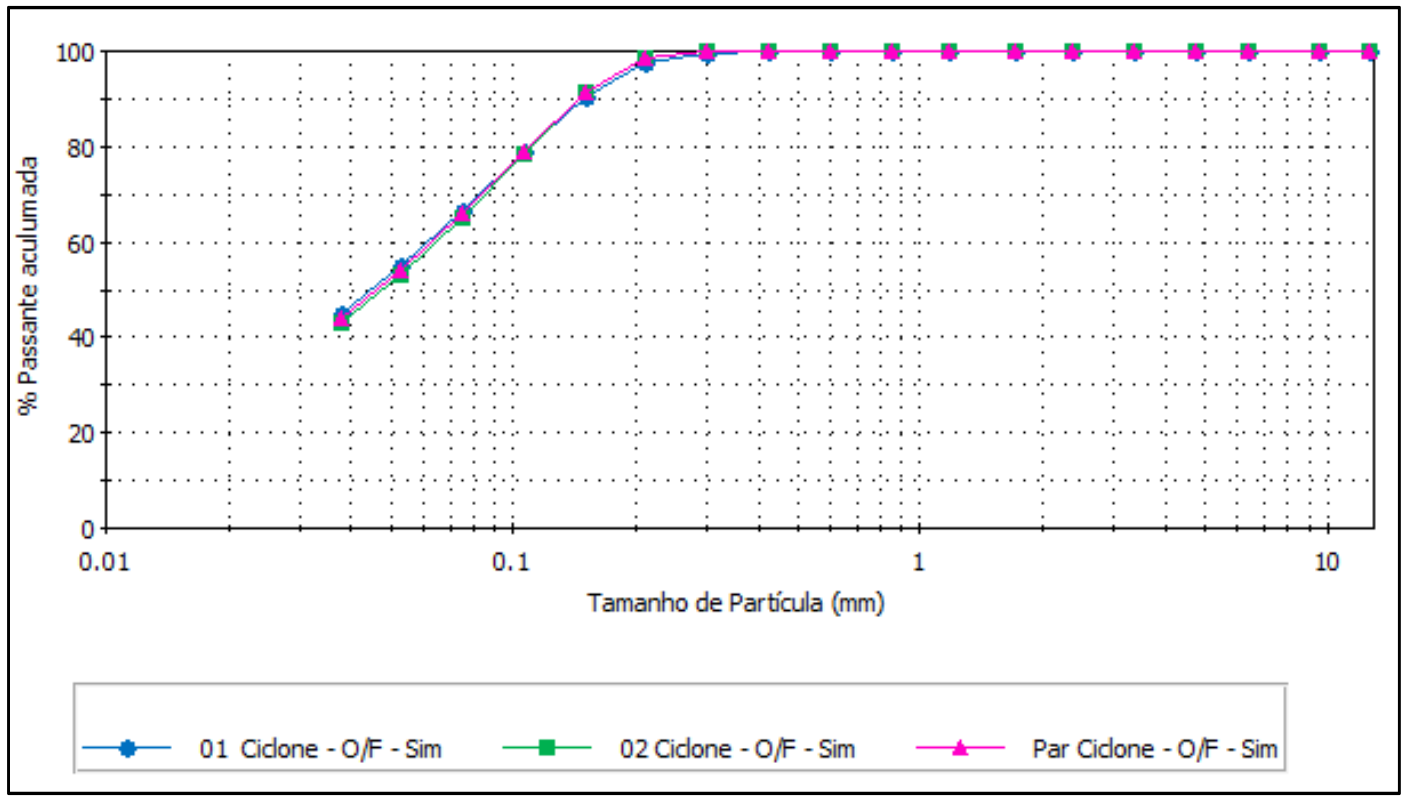

Fonte: Gerado pelo autor 
A Tabela 39 apresenta as dimensões e os parâmetros selecionados pelo autor como os mais recomendados para operação da bateria de ciclones do terceiro moinho em paralelo.

Tabela 39 - Dimensões e parâmetros para operação dos ciclones para cenário de moinho em paralelo

\begin{tabular}{|l|c|c|}
\hline Parâmetro & Un. & Valor \\
\hline Número de ciclones & & 3 \\
\hline Diâmetro do corpo & $(\mathrm{m})$ & 0,406 \\
\hline Diâmetro de Entrada (Dc) & $(\mathrm{m})$ & 0,111 \\
\hline Diâmetro Vortex (Do) & $(\mathrm{m})$ & 0.170 \\
\hline Diâmetro Apex Spigot (Du) & $(\mathrm{m})$ & 0.090 \\
\hline Altura do Cilindro (Lc) & $(\mathrm{m})$ & 0.522 \\
\hline Cone (Theta) & $(\stackrel{\circ}{)})$ & 10 \\
\hline Pressão de operação & $\mathrm{kPa}$ & 69 \\
\hline
\end{tabular}

A Tabela 40 apresenta as dimensões e os parâmetros selecionados pelo autor como os mais recomendados para operação do moinho modelado.

Tabela 40 - Dimensões e parâmetros para operação do moinho de bolas para cenário de moinho em paralelo

\begin{tabular}{|l|c|c|}
\hline Parâmetro & Un. & Valor \\
\hline Diâmetro interno & $(\mathrm{m})$ & 3.2 \\
\hline Comprimento interno & $(\mathrm{m})$ & 4.6 \\
\hline $\begin{array}{l}\text { Velocidade de rotação (\% do valor } \\
\text { crítico) }\end{array}$ & $(\%)$ & 70 \\
\hline Enchimento dos corpos moedores & $(\%)$ & 35 \\
\hline Diâmetro de corpos moedores & $(\mathrm{mm})$ & 60 \\
\hline Potência do motor & $(\mathrm{hp})$ & 1000 \\
\hline
\end{tabular}


Figura 56 - Fluxograma do circuito simulado para o cenário 2. Terceiro moinho de bolas em paralelo

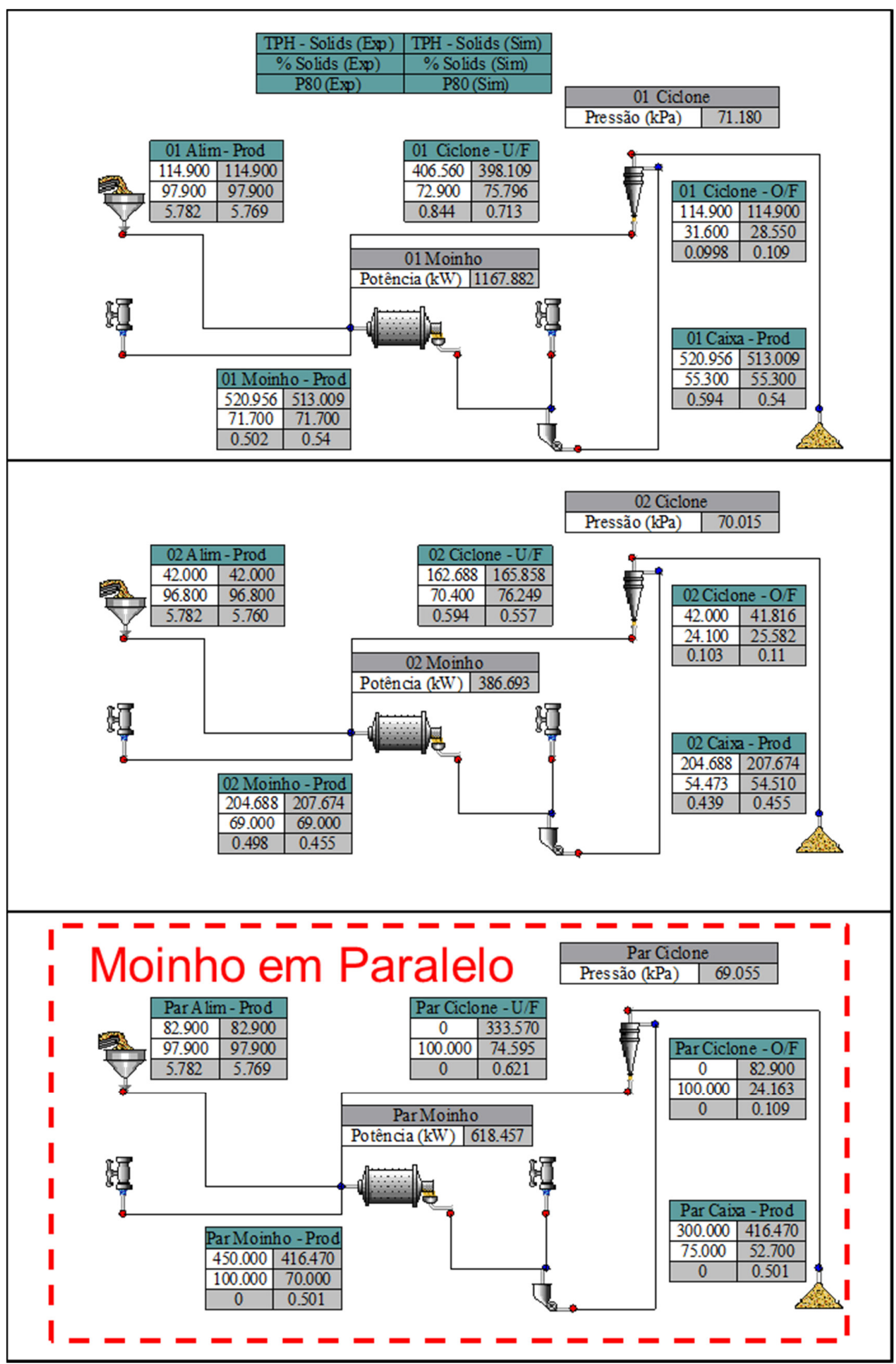

Fonte: Gerado pelo autor 


\subsubsection{Moinho vertical - Cenário 3}

O terceiro cenário selecionado considera a adição de um moinho vertical em série aos moinhos existentes para atingir a vazão de $243 \mathrm{t} / \mathrm{h}$, como apresentado na Figura 57.

Figura 57 - Circuito para simulação considerando um moinho vertical em série aos já instalados na usina da MSG

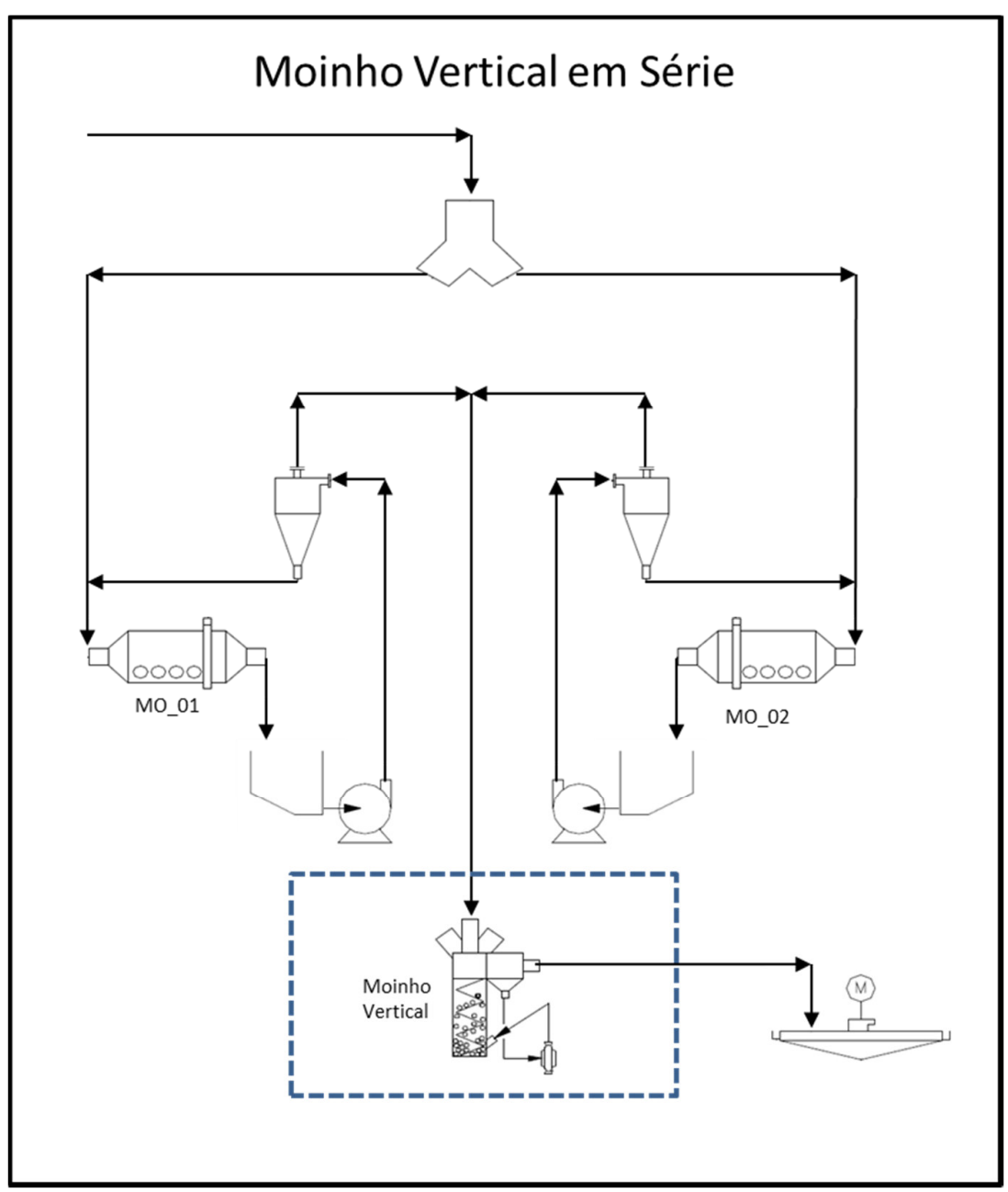

Fonte: Gerado pelo autor

Como o simulador JKSimMet, versão 6.0, não inclui modelos específicos para moinhos verticais, não foi utilizada neste caso simulação computacional. O método selecionado foi estimar a potência do moinho vertical por modelo energético. 
Para cálculo da potência necessária foram empregados os resultados obtidos dos ensaios específicos realizados para tal fim conforme apresentado na seção 6.1.5 baseados no método descrito na seção 5.1.1.7.

O dimensionamento do moinho vertical levou em consideração as simulações feitas para o circuito 1. Neste caso, o produto dos dois moinhos existentes apresentou P80 de $162 \mu \mathrm{m}$.

De desta informação foi elaborado um plano de ensaios de bancada, de forma a estimar a energia específica de cominuição necessária para gerar produto com $\mathrm{P}_{80}$ de $109 \mu \mathrm{m}$.

O primeiro procedimento realizado foi adequar em laboratório a granulometria do material que alimenta os ensaios de jarro. Após realizar a cominuição para os diferentes tempos de moagem selecionou-se o tempo de 60 min para gerar amostra com $\mathrm{P}_{80}$ de $165 \mu \mathrm{m}$.

Esse material foi então quarteado em três alíquotas de $913 \mathrm{~g}$ para alimentar três ensaios de jarro com tempos de moagem 3,5 e 10 min.

Após as moagens, o material foi devidamente peneirado, gerando as curvas granulométricas apresentadas na Figura 45 . Com base nos valores de $\mathrm{P}_{80} \mathrm{e}$ respectivas energias específicas para cada ensaio, foi produzida a curva ilustrada na Figura 58.

Como o ensaio de jarro com moagem em 3 minutos gerou produto com $\mathrm{P}_{80}$ inferior a $109 \mu \mathrm{m}$, decidiu-se interpolar o tempo de residência para atingir a granulometria estipulada $O$ valor assim calculado de energia específica foi $1,71 \mathrm{kWh} / \mathrm{t}$, o que resulta em $416 \mathrm{~kW}$ de potência para o moinho vertical. 
Figura 58 - Gráfico da energia específica consumida versus $\mathrm{P}_{80}$ para ensaios de jarro, com regressão linear para estimativa de energia consumida para produto requerido de $109 \mu \mathrm{m}$.

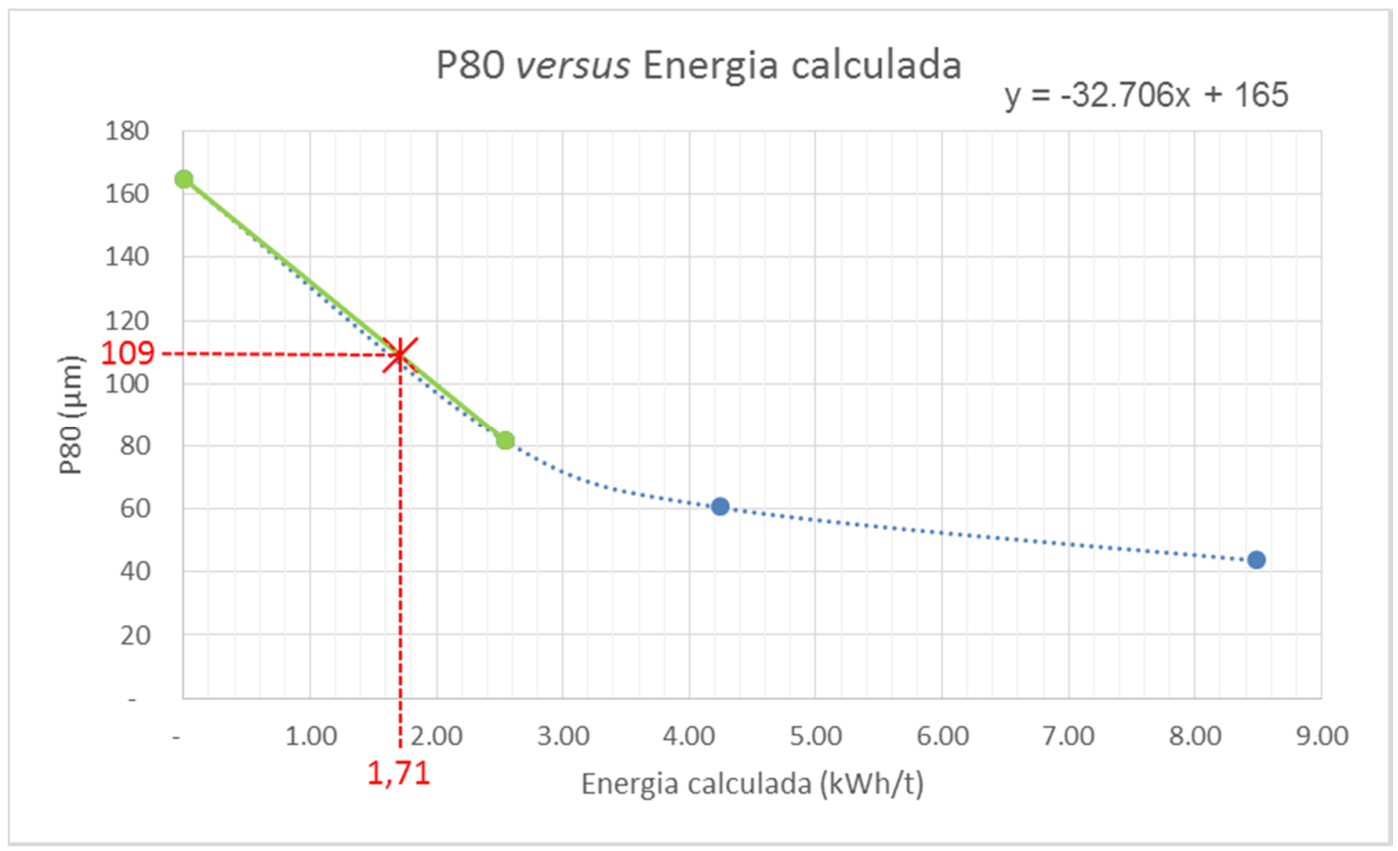

Fonte: Gerado pelo autor

Alguns pontos importantes para a seleção desse equipamento devem ser citados, em especial a adequação da curva granulométrica para alimentação do ensaio de jarro. Pela Figura 59 fica evidenciado que não foi possível gerar uma granulometria exatamente como a simulada para fazer a alimentação do ensaio de jarro. Portanto, o tempo de moagem foi selecionado pela curva que apresentou o valor de $\mathrm{P}_{80}$ mais próximo ao simulado de $162 \mu \mathrm{m}$. Essa curva foi obtida com 60 min de moagem e apresentou frações grosseiras próximas às simuladas. 
Figura 59 - Curvas granulométricas para geração de material para ensaio de jarro

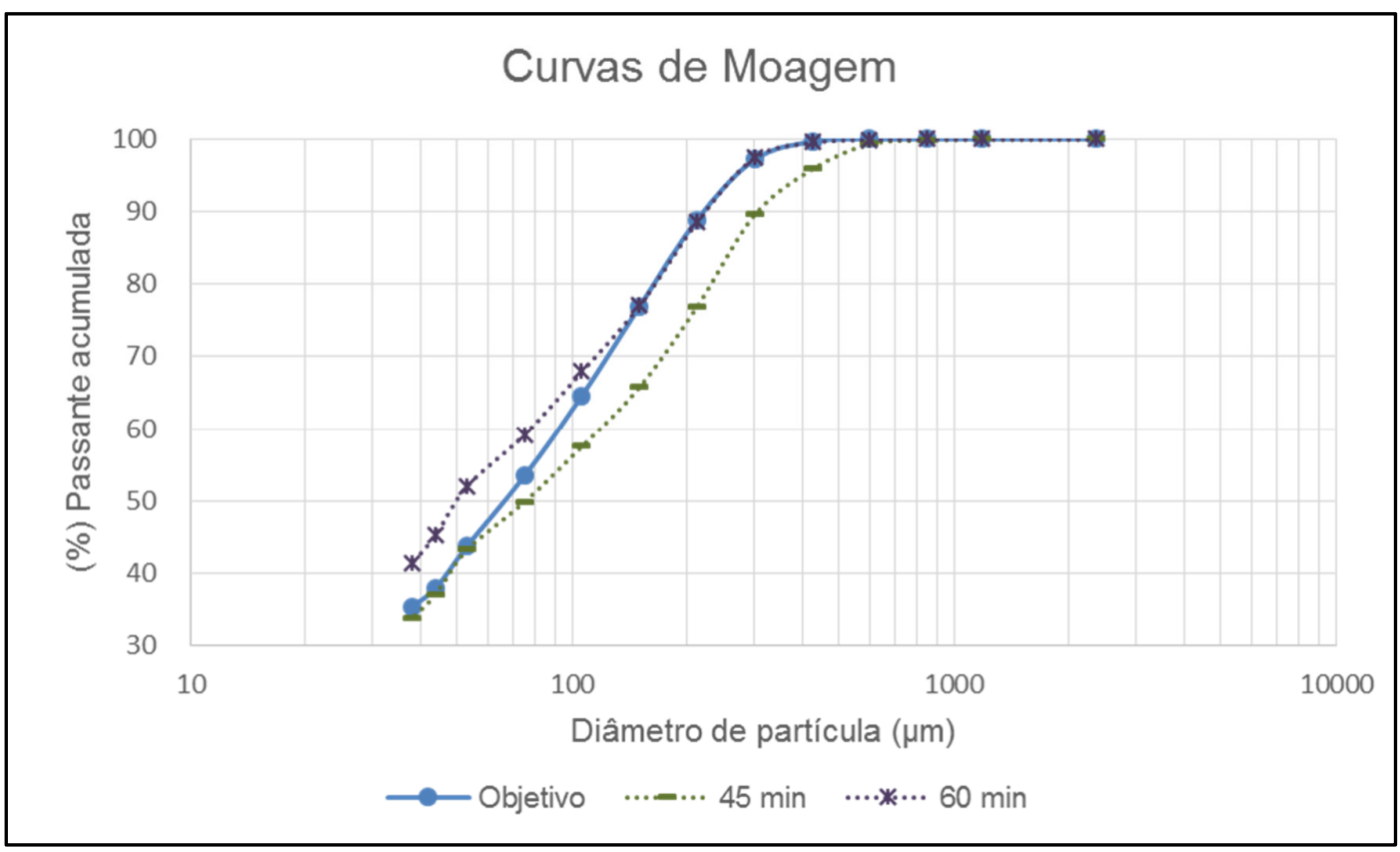

Fonte: Gerado pelo autor

De acordo com práticas usuais de engenharia considerou-se a eficiência de transmissão de energia pelo motor de aproximadamente $85 \%$.

Sendo assim, a potência requerida para o motor do equipamento seria de 540 kW. Neste caso, o equipamento selecionado seria o VTM-800-WB fornecido pela empresa Metso, conforme especificações apresentadas na Tabela 41.

Tabela 41 - Características do moinho vertical selecionado (Fonte: Metso, 2015)

\begin{tabular}{|c|c|c|c|c|c|}
\hline Modelo & $\begin{array}{c}\mathrm{H} \\
\mathrm{mm}(\mathrm{pol})\end{array}$ & $\begin{array}{c}\mathrm{L} \\
\mathrm{mm}(\mathrm{pol})\end{array}$ & $\begin{array}{c}\mathrm{W} \\
\mathrm{mm}(\mathrm{pol})\end{array}$ & $\begin{array}{c}\text { Potência do } \\
\text { motor } \\
\mathrm{kW} / \mathrm{hp}\end{array}$ & $\begin{array}{c}\text { Peso (vazio) } \\
\text { ton }\end{array}$ \\
\hline VTM-800-WB & $13.460(530)$ & $3.560(140)$ & $4.060(160)$ & $597 / 800$ & 100,4 \\
\hline
\end{tabular}




\subsubsection{Prensa de rolos - Cenário 4}

Este cenário considera a inclusão de uma prensa de rolos em etapa prévia à alimentação dos moinhos 01 e 02 , de forma a atingir a capacidade de $243 \mathrm{t} / \mathrm{h}$ na moagem. A Figura 60 apresenta o fluxograma selecionado para esta alternativa.

Figura 60 - Proposta de circuito para cenário 4. Prensa de Rolos

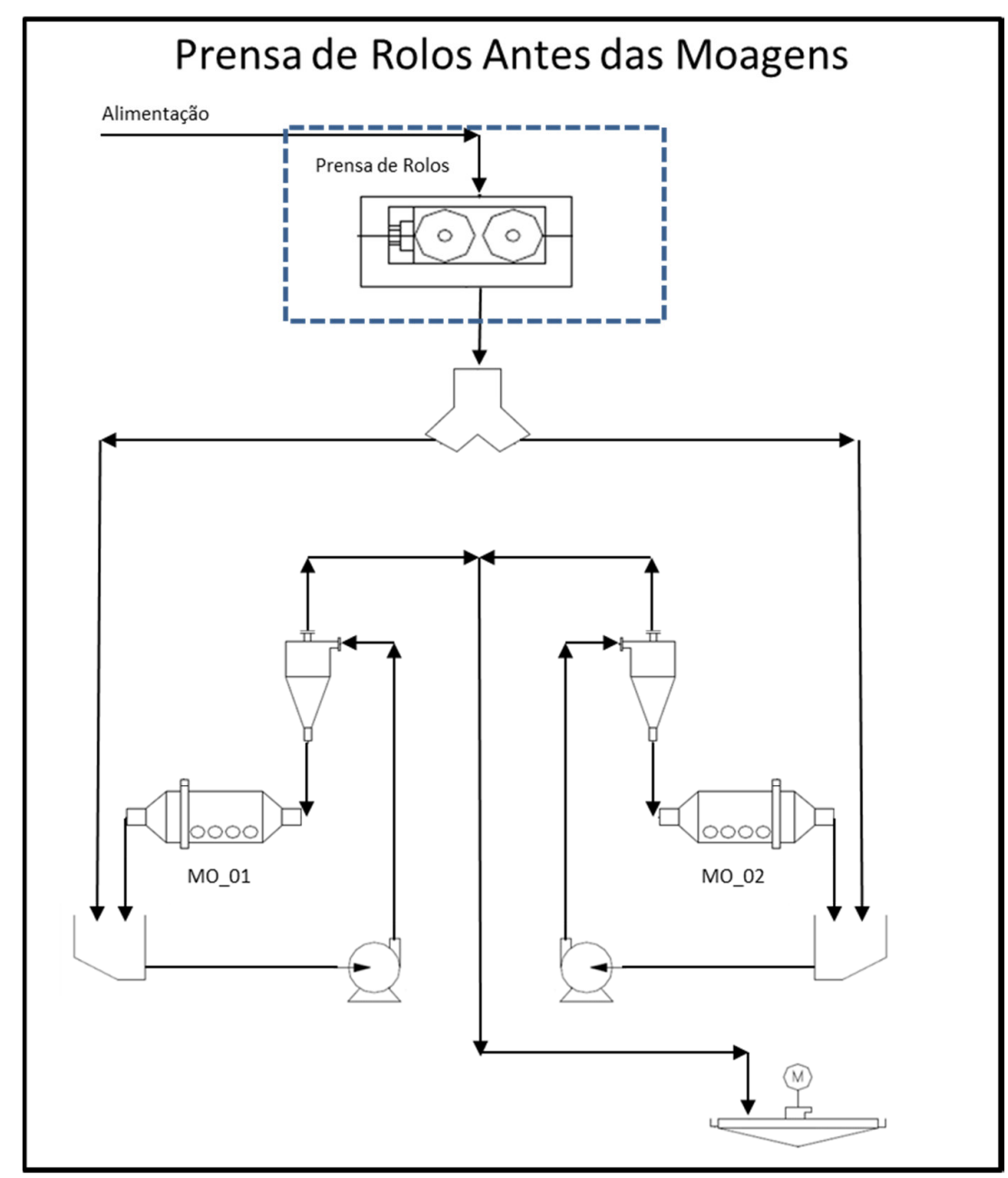

Fonte: Gerado pelo autor

O objetivo da inclusão da prensa de rolos no circuito foi reduzir a granulometria de alimentação do circuito de moagem existente, de forma a não incluir um terceiro moinho para atingir a capacidade estipulada para o circuito de moagem com $\mathrm{P}_{80}$ de produto igual a $109 \mu \mathrm{m}$. Assim, com um produto adequado da prensa de rolos, os dois 
moinhos existentes poderiam operar com capacidade de $243 \mathrm{t} / \mathrm{h}$ de forma a gerar o produto especificado.

O modelo de HPGR foi calibrado com base nos dados resultantes dos ensaios $D W T$ apresentados anteriormente nas seções 5.2 .5 e 6.1.3, bem como resultados dos ensaios CLP, conforme apresentados anteriormente nas seções 5.2.6 e 0.

Apesar de o ensaio de CLP ter sido realizado para três faixas granulométricas distintas, apenas os resultados da fração $+4,75-6,35 \mathrm{~mm}$ foi utilizado. Os outros ensaios foram realizados com a expectativa de gerar valores médios de resultados para alimentar o modelo de forma mais consistente, porém, como 0 P80 de alimentação da prensa de rolos para o cenário é $5785 \mu \mathrm{m}$, a proposta de usar a média de várias frações para esse tipo de modelagem não é usual. Foi, portanto, identificado como prática e melhor opção usar o ensaio em que a granulometria fosse a mais próxima da alimentação do circuito.

Os parâmetros de velocidade tangencial e a distância entre os rolos, que são discutidos a seguir, estão de acordo com as referências bibliográficas apresentadas no Capítulo 3.

A velocidade tangencial máxima de operação foi calculada pela equação (89), sendo obtido o valor de $1,48 \mathrm{~m} / \mathrm{s}$.

Também de acordo com a bibliografia analisada, o menor valor recomendado para abertura entre os rolos é igual a $6,35 \mathrm{~mm}$, tendo por base o top size da alimentação do circuito de 3/8" (9,52 mm).

Com base nas informações acima descritas, bem como os equipamentos listados na Tabela 7, o equipamento selecionado foi uma unidade do modelo $\mathrm{HRC}^{\mathrm{TM}} 1.200$ fornecido pela Metso, dotado de rolos com diâmetro de $1.200 \mathrm{~mm}$ e comprimento de $750 \mathrm{~mm}$.

A energia específica considerada para simulação foi $2,57 \mathrm{kWh} / \mathrm{t}$, valor obtido a partir da Tabela 34 e da energia global do circuito estimada pelo método de Bond. Embora o valor selecionado de energia específica esteja inserido na faixa recomendada ( 1 a $3 \mathrm{kWh} / \mathrm{t}$ ), a consolidação deste parâmetro deveria ser obtida a partir de ensaios em planta piloto, caso a alternativa fosse selecionada para evolução do projeto. 
O valor default do modelo foi adotados para a densidade do leito comprimido, assim como para as demais constantes e coeficientes do modelo de HPGR contido no simulador JKSimMet.

Com todos os parâmetros e premissas definidos foi realizado o cálculo da capacidade específica do equipamento por meio da equação (105).

$$
m=M / D L u
$$

Onde:

$\mathrm{M}=$ alimentação (t/h)

$M=$ capacidade específica $\left(\mathrm{t} . \mathrm{s} / \mathrm{m}^{3} \mathrm{~h}\right)$

$\mathrm{D}=$ diâmetro do rolo $(\mathrm{m})$

$\mathrm{u}=$ velocidade periférica do rolo $(\mathrm{m} / \mathrm{s})$

$\mathrm{L}=$ comprimento do rolo $(\mathrm{m})$

A capacidade específica calculada foi igual a $324 \mathrm{ts} / \mathrm{m}^{3} \mathrm{~h}$, valor classificado pelo autor como coerente em comparação aos praticados em operações com prensas de rolos.

O fluxograma adotado e resultados das simulações realizadas estão apresentados na Figura 62.

As curvas granulométricas obtidas pelas simulações estão apresentadas na Figura 61. 
Figura 61 - Curvas granulométricas da simulação para o circuito de prensa de rolos

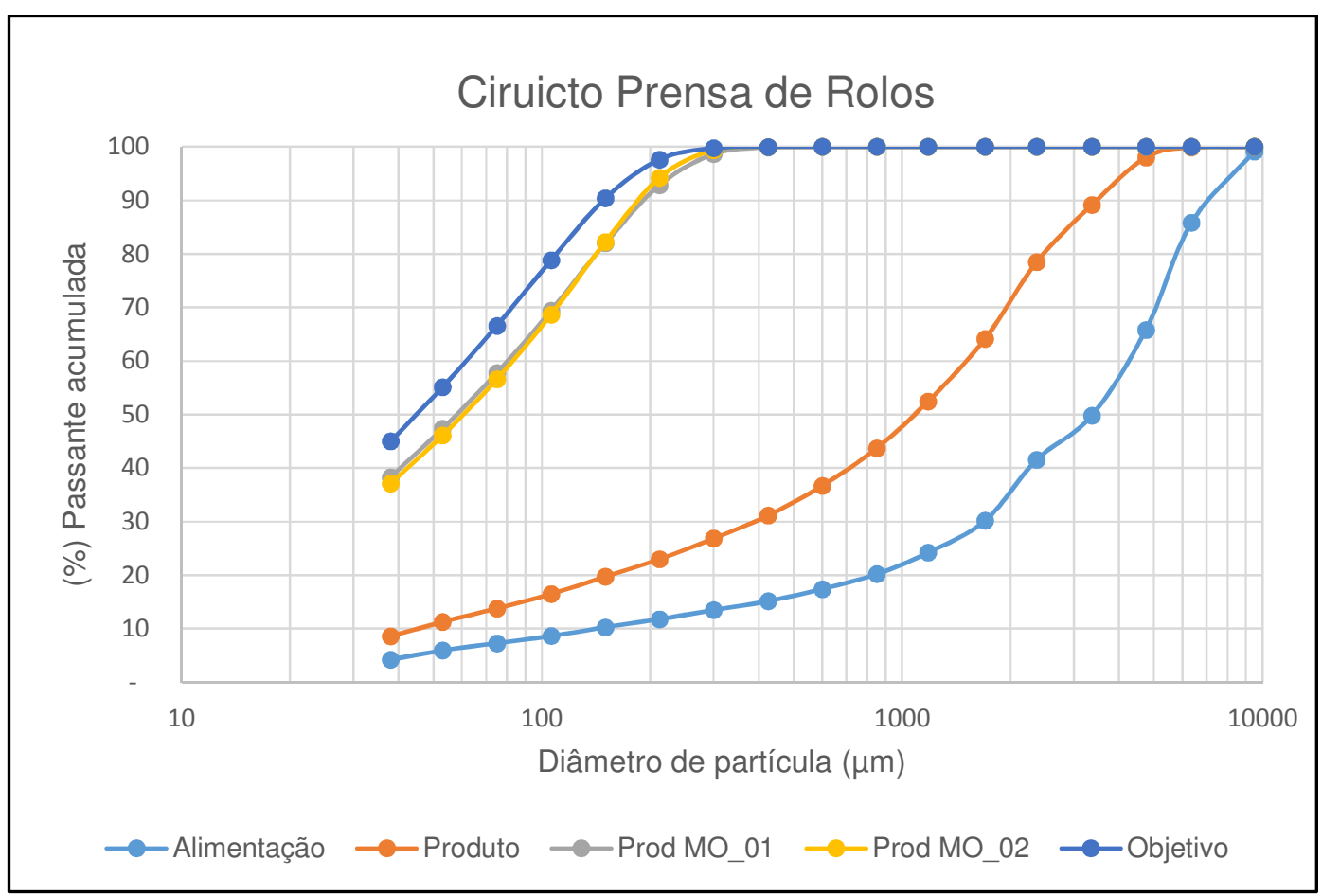

Fonte: Gerado pelo autor

De acordo com a o fluxograma da Figura 63 e o gráfico da Figura 62, para vazão de alimentação estipulada em $243 \mathrm{t} / \mathrm{h}$ foi obtido um produto com $\mathrm{P}_{80}$ final de $141 \mu \mathrm{m}$, valor este mais grosseiro do que o estipulado para a alternativa. No entanto, a razão de redução adotada para a prensa de rolos foi baixa $(2,3)$, uma vez que não foram encontrados na bibliografia revisada dados industriais de granulometria mais fina de produto, que assim permitissem aumentar a razão de redução adotada.

Desta forma, a evolução da alternativa HPGR ficaria dependente de uma campanha piloto consistente, que assim pudesse demonstrar, confirmar e consolidar um desempenho que justificasse a consideração de tal alternativa. 
Figura 62 - Fluxograma do circuito simulado para cenário 4. Prensa de Rolos

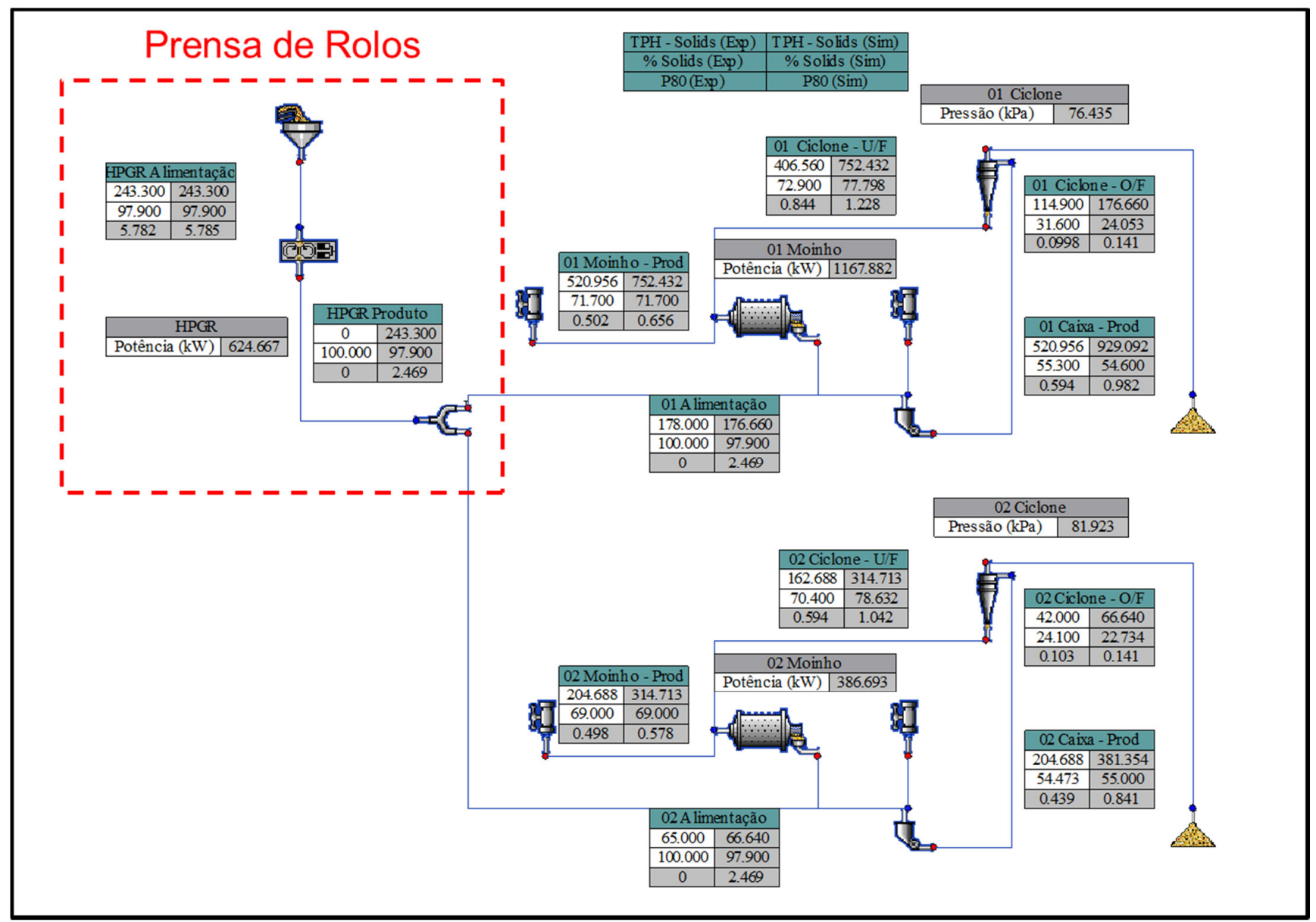

Fonte: Gerado pelo autor 


\section{CONCLUSÕES}

O circuito de moagem da Mineração Serra Grande foi amostrado e, posteriormente, calibrado, modelado e simulado com a utilização do software JKSimMet.

Os ensaios para determinação de parâmetros relativos à cominuição do amostrado minério da MSG foram realizados no Laboratório de Simulação e Controle da Escola Politécnica da USP, gerando assim resultados para os ensaios de DWT, CLP, Wi de Bond e de Remoagem.

Com base nos resultados dos ensaios, foram propostas quatro alternativas de fluxograma, de forma a elevar a capacidade de produção do circuito de moagem dos atuais 1,3 para 2,0 milhões de toneladas por ano. As alternativas simuladas foram as seguintes:

1. Moinho de bolas em série

2. Moinho de bolas em paralelo

3. Moinho vertical

4. Prensa de rolos

Os parâmetros adotados nas simulações de equipamentos de processo, como moinhos, ciclones e prensa de rolos tiveram por base a revisão da literatura específica, conforme descrita neste trabalho.

As alternativas de circuito 1, 2 e 3 acima listadas resultaram em cenários de operação considerados realistas, bem como equipamentos de processo de acordo com especificações sob padrões usuais da indústria. Todas as três primeiras alternativas listadas foram assim consideradas tecnicamente viáveis.

As simulações indicaram que o circuito mais eficiente em termos de utilização de energia foi aquele que utilizou o moinho vertical em aos moinhos já existentes. Ainda em termos de eficiência energética, o circuito que considerou o emprego de um moinho de bolas em série foi classificado em segundo lugar, seguido por uma pequena diferença do cenário com moinho de bolas em paralelo. 
A alternativa 4 de simulação, que incluiu prensa de rolos como etapa prévia à moagem existente não resultou em produto conforme a especificação granulométrica estipulada para a moagem. No entanto, tal alternativa não deve ser aqui descartada, pois relações de redução maiores do que a adotada para a prensa de rolos poderão ser exploradas em campanha específica recomendada para planta piloto e assim resultar em produto adequado da moagem existente para a capacidade de produção estipulada.

Conclui-se, portanto, que existem possibilidades tecnicamente viáveis para obter o aumento da capacidade do circuito de moagem de MSG para 2,0 mtpa e que, para realizar um projeto de expansão, são necessários estudos em outras operações unitárias da planta nas etapas anteriores e posteriores ao processo de moagem. 


\section{REFERÊNCIAS}

BARBATO, C. N.; SAMPAIO, J. A. Tratamento de minérios: práticas laboratoriais. Determinação experimental do índice de trabalho (WI). Rio de Janeiro CETEM/MCT, 2007. cap. 10, p. 179-192.

BAUM, W. et al. HPGR comminution for optimization of copper leaching. Minerals and Metallurgical Processing, 2011. p. 77.

BERALDO, J. L. Moagem de minérios em moinhos tubulares. São Paulo: Edgard Blücher, 1987. $143 p$.

BERGERMAN, M. G. Dimensionamento e simulação de moinhos verticais. Tese (Doutorado) - Escola Politécnica, Universidade de São Paulo, São Paulo, 2013. $282 \mathrm{p}$.

CEMI. Manual de operação do sistema Opt Density. CEMI tecnologia de processos e engenharia. Belo Horizonte, 2015. n. doc: 0013-006

CHAVES, A. P. Teoria e prática do tratamento de minérios: Britagem, peneiramento e moagem. 2. ${ }^{\text {a }}$ ed. São Paulo: Signus, 2003. v. 3. 236 p.

CHIEREGATI, A. C. Amostragem na indústria mineral. Apostila do curso PMI 5030 - Amostragem na indústria mineral - Escola Politécnica, Universidade de São Paulo, São Paulo, 2014.

CHIEREGATI, A. C. Novo método de caracterização tecnológica para cominuição de minérios. Dissertação (Mestrado) - Escola Politécnica, Universidade de São Paulo, São Paulo, 2001. 149 p.

CHIEREGATI, A. C. Reconciliação proativa em empreendimentos mineiros. Tese (Doutorado) - Escola Politécnica, Universidade de São Paulo, São Paulo, 2007. $201 \mathrm{p}$.

CORREIA, J. C. G. Tratamento de minérios. Classificação e Peneiramento. 5. ed. Rio de Janeiro: CETEM/MCT, 2010. cap. 6, p. 257-297. 
DANIEL, M. Energy efficient mineral liberation using HPGR technology. Tese PhD The University of Queensland, 2007. P. 216

DANIEL, M. J.; MORRELL, S. HPGR model verification and scale-up. Minerals Engineering, Autrália, 2004. v. 17, n. 11, p. 1149-1161.

DELBONI JR., H.; SAMPAIO, J. A.; LIMA, R. A. Tratamento de minérios. Circuitos industriais de moagem autógena e semiautógena. 5. ${ }^{a}$ ed. Rio de Janeiro: CETEM/MCT, 2010. cap. 5, p. 215-253.

DELBONI, JR. H. Modelagem e simulação de circuitos de cominuição e classificação. Apostila do curso PMI-5004 - Modelagem e simulação de circuitos de cominuição e classificação. São Paulo; Universidade de São Paulo, 2003.

FINCH, J. A. Modelling a fish-hook in hydrocyclone selectivity curves. Powder Technol, 1983. p. 127-129.

FIRJAN. Perspectivas do custo da energia elétrica para a indústria no Brasil em 2014 e 2015. Nota Técnica, 2014. Disponível em: <www.firjan.org.br>. Acesso em: 06 jun. 2015.

FRANÇOIS-BONGARÇON, D.; GY, P. Critical aspects of sampling in mills and plants: a guide to understanding sampling audits. Journal of the South African Institute of Mining and Metallurgy, 2002. v. 102, n. 8, p. 481-484.

GÓES, M. A. C.; LUZ, A. B.; POSSA, M. V. Tratamento de minérios. Amostragem. 5. ${ }^{\text {a }}$ ed. Rio de Janeiro: CETEM/MCT, 2010. cap. 2, p. 23-44.

GOMES, W. L. Integração de modelos energéticos e de balanço populacional para simulação de moagem em moinhos de bolas. Dissertação (Mestrado) Escola Politécnica, Universidade de São Paulo, São Paulo, 2014. 198 p.

GOOGLEMAPS. via GO-336. Disponível em: $<$ https://www.google.com.br/maps/dir/-14.5668892,-49.9637857/-14.5686468,49.9679398/@-14.5816298,-49.9677394,922a,20y,41.35t> Acesso em: 06 jun. 2015.

GY, P. Sampling for analytical purposes. $1^{\text {st }}$ ed., John Wiley \& Sons, West Sussex, England, 1998. 
JANKOVIC, A. Media stress intensity analysis for vertical stirred mills. Minerals Engineering, 2001. v. 14, n. 10, p. 1177-1186.

JOST, H.; TARSO, P.T.F.O. Gold deposits and occurrences of the Crixás Goldfields, Central Brazil. Mineralium Deposita, 2001, p. 358 -357

KELLERWESSEL, $\mathrm{H}$. High pressure particle bed comminution of mineral raw materials. Aufbereitungstechnik, Bauverlag GmbH, 1993. p. 243-243.

KELSALL, D.F. A further study of hidraulic cyclone. Chemical Engineering Science. 1953. v. 2, p. 254-273.

KLYMOWSKY, R. et al. Selection and sizing of high pressure grinding rolls.Mineral processing plant design, practice and control proceedings, 2002. v. 1, p. 636-668.

LMBA, Gold prices history. Disponível em: <www.lbma.org.uk/pricing-andstatistics>. London Bullion Market Association, Londres. Acesso em: 7 jun. 2015.

LYNCH, A. J.; RAO T. C. Modelling and scale-up of hydrocyclone classifiers. The XI International Mineral Processing Congress, Cagliari, 1975, p. 245-269.

LYNCH, A. J.; RAO, T. C. Digital computer simulation of comminution systems - Comm. Min. Metall. Cong., 8 Austrália, N. Z., Proceedings. 1965. v. 6.

METSO MINING AND CONSTRUCTION. Basics in Mineral Processing. 2015. $352 \mathrm{p}$.

MORLEY, C. Flowsheets for HPGR. Proceedings of the SAG Conference, University of British Columbia, Vancouver. 2006. p. 172-189.

MORLEY, C. HPGR-FAQ. Journal of the Southern African Institute of Mining and Metallurgy, 2010. p. 107-115.

MORRELL, S., SHI, F., TONDO, L. A., 1997. Modelling and scale-up of high pressure grinding rolls. Proceedings of the XX International Mineral Processing Congress (IMPC), Alemanha, 1997. 
MÖRSKY, P.; KLEMETTI, M.; KNUUTINEN, T. A comparison of high pressure roller mill and conventional grinding. Preprints XIX IMPC São Francisco, EUA, 1995.

NAGESWARARAO, K. Further developments in the modelling and scale-up of industrial hydrocyclones, Ph.D. Thesis, University of Queensland (JKMRC), Brisbane, Australia, 1978.

NAGESWARARAO, K.; WISEMAN, D. M.; NAPIER-MUNN, T. J. Two empirical hydrocyclone models revisited. Minerals Engineering, The University of Queensland, Brisbane, 2004. v. 17, n. 5, p. 671-687.

NAPIER-MUNN, T. J. et al. Mineral comminution circuits: their operation and optimization. Indoorroopilly: Julius Kruttschnitt Mineral Research Centre/University of Queensland, 1996. 413 p.

NORGATE, T. E.; WELLER, K. R. Selection and operation of high pressure grinding rolls circuits for minimum energy consumption. Minerals Engineering, 1994. p. 1253-1267.

NUNES, A. C. Sistema computadorizado para ajuste de balanço de massas e metalúrgico. Dissertação (Mestrado) - Escola Politécnica, Universidade de São Paulo, São Paulo, 1992. 76 p.

OLIVEIRA, R. N. M. Análise de desempenho do HRCTM HPGR em circuito piloto. Dissertação (Mestrado) - Escola Politécnica, Universidade de São Paulo, São Paulo, 2016. 173 p.

OUTOTEC. Tecnologia de moagem Outotec ${ }^{\circledR}$. Copyright ${ }^{\odot}$ Outotec Oyj. Finlândia, 2012. $12 \mathrm{p}$.

PATZELT, N.; KNECHT, H.; BAUM, W. Case made for high-pressure rollgrinding in gold plants. In: International Journal of Rock Mechanics and Mining Sciences and Geomechanics, 1995. 337 p.

PITARD, F. F. Pierre Gy's sampling theory and sampling pratice: heterogeneity sampling correctness, and statistical process control. $2^{\text {nd }}$ ed., CRC Press, Boca Raton, Florida 1993. 
PLITT, L. R. A mathematical model of the hydrocyclone classifier, CIM Bulletin, 1976. v. 69 , n. 776 , p. $114-123$.

ROWLAND, C. A. Ball Mill Scale-up-Diameter Factors., Advances in Mineral Processing. Society of Mining Engineers/AIME, 1986. p. 605-617.

ROWLAND, C. J. Selection of rod mills, ball mill, pebble mill and regrind mills. In: Andrew L. Mular and Gerald V. Jergensen, II (Editores) Design and installation of comminution circuits. Society of Mining Engineers. Nova York, 1982. p. 393-438.

SAMPAIO, J. A.; DA SILVA, F. A. N. G. Tratamento de minérios: práticas laboratoriais. Determinação das densidades de sólidos e de polpas. Rio de Janeiro CETEM/MCT, 2007. cap. 2 e 3, p. 37-72.

SCHÖNERT, K. A first survey of grinding with high-compression roller mills. International Journal of Mineral Processing, 1988. v. 22, n. 1, p. 401-412.

SHI, F. et al. Comparison of energy efficiency between ball mills and stirred mills in coarse grinding. Minerals Engineering, 2009. v. 22, n. 7, p. 673-680.

VALADÃO, G. E. S.; MONTENEGRO, L. C. M.; GALERY, R. Introdução ao tratamento de minérios. Balanço de Materiais. Belo Horizonte: Editora UFMG, 2007. cap. 2, p. 9-19.

VAN DER MEER, F. P.; MAPHOSA, W. High pressure grinding moving ahead in copper, iron, and gold processing. Journal of the Southern African Institute of Mining and Metallurgy, 2012. p. 637-647.

VIANA, I. L. Avaliação do comportamento dos minérios processados na planta metalúrgica da AGA Serra Grande: Determinação dos parâmetros ótimos do beneficiamento e extração do ouro. Projeto de encerramento do programa trainee AngloGold Ashanti, Mineração Serra Grande, Crixás, 2013. 49 p.

WALKER, W.H. ET AL. Principles of chemical engineering. MacGraw Hill Nova York, 1937.

WANG, C. Comparison of HPGR-ball mill and HPGR-stirred mill circuits to the existing AG/SAG mill-ball mill circuits. Thesis (Master) - University of British Columbia, Vancouver, 2013. 169 p. 
WATSON, S., BROOKS, M., KCGM evaluation of high pressure grinding roll technology. Fifth Mill Operators' Conference, Roxby Downs SA, 1994, p. 69-83.

WEIR MINERALS. Cavex Hirociclones: Máxima eficiência e menor custo de operação (WMB/HIDROCICLONES - 03/2011), São Paulo, 2011. 6 p.

WHITEN, W. J. Ball mill simulation using calculators. Proceedings AusIMM, 1976. p. 47-53.

WIKIPEDIA; Crixás - Wikipédia, a enciclopédia livre. Disponível em:

<http://pt.wikipedia.org/wiki/Crixás>. Acesso em: 5 maio, 2015.

WILLS, B. A. Wills' mineral processing technology: an introduction to the practical aspects of ore treatment and mineral recovery. Amsterdam Elsevier/BH Boston, 2008. 444 p. 


\section{APÊNDICE 1 - FOTOGRAFIAS DE EQUIPAMENTOS E PONTOS DE TOMADA DE AMOSTRAS DA PLANTA DA MSG}

Figura 63 - Fotografias equipamentos da planta de MSG

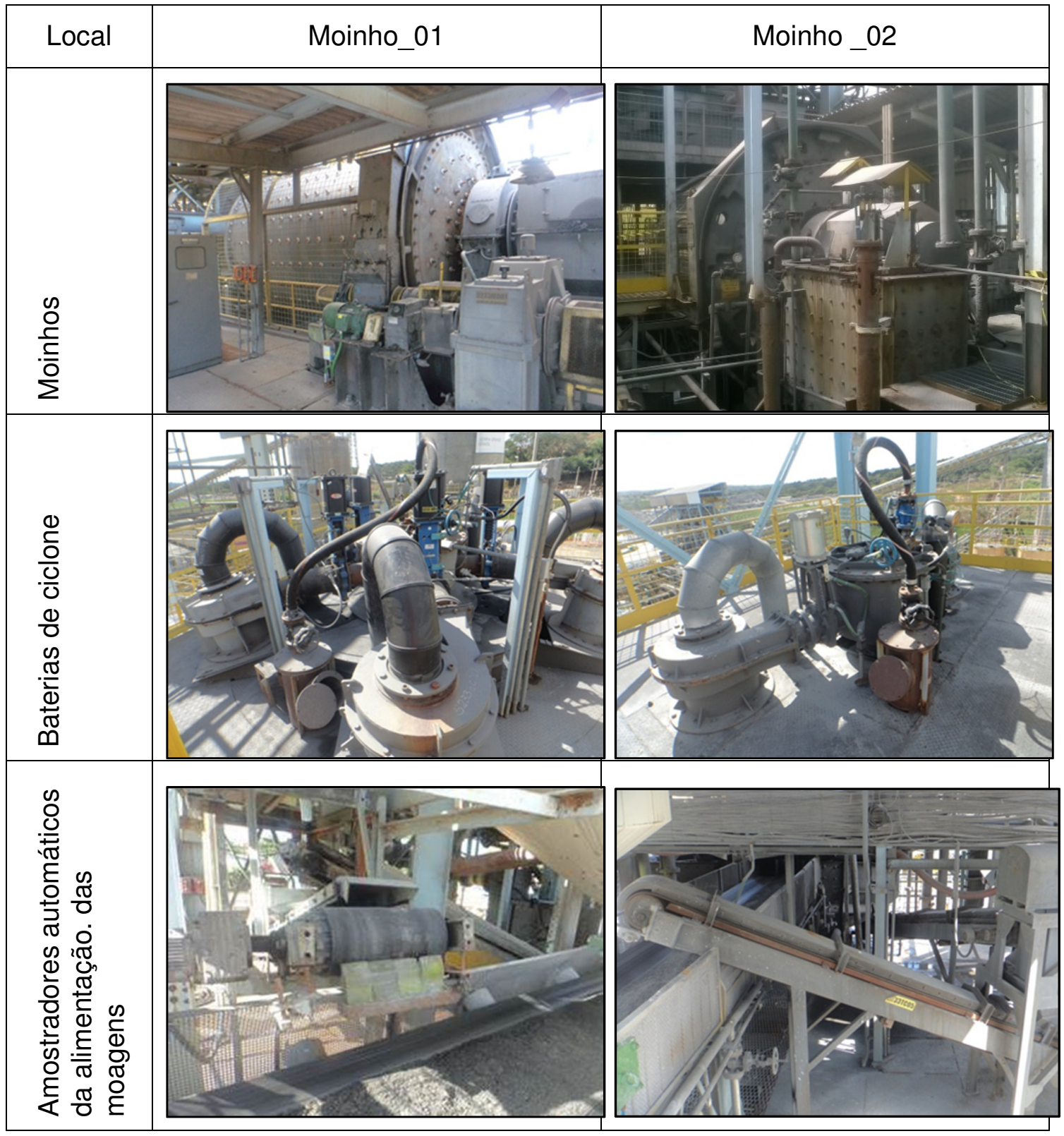

Fonte: Acervo de fotos do autor 


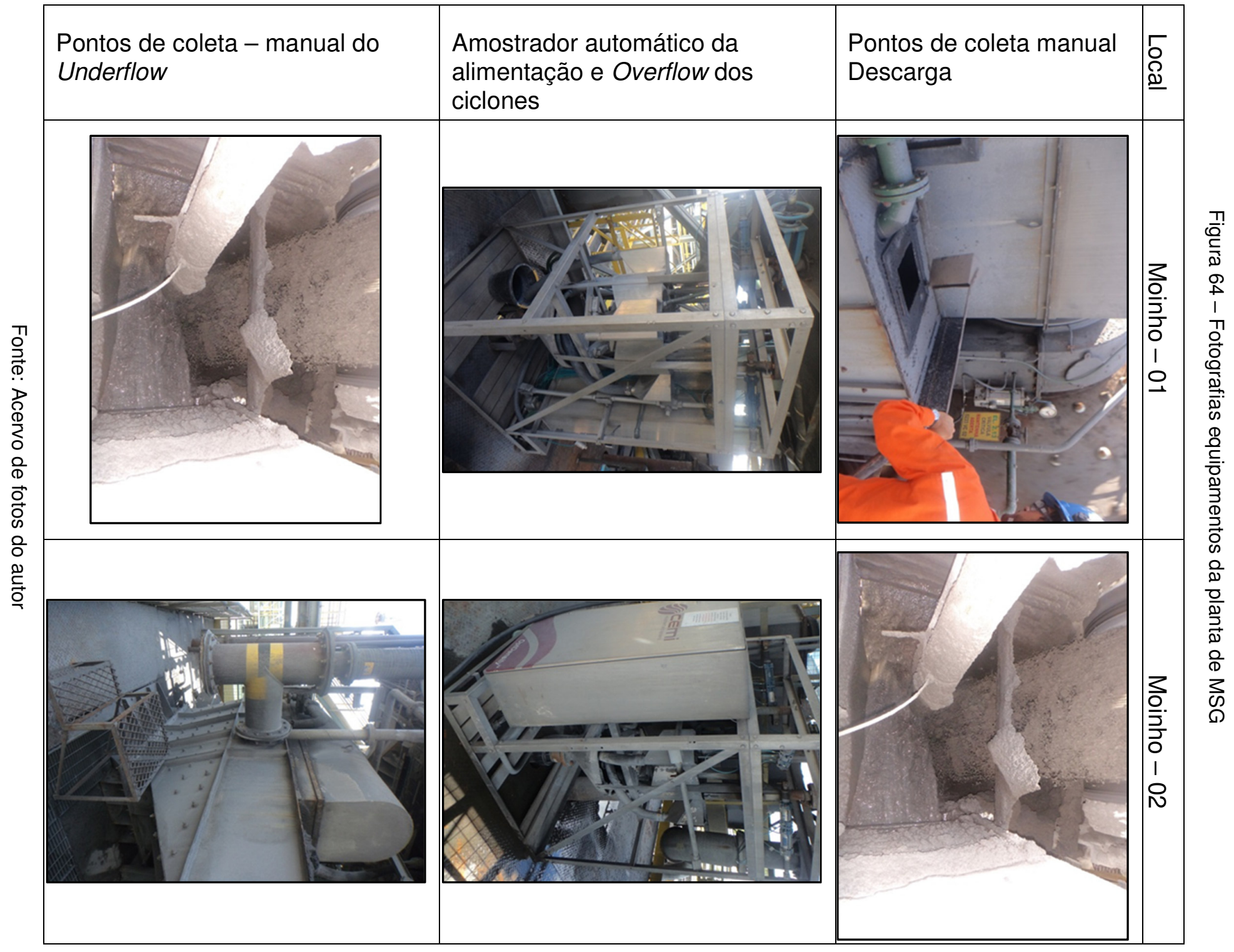




\section{APÊNDICE 2 - PARÂMETROS MEDIDOS DURANTE PERÍODO DE AMOSTRAGEM}

Gráficos gerados automaticamente pelo sistema de supervisão e controle durante o período de amostragem dos circuitos das Moagens 01 e 02

Figura 65 - Alimentação nova do Moinho 01 durante amostragem

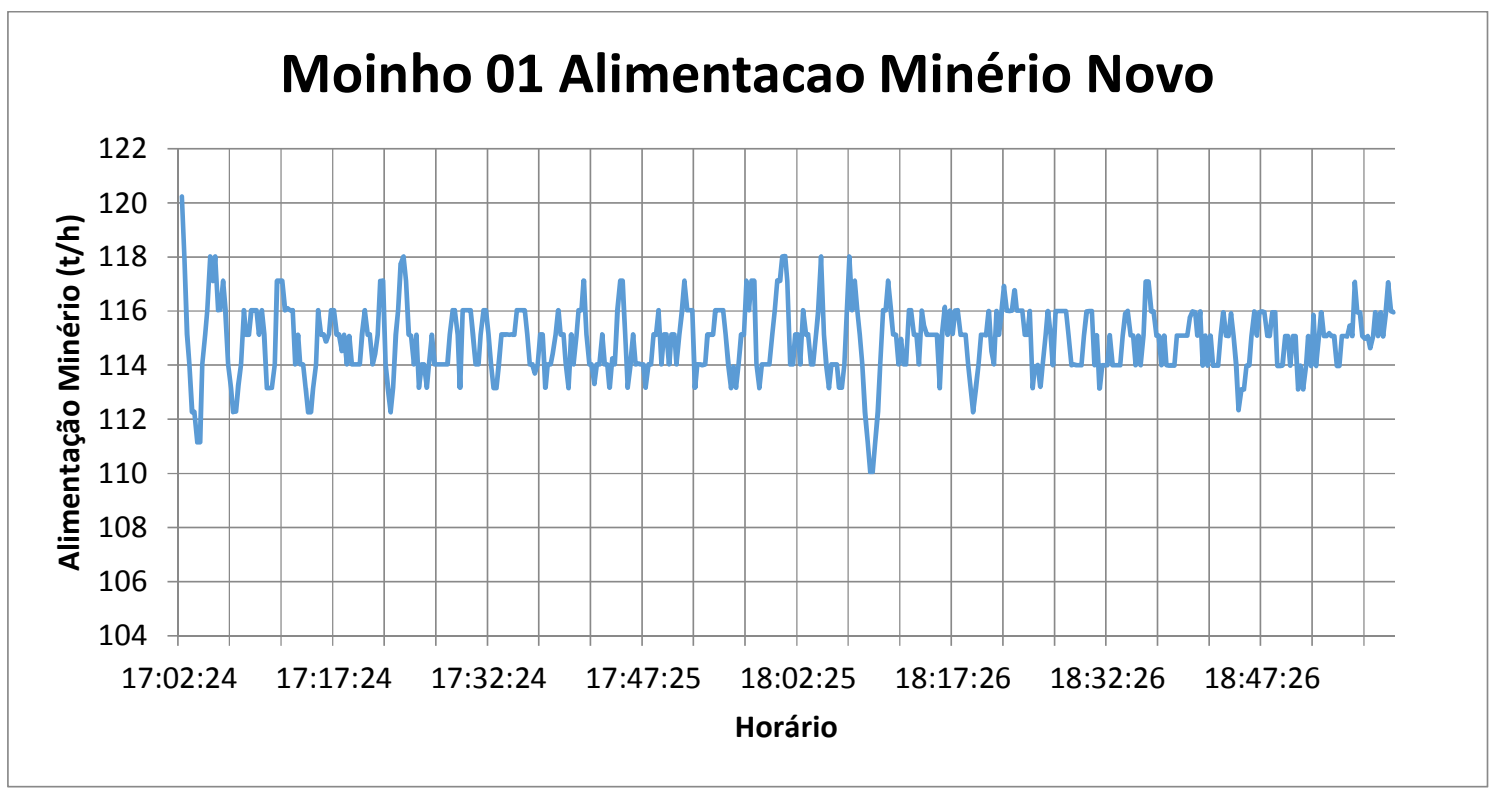

Figura 66 - Densidade na caixa de descarga do Moinho 01 durante amostragem

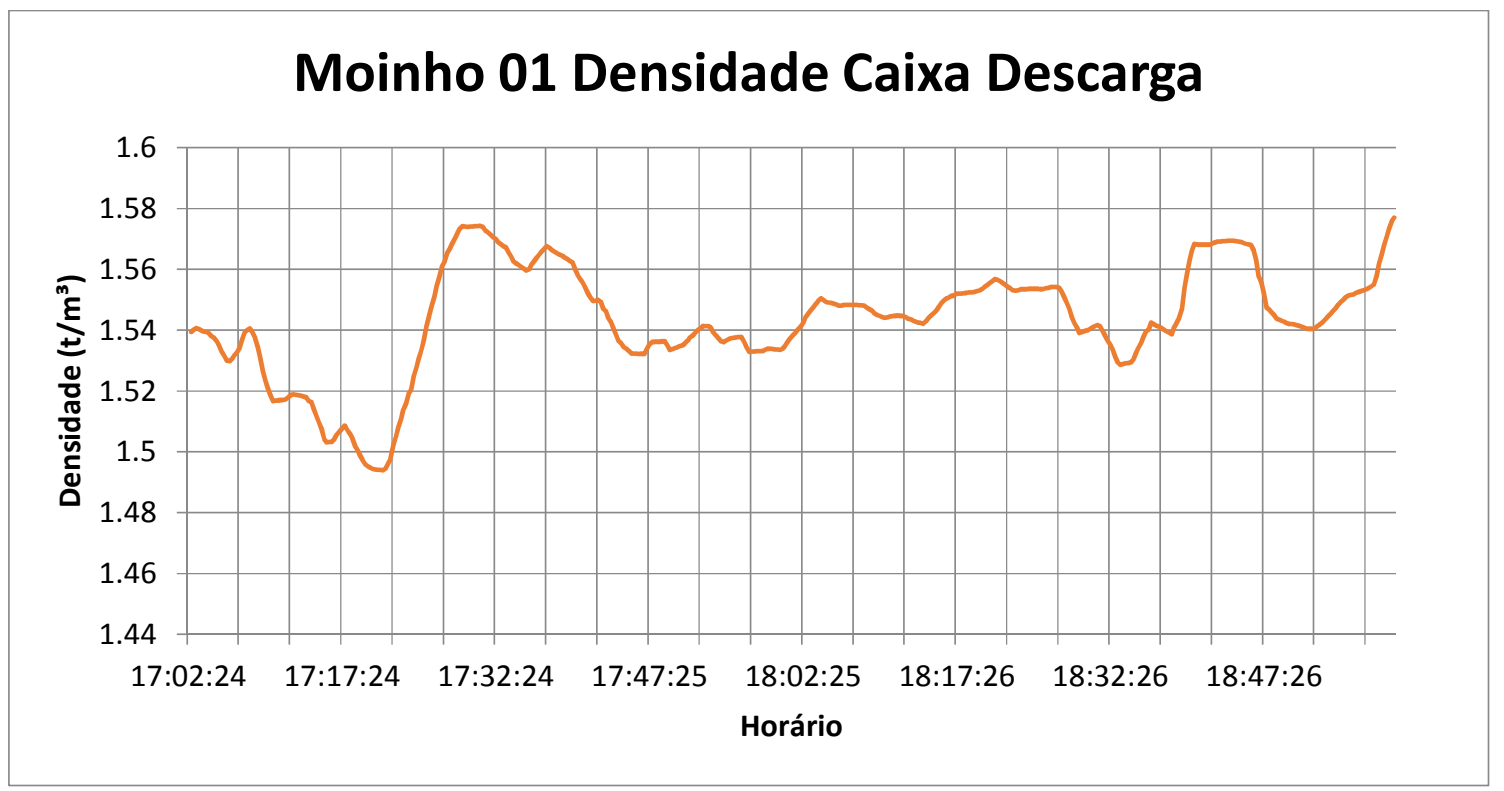


Figura 67 - Vazão de água na caixa de descarga do Moinho 01 durante amostragem

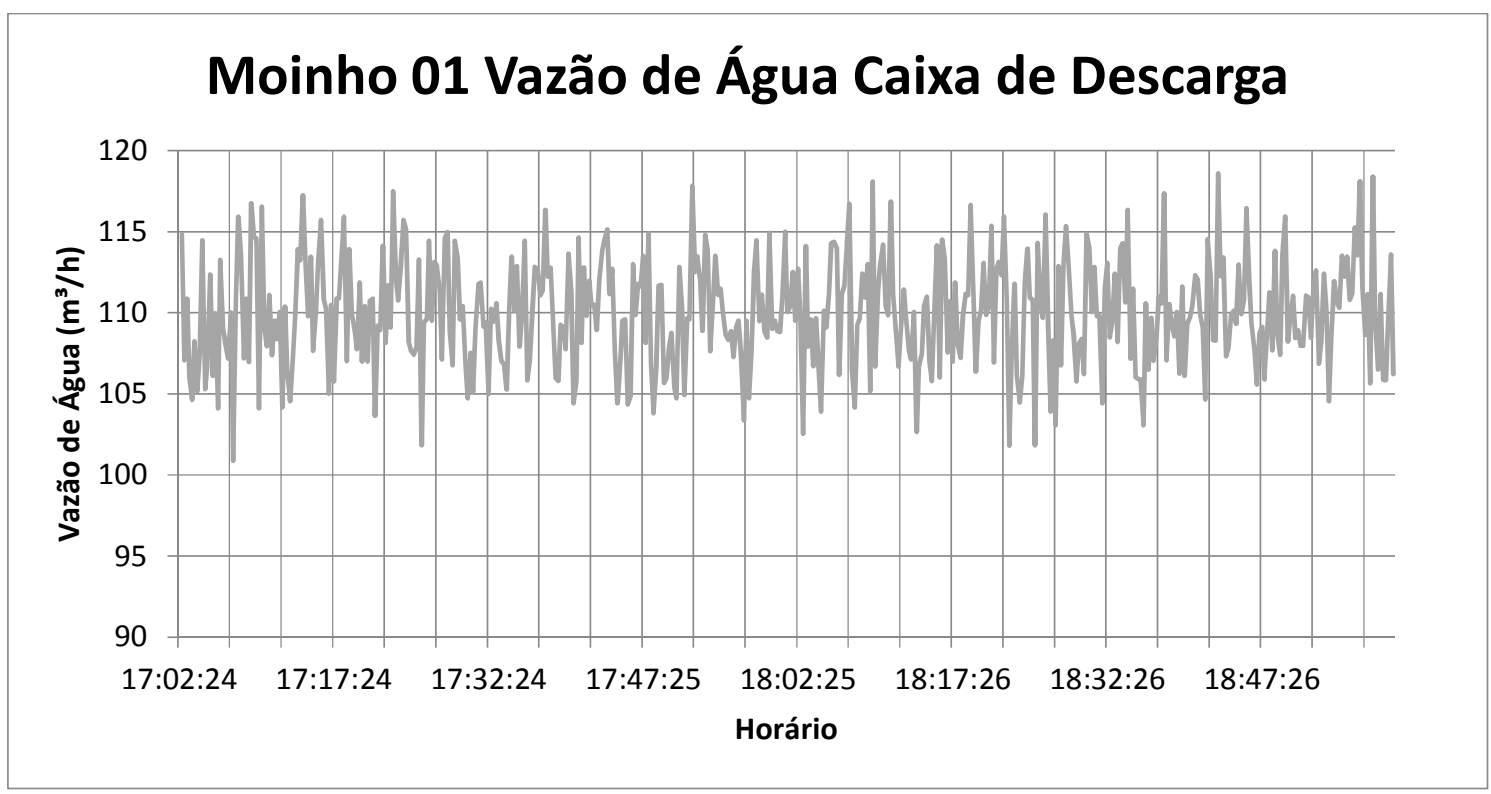

Figura 68 - Densidade de alimentação dos ciclones do Moinho 01 durante amostragem

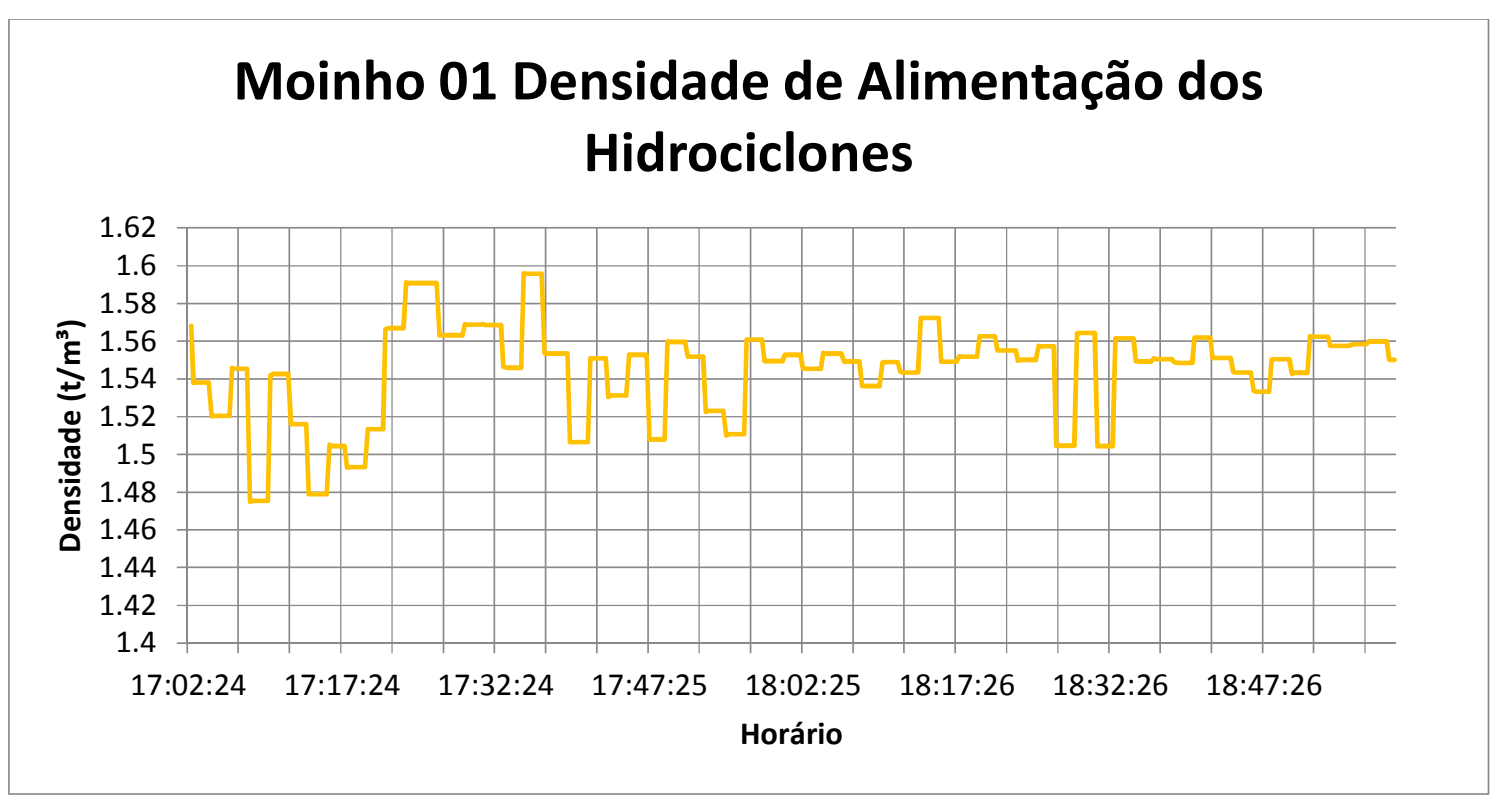


Figura 69 - Densidade do overflow dos ciclones do Moinho 01 durante amostragem

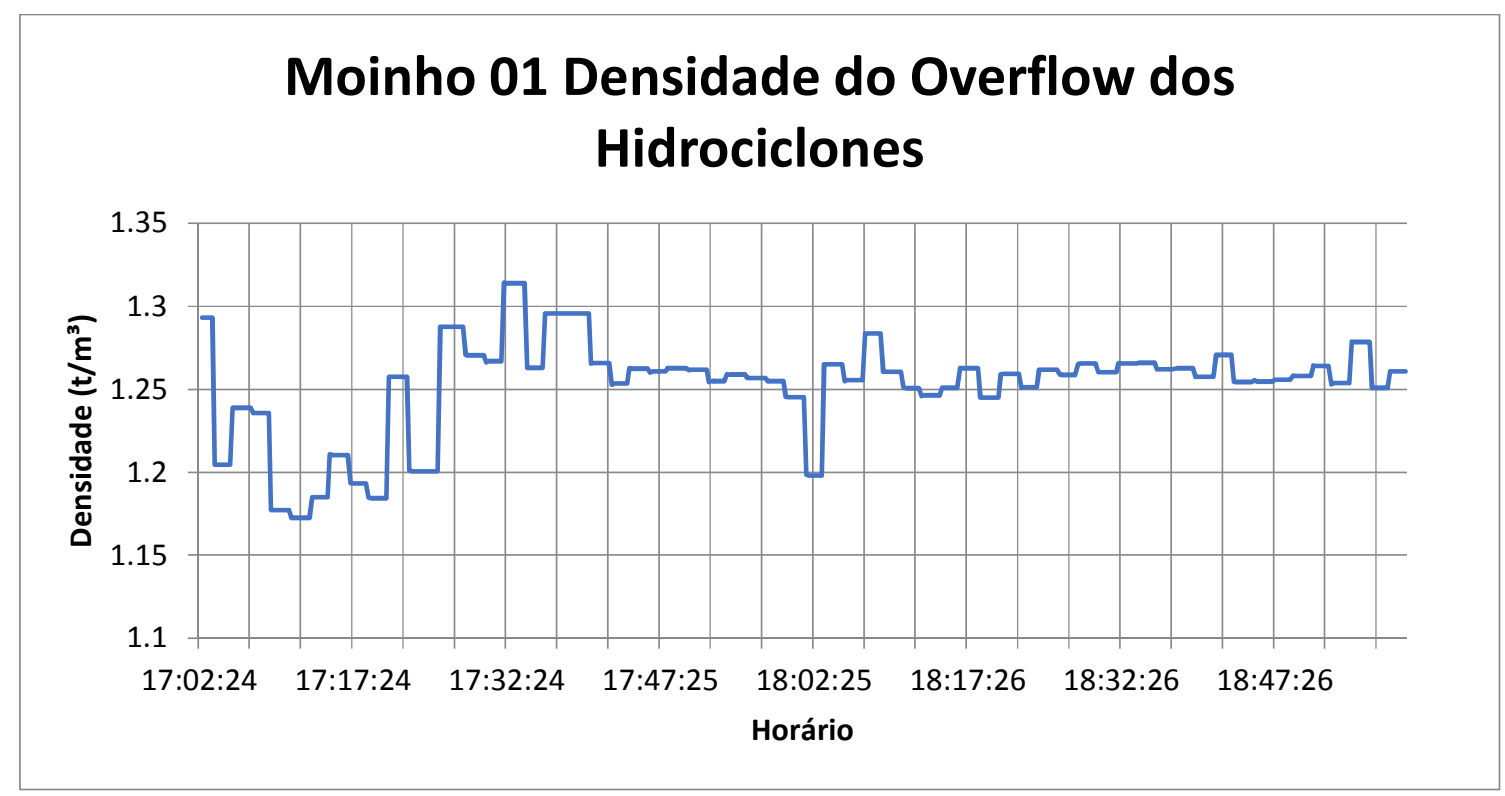

Figura 70 - Pressão nos ciclones do Moinho 01 durante amostragem

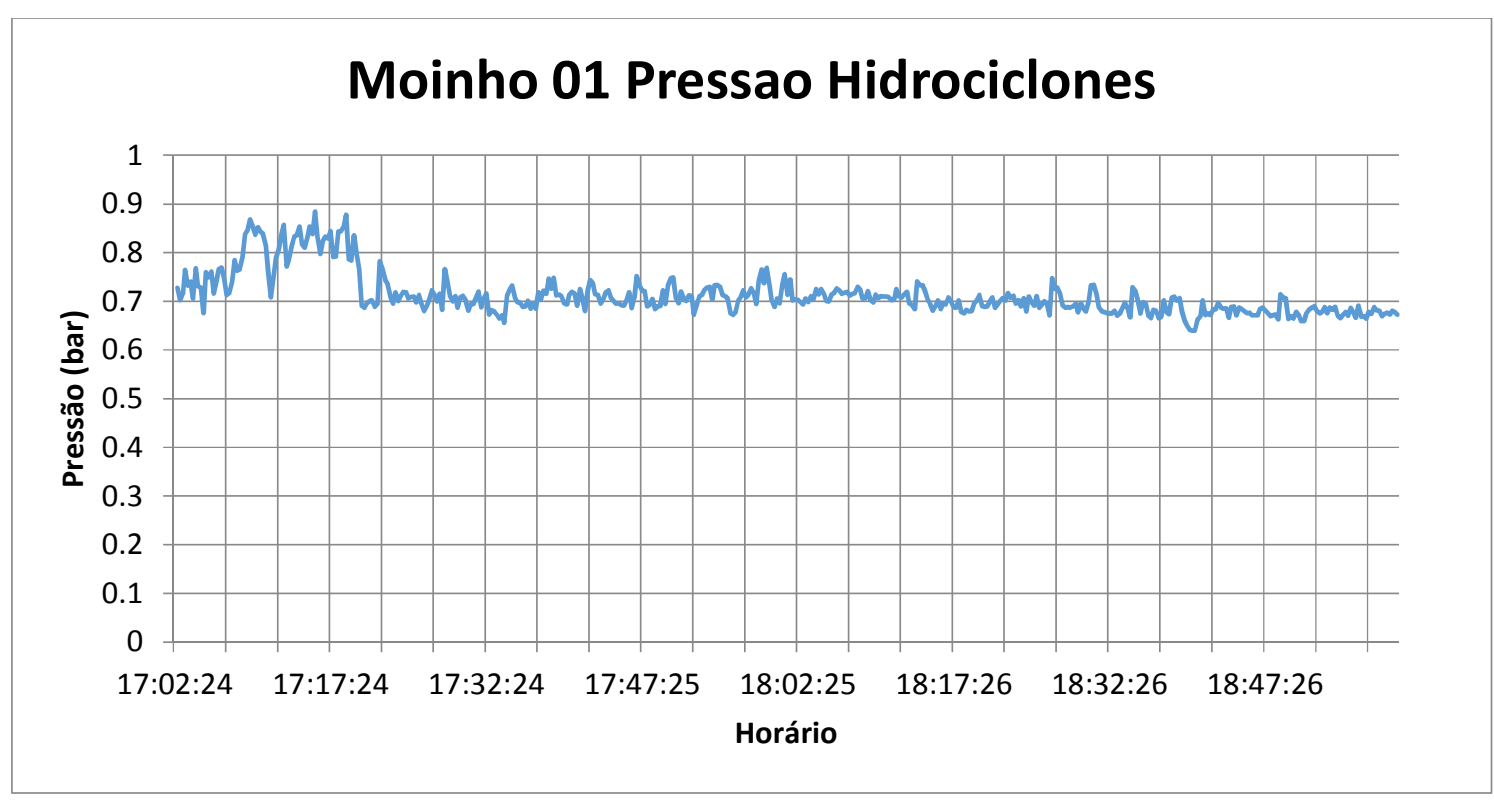


Figura 71 - Potência do motor do Moinho 01 durante amostragem

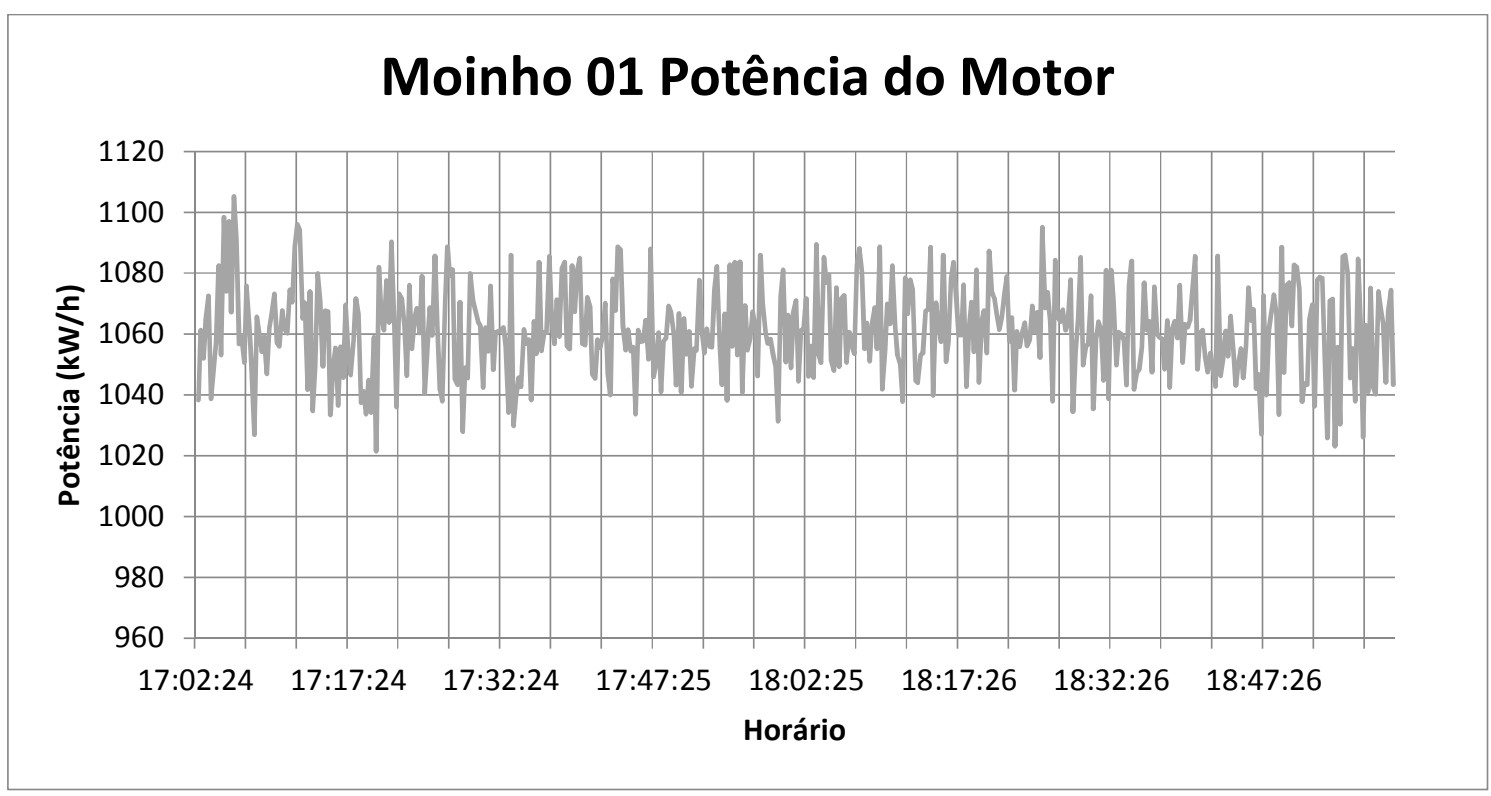

Figura 72 - Alimentação nova do Moinho 02 durante amostragem

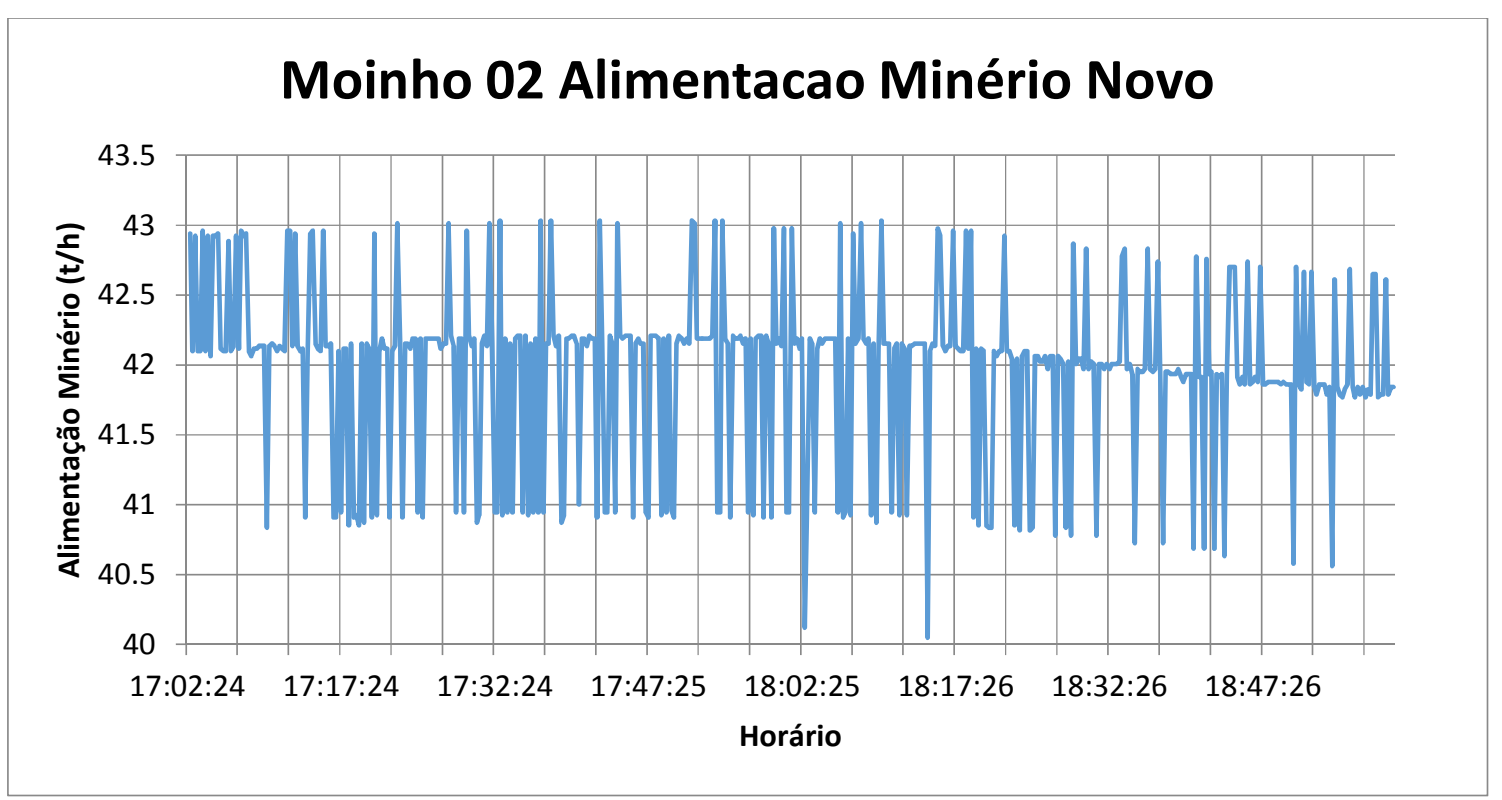


Figura 73 - Densidade da caixa de descarga do Moinho 02 durante amostragem

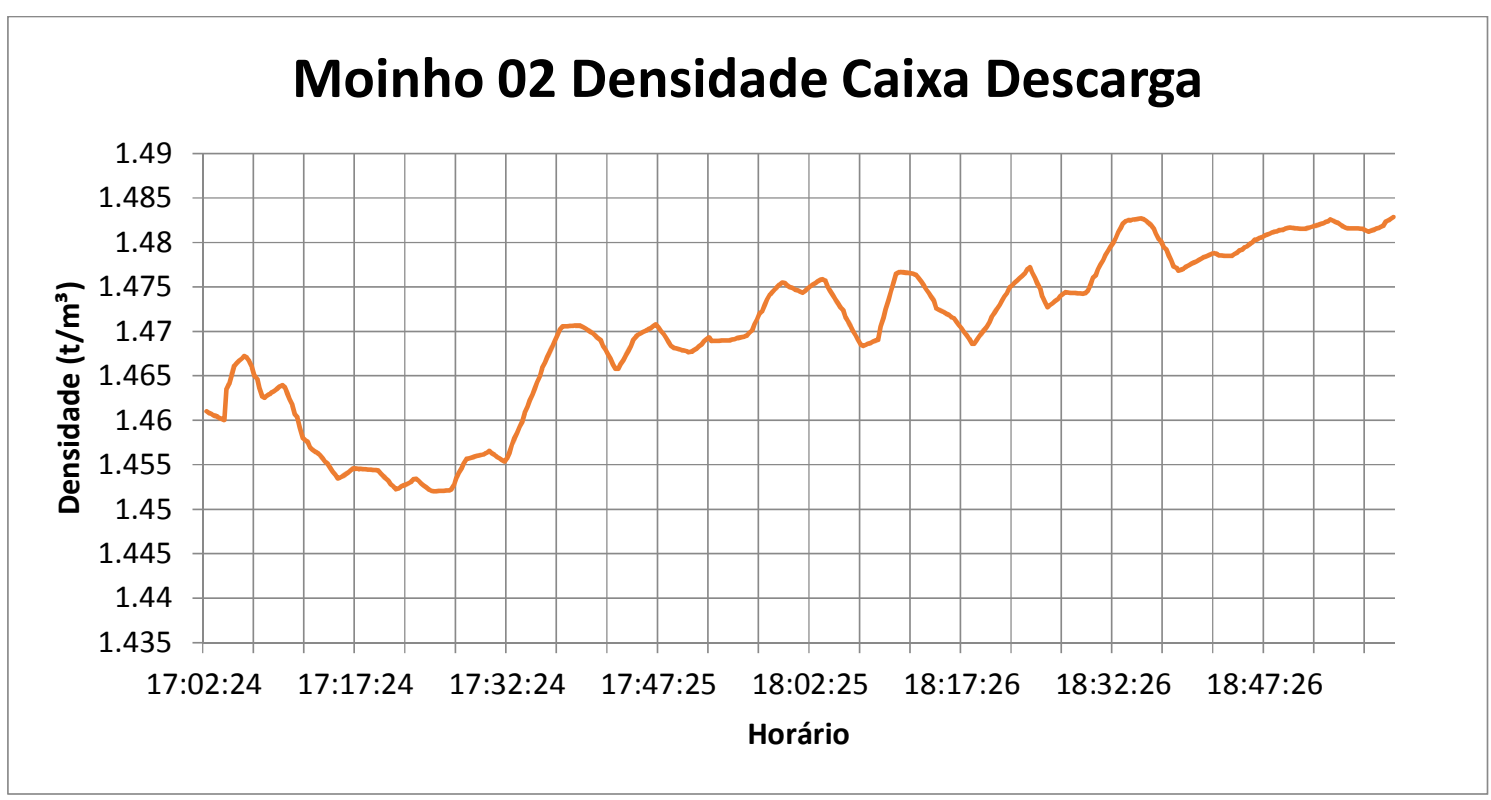

Figura 74 - Vazão de água na caixa de descarga do Moinho 02 durante amostragem

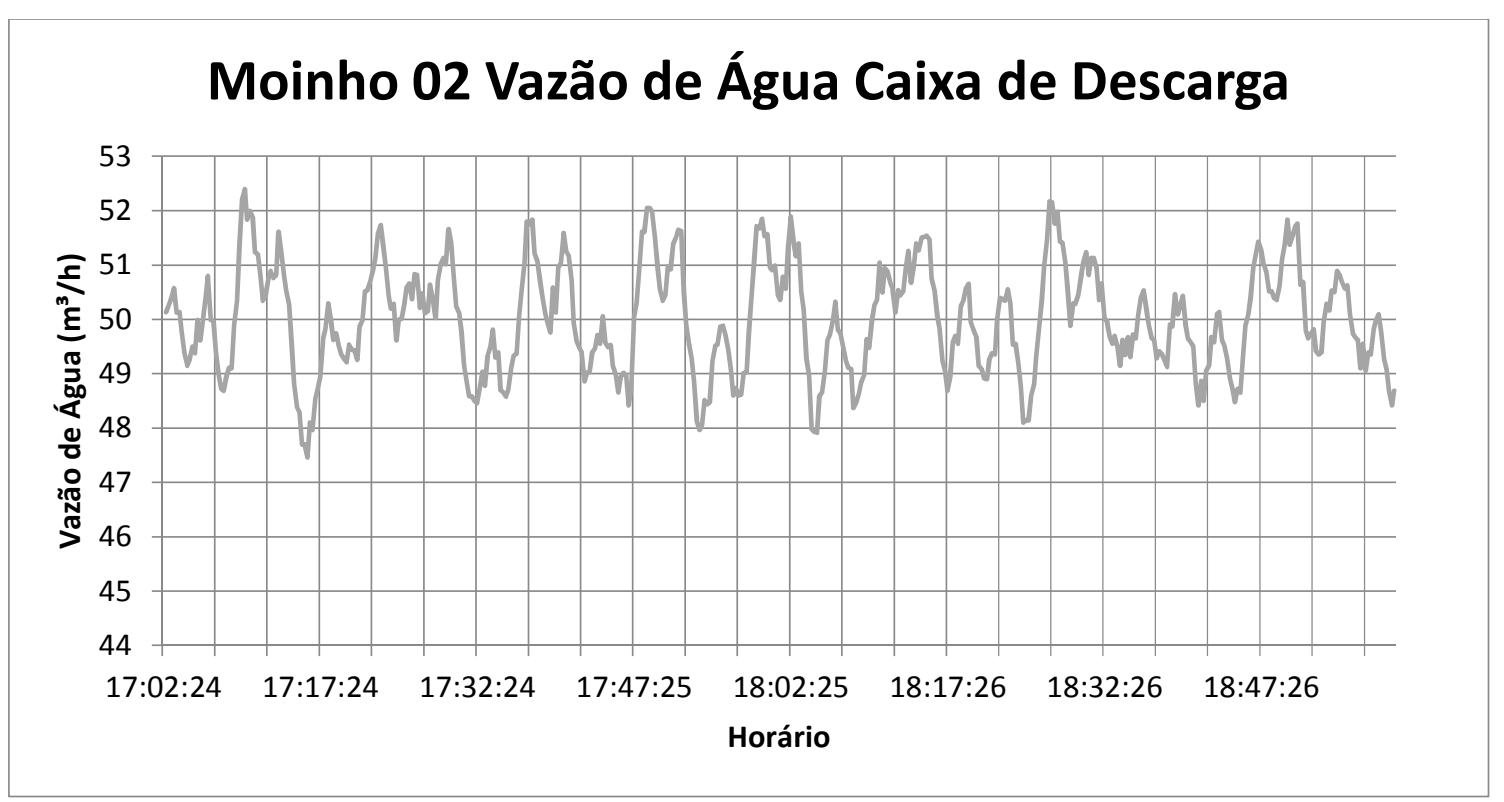


Figura 75 - Densidade de alimentação dos ciclones do Moinho 02 durante amostragem

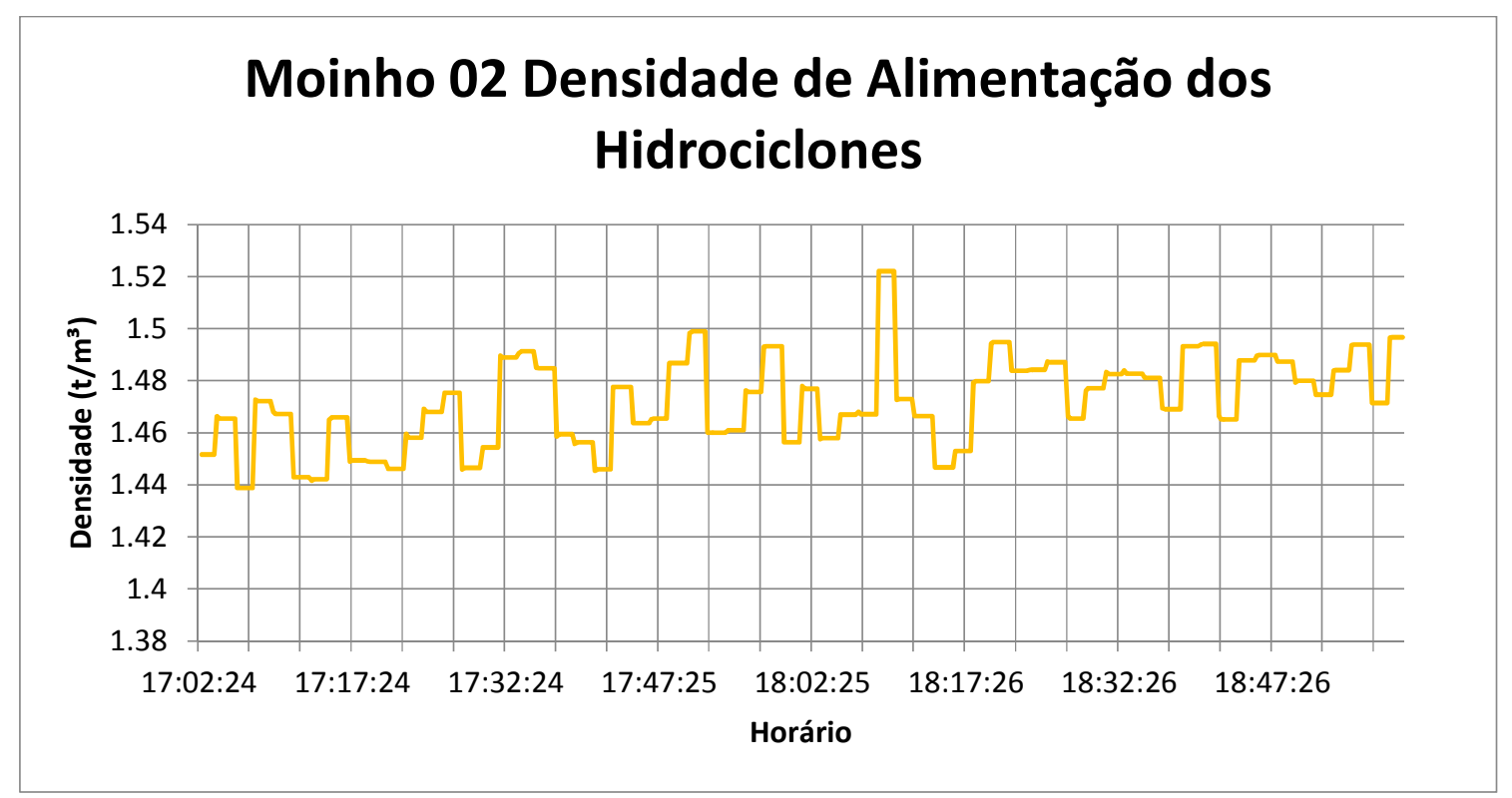

Figura 76 - Densidade do overflow dos ciclones do Moinho 02 durante amostragem

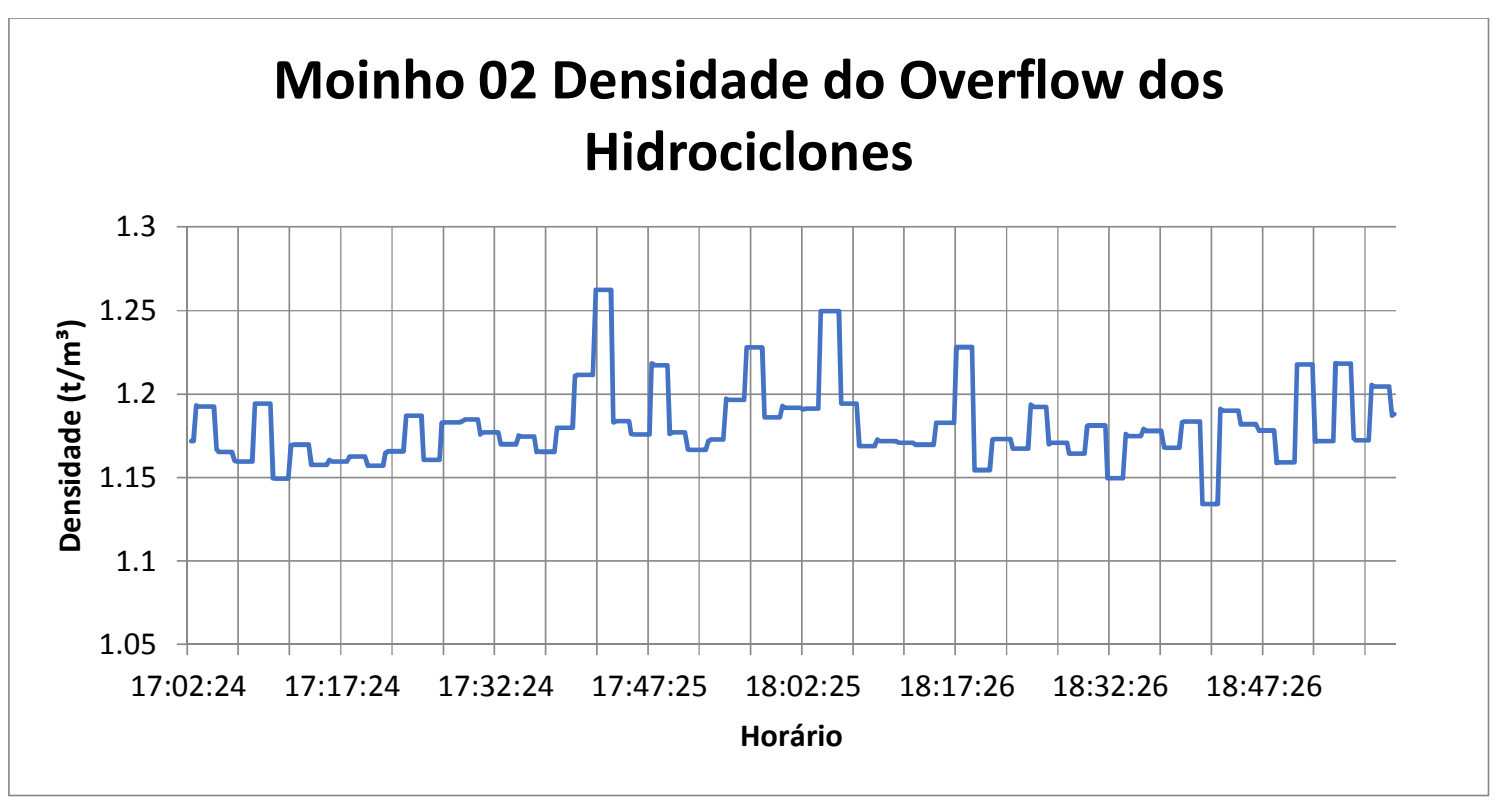


Figura 77 - Pressão dos ciclones do Moinho 02 durante amostragem

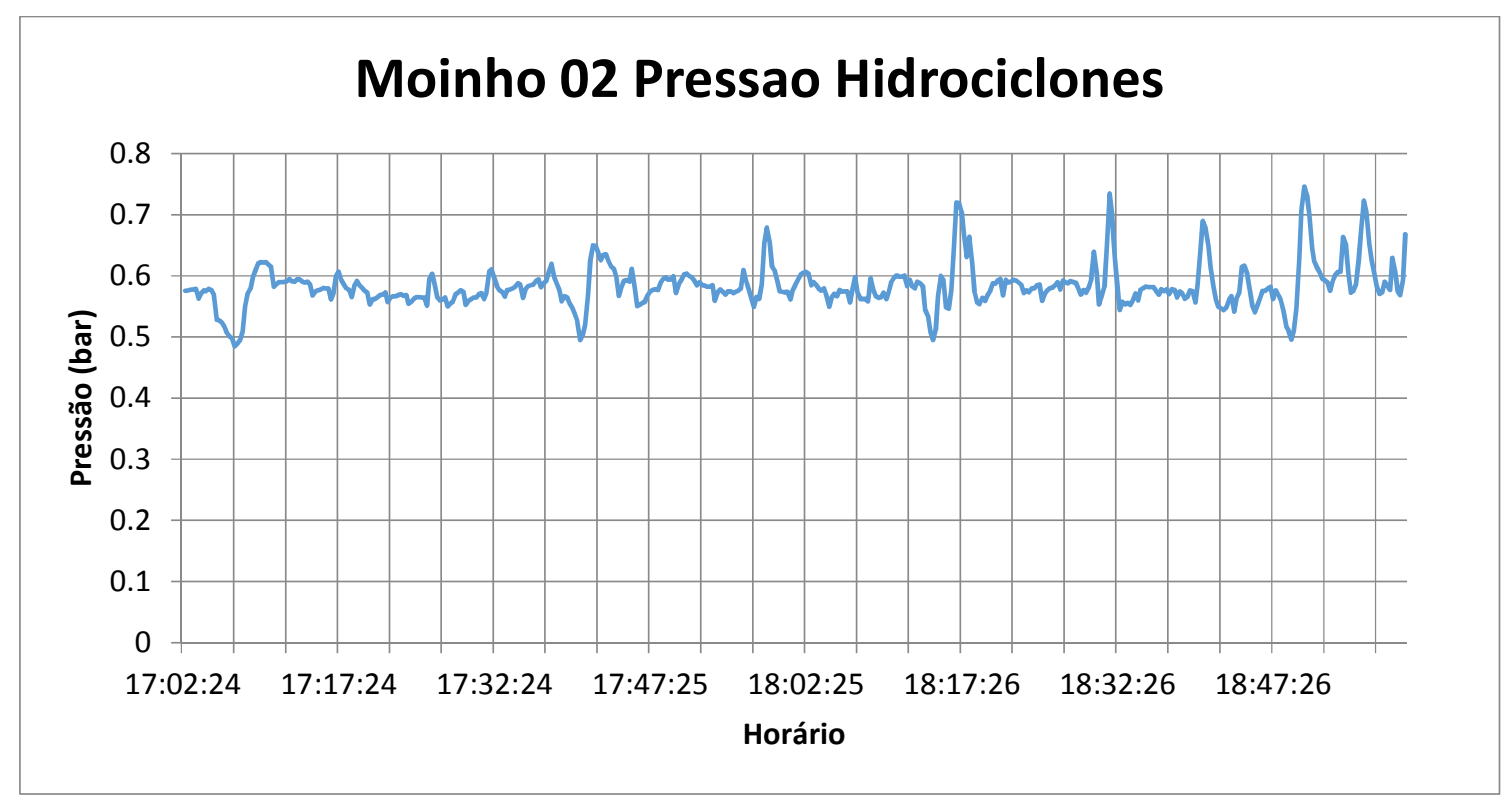

Figura 78 - Potência do motor do Moinho 02 durante amostragem

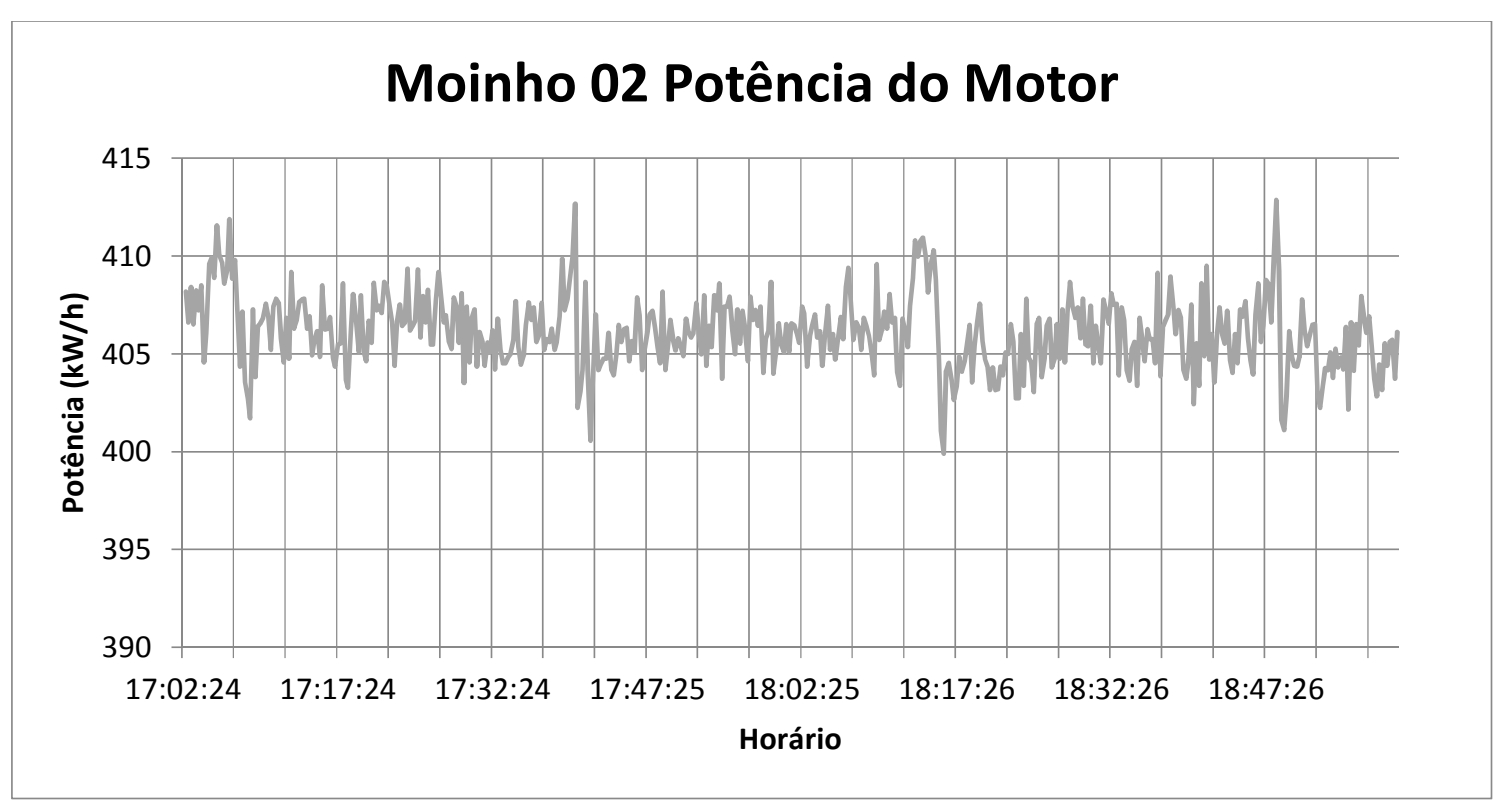




\section{APÊNDICE 3 - RESULTADOS DOS ENSAIOS DE JARRO}

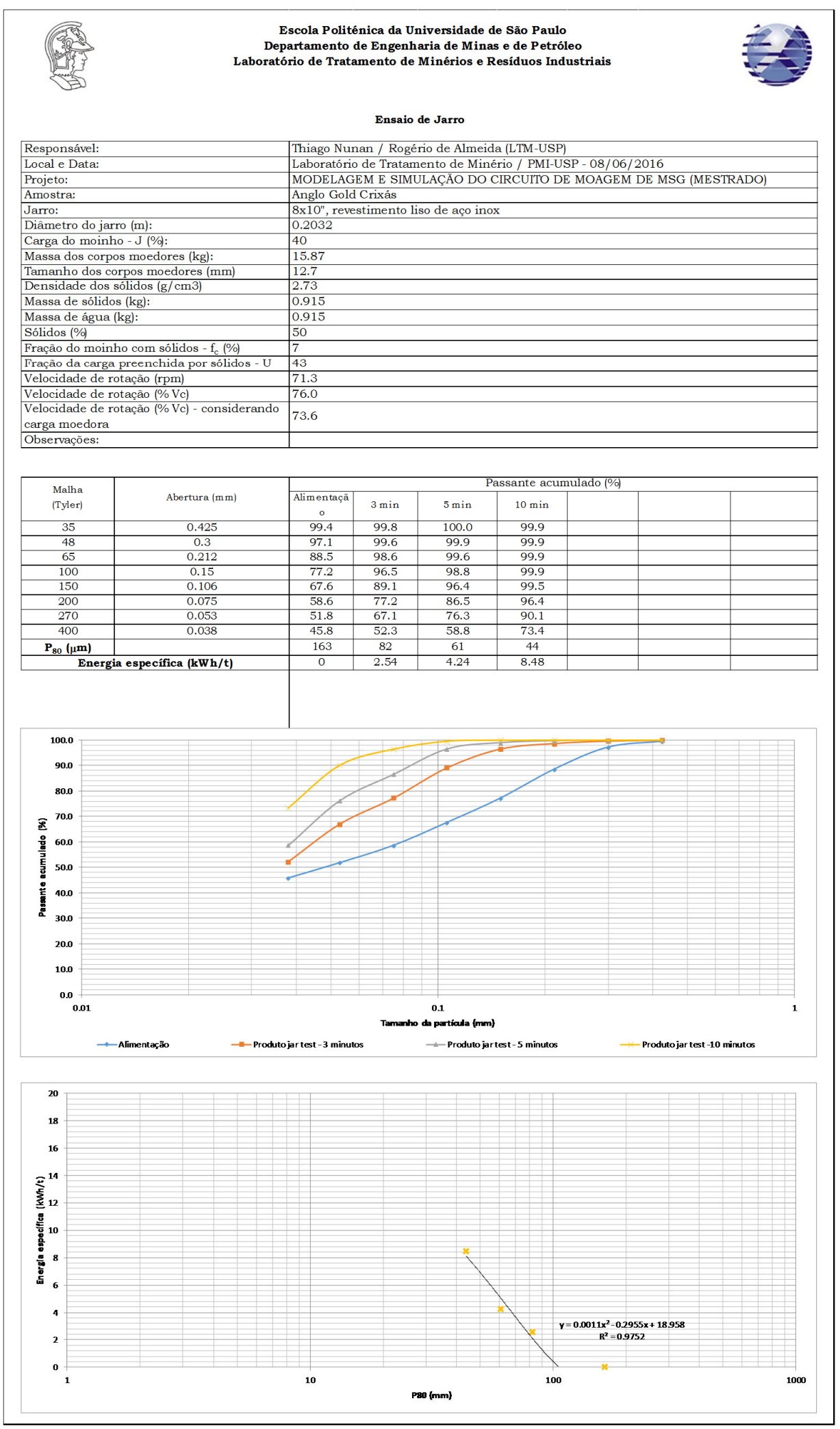




\section{APÊNDICE 4 - RESULTADOS DOS ENSAIOS DE CLP}

Figura 79 - Ensaios de CLP para fragmentos entre 4,75 e 6,35 mm
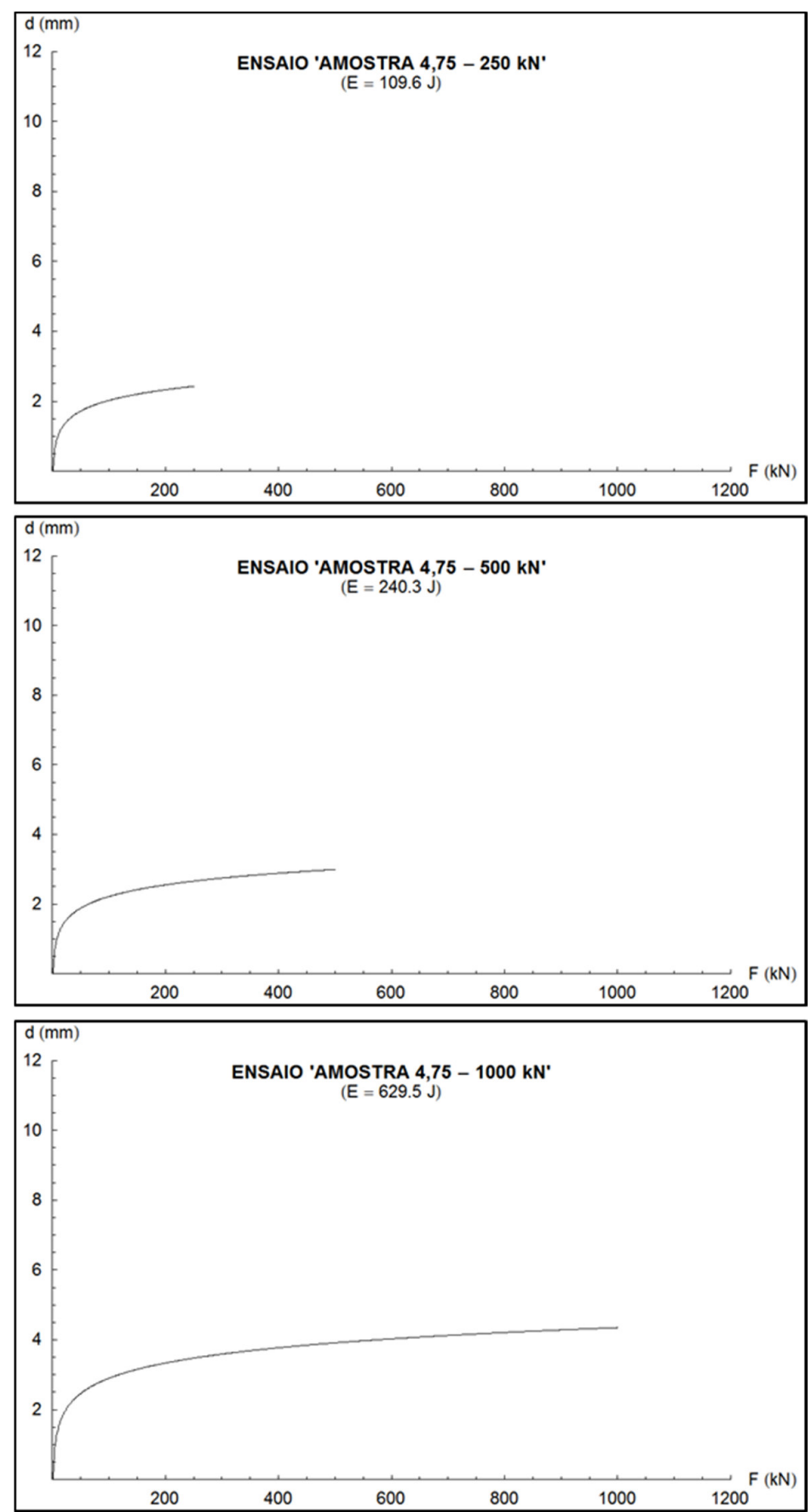
Figura 80 - Ensaios de CLP para fragmentos entre 6,35 e 9,5 mm
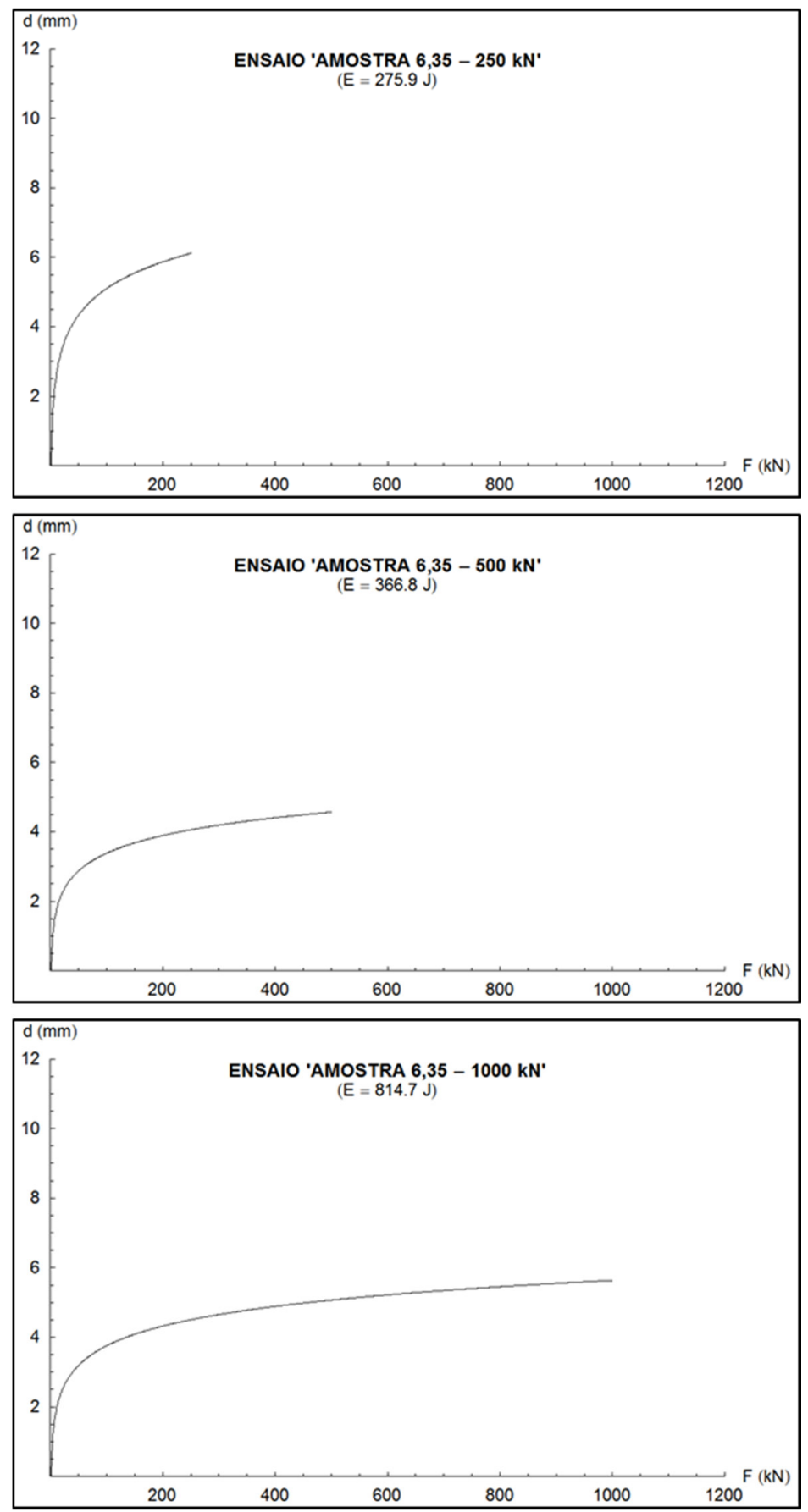
Figura 81 - Ensaios de CLP para fragmentos entre 9,5 e 12,7 mm
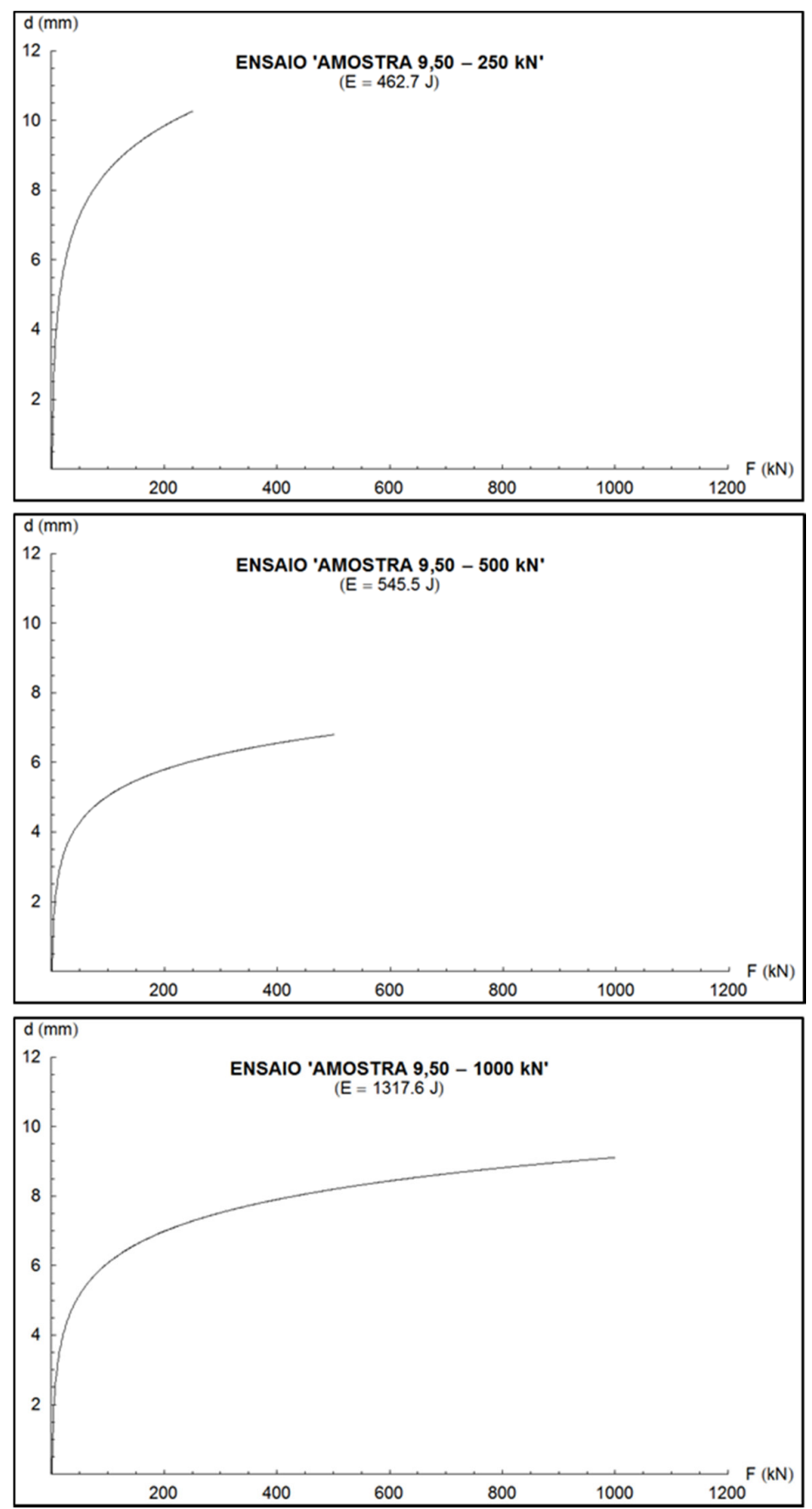